\title{
The USe OF Pragmatic DeVices by GERMAN NON-NATIVE SPEAKERS OF ENGLISH
}

\author{
By \\ Agnes Terraschke
}

\author{
A thesis submitted to the Victoria University of Wellington \\ in the fulfilment of the requirements for the degree of \\ Doctor of Philosophy \\ in Linguistics
}

School of Linguistics and Applied Language Studies

Te Whare Wananga o te Upoko o te Ika Maui

Victoria University of Wellington

Wellington, New Zealand 



\section{Abstract}

Mastering the pragmatic norms of another language is one of the greatest challenges to non-native speakers. One particularly difficult aspect of pragmatic conventions is the appropriate use of pragmatic devices such as like, you know, I think, and or something like that which have been found to serve a number of important textual and interactive functions in discourse. This study investigates the use of such devices by non-native speakers in cross-cultural conversations in terms of frequency and function in order to establish to what extent L2 usage differs from native speaker norms. In particular, the study examines the use of the English pragmatic devices like, eh and General Extenders (and things like that, or something like that) by German non-native speakers of English (GNNSE) in interactions with native speakers of New Zealand English (NSNZE). The results are compared with the use of these forms in native-native conversations in New Zealand English and the use of close equivalent forms in German by the same GNNSE. The analysis is based on a corpus of approximately $181 / 2$ hours of dyadic conversation or about 224,338 words of transcription.

Overall, the data shows that while GNNSE use all of the pragmatic devices included in the investigation, they consistently produced fewer tokens per number of words than their native speaker interactants. The use of the marker $e h$, which is regarded as a typical feature of NZE, seems to be an indicator of the speaker's level of linguistic and pragmatic proficiency in NZE as it was only used by GNNSE who had lived in New Zealand for an extended period of time. With regard to their functional application, GNNSE appear to use the pragmatic devices for the same purposes as NSNZE. The most notable difference in this regard is a markedly lower use of quotative like by GNNSE.

The data shows that NSNZE generally use fewer pragmatic devices when talking to non-native speakers. The data also suggests correlations between the way German speakers use pragmatic devices in German and English, and the analysis explores cases of L1 transfer. Thus, GNNSE's infrequent use of the like-quotative form appears to correspond to a low frequency use of the equivalent German form und ich so. Similarly, the most frequently used disjunctive General Extender by 
GNNSE is or so, which matches the German form oder so. As well as being a case of formal L1 transfer, the use of or so by GNNSE also indicates that they have not acquired the rules governing the use of or so which restrict it exclusively to numerical approximation. Factors found to influence the use of certain pragmatic devices by GNNSE are the speakers' length of exposure to informal English, length of stay in New Zealand, the use of corresponding forms in German, and the use of the forms by their native speaker interlocutor.

This analysis of paired interactions between native speakers of English and of German, and between members of each group speaking English to each other, contributes to the fields of cross-cultural and interlanguage pragmatics. In particular, this research extends our understanding of how non-native uses of pragmatic devices differ from the uses exploited by native speakers, and explores the effects of L1 transfer. The study provides a detailed qualitative analysis of three English pragmatic devices, leading to a better understanding of their functions. Moreover, it identifies possible German near-equivalents of the English pragmatic devices, and thereby highlights the differences and similarities between the two languages with regard to their uses of such devices. Finally, by considering the possible impact of the speakers' personal background and the interlocutor's language use, this research also adds to our understanding of the ways in which L2 learners acquire pragmatic devices in the absence of formal teaching. Overall, then, this research on pragmatic devices provides valuable insights into a specific area of cross-cultural contrast in language use, and identifies a number of interesting areas for further research. 


\section{Acknowledgements}

Behind every completed thesis is not only one tired student, but an entire army of supporters who deserve to be acknowledged. Without these people, this undertaking would not have been possible and importantly it would have been less enjoyable.

First of all I would like to thank my supervisors Janet Holmes and Laurie Bauer, for their help, advice, infinite knowledge in all things linguistic and for their seemingly endless patience with me and my overlong sentences. Their perspectives on my chosen topic forced me to constantly rethink and doublecheck my ideas, keeping me on my toes throughout the years.

I am also grateful to Victoria University of Wellington for their generous financial support in the forms of a $\mathrm{PhD}$ scholarship, a $\mathrm{PhD}$ completion scholarship and several Faculty of Humanities and Social Sciences research grants. This kept me well fed, watered and allowed me to undertake my somewhat expensive peoplecentred data collection.

Thanks are also due to the Language Learning Centre at Victoria University of Wellington, for allowing me to use their study room throughout the long course of my data collection. And naturally, I would like to acknowledge the contribution of my participants - without them there would be no data and no thesis.

A very greatful thank you goes to those people who have actively helped me complete this thesis. First and foremost, I am indebted to Marianna Kennedy, who foolishly volunteered her expert proof-reading skills and who did an amazing job noticing and fixing my mistakes. Many thanks also to Colleen Kelly and Sonja Jolles for their statistical advice and to the ever changing members of the LALS $\mathrm{PhD}$ group for their useful feedback on my work. I am also grateful to George Major, who provided proof-reading, advice, support, soup and encouragement whenever needed, day or night. 
Credit is also due to the School of Linguistics and Applied Language studies for letting me use the Wellington Corpus of Written and Spoken New Zealand English, and all the academic and administrative staff for their general support.

Finally, I would like to thank everyone who kept me sane and who made me feel at home when being far away from home. For one, this is directed at my fellow postgraduate students of the fourth floor, in particular Stephie, Angela, Anthea, Julia, Laura, Mitsumi and Dongkwang. A very special thank you goes to Tina Chiles, the world's greatest office-mate, who introduced me to the benefits of the gym. Thanks also to all my flatmates and friends for putting up with my thesisrelated grumpiness. Their kindness and support has helped more than they are probably aware of. 


\section{Table of Contents}

Agnes Terraschke .........................................................................................

Abstract

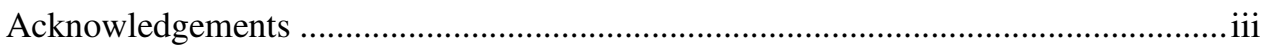

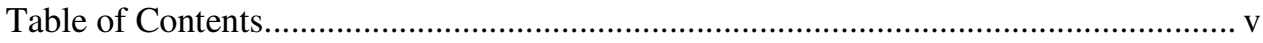

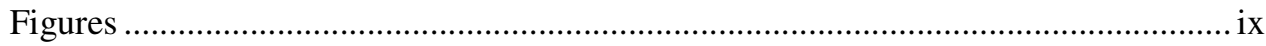

1. Introduction.............................................................................................................. 1

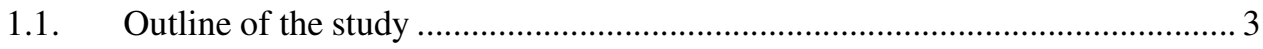

2. Pragmatic Devices in the Literature ................................................................5

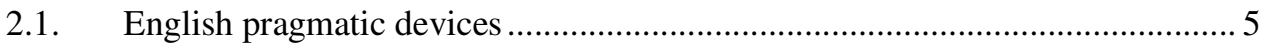

2.1.1. Characteristics of pragmatic devices .................................................................

2.1.2. Functions of pragmatic devices .....................................................................

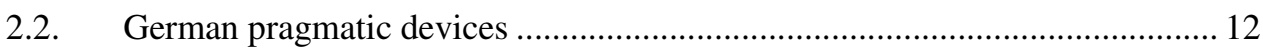

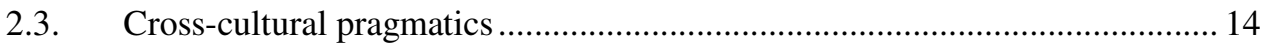

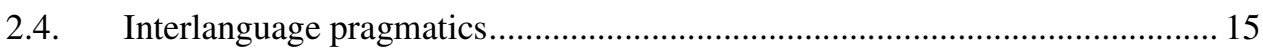

2.4.1. Factors influencing L2 language use ………….............................................. 17

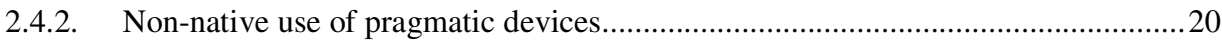

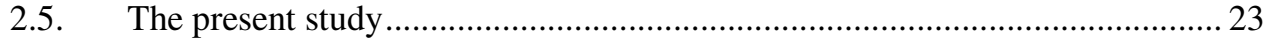

3. Methodology ....................................................................................................227

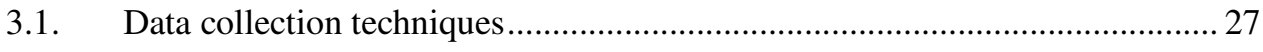

3.1.1. Discourse Completion Tests..................................................................................2

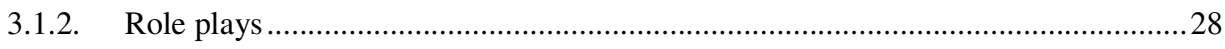

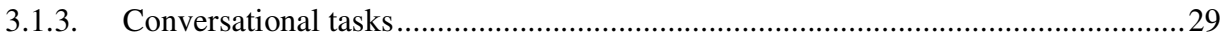

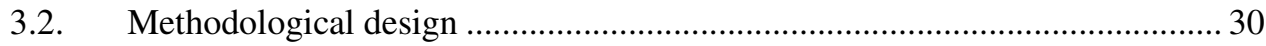

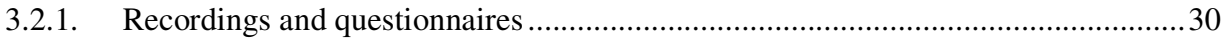

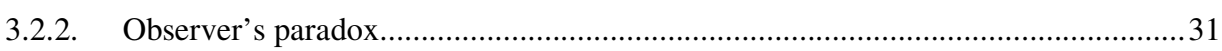

3.2.3. Suggested topics and picture description tasks....................................................... 31

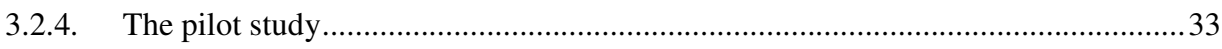

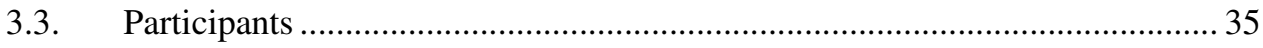

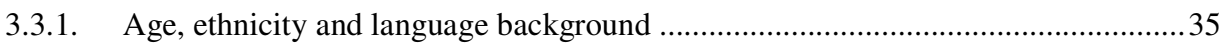

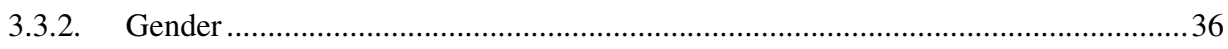

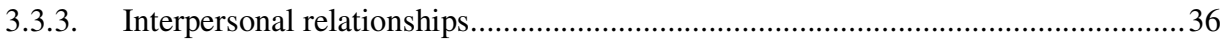


3.3.4. Time spent in New Zealand and NSGs' English language skills............................37

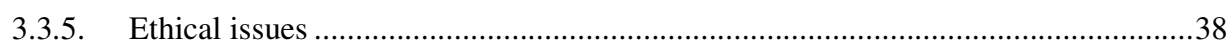

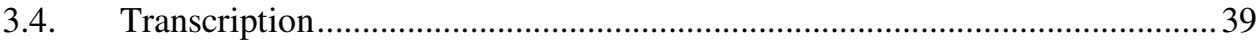

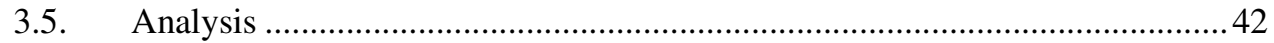

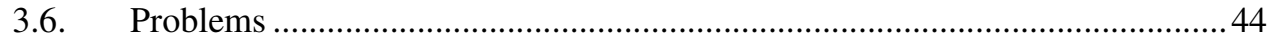

\section{Selection of Devices $\ldots \ldots \ldots \ldots \ldots \ldots \ldots \ldots \ldots \ldots \ldots \ldots \ldots \ldots \ldots \ldots \ldots \ldots \ldots \ldots \ldots \ldots \ldots \ldots \ldots \ldots \ldots \ldots \ldots \ldots$}

4.1. Pragmatic Devices ....................................................................... 47

4.1.1. Interactive politeness, content-oriented and speaker-oriented devices ..................47

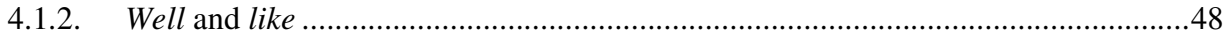

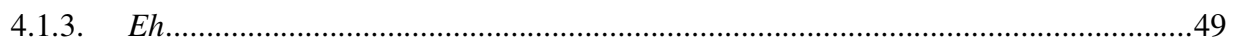

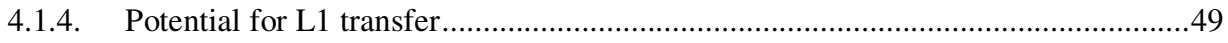

4.1.5. Pragmatic devices vs. grammatical structures ..............................................50

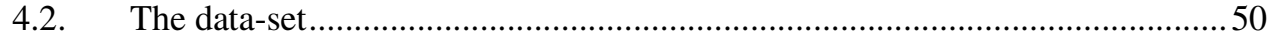

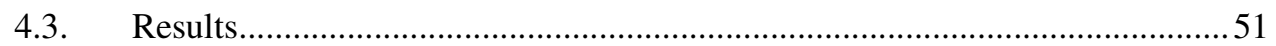

4.3.1. Use of Pragmatic Devices by NSNZE and GNNSE .......................................51

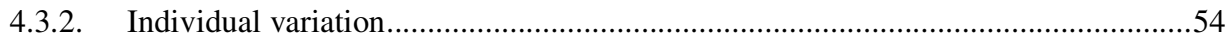

4.3.3. Impact of pragmatic devices on interactions ......................................................55

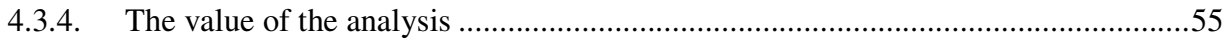

4.4. Selection of Pragmatic Devices for detailed analysis ................................55

5. General Extenders............................................................................59

5.1. Literature on General Extenders ...........................................................59

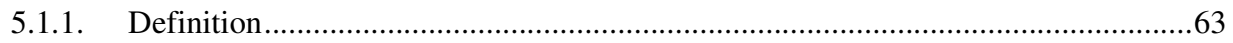

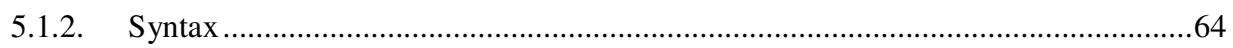

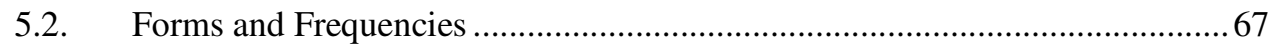

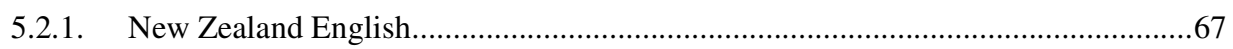

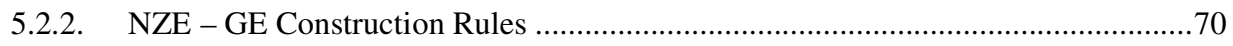

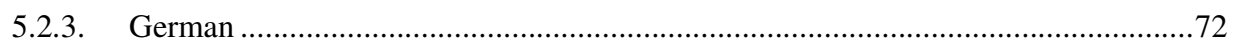

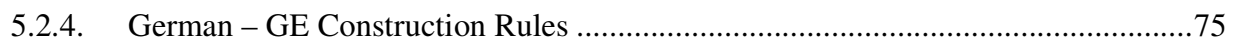

5.2.5. Implications for L2 learners and predictions for L2 speaker use ..........................77

5.2.6. Use of GEs by GNNSE and NSNZE in cross-cultural interactions .........................77

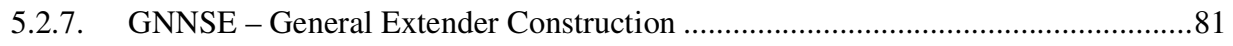

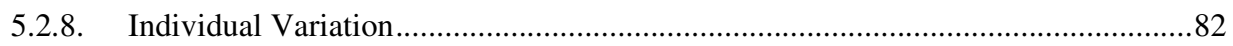

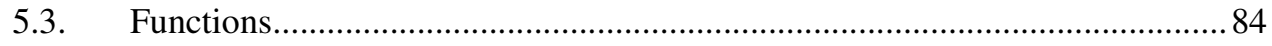

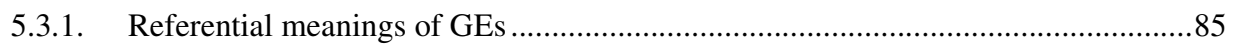

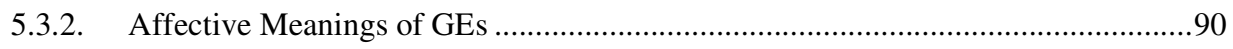


5.4. The functions of GEs as used by non-native speakers in cross-cultural

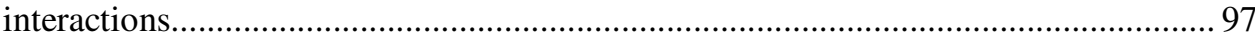

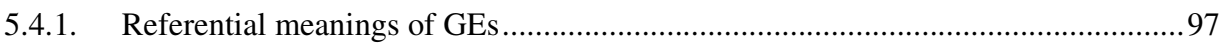

5.4.2. Politeness - Affective Meanings ........................................................................99

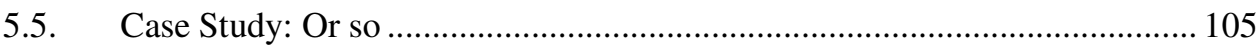

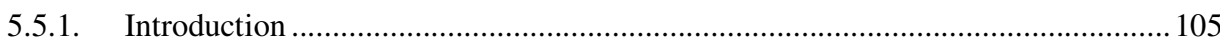

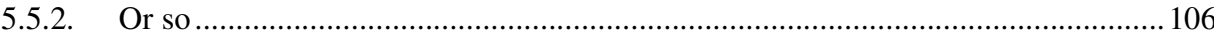

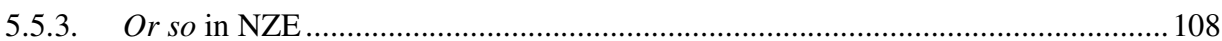

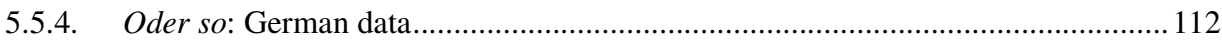

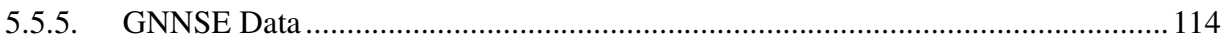

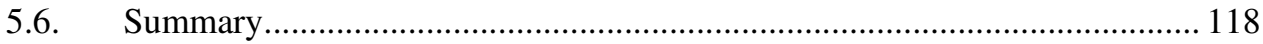

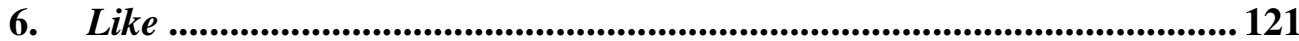

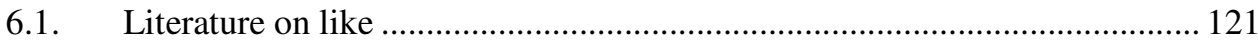

6.1.1. Discourse like versus Non-Discourse like ….......................................................... 122

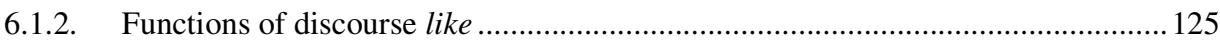

6.1.3. Like categories: A quantitative approach............................................................. 140

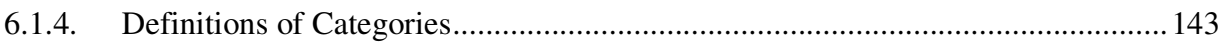

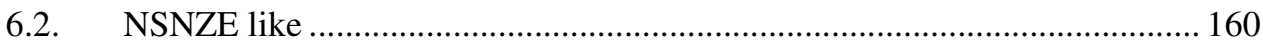

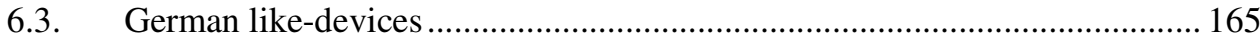

6.3.1. Like-like Devices in Other Languages................................................................ 165

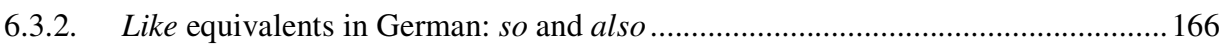

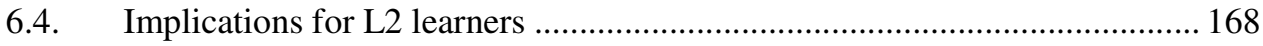

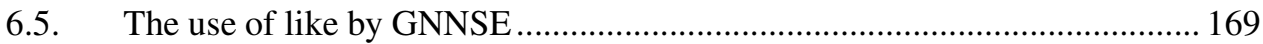

6.5.1. Quantitative analysis of the use of like by GNNSE and NSNZE in cross-cultural

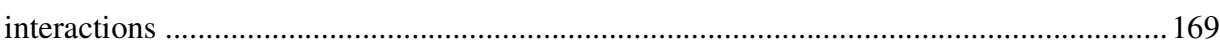

6.5.2. Functional analysis of the use of like by GNNSE .............................................. 172

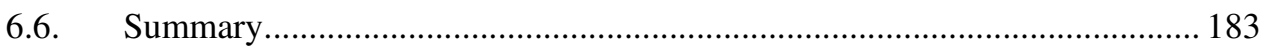

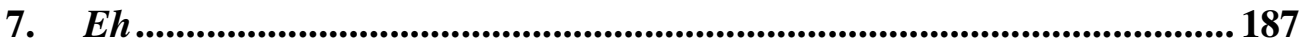

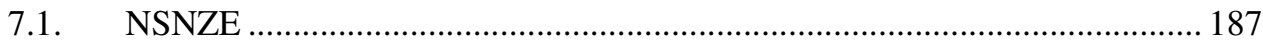

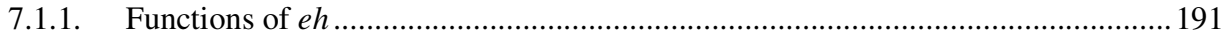

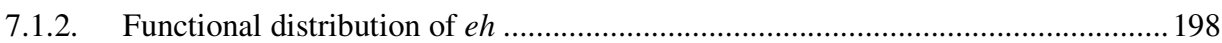

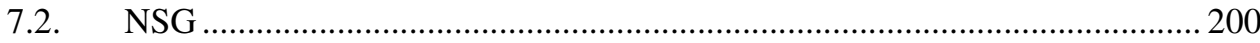

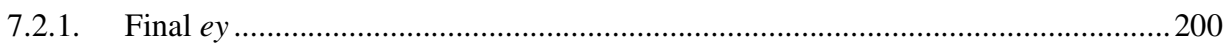

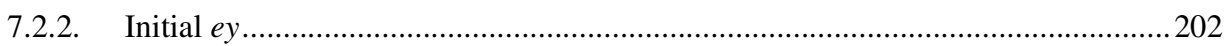

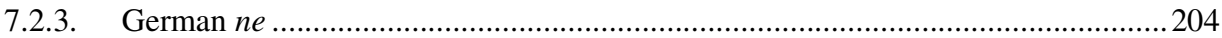


7.2.4. Functional distribution of NSG ey and ne

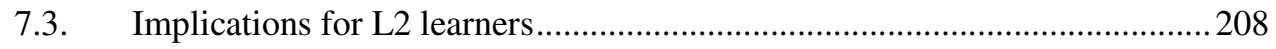

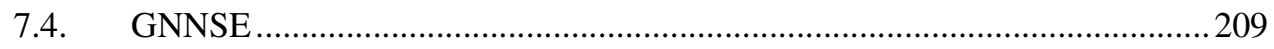

7.4.1. Functional distribution of $e h$ in cross-cultural interactions .................................209

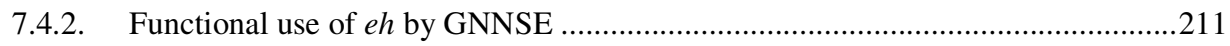

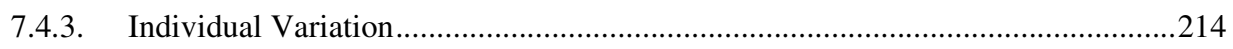

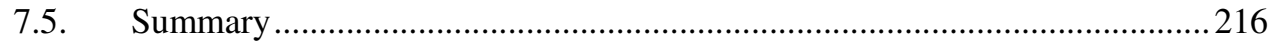

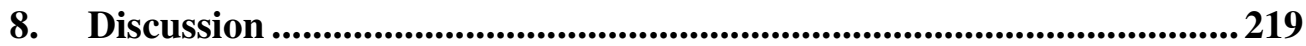

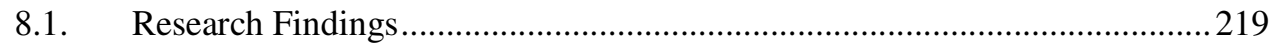

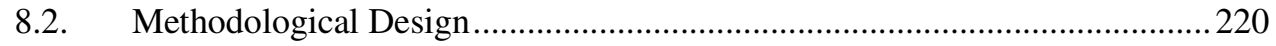

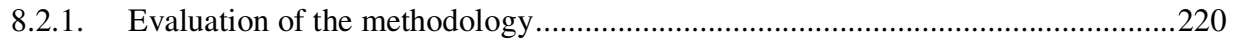

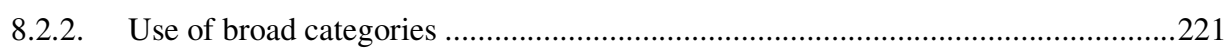

8.3. Differences in the use of pragmatic devices between GNNSE and NSNZE .222

8.3.1. Possible effects on perception of non-native speakers..........................................222

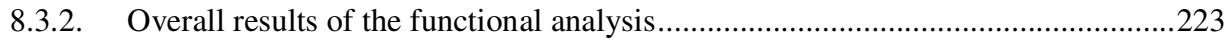

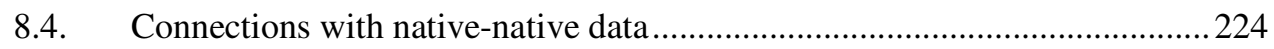

8.4.1. Differences in the language used by NSNZE in native-native and cross-cultural

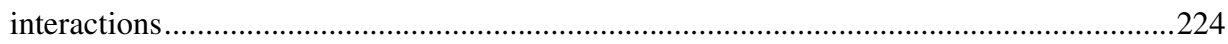

8.4.2. Influence of L1 on the use of pragmatic devices by GNNSE .............................225

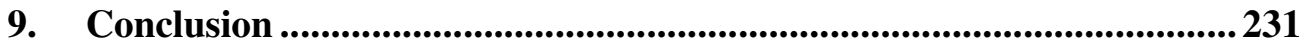

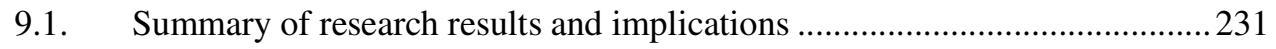

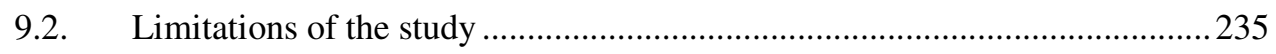

9.3. Possible directions for future research .......................................................223

10. Appendices......................................................................................221

Appendix 1: Background Information Sheet and Retrospective Conversation Ranking

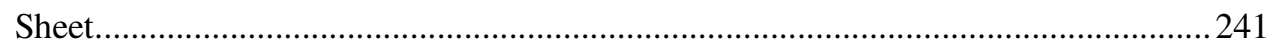

Appendix 2: Information sheet and Consent form ......................................................245

Appendix 3: English Version of the letter used to find participants ...........................247

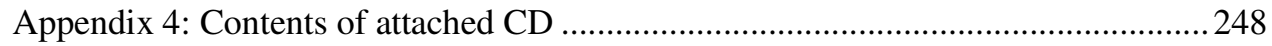

11. References...........................................................................................2251 


\section{Tables}

Table 1: Distribution of participants in dyads according to gender and first language .................36

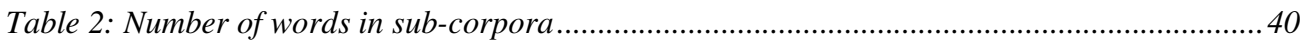

Table 3: PD use by NSNZE and GNNSE in cross-cultural interactions ........................................52

Table 4: Total number of GEs in NSNZE corpus and overall frequency per 100 words ...............68

Table 5: Total number of GEs in NSG corpus and overall frequency per 100 words..................... 73

Table 6: Total number of GEs used by GNNSE and overall frequency per 100 words.................. 78

Table 7: Total number of GEs in cross-cultural NSNZE data and overall frequency per 100 words

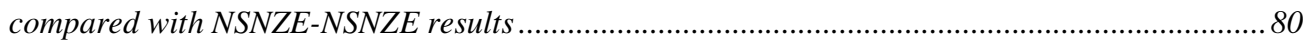

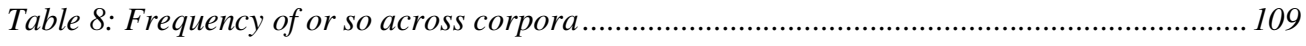

Table 9: Functional distribution of like in the NSNZE corpus..................................................... 161

Table 10: Discourse like vs non-discourse like ratio across corpora .......................................... 161

Table 11: Comparison of functional distribution of like between Andersen (2001), Müller (2005)

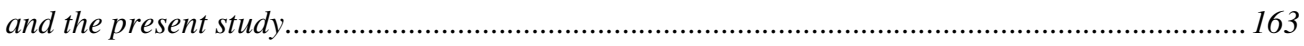

Table 12: Functional distribution of like in GNNSE corpus compared with NSNZE data ........... 169

Table 13: Functional distribution of like in the cross-cultural NSNZE corpus, compared with

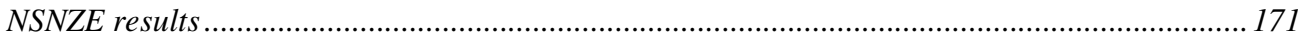

Table 14: Functional distribution of $e$ in the NSNZE corpus................................................. 198

Table 15: Functional distribution of ey in the NSG corpus .........................................................208

Table 16: Functional distribution of ne in the NSG corpus ..................................................... 208

Table 17: Functional distribution of eh in the GNNSE corpus compared with NSNZE data........ 209

Table 18: Functional distribution of eh in the cross-cultural NSNZE corpus compared with NSNZE data

\section{Figures}

Figure 1: PD use by NSNZE and GNNSE in cross-cultural interactions .....................................52

Figure 2: NZE GE Construction Map - And ....................................................................... 71

Figure 3: NZE GE Construction Map - Or..................................................................... 72

Figure 4: German GE Construction Map - Und ................................................................... 76

Figure 5: German GE Construction Map - Oder ............................................................... 77 



\section{Introduction}

The focus of research in the field of pragmatics to date has been to identify and describe the underlying rules of interaction. After all, language is not only used to communicate factual information; next to its explicit propositional content a single utterance can implicitly convey the speaker's attitude towards the interlocutor or the topic of discussion. It can even be used to convey the general context of the interaction and subtly connect it to the ongoing context of conversation. Accordingly, studies in pragmatics have investigated the sociopragmatic rules of a language, for example, the examination of culturally specific norms of speech acts such as complimenting or refusing in different social contexts, and the examination of expressions of linguistic politeness, as well as discourse management strategies such as turn-taking or the creation of coherence.

Research in this area has shown that interpersonal functions and discourse management strategies in conversations can be manifested in the use of vocabulary, sentence structure, modal verbs (e.g. Holmes 1982), intonation (e.g. Allan 1990; Britain 1998), extra-linguistic features and a set of expressions that appear to be propositionally empty. These expressions, which include items such as sort of, I think, and you know (e.g. Bublitz 1978; Holmes 1986; Schiffrin 1987; Lindner 1991; Östman 1991; Meyerhoff 1994; Holmes 1995; Stubbe and Holmes 1995; Nikula 1996; Andersen 2001), are also referred to as 'pragmatic devices'. Pragmatic devices are important items in the management of talk and interpersonal relations and are considered to help facilitate the flow of communication (Stubbe and Holmes 1995: 63). Nevertheless, it is nearly impossible to pinpoint an exact meaning for any of these linguistic items since the majority have different connotations depending on the context. In other words, 
interpersonal and textual meanings are not necessarily made explicit in communication but tend to underlie the surface form of an utterance. Even native speakers are usually not consciously aware of the ways pragmatic devices function in conversation, but they subconsciously understand their meanings.

Native speakers acquire this sociopragmatic knowledge naturally and instinctively along with their mother tongue. Non-native speakers, however, do not have this opportunity. While the sentence structures of a language are usually taught in the second language classroom and even conventional verbal routines such as thanking or requesting can be practiced, the same is not necessarily true for the implicit pragmatic norms of a language. Müller (2005: 250), for example, points out that in three basic German text books of English well and so are the only pragmatic devices that are explicitly introduced.

Even though non-native speakers might have a basic grasp of the grammar and phonology of a language and be able to express propositional content, they can lack the pragmatic knowledge needed to establish and maintain friendly interpersonal relations in their second language. It is these pragmatic aspects of language that often make it possible to identify even the most fluent second language speaker as non-native. For example, I and other German non-native speakers of English noticed the typical New Zealand English marker $e h$ and started using it. However, my flatmate (a native speaker of New Zealand English) pointed out that I was using it somewhat differently from New Zealanders, although he could not identify exactly what was different about it. Closer examination is required to determine whether non-native speakers actually do use pragmatic devices for different functions or whether there are other reasons that make the use of pragmatic devices by non-native speakers sound odd to the ears of native speakers.

Most previous research in interlanguage pragmatics has focused on the differences in the execution of speech acts by native and non-native speakers rather than the use of pragmatic devices, which means that this field is still relatively new. Research is needed to establish how well non-native speakers adapt to the discourse management strategies of their target language and culture, and to the 
Introduction

strategies used to express interpersonal affiliation and establish rapport. One aspect of this is the use of pragmatic devices. Moreover, the issue of first language (L1) transfer has not been thoroughly explored in connection with pragmatic devices.

The aim of this study is to investigate the non-native use of English pragmatic devices as discursive strategies in the speech of German non-native speakers of English (GNNSE). Furthermore, based on the establishment of the conventions of use of pragmatic devices by native speakers of German (NSG) and native speakers of New Zealand English (NSNZE), the study seeks to examine the impact of L1 interference in the use of pragmatic devices by GNNSE.

\subsection{Outline of the study}

The first four chapters of this thesis provide a foundation for the analysis of nonnative uses of pragmatic devices. The literature survey defines the goals of the research, highlights the theoretical issues involved and develops the specific research questions that guide the study. Since the type of data used inevitably has an effect on the results (Kasper and Dahl 1991: 216), a detailed description of the methodology used for the data collection, compilation of the corpus and the analysis is provided in Chapter 3. Chapter 4 is the final part of this initial scenesetting section, and details the selection of the pragmatic devices that are closely examined in the following analysis chapters. Thus, Chapter 4 presents the results of a preliminary analysis of a sub-set of the corpus which looks at differences in the use of a pre-selected set of pragmatic devices by NSNZE and GNNSE. This chapter concludes by explaining the choice of General Extenders (and things like that, or something, etc.), like and New Zealand English eh as the focus of the study.

Chapters 5 to 7 present in-depth analyses of the selected devices. The first set of devices examined are General Extenders (GEs). Chapter 5 gives an overview of previous research on GEs and establishes L1 conventions of use for both German and New Zealand English (NZE) in terms of forms, functions and frequency of use. Aspects that may have influenced individual variation among the GNNSE are discussed, including personal background, use of GEs in German and the 


\section{Introduction}

influence of the native speaker interlocutor. The GE chapter also includes a case study of differences in the use of or so by native and non-native speakers. Chapter 6 looks at the uses of like. It follows a similar outline to that of chapter 5, comparing the functions of like in English with potential German equivalents, and examining patterns of non-native use. The chapter also contains a quantitative analysis of different functions of like. Finally, chapter 7 examines uses of the pragmatic device $e h$, which can be regarded as a typical NZE feature, and the phonologically similar German $e y$ as well as the functionally similar German $n e$.

The results of these subsections of the analysis are summarised in chapter 8 . This chapter considers the study's methodology, differences in use between native and non-native speakers, differences in use between NSNZE in native-native and cross-cultural interactions, as well as L1 transfer in the GNNSE data. These results are then discussed in relation to their implications for interlanguage pragmatics and second language acquisition and teaching. Finally, chapter 9 provides a summary of the results, highlights the limitations of the study and makes suggestions for future research in the area of cross-cultural and interlanguage pragmatics. 


\section{Pragmatic Devices in the Literature}

This chapter provides an overview of previous research describing the general characteristics and functions of pragmatic devices in English and German. It discusses the degree of comparability of English and German forms and gives a brief account of issues relating to second language acquisition in general and the acquisition of pragmatic devices. This review provides a research context for the development of the research questions. Detailed background information on those devices that are closely analysed in this thesis is presented and discussed in the relevant chapters.

\subsection{English pragmatic devices}

Academic interest in the forms, functions and structural characteristics of pragmatic devices in English started in the 1970s, most prominently with Lakoff's (1975) account of the functions of forms such as I think and you know in conversations. In this description she linked the use of these devices solely with an expression of the speaker's uncertainty. This was followed by numerous investigations looking at the different uses of these small, seemingly meaningless devices. These studies considered gender, age, social class, speaker roles or the general context of the conversation as potential variables. Despite extensive academic attention, however, researchers still have not agreed on an allencompassing definition, an exhaustive inventory, or even a common label. Thus, pragmatic devices have been referred to as 'fumbles' (Edmondson 1981), ‘pragmatic particles' (Holmes 1995), ‘pragmatic markers' (Brinton 1996; Andersen 2001), 'discourse markers' (Schiffrin 1987; Lenk 1996), 'discourse particles' (Schourup 1982), 'pragmatic force modifiers' (Nikula 1996) and 'modal

particles' (Bublitz 1978; Abraham 1991; Lindner 1991; Durrell 1996; Möllering 
2001). Each of these terms and its respective definition can be taken as a reflection of the researcher's specific focus.

In the following discussion, the term 'pragmatic devices' will be used as a general term for these forms, with the labels 'discourse markers', 'boosters' and 'hedges' serving to denote more specialised sub-categories of pragmatic devices. This approach follows Fraser (1999: 950), who considers discourse markers to differ from other pragmatic expressions in that "they signal a relationship between the segment they introduce $[\ldots]$, and the prior segment". According to this conception, discourse markers can be said to serve textual or discourse structuring functions. The terms 'boosters' and 'hedges' are used to refer to sub-groups of interpersonal politeness devices in the sense of Brown and Levinson's (1987) Politeness Theory. Thus, 'boosters' are items that can serve to emphasise and strengthen the illocutionary force of an utterance, e.g. exactly or precisely. Items such as sort of or and things like that, which can help to soften the illocutionary force, are referred to as 'hedges'. In other words, boosters and hedges serve to express the speaker's subjective stance. On an interpersonal level, pragmatic devices serve to convey the speaker's attitude towards the content of the utterance and the listener, and thereby can help negotiate rapport. These two sub-categories of discourse markers and boosters/hedges are anything but mutually exclusive as pragmatic devices can fulfil both textual and interpersonal functions at the same time.

The term 'pragmatic devices' was chosen to denote the class of items under investigation as the word 'pragmatic' conveys that the analysis concentrates on the interactive nature of the forms and the role they play in conversations. This follows Andersen (2001: 40) who states that 'the label 'pragmatic' is meant to suggest a relatively low degree of lexical specificity and a high degree of contextual sensitivity". The word 'device' was favoured over 'particle' since the latter is usually applied to a clearly defined syntactic entity and is often used in research on the functions of German devices (Müller 2005: 3). Moreover, 'particle' is commonly associated with short single words, not collocations. The set of pragmatic devices considered in this study contains forms from a range of syntactic classes, i.e. items that do not necessarily belong to the class of particles, 
and it also includes multi-word forms such as you know or and things like that. Therefore, the word 'device' was considered to be more suitable as it is relatively unspecific and does not restrict the number of possible forms.

\subsubsection{Characteristics of pragmatic devices}

The main problem with providing a detailed and exhaustive definition for pragmatic devices is that researchers have included a range of different items in this category with a variety of functional and structural properties. Among the forms that have been included in studies on English pragmatic devices are particles such as eh (Meyerhoff 1994), parentheticals such as you know or I think (Holmes 1985, 1986, 1995), conjunctions such as so or furthermore (Fraser 1999) and even prosodic features such as High Rising Terminals (HRTs) (Britain 1998). This variability makes it virtually impossible to identify characteristics that describe all possible devices, which is why the features listed in most definitions do not necessarily apply to all items. For example, while pragmatic devices such as you know and I think are relatively short and can be phonologically reduced, this does not apply to longer forms such as or something like that. Jucker and Ziv (1998: 2-3) propose that, depending on the number of features a device fulfils, a feature can be considered as either a core or a more peripheral member of the group of pragmatic devices.

One characteristic mentioned in the literature is that pragmatic devices predominantly occur in oral communication (e.g. Brinton 1996: 33) and seldomly appear in formal writing such as newspaper articles, reports or official letters. Müller (2005: 7) points out, though, that this characteristic might merely reflect the research focus of the majority of studies on pragmatic devices, since most studies in this area deal with spoken rather than written language. Another commonly described feature of pragmatic devices is that in speaking they are often phonologically reduced and detached from the prosodic pattern of the utterance by a short pause, forming a separate tone group (Schiffrin 1987: 35; Quirk et al. 1985: 1112). An exception to this might be the device like, as Miller and Weinert (1995: 373) comment that most of the instances of like as a pragmatic device in their data were not separated by a pause. 
Pragmatic devices are also believed to carry only some of their original conceptual meanings. Therefore, they are regarded as optional elements that do not play a vital part in the syntactic make-up of an utterance (Schiffrin 1987: 328; Ariel 1994: 3251; Brinton 1996: 34; Andersen 2001: 21; 40-1). This allows them to be omitted without rendering the sentence ungrammatical (Schiffrin 1987: 31; Brinton 1996: 34; Müller 2005: 6). Andersen (2001: 41; 48) points out that some pragmatic devices can have an effect on the meaning of a sentence by indicating "constraints on the interpretational procedure". For example, pragmatic devices can convey lexical inaccuracy as in someone who sort of fancies me (example taken from Andersen 2001: 48).Thus, the use of sort of indicates that the word 'fancy' should not been taken too literally. In this case, it modifies the meaning of fancies to mean "someone who merely expresses a mild interest in rather than someone who is completely attracted to me". As Andersen (2001: 48) points out, “'fancying' and 'sort of fancying' are not identical from the point of view of propositional meaning".

The position of pragmatic devices within discourse has been analysed with regard to their location within the sentence (e.g. Andersen 2001) and within the turn as a whole (e.g. Schiffrin 1987). In both cases, pragmatic devices have been found in initial, medial and final position (Brinton 1996; Hasund 2003), with either a forward (e.g. well) or backward scope (e.g. and things like that). Even though pragmatic devices can be found in sentence medial positions, it has been proposed that they cannot occur randomly in a sentence. The device like, for example, is subject to a range of syntactic restrictions (Andersen 2001; D'Arcy 2005). Thus, D'Arcy (2005: 184) suggests that the fact that like can occur immediately to the left of a non-finite copula but not a finite one is related to the position of these items within the structure of the sentence: the finite copula is situated above the position where like can occur whereas the uninflected form is situated below it.

Finally, one of the most important characteristics of pragmatic devices frequently mentioned in the literature is their multifunctionality (e.g. Brinton 1996; Lenk 1996; Andersen 2001; Müller 2005). This means that pragmatic devices can take on different meanings in different contexts. For instance Holmes (1986) demonstrates that $I$ think can be used to express both certainty and uncertainty 
towards the propositional content of an utterance. The difference between the two uses is marked by contrasting prosodic patterns. Nevertheless, despite the multitude of purposes pragmatic devices serve in conversation, it is usually possible to determine which meaning of the pragmatic device is the most salient when taking into account the context.

\subsubsection{Functions of pragmatic devices}

As illustrated above, pragmatic devices have been found to serve a wide array of different textual and interpersonal functions in discourse. Müller (2005: 8) suggests that the most relevant theoretical frameworks for analysing the different functions of pragmatic devices on these two levels are Coherence Theory and Relevance Theory (Sperber and Wilson 1986); however, it seems that Politeness Theory (Brown and Levinson 1987) and Rapport Management (Spencer-Oatey 2000) can also be usefully employed. The notion of Coherence is concerned with the discourse marking functions of pragmatic devices in that it focuses on the ways they indicate the relationships between segments of discourse (Fraser 1999). For instance, the discourse marker use of well, however, you know or so assists in creating discourse coherence by indicating how adjoining discourse segments are connected, thereby signalling "structural organization within discourse" (Lenk 1996: 1; also Schiffrin 1987) with both a local and a global orientation. On a textual level, pragmatic devices have also been found to work as backchannels, to indicate and negotiate turn-taking, introduce new topics, create emphasis on a particular linguistic item or a proposition, serve as verbal fillers that give the speaker more time to structure an utterance (Brinton 1996: 37; Andersen 2001: 60; Müller 2005: 9), and to express epistemic modality (Holmes 1995), i.e. convey speakers' degree of certainty in their utterances.

Relevance theory, on the other hand, is not concerned with the creation of textual meaning in communication, but instead "focuses on the cognitive processes" (Müller 2005: 9) that are required to determine the most salient interpretation of an utterance. In this sense, it is a theory of how people manage to infer meanings that are not explicitly stated from utterances. The basis of this "cost-benefit model of human cognition" (Lenk 1996: 22) is the assumption that all utterances are designed and expected to be optimally relevant. Thus, the listener expects the 
choice of words, sentence structure, the organisation of information for each turn, use of pragmatic devices, etc. to be relevant for the interpretation process. Similarly, speakers structure their contribution in such a manner as to convey the intended meaning, both propositional and meta-linguistic, as efficiently as possible (Sperber and Wilson 1995: 158). For example, the utterance He is a bastard (example taken from Sperber and Wilson 1995: 175) requires inferences about the person the pronoun refers to and about whether the speaker means that he is a mean person or an illegitimate child. All this information is encoded in and conveyed by the utterance within its given context. A basic belief of Sperber and Wilson's theory is that understanding indirect meaning requires more cognitive work from the listener. Meaning can be deduced by a series of logical conclusions, which are based on assumptions drawn from either general knowledge or from interlocutors' shared background knowledge. This makes Relevance Theory a useful framework to determine the level of indirectness (Thomas 1995: 135). For the analysis of pragmatic devices, Relevance Theory is a means to conceptualise the indirect assumptions and presuppositions that are communicated by these markers. These presuppositions influence the listener in his or her interpretation of the utterance by "constraining the number of possible interpretations" (Müller 2005: 9). Thus, while according to the Coherence approach, pragmatic devices serve as coordinates of talk that indicate how discourse segments relate to one another (Schiffrin 1987: 326), Relevance Theory regards them as indicators for how to interpret the utterance as a whole.

In their approach to communication, Brown and Levinson (1987) are less concerned with the creation of meaning and instead concentrate on the interpersonal aspects of communication. According to Politeness Theory, all people have positive face, i.e. a sense of worth that they want others to appreciate and negative face, i.e. a desire not to be imposed upon (Brown and Levinson 1987: 61). Communication, then, is negotiation between wanting to achieve one's conversational goals such as making a request as efficiently as possible, whilst maintaining the other's face and protecting one's own. Depending on the kind of imposition made by a particular speech act, as well as the social distance and power relations between the interactants, a speaker may or may not choose to make his or her intentions explicitly known, and may use verbal redress strategies 
to minimise the impact of a potential face threat. In New Zealand English, Holmes (1988) shows that when complimenting, men tend to attend more to the other's negative face by attenuating the compliment, whereas women choose more often to appeal to the other's positive face by strengthening the compliment.

Spencer-Oatey (2000) adopts Brown and Levinson's general approach but removes its inherent focus on western culture and its conception that all speech acts are potentially face threatening, developing it further into what she refers to as Rapport Management Theory. Thus, to the notion of face Spencer-Oatey adds the notion of sociality rights. Sociality rights are subdivided into equity rights, referring to a person's demand for consideration in interactions, and association rights, which are concerned with one's expectation of the appropriate form of specific social interactions. Face consists of quality face, referring to a person's positive evaluation of his or her personal traits, and identity face, which is concerned with the maintenance of one's position in society and one's relationship with the interactant. In other words, Spencer-Oatey conceptualises face as a person's sense of dignity and honour while sociality rights refer to what a person feels entitled to and expects others to comply with, such as fairness and consideration (Spencer-Oatey 2000: 14).

Rapport management is not just restricted to speech acts but can be traced in areas such as illocution, discourse management, style, turn taking, and non-verbal behaviour. Again, there are certain strategies which the speakers adopt in a specific situation. Like Brown and Levinson's Politeness Theory, Rapport Management looks predominantly at the use of semantic components, illocutionary effects, indirectness/directness and the use of pragmatic devices in order to establish form and function of politeness or rapport managing strategies. And as with Brown and Levinson, different societal norms of politeness and rapport management can lead to cross-cultural misunderstandings. Thus, while the notions of Coherence and Relevance mainly deal with the textual level of an interaction, the Politeness Theory/Rapport Management perspective relates to the affective level. According to Politeness Theory/Rapport Management, pragmatic devices can be used to express the speaker's attitude towards the topic of discussion, the discourse situation and the interlocutor. Pragmatic devices have 
also been found to invite the interlocutor to participate in discourse (e.g. Holmes 1982, 1985; Meyerhoff 1992; Cheng and Warren 2001), indicate the assumption of shared knowledge and common ground (e.g. Meyerhoff 1994; Overstreet 1999) and serve as an appeal for the interactant's understanding (Holmes 1986). In this sense, they serve to establish interpersonal solidarity and minimise the social distance between the speakers, thereby playing a subtle yet important role in the expression and conveyance of linguistic politeness.

\subsection{German pragmatic devices}

The main group of German devices investigated are Modalpartikeln 'modal particles'. Modalpartikeln are a range of small uninflected lexical items from different syntactic classes that serve a variety of discourse structural and interpersonal functions (Abraham 1991; Durrell 1996). Like English pragmatic devices they are multifunctional items whose meanings are context-dependent and convey the speaker's attitudes towards the proposition. Unlike English forms, though, German particles cannot occur in sentence initial position and they are integrated into the syntactic make-up of the sentence (Weydt 1969: 68f as cited in Cárdenes Melián 1997: 4). Wauchope (1992: 380) points out that, because particles as a class are mostly defined by formal and syntactic features, "there is no identical particle set in English" and therefore Modalpartikeln are not directly translated here.

This rather large group of German Modalpartikeln is generally thought to consist of a number of different sub-groups. However, as in English, there is still some debate about what categories are to be used and which items belong in each of these categories (Durrell 1996: 175). According to Fleischer, Helbig and Lerchner (2001: 272-273) the rather large class of particles itself consists of three main groups. The first group is that of Modalpartikeln 'modal particles' or Abtönungspartikeln 'hedging particles' (e.g. aber, denn, nur etc.), which serve to convey the speaker's attitude towards and commitment to the propositional content of an utterance (Fleischer et al. 2001: 272). On an interactional level, they can be used to "alter the tone of what is being said and, for example, appeal for agreement, express surprise or annoyance, soften a blunt question or statement or sound reassuring" (Durrell 1996: 173), while on a textual level they convey the 
relationships between discourse segments (Fleischer et al. 2001: 274). When used like this, they can modify the illocutionary force of a whole sentence or utterance. The second group of particles, Gradpartikeln 'degree particle' or Fokuspartikeln 'focus particles' (e.g. sogar, nur, auch, insbesondere etc.) modify only one particular part within the clause and mark the speaker's assumptions regarding the content of the utterance and the interactant's shared knowledge and beliefs thereof (Fleischer et al. 2001: 272-3). The last group are Steigerungspartikeln or Intensivpartikeln 'intensifying particles' (e.g. sehr, ziemlich etc.), which serve to modify adjectives in order to boost or hedge their strength.

Another approach to categorising German particles focuses on the group of Gliederungspartikeln 'discourse structuring particles', which includes modal particles, interjections, backchannels and Vergewisserungsfragen 'question tags' such as ne or oder. These markers serve discourse structuring functions such as turn-taking and marking the beginning and end of discourse segments (Willkop 1988: 58-60). Auer and Günthner (2003), on the other hand, speak of German Diskursmarker 'discourse markers' to denote a set of forms such as nur, blo $\beta$ or jedenfalls, which have relative syntactic freedom and serve both discoursestructural and interpersonal functions in conversations. That some forms such as nur can be grouped in two or more categories further emphasises the multifunctional nature of these items and indicates that the categories are not distinct groups but based on the functions of items in specific contexts.

The majority of research into the uses and functions of German particles has focused on these modal particles. In comparison, German forms similar to English pragmatic devices, e.g. weißt Du 'you know' or ich mein 'I mean', have received little academic attention. Günthner and Imo (2003) were among the first to look at the use of ich mein in interactions. They showed that the construction is used not only according to its dictionary description, i.e. to precede a direct object or a complement clause as an expression of an opinion, but that it also serves as a discourse marker to introduce self-repairs, summaries or conclusions (Günthner and Imo 2003: 195). While Günthner and Imo (2003) also touched on the interactive functions of ich mein, the study of German pragmatic devices appears to have mostly concentrated on their textual functions. A closer investigation of 
these forms from a Politeness Theory and Rapport Management perspective would be a valuable addition to our understanding of German pragmatic devices.

\subsection{Cross-cultural pragmatics}

Politeness and Rapport Management Theory not only help to determine the conversational norms of one language, they also offer a framework for crosscultural comparison. Brown and Levinson (1987), for example, compare linguistic politeness in data from English, Tzeltal and Tamil. A comparison between conventions of giving compliments in Syrian Arabic and American English (Nelson et al. 1996) has demonstrated that Syrian Arabic compliments are much longer and more formulaic than in American English. Moreover, for a Syrian Arab male to compliment a female on her looks carries more romantic connotations than in American society and thus it could be considered culturally inappropriate if an American male were to compliment a Syrian Arab woman in this way.

Just as different cultures have different norms for the appropriate execution of speech acts, speech communities vary in their use of pragmatic devices. Since pragmatic devices are usually difficult to define semantically, translating them into another language can be challenging. This problem has motivated a number of contrastive investigations dealing with the comparability of pragmatic devices across a variety of languages. For example, Cárdenes Melián (1997) identified the Spanish equivalents of German modal particles aber, denn, doch and eben and Kärnä (1983) compared German with Finnish forms, while Weydt (1983) studied the different uses of mais, but and aber in French, English and German respectively.

The differences and similiarities between German modal particles and their English counterparts were investigated by Wauchope (1992). She concludes that, even though German has a greater variety of modal particles, English still has a number of particles that can express a similar range of meanings. Bublitz (1978: 226-7) suggests that German predominantly relies on modal particles to express emotive modality, while English uses a greater variety of prosodic, syntactic and lexical items for the same purpose. These include intonation, stress, tag-questions, 
interjections and quasi-interjectional words or exclamations and quasi-particles such as you know, you see, I suppose. Similarly, Fischer (2007) suggests that certain English relational words such as better and the subjunctive mood are able to convey the notion of common ground expressed by German modal particles.

All of these investigations used German as the base-line, trying to find comparable English constructions. Few studies have begun with English forms in order to determine the similarities with comparable forms in other languages. Overstreet's (2005) comparison of English and German General Extenders, i.e. expressions such as and stuff, and things like that, or something/ und so, oder so, oder was weiß ich, etc., is one exception to this. In her study, Overstreet (2005) extends the notion of General Extenders to comparable German forms and shows that there are many parallels between the two languages even on a pragmatic level. Nevertheless, Overstreet points out some subtle differences: English General Extenders seem to be used more often as intensifiers than in German and the German phrase oder was weiß ich (noch alles) does not appear to have an English functionally equivalent form. It remains to be seen whether other English devices and their German equivalent forms also serve similar functions.

\subsection{Interlanguage pragmatics}

Culture-specific interactional conventions become particularly obvious in crosscultural conversations when speakers' cultural and linguistic backgrounds influence their non-native language production. Originally, interlanguage studies focused on the structural properties of non-native speech such as syntax or phonology. More recently it has been acknowledged that pragmatics and culturespecific conversational conventions also play a crucial role in cross-cultural communication (Blum-Kulka et al. 1989: 9). Studies in interlanguage pragmatics have mainly dealt with differences in the execution of speech acts such as requests, invitations or apologies by native and non-native speakers. One example for this is Maeshiba et al.'s (1996: 181) study on the speech act of apologies by Japanese non-native speakers of English, which demonstrates that intermediate learners use "a less elaborate, first language-based approach to redress offences" as opposed to native speakers and more advanced learners. Morrison (2005) shows that in refusals, German non-native speakers of English often place the 
core rejection at the start of the refusal, followed by a number of redress strategies, whereas among native speakers of New Zealand English it is the other way around.

The potentially critical interpersonal effects of applying different pragmatic conventions were highlighted by House (2000). Adopting Spencer-Oatey's framework of Rapport Management, House (2000) examined intercultural misunderstandings in interactions between German and German-speaking American students in Germany. She points out that, in cross-cultural conversations, speakers often evaluate the interlocutor's communicative behaviour according to their own cultural norms. In these cases, different discourse behaviour is not always attributed to the person's cultural backgrounds but to their personality, which can lead to negative perceptions of the other speaker.

In evaluating the speakers' conversational preferences, House proposes that Germans show a greater preference for direct, explicit and content-oriented interactions while Americans favour verbal routines and interpersonally active discourse strategies. These different approaches to communication can not only lead to misunderstandings but also to cultural stereotyping and they can have serious personal consequences. Some of the American students commented that they felt offended by their German friends' lack of interpersonal attention and came out of the conversation liking them less than before (House 2000).

This tendency of German speakers to opt for more explicit and direct conversational strategies was also discussed in Günthner's (2001) investigation of German and Chinese expressions of politeness. She suggests that these different politeness strategies can be transferred to intercultural interactions. However, Günthner (2001: 131) also points out that awareness of the other's politeness norms can cause speakers to converge or even hypercorrect their linguistic behaviour so that in intercultural conversations speakers do not necessarily adhere to either L1 or L2 conventions but to a different set of conventions that are born out of the intercultural situation itself. Günthner's propositions would agree with the concept of linguistic convergence (Giles, Coupland and Coupland 1991: 5), 
where speakers conform to one another in order to minimise differences and therefore enhance interpersonal rapport.

\subsubsection{Factors influencing $L 2$ language use}

Many language learners first acquire another language in a classroom context long before they have the opportunity to talk to native speakers or even live in the relevant speech community. As a result, learners are not exposed to native speaker norms of communication, which leaves the acquisition of the pragmatic rules of a language in the hands of the teacher. However, even though theoretical and practical issues of teaching pragmatic devices in the classroom have been researched (e.g. Horst and Rump 1989; Rathmayr 1989; Möllering 2003), pragmatic devices are usually not taught in schools (Sankoff et al. 1997; Müller 2005). This makes the acquisition of pragmatic devices mostly a process of unguided learning and ultimately depends on the learner's access to native speaker interactions. In this sense, non-native use of pragmatic devices could be taken as an indicator of the degree of the speaker's communicative competence and their pragmalinguistic and sociopragmatic knowledge (Sankoff et al. 1997: 209-210).

The unguided acquisition of native speaker conventions is not always a smooth process. Its success seems to be dependent on a number of variables such as the level of the speaker's linguistic ability as well as linguistic, pragmalinguistic and sociopragmatic influence from the speaker's first language (Kasper 1998: 188). Studies investigating the learning of non-standard language by non-native speakers often differentiate between "which aspects of second language development and use are universal and which are specific to particular target and native languages, learning environments, and learner variables" (Færch and Kasper 1989: 221). With regard to universal aspects of language acquisition, it can be noted that the acquisition of an L2 word by a non-native speaker can be facilitated or impeded by a large variety of different factors, among them the specific properties of the word itself. Laufer (1990b) lists a number of these intralexical factors, such as the pronounceability, length, inflexional complexity and polysemous status of a word. Another factor influencing the acquisition of L2 vocabulary is the degree of semantic overlap of L1 and L2 words. This is reflected 
in a vocabulary acquisition tactic that is commonly used among second language learners in which the learner merely re-labels a familiar or native concept with an L2 word (Laufer 1990a). This technique has been referred to as the semantic equivalence hypothesis (Ijaz 1986: 443). Ijaz (1986: 443) states that, generally, learners seem to favour "lexical/semantic structures that [have] close equivalents in their native language". It remains to be seen whether this also applies to the use of pragmatic devices.

This particular learning strategy also seems to be at the core of instances of L1 transfer, related to particular features of the first and target languages involved. Corder (1992: 29) points out that "since successful communication does not entirely depend upon the formal correctness of the utterance, items and features which have been borrowed but which are not similar to the target language may get wrongly incorporated into the interlanguage system giving rise to error which may sometimes be fairly persistent". Thus, when there is not a direct correspondence between L1 and L2, and when "concepts underlying words in the L1 are transferred to the L2 and mapped onto new linguistic labels, regardless of differences in the semantic boundaries of corresponding words" (Ijaz 1986: 405) this can lead to incorrect or non-native-like uses of L2. This process has been observed by Dagut (1977) in his analysis of common lexical errors made by Hebrew speaking learners of English. According to his study, Hebrew speakers often fail to make lexical distinctions between two separate English concepts such as poem and song or shade and shadow as Hebrew uses only a single word for them.

Conversely, L1 interference can also occur when non-native speakers have to learn one L2 word that covers the semantic field of several L1 terms. Laufer (1990b: 303) notes that learners often encounter problems with the comprehension and acquisition of the different meanings of polysemous L1 words. This type of difficulty has been illustrated by Ijaz's (1986) study on the use of English prepositions by native speakers of English and advanced L2 learners. Ijaz found that German non-native speakers' frequent incorrect use of at can be related to L1 transfer. The English preposition on covers a semantic field that is roughly divided into two separate concepts in German which require two lexical items, auf 
('on top of') and an ('by', 'next to') (Ijaz 1986: 434-5). However, in a number of contexts the semantic dimension of German an also coincides with that of English at, which Ijaz (1986: 435) considers to be the closest translational equivalent to German an. German L2 speakers exhibit a tendency to favour the use of English at in contexts where on would have been appropriate when an would have been used in German. This suggests that, in the case of prepositions, German speakers re-label their native semantic concepts with a new English word, thereby imposing the distinction they make between concepts in L1 on L2 in a way that does not conform with how the terms are used in L2.

While it seems possible that native speaker interlocutors pick up on relatively overt cases of lexical L1 interferrence like the ones mentioned above, this might be different for the pragmatic aspects of a language, such as speech acts or pragmatic devices. For example, Færch and Kasper (1989) show that Danish learners of English often use a specific syntactic construction for requests that is perfectly appropriate and polite in Danish but conveys annoyance in English. In these cases, functional L1 transfer seems to happen mostly subconsciously and often goes unnoticed by both native and non-native speakers, potentially with negative interpersonal consequences (see section 2.4.). Generally speaking, though, it seems that if the native and the target languages are closely related, learners often come close to native speakers' language use in terms of the amount of face work used and the types of interactional strategies employed (Færch and Kasper 1989: 244-5).

Another influential variable that affects non-native speakers' linguistic performance and influences the occurrence of transfer appears to be the speakers' knowledge of the pragmatic conventions of a language and their level of linguistic proficiency (Kasper 1998: 196). L1 transfer can occur with both high and low proficiency speakers. For example, some advanced L2 speakers may transfer L1 norms because they have learnt the relevant words to do so, while the speech of others does not have signs of L1 interference because they have a higher sociopragmatic and pragmalinguistic awareness. Factors such as exposure to native speakers and a general pragmalinguistic awareness that allows language learners to pay attention to and notice particular constructions (Schmidt 1990) 
help non-native speakers acquire pragmatic conventions. This suggests that L2 performance is dependent on a range of personal variables, which makes them difficult to predict and explain.

\subsubsection{Non-native use of pragmatic devices}

The occurrence of pragmatic devices in discourse has been described as "a kind of lubrication in dialogue" (Durrell 1996: 173) which helps create a more informal and personal conversational setting and ensures that the speaker is not considered "awkward to talk to" (Svartvik 1980: 171). Therefore, their appropriate use seems to be a relevant topic for interlanguage pragmatics. Nevertheless, while speech act performance by non-native speakers has been studied in interlanguage pragmatics since the 1980s, non-native use of pragmatic devices has only received a small amount of academic attention. In addition to finding marked differences in the uses of pragmatic devices by native and non-native speakers, researchers have commented on the influence of L1 interference on both the form and function of non-native uses of these devices.

Instances of L1 influence on the use of pragmatic devices for both form and function have been observed in several studies. For instance, Cheng and Warren (2001) found that non-native speakers of English with a background in Cantonese were more likely to use tag questions as invariant tags, disobeying the rule that a positive or negative tag questions has to be in contrast with the proposition. Moreover, non-native speakers were found to use pragmatic devices more for expressing propositional uncertainty while their native interlocutors tend to use them for politeness functions. Cheng and Warren argue that these characteristics can be linked to the form and function of tags in Cantonese, making this a case of L1 transfer. A relatively clear case of functional L1 transfer was found in an investigation of the language of Anglophone speakers of Montreal French (AMF) (Sankoff et al. 1997). The researchers noticed that the use of the French device comme 'like' by AMF seems to be influenced by English like. The most prominent evidence for this suggestion is AMF's use of comme as a quotative marker. This quotative function is a typical feature of English like, however, it is not part of the functional repertoire of French comme. Similarly, Aijmer (2001: 256) found that Swedish students writing argumentative texts in English "overuse 
I think in order to make their claims more persuasive and to provide more weight to issues discussed while native speakers use a less rhetorical style". She suggests that this use of I think might correspond to different writing conventions for argumentative texts in Swedish.

Other studies have focused on the effects of native speaker interaction on the use of pragmatic devices by non-native speakers. Thus, Sankoff et al (1997) propose that là, a characteristic feature of Montreal French, was only used by AMF who were exposed to Montreal French in their childhood. Furthermore, it seems that the age of arrival in a foreign country also has an impact on the speaker's use of pragmatic devices. Lee's (2004: 121) study of the speech of different generations of Korean immigrants to the United States shows that speakers who arrived in the United States before the age of 18 use pragmatic devices more often than speakers who arrived after 18 and second generation immigrants. It is suggested that one reason for this trend could be that this particular group "is under the most pressure to assimilate to linguistic and cultural norms and therefore may have pressure to appear competent in English by attempting to produce continuous flowing speech" (Lee 2004: 121). As noted in Aijmer's (2001) study on I think, this pressure can result in overgeneralisation and excessive use of certain forms. Generally speaking, though, the literature indicates that non-native speakers appear to use pragmatic devices less than native speakers (e.g. Nikula 1996; Müller 2005; Overstreet 2005).

This trend for non-native speakers to use more overt and direct rather than implicit strategies has also been observed for the uses of pragmatic devices by native speakers of English and Finnish non-natives of English (Nikula 1996). Nikula proposes a model which divides pragmatic devices into explicit and implicit forms. According to this approach, forms such as I think, sort of, kind of or GEs are considered to be explicit as they openly convey the speaker's degree of commitment towards the proposition or "their willingness to leave their message vague" (Nikula 1996: 52). Forms such as you know, I mean, like, well or tag questions, on the other hand, are categorised as implicit because their functions are "not as closely tied to the literal meaning of these expressions" (Nikula 1996: 52). This differentiation between pragmatic devices appears to be problematic as 
the definitions of the categories leave room for interpretation, making the classification unclear and difficult to replicate. For example, I mean is considered to be an implicit device even though it often appears to rather explicitly mark a self-correction on a discourse functional level. These inconsistencies notwithstanding, Nikula's results indicate a preference for explicit pragmatic devices among Finnish NNS, while native speakers prefer implicit devices. In this case, though, the study shows that this marked preference for explicit devices by Finnish NNS cannot be found in the native Finnish data and therefore is not necessarily related to $\mathrm{L} 1$ transfer.

The most comprehensive study on the use of pragmatic devices by GNNSE was conducted by Müller (2005). Her study looked at the differences in the uses of so, well, you know and like by native and non-native speakers in the Giessen-Long Beach Chaplin Corpus (GLBCC). The results suggest that GNNSE use the selected pragmatic devices for mostly the same functions as identified in the native speaker data, albeit in different frequencies. Moreover, GNNSE appear to use well not only more often than American speakers overall, but also in more functions, with four functions being used significantly more frequently by GNNSE than by native speakers. Müller (2005: 250) proposes that the linguistic behaviour of the non-native speakers might have been influenced by English text books in German schools, as these include devices such as well and so but not you know.

With regard to L1 transfer, Müller indicates that speakers might consciously try to avoid translational equivalents of German forms and prefer to use more English sounding forms instead. However, while a general preference for more typically English sounding pragmatic devices might have an influence on the forms and frequencies used by non-native speakers, the sub-conscious nature of the use of pragmatic devices makes it unlikely that non-native speakers are able to monitor themselves continuously when using these forms. Müller (2005: 251) also identifies translational equivalent forms in a speakers' L1 as another potential area that may influence the use of pragmatic devices by non-native speakers. A small scale investigation of the correlation between you know and the German translation equivalent weißt Du/weißte suggests that there might be a connection 
regarding their frequency of use. A more in-depth analysis of German translational equivalents and how they correlate with the forms used by nonnative speakers will shed further light on the issue of L1 transfer.

\subsection{The present study}

Despite an increased interest in non-native uses of pragmatic devices in the last ten years, research in this area is still relatively under-developed. Most previous studies in this field have focused on patterns and factors that might contribute to the acquisition and native-like application of these devices. The present study will enhance what is known in this area, particularly with regard to the uses of pragmatic devices by GNNSE and the effect of L1 interference from close German translational equivalents. As Müller's (2005) investigation of GNNSE focussed on a limited number of devices, the present study offers the opportunity to expand the analysis to a range of different devices, thereby contributing to what is already known about the specific applications of pragmatic devices by GNNSE. Moreover, since Müller's (2005) analysis concentrated primarily on the discourse structural functions of these forms, an approach with an emphasis on the interpersonal and rapport enhancing functions will provide a more balanced and rounded picture of non-native uses of these devices. In this sense, this study addresses the following overall research question:

Are there differences in the uses of pragmatic devices by native speakers of New Zealand English (NSNZE) compared to German non-native speakers of English (GNNSE)?

In examining this general issue, a number of more specific questions can be identified. The first task involved in answering this question is the selection of suitable forms for further analysis. Müller (2005: 26) uses a combination of practical and theoretical factors by selecting the most promising and academically interesting devices from the most frequently occurring forms. This procedure ensures that the data contains enough examples of the selected items. Following Müller's approach, quantitative analysis of a wide range of pragmatic devices in the corpus was undertaken. 
Furthermore, as mentioned above, it has been suggested that the use of pragmatic devices in the first language of non-native speakers may have an influence on their use in the L2. However, since Müller's (2005: 251) study took only a cursory look at this issue through mentioning a quantitative analysis of you know and weißte/weißt $\mathrm{Du}$ in comparable corpora, it seems that this issue of L1 transfer deserves further attention. In relation to this, the issue of what constitutes a comparable form may be of interest: some forms will have clear structural equivalents that may not be exact translations of the English forms, whereas other devices may share comparable syntactic positions, phonological shapes or interpersonal functions. Thus, in addition to finding comparable forms, a comparison of the functions of corresponding pragmatic devices in English and German is required to identify cases of L1 transfer. Based on these considerations, the present study also addresses the following set of more specific questions:

\section{1. a) Which English pragmatic devices in the corpus most clearly deserve close examination? What are their German counterparts? \\ b) Do these selected English pragmatic devices and their German equivalents serve comparable sociopragmatic functions?}

The analysis of non-native uses of pragmatic devices requires a comparison between native and non-native conventions for both frequencies and functional application (e.g. Nikula 1996; Müller 2005 etc.). Nikula (1996) suggests that nonnative speakers prefer explicit forms over implicit ones and Müller (2001) has shown that German non-native speakers differ somewhat from native speakers of English in their functional application of these markers. An analysis of the corpus of cross-cultural interactions between GNNSE and NSNZE collected for this study will allow evaluation of these previous findings. The present investigation does not attempt to compile the entire inventory of pragmatic devices contained in the corpus, and since the distinction between explicit and implicit markers is not considered a useful method of consistently and reliably grouping pragmatic devices, Nikula's (1996) framework is not applied to the data. Instead, the study follows Müller's (2001: 12) stance of taking a corpus driven approach to the data where all data is analysed and described on its own merit without superimposing other researchers' categories. 
2. Are there differences in the use of English pragmatic devices between NSNZE and GNNSE in terms of frequency and function?

The next step in the analysis of the data is an examination of the contrasts and similarities between the use of forms by GNNSE and the forms that occur in the native German data. This analysis includes a comparison of the frequencies of English forms and their German equivalents. These findings will then be used to predict potential areas of transfer, including the transfer of form, function, application or syntactic positions within the clause. The uses of pragmatic devices by GNNSE are then contrasted with the German conventions to identify actual cases of L1 transfer. These issues are incorporated into the more generally phrased research question:

3. Can L1 transfer be observed in the use of pragmatic devices by GNNSE?

Previous investigations of non-native use of pragmatic devices have considered a range of factors that might influence the frequency of certain forms, such as speaker role, L1 interference or the speaker's proficiency level. However, most studies have not considered how the linguistic behaviour of a native speaker interlocutor relates to the non-native speaker's language use nor how native speakers' use of pragmatic devices differs depending on whether they are talking to a native or a non-native speaker. Therefore the present study also investigates the following question:

\section{Do NSNZE modify their discourse strategies and use of pragmatic devices when talking to GNNSE?}

The last issue of interest is how the factors of L1 interference, non-native speech and native speaker language use influence intercultural communication. The following question thus examines the effects of the use or omission of pragmatic devices in individual conversations as well as identifying areas of interest for second language teaching and pinpointing issues that require further research:

5. a) What are the implications of the findings for cross-cultural communication?

b) Is the use of pragmatic devices in conversations a source of potential miscommunication? 



\section{Methodology}

This chapter describes the methodology of the present study. It discusses the theoretical issues in the methodological design. Then it provides an account of the data collection process. In particular, this section describes the setting for recording the corpora, including the advantages and disadvantages of the chosen approach. This chapter considers relevant aspects regarding the participant recruitment process and finally presents relevant background information relating to the interactants.

\subsection{Data collection techniques}

As discussed in chapter 2, the present study focuses on the textual and interpersonal uses of pragmatic devices and examines correlations between L1 norms and L2 performance, as well as whether native speakers of English change their usage when talking to non-native speakers. Like Nikula's (1996) study of non-native use of pragmatic devices, these questions require data from three parallel corpora: one set featuring native New Zealand English interactions, one set of native German interactions, and thirdly one set of English conversations between NSNZE and GNNSE. This allows for the study of culture specific patterns in the uses of pragmatic devices for German and New Zealand English.

\subsubsection{Discourse Completion Tests}

On the assumption that pragmatic devices are a feature of informal speech, the collection of natural conversational data seems to be the most valuable approach. Other data collection techniques commonly used in pragmatic research, such as role-plays or written discourse completion tests (DCT), do not appear to be appropriate means for the present study. While the DCT technique has been used in studies on pragmatic devices by Hentschel and Weydt (1983), their main 
objective was to establish the affects of the particles denn and eigentlich on a proposition. As I am interested in the uses of pragmatic devices in discourse rather than in whether speakers are aware of their functions, a DCT does not promise to yield useful data for the present investigation. Moreover, the fact that written DCTs require participants to note their reply to a contrived prompt means that the results depend on the participants' ability to "imaginatively place themselves in the scenario" (Morrison and Holmes 2005: 49). Since speakers are generally unable to objectively report on their own language use (Wolfson, Marmor and Jones 1989: 181-2), this could affect the participants' response in that it "may not correspond to the way speakers would behave in spoken interactions" (Nikula 1996: 58), both with regard to the length of the reply and particularly the amount of face work employed (Wolfson, Marmor and Jones 1989: 183; Morrison and Holmes 2005: 59). Thus, instead of serving as a means to collect natural and spontaneous talk, written DCTs are mainly used to investigate the patterns of what speakers perceive as the stereotypical appropriate response or speech act (Beebe and Cummings 1996: 80). This technique also seems unsuitable for the present research as non-native speakers might approach the filling in of a written DCT as a writing task and produce more complex language than they would in normal interactions (Hinkel 1997).

\subsubsection{Role plays}

Role plays are often considered to be similar to DCTs as they also create an artificial situation in that participants are asked to act out a certain situation on command (Morrison and Holmes 2005: 50). Closed role plays, which provide participants with specific directions regarding the expected reactions and outcomes of a situation, are often regarded as spoken versions of DCTs, producing results of similar quality (Gass and Houck 1999: 27 as cited in Morrison and Holmes 2005: 50-1). On the other hand, open role plays, which merely outline a situation without prescribing the outcome, are believed to elicit data that seems much closer to natural speech (Morrison and Holmes 2005). Nevertheless, the simulated setting is likely to have an impact on the language use such as the amount and nature of the face work used. Moreover, even though imposing a particular conversational scene on the participants may guarantee comparability across the data, it also restricts the type of strategies and pragmatic 
devices used to perform these speech acts. DCTs and role-plays have proved to be valuable strategies to obtain comparable and quantifiable data on speech act performance. However, these techniques are not useful approaches for the current research as they elicit written language or language from artificial settings and therefore do not adequately represent the use of pragmatic devices in discourse.

\subsubsection{Conversational tasks}

Another data collection technique that has been used for the study of pragmatic devices is an experimental design where participants are asked to engage in a communicative task such as a picture description, the retelling of a story or a map task (e.g. Meyerhoff 1986, Müller 2005 and Miller and Weinert 1996 respectively). The influence of a conversational task on the participants' language can be seen in Meyerhoff's (1986) investigation of gender differences in the use of hedges in New Zealand English. For her data collection, Meyerhoff used a picture description task involving a relatively unclear picture by Dürer, since it seemed to provide the participants with a topic that was likely to require the use of hedges. Her study suggests that this is an effective approach as her participants produced sizable amounts of hedges such as the content oriented devices sort of, kind of and general extenders. An advantage of the experimental design is the high degree of comparability between the different conversations with regard to speech situation and content. After all, even though the study of pragmatic devices should ideally be based on natural conversational data, the collection of such naturally occurring interactions is difficult to organise and the recorded conversations are also bound to be influenced by a range of external variables, which makes it difficult to compare the results. On the other hand, using such a methodological design has the disadvantage that "due to the experiment design, it [can] not be expected that all discourse markers would be used, nor that those which occurred would be used in all their functions" (Müller 2005: 34). In this sense, the provision of strict conversational tasks might not be the best approach to collect data on the patterns of use of pragmatic devices in general. 


\subsection{Methodological design}

\subsubsection{Recordings and questionnaires}

In order to simplify the collection of naturalistic if not natural conversational data, I decided to follow Nikula's (1996) methodological design and record interactional data in a controlled setting. Participants were asked to conduct, record and video-tape a conversation in a neutral room at a university campus. However, unlike Nikula's approach to use different participants for each interaction, I decided to ask the speakers to participate in two conversations, one with a German and one with a New Zealander. This approach has the advantage that potential individual characteristics in the use of pragmatic devices and other discourse management strategies can be taken into consideration for the analysis. In addition a direct comparison between the two speech situations is possible.

Instead of using groups of four as Nikula did in her study, I decided to limit the number of interactants to two. Even though a larger group of speakers might help create a more relaxed conversational atmosphere, it was decided to rely on dyads since it is easier to transcribe transactions between two than between four conversants, as it minimises the occurrence of overlap and facilitates the identification of speakers (Holmes 2003). The data collected from the video and audio recordings was further supplemented by a brief questionnaire. At the end of each recording the participants were invited to fill in a short questionnaire which asked them to indicate on a one-to-five scale how much they enjoyed the conversation and how much they were aware of the microphone and the videocamera. Participants also filled in a background information sheet which served to identify the person's age-range, ethnic identity, education, socio-economic background, major subject of studies, extended stays in English speaking countries and any relationship with the interlocutor prior to the recording. NSG were asked to provide additional information about when they arrived in New Zealand and about when they started using English for social purposes (see Appendix 1 for the questionnaire and the Background Information Sheet). 


\subsubsection{Observer's paradox}

To sit down in a somewhat impersonal university room to record a conversation with a complete stranger is likely to be perceived as stressful by the participants. Therefore, it was important to remove additional sources of stress in order to minimise any effects on the language use. The impact of the Observer's Paradox (see Labov 1966) was reduced by recording the dyadic conversations in the absence of the researcher. On top of audio recordings, video tapings were used to collect information on the provision of non-verbal feedback, body posture and gestures which could give clues regarding the interpersonal relation between the speakers. Considering, however, that the video recorder adds another element of intrusion, the participants were asked prior to the recording whether they would be comfortable being videoed. Most participants agreed to the video-taping. However, if a conversant expressed concern either initially or after the first recording, the video camera was switched off or completely removed from the room. All together, 55 out of 60 conversations were video-taped. For the most part, the video recordings were not used for the data analysis as the recordings proved to be sufficiently rich and a detailed analysis of this additional material would have been beyond the scope of this thesis. However, the video data was consulted in one instance when it sounded like non-verbal elements were used to make a point (see Example 92).

Generally speaking, leaving the interactants alone during the recording proved to be an effective procedure as most participants reported that they forgot about the recording devices after a few minutes and overcame the initial awkwardness of the situation. A few dyads even got on so well that they exchanged email addresses in order to meet up again at a later stage. All interactions were recorded onto minidisc using a sound-grabber microphone and most were video-taped with a VHS video-camera.

\subsubsection{Suggested topics and picture description tasks}

In Nikula's design, the participants were allowed to talk about whatever they wanted. However, she also offered them suggested topics they could use in case they could not think of anything or were running out of things to say. In addition to offering the participants suggested topics, I also decided to include small ice- 
breaker games the participants could choose to play. These materials were printed on paper, laminated and placed so that the participants could not initially see what was on them. The task and the topics were incorporated into the set-up to give the participants the freedom to do and talk about what they would be most comfortable with and thereby ensure that the participants felt as much at ease as possible. The decision to give participants a number of options for their conversations was supported by feedback from the pilot study. Most speakers agreed that suggested topics and games would be helpful if interlocutors did not know each other. One person stated that he did not like participating in any form of game or task so that forcing him to do so could be counterproductive and reduce his engagement in the conversation. Nevertheless, the provision of suggested topics and a task often generated useful stretches of talk even if the interaction was about negotiating whether or not the interlocutors wanted to use the provided materials. This sometimes extended to making fun of them. Encouraging the participants to talk about the same topics also allowed for a more direct comparison between the different sets of interlocutors.

Another reason for the inclusion of suggested topics and small tasks was to encourage the use of pragmatic devices; research has shown a connection between the use of pragmatic devices and specific discourse situations (Allan 1990; Meyerhoff 1994; Holmes 1995; Britain 1998). You know and eh, for example, have been found to occur more often in sustained narratives where the speaker negotiates a common ground with the listener (Holmes 1986: 15; Holmes 1995: 91; Stubbe and Holmes 1995: 83), while the speaker-oriented forms I think and I mean are more closely associated with the expression or modification of personal opinions and argumentations (e.g. Aijmer 2001). Prompting participants to engage in a discussion or provide a narration would therefore increase the likelihood of pragmatic devices being used.

One difficulty of including suggested topics into the set-up of the data collection was to find topics that both Germans and New Zealanders would find sufficiently appealing without them being too personal and face threatening. After all, while some participants might accept the proposed topics and engage in a lively discussion, others might not know much about a specific subject or might just not 
be interested in it. In this sense, the same theme might produce very different sets of data depending on the participants involved. Moreover, it was also important to choose the questions carefully to cover a range of discourse situations, e.g. discussion and narration, in order to avoid a bias towards specific pragmatic devices. These issues were taken into consideration in the selection of suggested topics.

\subsubsection{The pilot study}

In the pilot study I tested a range of discussion and narrative topics, picture description tasks, and problem solving tasks with six participants. This helped to establish the usefulness of each item and tested the best way of combining questions with tasks. Moreover, the pilot study gave me an opportunity to trial the execution of the data collection, i.e. the set-up of the equipment, what instructions to give, and the value of the questionnaire. Based on the participants' feedback and the recordings of the pilot study, I decided on two sets of questions: one for native-native conversations and one for native-non-native conversations. Each set included one general discussion topic and one topic designed to encourage narration. For the native-native conversations I selected questions about their position on the introduction of the ban of smoking in bars in New Zealand and encouraged narratives by asking about their most memorable holiday experiences. The cross-cultural conversations were supplied with a discussion-prompting topic regarding the legal drinking age and questions about the participants' university experiences to encourage narratives. The pilot study showed that a problemsolving task would be too complex and time consuming and so it was decided to provide both native and cross-cultural interactions with different description tasks.

On the whole, most participants looked at the tasks and the topic suggestions, but most groups decided not to use them. Only five dyads chose to do the picture description task, some using it at the start of the conversation and some towards the end. The interactions relating to the picture description task were transcribed but not included in the final corpus used in this study. This is because they artificially generated an increased use of content-oriented devices, which would make comparison across conversations less valid. 
Part of the original methodological design included the use of audio-visual materials to promote discussion, as it was hoped that this might ensure that both participants had the same knowledge basis which could help to overcome topicspecific inhibitions. Anti-smoking ads that are regularly screened on New Zealand television were considered to be useful lead-ins to a discussion on shockadvertisement practices and the impending smoking ban in bars. In addition, a beer commercial was used as a starting point for a discussion on sexism in advertisement. However, in the course of the pilot study it became clear that including extra audio-visual material involved giving even more instructions to the participants, which was sometimes rather unnerving for them. Moreover, it increased the technical complexity and physical effort on my part as carrying, handling and setting up the equipment turned out to be quite difficult to manage. Thus, the final decision to remove the anti-smoking advertisement from the set-up was made after forgetting the tape for the first recording session. Unfortunately, this meant that the question still had a reference to the clip that they were supposed to watch. Even though this caused momentary confusion among some participants, all speakers appeared to be familiar with the type of commercial so that they were able to continue the conversation regardless.

To summarise the data collection process: Participants were asked to take part in the recordings of two dyadic conversations, one with a German and one with a New Zealander, conducted at a small study room at the Language Learning Centre at Victoria University of Wellington. All participants read an information sheet containing the relevant details about the researcher and the research study and signed a consent form before the recording began (see Appendix 2 for the Information Sheet and Consent Form). The interactants were provided with juice to drink and were told that they were free to talk about anything they wanted to. It was pointed out that cards with suggested topics and the picture description tasks were at their disposal if they wanted to use them and the cards were either folded or placed upside down so that their content was not immediately visible. After the participants agreed to being videotaped, the video camera and the mini-disc player were set to start recording and the participants were left to their own devices for about 15 to 25 minutes, depending on the time available. At the end of the 
recordings, the participants completed a background information sheet and a feedback form asking for their perception of the conversation.

It is acknowledged that the speech collected in this study is not representative of informal relaxed conversation. However, the interactions were authentic and genuine. Participants used spontaneous and natural speech to conduct a conversation and establish good rapport with a stranger. This authentic situation provided recorded data suitable for the purposes of the current study.

\subsection{Participants}

\subsubsection{Age, ethnicity and language background}

In order to minimise the influence of variation in the speakers' backgrounds on their language use, I tried to recruit people with very similar profiles. All participants were either native speakers of NZE or German, i.e. have lived in and attended school in that country since they were 10 or younger. All participants were between 20 and 30 years of age, and all but two were enrolled at Victoria University at the time of the recording: one female NSG had already finished her degree and was working as a research assistant and one female NSNZE had attended Art School and was working in a bookshop at the time. Ethnicity was also controlled as a personal variable. Due to some recorded linguistic differences between Pākehā and Māori New Zealanders (i.e. New Zealanders of European descent and descendants of the indiginous indigenous New Zealand population) such as the use of the particle $e h$ as a marker of in-group solidarity and cultural differences (Meyerhoff 1994), it was decided to concentrate on Pākehā New Zealanders. Nevertheless, because it did not always seem appropriate or necessary to check participants' ethnicity prior to recordings, the NSNZE population contains two speakers who identified as Māori, one as NZ Tongan and one as NZ Chinese. One participant turned out to be bilingual in German and English as she was born in Germany and moved back and forth between Germany and New Zealand until 1995. I decided to add her to the NSNZE group because she was a native speaker of NZE and at the time of the recording she had lived in New Zealand for about nine years at a stretch of time. Bearing in mind the rather large range of individual variation within each group, there is no evidence in the data 
that suggests that the ethnic identity of the NSNZE had a noticeable influence on the frequency of use of pragmatic devices by these participants.

\subsubsection{Gender}

In this study, gender is considered to be a potentially relevant variable in the use of pragmatic devices. Unfortunately, the scope and timeframe of this thesis did not allow for a detailed investigation of gender differences. However, in order to ensure that the corpus contained balanced data, it was decided to include the same numbers of male and female speakers. This also included matching them in even numbers of same-sex as well as cross-sex dyads. 30 Germans and 30 New Zealanders were recruited in order to provide a reasonable basis for quantitative analysis. Both sets consisted of 15 females and 15 males, which were then matched in 10 female same-sex dyads, 10 male same-sex dyads and 10 mixed-sex dyads. Since the cross-cultural dyads were to be compared with data from the native speakers of both languages, the same native speakers of both languages were further matched into 5 same-sex male, 5 same-sex female and 5 mixed-sex dyads each. Thus, there were 30 GNNSE-NSNZE dyads, 15 NZE and 15 German dyads. The distribution of male and female speakers across the German and the New Zealand population and the number of dyadic conversations in the different male and female combinations is represented in Table 1.

Table 1: Distribution of participants in dyads according to gender and first language

\begin{tabular}{llll}
\hline & NSNZE & NSG & GNNSE-NSNZE \\
& $30(15 \mathrm{~F} / 15 \mathrm{M})$ & $30(15 \mathrm{~F} / 15 \mathrm{M})$ & \\
\hline Female-Female & 5 & 5 & 10 \\
Male-Male & 5 & 5 & 10 \\
Female-Male & 5 & 5 & 10 \\
Total & 15 & 15 & 30 \\
\hline
\end{tabular}

\subsubsection{Interpersonal relationships}

The final participant variable that was controlled in the data collection was the relationship between the speakers. In my pilot study, I used dyads of native-native and native - non-native acquaintances who had known each other for at least a 
few months. The problem I had to face with this approach was that some Germans who were asked to participate in the pilot did not know any New Zealanders or felt genuinely uncomfortable asking them to participate. This put them under a fair amount of stress before the recording even began and therefore this was deemed not to be the best approach. Moreover, it seemed rather unlikely that I would find many German-New Zealander dyads who have known each other for a similar amount of time and who have comparable relationships. While some might know each other from class, others might know each other from flatting together, both of which might result in different degrees of intimacy and therefore different patterns of interactions. These problems were finally avoided by adopting Nikula's approach of recruiting participants who had never met before. Nikula (1996: 60) states that, since all participants were university students, the interaction would be of social consequence as the interactants might run into each other again on campus. In other words, even though they did not know each other and might not meet again afterwards, the participants were likely to want to make a good impression. While it cannot be guaranteed that the interlocutors establish a good rapport, the fact that all participants volunteered for the project is considered to be a good indication that they were willing to make an effort. However, as there is only a small pool of German speakers enrolled at university each year, it was unavoidable that some dyads had met before: four NSG dyads and two NSNZE dyads were acquainted to some degree before the recording took place. Again, this fact does not seem to have had a noticeable impact on the speakers' uses of pragmatic devices.

\subsubsection{Time spent in New Zealand and NSGs' English language skills}

Other variables that might influence the data could not be controlled for but were noted and taken into consideration in the data analysis. One of these was the German speakers' length of stay in New Zealand prior to the recordings. Length of stay varied between approximately two months and six years at the time of the recordings.

Similarly, all German participants had varying degrees of exposure to English before coming to New Zealand. For example, some speakers had learned English exclusively in the classroom at school while others had overseas experiences 
before coming to Wellington. Three German speakers had English speaking parents or family members and one of them also attended an English speaking school for some time. Nevertheless, even though these speakers had been exposed to English at an early age, all of them stated that they did not have a bilingual upbringing.

No proficiency tests were conducted with the GNNSE group and no data on official language test results such as IELTS or TOEFL were collected. In the following, any reference to individual levels of language proficiency are based on my own subjective evaluation of their speech with regard to the level of fluency (e.g. to what extent they hesitate in order to search for a word and the number of time they do not know a word) overall impression of their confidence in their speech, the appropriate use of non-standard English and Kiwi-isms and the extent of their German accent. Based on these criteria, there were a few GNNSE I considered to be more proficient than others. Notably, this group included, among others, many GNNSE with family connections to English and speakers who have lived in an English speaking country for a long time. However, not all GNNSE with such a background were considered to be high proficiency speakers. Similarly, those speakers who appeared to hesitate more in their speech and those who appeared more insecure were regarded as less proficient, regardless of their background. While this is not an accurate measure of an individual's levels of proficiency, it gives an indication of the different levels of language use among GNNSE and it might help give a better idea with regard to what factors influence the use of pragmatic devices among non-native speakers.

\subsubsection{Ethical issues}

All participants included in this study were fully aware that they were being recorded for linguistic research. However, they were not informed about the exact focus of the study. Participant recruitment and recording started only after ethical approval was given. NSNZE participants were recruited by means of posters that were put up on notice boards all over university and by personal connections. German speakers were recruited via posters and through an email asking for German participants sent to all international students through the international office at Victoria University of Wellington (see Appendix 3 for the English version). German participants were also recruited through my German network 
and I additionally volunteered as a helper during Orientation Week for new international students specifically to meet more Germans. Furthermore, another study comparing the language use of New Zealanders and Germans was conducted at the school at the same time and volunteers recruited for that study were referred to mine and vice versa. At the end of their second conversation, participants received a $\$ 15$ book or music voucher as a token of appreciation for their time.

\subsection{Transcription}

At the beginning of the transcription process I explored several options for obtaining the relevant data from the corpus of recording. Close transcriptions are time-consuming and require a high degree of concentration since pragmatic devices are often phonologically reduced and therefore difficult to hear. An initial test examined the accuracy of merely listening to the recordings and making notes to keep count of the occurrences of one particular pragmatic device. This approach proved to be highly unreliable. In some cases the listening method yielded fewer tokens than was accurate whereas in other cases it produced a noticeably higher count. This method would also require some transcription as not having a written record of the examples would make a qualitative analysis more challenging.

I also explored to what degree a five minute excerpt would be representative of the twenty minute conversation. The trial showed that this method was only partially reliable, as some pragmatic devices were used relatively consistently whereas others occurred in varying frequencies throughout the conversations. On the whole, it seemed that this approach did not markedly affect the relative occurrence of frequently used pragmatic devices. However, this method does not account for the infrequently occurring devices. In the end, mainly due to time restrictions, it was decided to complete close transcriptions of 30 complete conversations and close transcriptions of 10 to 15 minute excerpts of the remaining 30 conversations. The 10 minute excerpts were taken starting from 10 minutes into the conversation as the speakers were most likely to have become comfortable with the recording situation at that point. 
Unfortunately, because the decision to not transcribe all interactions in full was made after beginning the process, the number of full transcriptions are not evenly distributed across the various sub-corpora. As a result, the majority of nativenative but only slightly less than half of the cross-cultural interactions were transcribed in full. Moreover, only 8 out of 20 male-male interactions were transcribed in full as opposed to 12 out of 20 for the female-female interactions. This difference can be seen when looking at the overall size of the male-male corpus which features noticeably fewer words than the other sets as shown in Table 2. This is particularly true for the German male-male interactions. In this group, only 1 conversation out of 5 was transcribed in full, which would explain why this sub-set contains the smallest number of words of all corpora.

Table 2: Number of words in sub-corpora

\begin{tabular}{|c|c|c|c|c|}
\hline & NSNZE-NSNZE & NSG-NSG & GNNSE-NSNZE & Gender Total \\
\hline \multirow{3}{*}{$\begin{array}{l}\text { Female- } \\
\text { Female }\end{array}$} & \multirow[t]{3}{*}{20,174} & \multirow[t]{3}{*}{22,859} & 37,415 & \multirow[t]{3}{*}{80,448} \\
\hline & & & (GNNSE 19,161 & \\
\hline & & & NSNZE 18,254$)$ & \\
\hline \multirow{3}{*}{$\begin{array}{l}\text { Male- } \\
\text { Male }\end{array}$} & \multirow[t]{3}{*}{17,637} & \multirow[t]{3}{*}{14,947} & 31,197 & \multirow[t]{3}{*}{63,781} \\
\hline & & & (GNNSE 17,626 & \\
\hline & & & NSNZE 13,571$)$ & \\
\hline \multirow{3}{*}{$\begin{array}{l}\text { Female- } \\
\text { Male }\end{array}$} & \multirow[t]{3}{*}{21,058} & \multirow[t]{3}{*}{22,080} & 36,971 & 80,109 \\
\hline & & & (GNNSE 16,343 & (M: 42,999 \\
\hline & & & NSNZE 20,628) & F: 37,110) \\
\hline Total & 58,869 & 59,886 & 105,583 & 224,338 \\
\hline
\end{tabular}

Although there are obvious shortcomings with this transcription procedure perhaps most notably that it did not sample all interactions equally - it did provide corpora of NSNZE and NSG native-native dialogues of approximately the same size. It also produced a comparable corpus of intercultural dialogues in terms of size. These three corpora are, moreover, all relatively large and therefore likely to to provide a suitable basis for analysis.

As described, the 60 conversations, equalling approximately 18.5 hours of conversation, were transcribed and analysed with regard to the use of pragmatic 
devices. After adding a series of track-marks to the recordings, the data was transcribed in 30 second segments directly from the mini-discs, which was used for the coding system to show where within the transcription the example can be found. The codes used for every example taken from the present corpus includes a reference to whether it is a conversation between two Germans, two New Zealanders or one German and one NSNZE (G-G; NZE-NZE; NSNZE-GNNSE), a reference to whether it is a same-sex or a mixed sex interaction (F-F; M-M; F-M), the number of the interaction as it occurs in the corpus (see attached CD) and the time indicating how far into the conversation the example occurred. For instance, example 1 is labled NZE-NZE/M-M/51/3:30 because it occurred in an interaction between male New Zealanders and can be found in the corpus in conversation 51 after minute 3:30. For a table of contents of the $\mathrm{CD}$ featuring all conversations see Appendix 4.

For the purpose of this study it was decided that an orthographic transcription would suffice, as phonological features or intonation units would not be considered for the analysis. After all conversations were transcribed, the accuracy of the transcriptions was checked against the recording. Transcription conventions, following those used by the Language in the Workplace Project at Victoria University of Wellington, include the use of pseudonyms for all names and the following symbols: 


\begin{tabular}{|c|c|}
\hline [university name] & used when real name is being withheld \\
\hline [laughs] & Paralinguistic features in square brackets \\
\hline \multicolumn{2}{|l|}{ [drawls] } \\
\hline & Pause of less than a second \\
\hline+ & Pause of up to one second \\
\hline++ & Two second pause \\
\hline$\ldots . / / \ldots \ldots . . .$. & Simultaneous speech \\
\hline \multicolumn{2}{|l|}{.../........II... } \\
\hline$\uparrow$ & High rising terminal on declarative \\
\hline Publicat- & Incomplete or cut-off utterance \\
\hline Bold & Pragmatic device \\
\hline Italics & German translation \\
\hline Underlined & Modified element \\
\hline [pragmatic device] & German pragmatic device in English translation \\
\hline
\end{tabular}

Excerpts from the German corpus used in this thesis are annotated with English translations and I tried to provide as accurate translations as I could. German pragmatic devices were not translated not because they are unimportant or serve no function but due to the differences between German and English forms, which makes direct translations rather difficult. Nevertheless, I tried to incorporate the illocutionary effect of the devices into the translation whenever possible. Moreover, for the English translations I also decided to not include German devices in their original form as German devices occur in synactic positions that do not coincide with English sentence structure. Therefore it would have been difficult to decide where within the sentence the brackets should be inserted. However, German devices were included in brackets when necessary, e.g. when a sentence starts with a device or if the device seems prominent in another way.

\subsection{Analysis}

Quantitative analysis of pragmatic devices is based on the number of pragmatic devices relative to the number of words uttered by an individual speaker or a group of speakers. This may not be the most ideal unit to compare the use of devices in German and English as word lengths differ from language to language. Nevertheless, the dialogic nature of the interactions, involving overlaps and one 
word turns, makes it too difficult to measure individual talk times. Despite these potential inaccuracies, the number of words spoken by each individual is considered to serve as a sufficient unit to assess relative pragmatic device frequency.

In addition to conducting a simple comparison of the frequencies of use by the various groups, it was also decided to perform a simple statistical analysis test. Based on the relatively large sample size of 60 conversations and the high occurrence of the devices under investigation in addition to the paired methodological design, it was decided to do a paired t-test. This test looks at the differences between the uses of devices in NZE-NZE interactions and those used by NSNZE in cross-cultural interactions and the differences between GNNSE and NSNZE in cross-cultural interactions. In other words, the paired t-test analyses the differences in the frequency of use by NSNZE depending on whether they talk to a native or a non-native interactant. It was decided that a paired t-test was not possible for the German group as the English and German forms that were found to be too different to warrant a comparison. The statistical calculations were conducted by a statistical consultant using SPSS software.

Close transcriptions of the conversations, excluding the picture description segments, were first transcribed and then analysed using the corpus analysis programmes Word Smith Version 3 (Scott 1999) and the freeware ConcApp Concordance and Word Profiler Version 4 (Greaves 2005). The files were searched for specific words or word strings involving the pragmatic devices under investigation. Each individual example was analysed to determine whether it qualified as a pragmatic device and then allocated to the person who used it. Instances where the same form as a pragmatic device is used as a lexical item, e.g. Do you know David? or it's the kind of game where you work in teams, were not included in the data set. My interpretations of individual devices as well as a number of examples from functional categories were shown to and discussed with my supervisors and the Postgraduate Group at Victoria University of Wellington, to ensure the relative reliability and accuracy of my analyses. 


\subsection{Problems}

On the whole, once I established a routine for setting up the equipment and giving the appropriate instructions to the participants the data collection process ran smoothly. One of the main problems during the data collection process was the recruitment and the coordination of participants. As the set-up of the recordings may have seemed rather stressful, face threatening and possibly time-consuming to some, it took a long time to find enough volunteers. Another difficulty was to organise the conversations themselves. I had to find times for two people with the relevant profile to be at the same place at the same time. As I was only allowed to book the room for two hours at a time, three days a week, this meant that a maximum of three interactions could be recorded per day. I was thus working on a relatively tight schedule. On a few occasions participants forgot about the appointment or could not find the room, arriving late or not at all. As a result, there were delays not only for one conversation but for the following ones as well.

A further problem of the data collection process was the amount of time between the two conversations for each participant. Most participants conducted their conversations on two different days. However, in order to minimise the imposition on participants and to facilitate a swift succession of conversations, some participants were involved in two conversations in a row. While this arrangement did not seem to affect most participants, some speakers appeared to be tired and possibly not as willing to engage in the conversation in their second interaction. Another shortcoming of the set-up of the recordings was that participants filled in the questionnaire in the same room where the recording took place. Since it was a rather small room and the interactants were sitting right opposite each other, it was possible for them to look at the other's form, which might have made it more difficult for them to give the conversation a lower rating. Nevertheless, personal feedback at a later stage, in conjunction with the tone of the interaction itself, gave a good impression on the kind of rapport speakers had established.

In the course of the data collection I also experienced a number of technical difficulties. These included problems with the microphone, which added a high 
pitch sound to the recording or completely corrupted it. In those cases where no transcription could be made using the mini-disc, an audio-recording of the videotape was used instead. On one occasion I only remembered to turn on the mini-disc player a few minutes into the conversation so that the beginning was not recorded. With regard to the transcription, apart from the general difficulties of closely transcribing large amounts of dialogue, there were no extra problems.

In this chapter I have presented the research methodology used for this study, including details on the reasoning behind the particular set-up of the data collection as well as information on the participants, the recruitment process, the transcription and analysis processes. I have also noted problems that occurred during the data collection. Following this general description of the nature of the data used in this study I will now present the results of the initial and then more in-depth analyses of the corpus. 



\section{Selection of Devices}

This chapter features an investigation of the frequencies of a range of pragmatic devices in a small sub-set of the corpus, with a focus on their use by NSNZE and GNNSE in cross-cultural interactions. In this chapter, I provide a general introduction to those pragmatic devices included in this investigation and describe the sub-set of the corpus chosen for this analysis. This is followed by a discussion of the results of the preliminary study. Finally, the three pragmatic devices chosen for more in-depth analysis are presented along with a justification for their selection.

\subsection{Pragmatic Devices}

\subsubsection{Interactive politeness, content-oriented and speaker-oriented devices}

This preliminary analysis of the use of pragmatic devices by NSNZE and GNNSE focuses on the forms you know, eh, tag questions, general extenders (e.g. and stuffl or things like that), sort of, kind of, I mean, I think, like and well. For the most part, with the exception of like and well, the devices were selected because they were included in Stubbe and Holmes' (1995) study of pragmatic devices in NZE. Their investigation suggested that these devices are frequently occurring markers in NZE, which makes them relevant features for the present study. Stubbe and Holmes (1995) propose a framework of grouping pragmatic devices according to their primary functions by dividing them into three categories: Interactive politeness devices (e.g. you know, eh and tag questions), contentoriented (e.g. general extenders, kind of and sort of) and speaker-oriented devices (I think and I mean). The primary function of interactive politeness devices is not to express epistemic modality but to include the addressee in the discourse and to help check the level of shared knowledge and values. Their inherent question-like 


\section{Selection of Devices}

form helps to negotiate common ground and to establish solidarity by minimising differences between speakers (Holmes 1985; Holmes 1986; Meyerhoff 1994; Holmes 1995).

According to Stubbe and Holmes (1995: 69), content-oriented devices mainly function to indicate epistemic modality as they "signal various kinds of lexical and/or propositional imprecision". By not fully committing to the accuracy of the proposition, the speaker pre-emptively attends to his or her own negative face needs to avoid being proven wrong later on. Sort of was also found to create an atmosphere of informality between the speakers and thereby help to reduce social distance and establish interpersonal rapport (Holmes 1988: 116). General extenders (Overstreet 1999) may be of particular interest in connection with nonnative use because of the relatively large number of forms that belong to this group. Their structurally flexible pattern of "conjunction and noun phrase" (Overstreet 1999: 3) allows for the construction of a variety of forms, which may result in the transfer of German forms to English. Finally, speaker-oriented devices focus on the speaker's attitudes in that they serve to express the speaker's degree of certainty or uncertainty in relation to the propositional content of the utterance or to initiate a self-modification of a preceding statement. I mean also functions as a marker of informality that serves to create interpersonal rapport (Stubbe and Holmes 1995: 70).

\subsubsection{Well and like}

The decision to concentrate on well and like in the preliminary investigation is further supported by Nikula's study (1996). According to her data, all of the forms listed in 4.1.1 except eh are among the most frequently occurring pragmatic devices in the speech of native speakers and also strongly feature in the speech of Finnish non-native speakers of English (Nikula 1996: 75). Moreover, the devices like and well were included in the analysis because they were among the most frequently used devices by the non-native speakers in her study. While native speakers in cross-cultural interactions use like, I mean, you know and well most frequently, non-native speakers appear to prefer well, I think, like and I mean. The device like also features frequently in Lee's (2004) corpus of Korean non-native 
speakers of English, which further supports the notion that this marker is frequently occurring in the language of non-native speakers.

Like and well are both multifunctional devices that can take on a number of different functions in discourse. Well, for example, can be used as a quotative marker, to introduce a new topic or resume a previous one or to rephrase or correct an utterance (Müller 2005). Some of the functions of like include hedging the propositional content of an utterance (e.g. Schourup 1985; Müller 2005) and introducing clarifications or elaborations (Miller and Weinert 1995). This makes especially like difficult to incorporate into Stubbe and Holmes' categories, as it would qualify as both a content-oriented and speaker-oriented device. Due to this incompatability, the devices like and well are not be integrated into the interactive/speaker-oriented device continuum and in FigureFigure 1 below they are placed to the left of the other devices.

\subsubsection{Eh}

Eh was included in the analysis regardless of its relative low frequency of occurrence in Stubbe and Holmes' (1995) study and its total absence from Nikula's (1996) data, as it is generally considered to be typical of NZE (Stubbe and Holmes 1995: 68). Eh does not feature prominently in either American or British English - the two varieties of English Germans are mostly exposed to. Patterns of use by GNNSE could therefore give relevant information on how readily GNNSE adopt pragmatic devices into their repertoire. Moreover, GNNSE's use of eh might be indicative of speakers' levels of acquired communicative competence.

\subsubsection{Potential for L1 transfer}

An additional advantage of the selected items is their ability to provide useful data about the influence of L1 on non-native speakers' use of pragmatic devices. The chosen forms contain both items that appear to have an overtly translational equivalent German form (e.g. you know/weißt du; I mean/ich mein; I think/ich denke; and things like that/und solche Sachen) and devices that do not seem to have direct form-functional translational equivalents (e.g. tag questions; like, well). In this sense, the present range of items can be considered to be a balanced 


\section{Selection of Devices}

selection of devices, covering both textual and interactive markers, as well as frequently and not frequently occurring items and devices that appear to have formal or form-functional equivalents in German.

\subsubsection{Pragmatic devices vs. grammatical structures}

Potential instances of pragmatic devices were identified using an electronic search of the transcripts for the relevant using Wordsmith and ConcappV4. However, not all occurrences of these forms could be counted. The form you know, for example, is syntactically embedded within an utterance when a speaker is making a genuine inquiry about whether the other is aware of some piece of information as in do you know what the weather is going to be like? Similarly, kind of can also denote a type or variety of something, as in when you finish do you know what kind of law you want to practice? Consequently, each occurrence had to be thoroughly checked and only instances of pragmatic devices were included in the count. Repetitions of markers and cut-off clauses where the sentence containing the marker is abandoned in favour of another one, e.g. which is I mean I don't where I go back to I don't know maybe I stay longer here?, were also excluded from the analysis.

\subsection{The data-set}

This preliminary analysis is based on a sub-set of the corpus consisting of approximately three hours or 43,870 words of transcription overall. Since the pragmatic devices you know, I think, tag questions and GEs are counted as one token even though they contain two or more words, all additional words were deducted from the word count. This leaves a corpus of 43,205 words. The corpus includes nine cross-cultural interactions featuring nine NSNZE (5 females/4 males), who produced 21,066 words, and nine German non-native speakers of English (GNNSE) (4 females/5 males) who contributed 22,139 words to the corpus. Of the nine conversations, three were conducted between two females, three between two males and three between a male and a female. The conversations were chosen randomly from the set of interactions that were already transcribed at the time of analysis. 


\section{Selection of Devices}

For studies such as this, the raw number of pragmatic devices uttered by each speaker cannot be taken as a basis for comparison. Instead, the frequency of use has to be considered relative to the amount of talk produced during the conversation. Therefore, frequencies have been calculated by dividing the number of words spoken by each participant by the number of pragmatic devices produced in the course of the conversation, producing the pragmatic device frequency per 100 words $(\mathrm{pd} / \mathrm{cw})$. This approximate rate per 100 words allows for a direct comparison between the different corpora. This method has been used to calculate the figures used in the remainder of this study.

\subsection{Results}

\subsubsection{Use of Pragmatic Devices by NSNZE and GNNSE}

Figure 1 and Table 3 show the average frequencies of pragmatic devices produced by NSNZE and GNNSE in the selected conversations. The distribution of pragmatic devices in the graph shows that, with an average frequency of 3.32 $\mathrm{pd} / \mathrm{cw}$, NSNZE use the markers more often than their non-native interlocutors, who produced a frequency of $2.53 \mathrm{pd} / \mathrm{cw}$. This higher frequency use of pragmatic devices by native speakers confirms previous findings by Cheng and Warren (2001), Nikula (1996), Lee (2004) and Müller (2005). Nevertheless, even though GNNSE differ from NSNZE in terms of overall frequency, they do use all of the pragmatic devices under investigation - including a few instances of $e h$, the pragmatic device most idiosyncratic of NZE. 
Table 3: PD use by NSNZE and GNNSE in cross-cultural interactions

\begin{tabular}{lrrc} 
& NSNZE & GNNSE & \\
\hline eh & 0.15 & 0.01 & \\
you know & 0.35 & 0.27 & Interactive \\
tag questions & 0.02 & 0.04 & politeness devices \\
\hline kind of & 0.21 & 0.07 & \\
sort of & 0.14 & 0.07 & Content-oriented \\
GE & 0.28 & 0.29 & devices \\
\hline I think & 0.26 & 0.24 & Speaker-oriented \\
I mean & 0.16 & 0.38 & devices \\
\hline well & 0.20 & 0.13 & \\
like & 1.51 & 0.99 & \\
\hline Total & 3.27 & 2.50 &
\end{tabular}

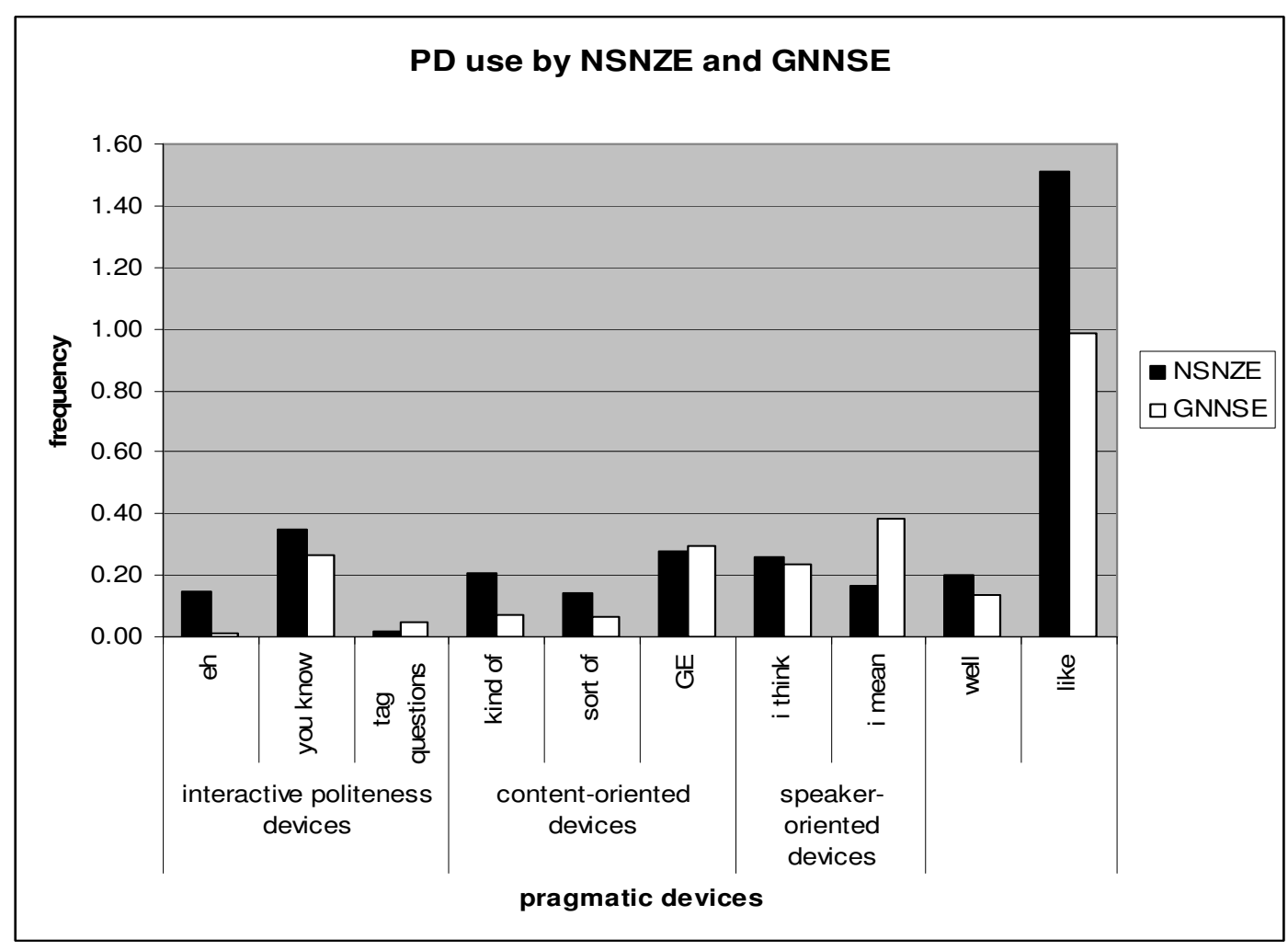

Figure 1: PD use by NSNZE and GNNSE in cross-cultural interactions

When comparing the present NSNZE results with Stubbe and Holmes' (1995:73) frequency index for young middle class speakers in conversational data, it is remarkable to find that pragmatic devices (excluding like and well) were used at a very similar rate in both data sets. The main difference appears to be that in 


\section{Selection of Devices}

Stubbe and Holmes' data tag questions were used relatively often, whereas the present native speaker corpus contains more tokens of kind of and sort of. Overall, it can be noted that native speakers in the present corpus use slightly more content-oriented tokens and somewhat fewer speaker-oriented devices than the young middle class speakers in Stubbe and Holmes' data. In Nikula's data, native and non-native speakers also used the forms (with the exception of $e h$ ) at a similar rate to the present study, with native speakers using the devices with a somewhat higher frequency. One possible explanation for the higher frequency of use of pragmatic devices by native speakers in Nikula's study could be because her data is based on group interactions of four speakers. Even though the two native and the two non-native speakers knew each other before the recording, conducting a conversation in a larger group might have been perceived as more stressful or even face threatening and consequently might have increased the use of face work.

When looking at the distribution of frequencies for pragmatic devices by GNNSE and NSNZE, it can be noted that both groups use like far more often than any of the other devices. This result diverges from Nikula's (1996) study where well was the device most frequently used by non-native speakers. Even though both groups use like more than any other device, the frequency rankings for the remaining devices differ for NSNZE and GNNSE. An interesting difference between frequencies of use by the two populations is that while NSNZE and GNNSE produce similar frequencies for GEs and I think, GNNSE use I mean more than twice as often as NSNZE. GNNSE also use I mean noticeably more frequently than I think, which differs from Nikula's non-native speakers results. This might suggest that the preference for I mean by GNNSE is related to L1 interference.

The graph further indicates that GNNSE produce more instances of tag questions than NSNZE, a result that differs notably from both Cheng and Warren (2001: 1426) and Nikula (1996: 75). Since there is not a direct equivalent of tag questions in German, this result cannot be explained with reference to L1 transfer. Nevertheless, one possible explanation for this could be that the use of tag questions was part of the English curriculum at German schools, which might have encouraged their use and increased the association of tag questions with good and proper English (Müller 2005: 251). The last point of interest is that 


\section{Selection of Devices}

GNNSE use the content-oriented devices sort of and kind of relatively rarely compared to NSNZE, with GEs being their preferred marker from the group of content-oriented devices.

Overall, NSNZE appear to use interactive politeness, content-oriented and speaker-oriented devices at a roughly similar frequency, with content-oriented devices being used the most and speaker-oriented devices the least. GNNSE diverge from this pattern as they appear to mainly use speaker-oriented devices, particularly I mean, and interactive devices less frequently.

\subsubsection{Individual variation}

The data contains a large amount of individual variation among NSNZE and GNNSE. Frequencies among NSNZE range from 1.4 to $9.58 \mathrm{pd} / \mathrm{cw}$ and among GNNSE between 0.42 and $5.97 \mathrm{pd} / \mathrm{cw}$. A look at the distribution of tokens among speakers shows that the high frequency occurrences of $e h$ and like in the NSNZE group were mostly produced by a single speaker. The notion of taking individual variation into consideration for the analysis is also important when looking at the GNNSE data. For this sub-set of the corpus it is noteworthy that the three speakers with the most frequent use of pragmatic devices can be considered highly proficient speakers. Two of them had lived in an English speaking country for a year or more prior to the recording, two of them have either an English speaking parent or relatives living in English speaking countries, and one of them has attended an English language school. In other words, the GNNSE who used pragmatic devices more frequently either come from a semi-bilingual background or have lived in an English-speaking environment for an extended period of time. Conversely, the two GNNSE with the lowest frequencies of pragmatic device use could be placed in the lower proficiency group. They either had just started their first year abroad at the time of the recording or mainly used German for their social interactions while overseas and therefore might not have acquired full pragmatic competence. In this sense, the data suggests a correlation between the use of pragmatic devices and language and pragmatic proficiency. However, it is also possible that having a native speaker interlocutor has an influence on the use of pragmatic devices by GNNSE, as in most of the dyads both speakers produced similar overall frequencies. 


\subsubsection{Impact of pragmatic devices on interactions}

The use of pragmatic devices is generally regarded as contributing "to the pragmatic meaning of utterances" (Müller 2005: 1) and performing "an indispensable function in oiling the wheels of verbal interaction" (Stubbe and Holmes 1995: 63), however their use is neither a guarantee nor a requirement for friendly informal conversations. After all, those interactions where speakers used only few pragmatic devices did not necessarily seem unfriendly, laborious or stilted. Nevertheless, raising non-native speakers' awareness of the interpersonal functions of pragmatic devices is likely to facilitate the creation of an informal conversational atmosphere, assisting non-native speakers fit into the new cultural environment.

\subsubsection{The value of the analysis}

The preliminary analysis suggests that there is ample ground for an investigation into differences in the use of pragmatic devices by NSNZE and GNNSE. Though the differences noted above are exclusively quantitative, the variation noted promises to be a good starting point for a more detailed analysis of the functional applications of pragmatic devices. Moreover, a closer investigation of the entire NSNZE data-set could help to either confirm or dismiss the slight divergence of the results from previous studies as the influence of individual variations on the data will be minimised by the larger corpus. Finally, this preliminary analysis highlights the importance of considering the influence of the interlocutor on the speech of non-native speakers and the impact of L1 transfer when analysing nonnative uses of pragmatic devices.

\subsection{Selection of Pragmatic Devices for detailed analysis}

Based on the patterns of use of pragmatic devices observed, all of the devices examined in this preliminary analysis promise to provide interesting data if included in a more detailed analysis. However, fully analysing all items would create a project of greater scope than would be suitable for this thesis. In order to narrow down the scope of the project to a manageable size, this research concentrates on a group of three devices. 


\section{Selection of Devices}

The selection of these three devices is based on a range of factors. One of these factors is the number of tokens in the corpus. A sizable amount of data is needed to add credibility and validity to the result. A high frequency device would also have greater relevance to non-native speakers, who would benefit from an investigation into how their use of the marker deviates from the native speaker norms. Another aspect to consider is the availability of comparative data from other studies as this would allow for a direct comparison. The existence of corresponding German markers to the English forms also influences the selection process. Including forms that have direct and no direct counterpart in German would provide useful information as to what degree L1 patterns influence L2 production of pragmatic devices. Finally, the selection of the devices considers promising patterns of use that have been noted in this preliminary analysis.

The first device that appears guaranteed to provide useful data is like. It is the form with the highest frequency of use for both NSNZE and GNNSE and therefore the form with the greatest relevance for cross-cultural interaction in the present corpus. The multifunctional nature of like also makes it a promising device to analyse as it has been found to serve textual and affective purposes (e.g. Schourup 1982; Miller and Weinert 1995; Müller 2005). A classification of the various uses of like by GNNSE and NSNZE and an analysis of its distribution across the different functions would seem to offer a useful point for comparison between the two groups as it would indicate the extent to which the implicit pragmatic functions of like have been recognised and acquired by non-native speakers. Regarding the existence of comparable German forms, it seems that German does not necessarily have one equivalent device that can serve all functions of like. This difference between German and English has the potential to provide useful information on the extent to which L1 influences the development of the non-native speaker's pragmatic knowledge.

Another obvious choice for a close analysis is the interactive device $e h$, a distinctive feature of NZE. Despite the rather small GNNSE sample size for $e h$ in the corpus, an investigation of its use by non-native speakers seems likely to be useful as it could confirm whether its use and application can serve as an indication of the level of acquired pragmatic competence of non-native speakers. 
The inclusion of $e h$ as a device for detailed examination also promises to be interesting and valuable because German has a phonologically similar form, ey, which appears to serve a different set of functions. Thus, the marker has the potential to provide data on functional L1 transfer of German ey functions by GNNSE.

The last device selected for further analysis is the set of GEs (and things like that, or something, etc.). While there does not appear to be a great difference between native and non-native speakers in their frequency of use, the structural variability of the device offers a useful basis for comparison of the GE repertoire of GNNSE, NSNZE and the set of similar forms in German. There is also great potential for transfer of forms from German to English by GNNSE, which might lead to the construction of non-native-like GE structures. These three pragmatic devices chosen for detailed study in this research project appear to represent a good balance of forms with each of the markers promising to cover different issues related to the acquisition and application of pragmatic devices by non-native speakers.

Other potentially interesting devices that will not be further investigated in this research study are the uses of I mean and I think by GNNSE and NSNZE. The preliminary analysis suggests that GNNSE use I mean substantially more often than the native speakers. However, English I mean and German ich meine appear to serve fairly similar pragmatic functions in that they provide clarifications of preceding proposition. This might have the effect that the marker does not generate data as useful for comparison between the groups as the other markers. Nevertheless, as this is merely speculation, a detailed analysis of this form might provide an interesting avenue for future research.

In this chapter, I have looked at the quantitative distribution of you know, eh, tag questions, GEs, sort of, kind of, I mean, I think, like and well in a sub-set of the corpus. The results of this preliminary analysis were used as a basis for the selection of three devices for closer examination, all of which represent different types of potential L1 interference. Thus, GEs were chosen because the structural and functional similarities between German and English forms offer room for L1 


\section{Selection of Devices}

transfer. Conversely, like was included as it does not have one clear functional and translational equivalent in German, which might have an effect on its use by GNNSE. Finally, eh is believed to provide insights into the acquisition of idiosyncratic forms by non-native speakers and to potentially be affected by L1 interference from the phonologically similar device $e y$. 


\section{General Extenders}

This chapter focuses on native and non-native use of General Extenders. The analysis has been divided into three parts. First, it discusses the forms of General Extenders used by native speakers of German (NSG) and New Zealand English (NSNZE) and compares these to the forms found in the speech of German nonnative speakers of English (GNNSE). The second section examines the different possible discourse functions of General Extenders in the three sets of data. Finally, a case study compares native and non-native use of the general extender or so and its German translational equivalent oder so.

\subsection{Literature on General Extenders}

The term 'General Extenders' (henceforth GEs) was introduced by Overstreet (1999). It refers to a set of pragmatic devices generally assumed to express epistemic modality. In previous studies, GEs have been given a large array of different labels including 'set-marking tags' (Dines 1980; Ward and Birner 1993), 'vague category identifiers' (Channell 1994), 'referent final tags' (Aijmer 2002) or 'generalized list completers' (Jefferson 1990; Lerner 1994). It has been proposed that GEs follow the general formula of "conjunction and noun phrase" (Overstreet 1999: 3), e.g. and things like that, or something or German und solche Sachen, oder so was. This open formula allows for a large number of combinations and new creations. The conjunctions and and or provide a basis for dividing GEs into two broad categories: adjunctive (and) and disjunctive (or) GEs (Overstreet 1999: 4).

Like other pragmatic devices, GEs are multifunctional devices that can operate on both a referential and an interpersonal level. This has led to a range of different descriptions of their functions, with previous studies mostly concentrating on their 
referential, intra-textual use. One such investigation of these forms in Australian English focused on their referential, intra-textual use (Dines 1980). Dines (1980: 22) maintains that "in every case their function is to cue the listener to interpret the preceding element as an illustrative example of some more general case" (italics in original). This would mean that, for example, the modified noun phrase pencils in he bought pencils and things is representative of either the general category "stationery" or "art supplies" and that other items from these categories are also implied. It is this function of category implication that has dominated research on extender forms for many years (Ward and Birner 1993; Channell 1994). Furthermore, based on the results of an informal investigation, Dines (1980: 18) proposes that extenders are considered "to reflect vague and inexplicit speech".

Overstreet (1999) and Aijmer (2002), on the other hand, consider both the referential and the interpersonal functions of GEs. Thus, Aijmer (2002: 248) describes them as having both interpersonal politeness and textual functions as category implicators and markers of epistemic modality. Overstreet (1999) highlights the interpersonal functions of GEs by drawing on Grice's Conversational Maxims (1975) and Brown and Levinson's Politeness Theory (1987). For her study on GEs in American English, Overstreet collected a corpus of 10 hours consisting of both personal face-to-face and telephone interactions between familiars. Overstreet decided to use only people she was familiar with herself, which she believed helped her in assessing the discourse functions of a GE in a specific context (1999: 16-7). She maintains (1999: 126) that adjunctive markers function as hedges on the Maxim of Quantity in that they allow the speaker to indicate that more could be said without actually having to say it. Disjunctive extenders function as hedges on the Maxim of Quality in that they mark what has been said as possibly inaccurate (Overstreet 1999: 112). As such, both extenders function as markers of imprecision and can be used to express epistemic modality.

Imprecision or vagueness can also serve as a strategy for conveying affective or interpersonal meaning. By being vague, the speaker marks what has been left out as shared knowledge. Since a vague utterance conveys the implication that more 


\section{General Extenders}

could be said, its use seems to suggest that the speaker treats the hearer as someone who understands the implication. This assumption of a common ground reduces social distance and helps create interpersonal solidarity. Hence, GEs work as positive politeness devices since they invite solidarity (Overstreet 1999: 104). GEs can also work as negative politeness devices in that they can hedge the illocutionary force of negatively affective speech acts such as making suggestions, thereby signalling concern for the addressee's need for autonomy (Overstreet 1999: 106).

In her analysis of the London-Lund corpus, Aijmer finds a number of correlations between a category-implying GE and its referent. Thus, Aijmer (2002: 214-5) suggests that stuff modifies concrete mass nouns while thing goes with both concrete and abstract nouns. However, these links are not fixed, as there are many cases where there is no clear connection between and element and its tag (Aijmer 2002: 215). With regard to GE constructions, Aijmer (2002: 223) notes that adjunctive markers predominantly collocate with universal quantifiers such as all and everything while disjunctive markers go with a variety of the existential quantifier some, e.g. or something, or somewhere. Researchers have also noted a difference in the use of anything and everything. Thus, anything usually occurs in a GE in negative, non-assertive utterances, together with the disjunctive conjunction or, while everything is used in positive assertive utterances using an adjunctive conjunction (Channell 1994: 132; Overstreet 1999: 80; Aijmer 2002: 220). Channell (1994: 132) notes that or anything and or something occur in complementary distribution, with or anything being used in non-assertive contexts and or something in assertive ones as illustrated in Example 1 and Example 2 taken from my data.

\section{Example 1: NZE-NZE/M-M/51/3:30}

Reuben: yeah oh I haven't played for any awesome teams or anything just yeah. it's my rugby mates

\section{Example 2: NZE-NZE/F-M/5/15:30}

Kim: and then there was one with flames outside or something

Very little research has looked at the forms and functions of GEs in German. One of the early references of the German GE und so can be found in Betten (1976). In 


\section{General Extenders}

her discussion of the uses of ellipses, anacolutha and parenthesis in spoken language, Betten (1976: 221) mentions that the frequently occurring end tag und so is mainly used to indicate that more information could be given but that the speaker chooses not to in order to avoid talking for too long. Moreover, Betten proposes that forms such as und so could also be used in order to avoid elaborating on a potentially embarrassing topic. Henne (1986: 147-148) recognises the interpersonal functions of GEs, saying that they do not just function as structuring particles due to their relatively fixed position at the end of an utterance or a statement. Instead, he maintains that these extension particles also serve to express insecurity or epistemic modality, which simultaneously serves as an appeal to the interlocutor to fill in the gap (Henne 1986: 211).

Other researchers merely mention German GEs in passing while discussing larger groups of particles. Schmidt (1988), for example, labels the German extenders oder so, und so, und so weiter, und und und and others as an Abtönungspartikeln, a subclass of Gesprächspartikeln, that mainly serve to convey vagueness. Similarly, Schwitalla (1997) groups oder so and und solche Sachen under two headings: Heckenausdrücke 'hedges' and Etceteraformeln 'extenders', both of which are a subordinate class of what he terms lexikalische Gliederungssignale or 'lexical structuring signals'. Without discussing their forms and functions in any detail, Schwitalla identifies their main meaning as expressions of epistemic modality and the abbreviation of lists.

In a later study, Overstreet (2005) takes a closer look at German GEs and compares their forms and functions to English extenders. Based on relatively small corpora, her study reveals that even though German and English extenders are very similar in form and function, there are also some notable differences. Thus, generally speaking, disjunctive extenders seem to be used more often than adjunctive extenders in both German and American English. In both languages extenders can be used to "mark assumptions of being similar, informative, accurate and polite" and to add emphasis (Overstreet 2005: 1861). However, Overstreet (2005: 1861) maintains that in English GEs are used more often overall and have a greater variability of forms than German extenders. Furthermore, Overstreet points out that German GEs are syntactically more flexible than 


\section{General Extenders}

English ones. German GEs can occur clause medially before past participles or the verb of a subordinated clause, while English ones predominantly occur clause finally (Overstreet 2005: 1849). Overstreet (2005: 1860-1) also identifies a number of idiosyncratic forms such as or what and oder was weiß ich (noch alles) that do not seem to have a formal and functional equivalent in the other language.

\subsubsection{Definition}

As discussed, some studies have used different definitions for the specific set of GEs under investigation. For example, while Dines' (1980) set of GEs only included a limited set of forms that follow a specific pattern and have category implicating functions, Overstreet's (1999) study included all GEs which complied with a predefined structural pattern. These different approaches can give rise to inconsistencies in the range of forms categorised as GEs. Thus, as a result, Overstreet considered forms such as or what and or whatever, which were not included in Dines' analysis. The definition of GEs for this study includes reference to their form and both referential and interpersonal functions as described in 5.1. Conjunction-less GEs have been excluded mainly because it has not been established whether these forms serve the same communicative purposes as GEs and doing so would be beyond the scope and aim of this thesis. For the purpose of this study, GEs are defined as forms which serve referentially as expressions of vagueness, and interpersonally to build rapport, and which conform to a specifiable structural pattern.

In English this structural pattern can be described as in (A).

(A) AND/OR + (PREMODIFIER) VAGUE EXPRESSION (LIKE THAT)

In German it takes the form specified in (B).

(B) UND/ODER + (PREMODIFIER) VAGUE EXPRESSION (POSTMODIFIER)

The formulas in (A) and (B) allow us to formulate a general structure for GEs in both English and German, as specified in (C).

(C) CONJUNCTION + (PREMODIFIER) VAGUE EXPRESSION (POSTMODIFIER) Since Overstreet's (1999: 3) proposed basic pattern of conjunction and noun phrase does not accommodate for nounless GEs such as and so on and or so, the term vague expression is used. It will be interesting in future research to see whether this formula can account for instances of GEs in larger data sets. It will also be interesting to explore whether, with appropriate ordering amendments, this 
relatively vague basic GE pattern applies to other languages too or whether the pattern would be more specialised, allowing for less variation.

A basic GE can consist only of a conjunction and a core vague expression, e.g. or something. With regard to modified GEs, both Dines and Overstreet included only extenders in their studies which feature non-specific premodifiers such as kind of or sort of. The present research, however, also includes instances of what Overstreet terms specific extenders, i.e. GEs with adjectival premodifiers such as funky in and kind of funky stuff like that in Example 3.

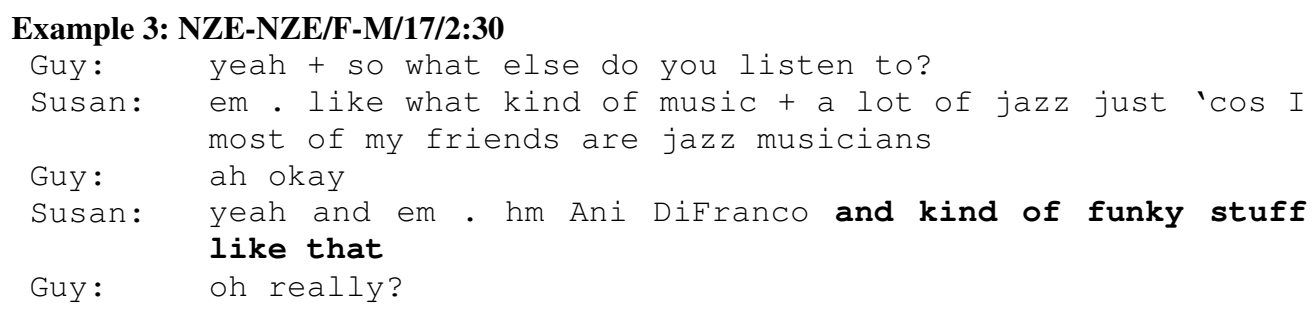

Overstreet's (1999: 52) reason for excluding these forms is that GEs "are necessarily non-specific" and therefore should not contain specific lexical items. However, I claim that additional lexical material like funky does not make the extender notably less general as it is still not clear what other musicians or types of music Susan would classify as 'funky'. Other examples include and anything important like that and und lauter solche schönen Sachen 'and lots of nice things like that'. In all these examples the adjectives seem to be non-specific enough that they do not narrow down the number of possible interpretations. Instead, these GEs appear to add the speaker's personal evaluation of what is implied in the proposition. This makes these extenders similar to forms without adjectives or forms featuring evaluative vague nouns such as rubbish or shit. Based on this assumption, these forms have been included in the group of GE forms.

\subsubsection{Syntax}

In English, GEs usually occur at the end of a clause (Dines 1980: 18; Overstreet 2005: 1849) and have a backwards scope as illustrated in Example 4. 
refers to. In Example 6 the extender precedes an adverb and in Example 7 it precedes the main verb.

As Overstreet (1999: 10) points out, GEs can modify more than one element within a clause and quite often it is not clear which element they refer to. This applies to English extenders as well as to German ones. In the present corpus, GEs were found to modify nouns (Example 8), verbs (Example 9), adjectives (Example 10) and entire sentences (Example 11).

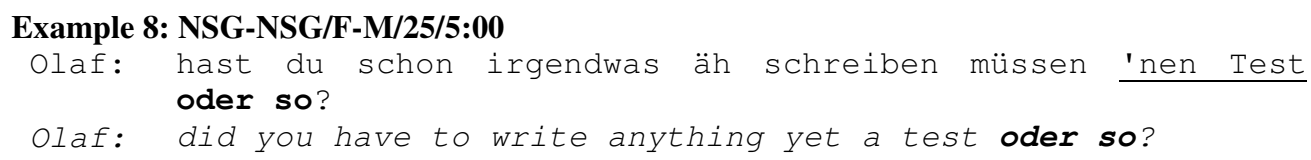

\section{Example 9: NSG-NSG/F-F/43/15:30}

Lotta: ich würd dann halt irgendwie zwei Wochen vorm Examen oder so anfangen zu lernen und würd's nich schaffen oder so

Lotta: I would start studying two weeks before the exam oder so and then I wouldn't make it oder so

Example 10: NZE-NZE/F-M/23/8:00

Bobby: like you know you can have a completely boring life and do absolutely nothing but hey you know my lungs are still clean it's like. I don't know I guess you know it could be it can be important and stuff but [sighs]

\section{Example 11: NZE-NZE/F-M/14/13:00 \\ Carl: the thrill is 'cos it's got a double a double barrel + and two triggers em you can nah it's not true it's not that close but you know and it's sort of like overkill + like using a cannonball to kill a horse or something but a little bit but em}

Even though German allows GEs to occur clause medially more freely than English, GNNSE participants have not transferred that property to their L2. Thus, in the GNNSE data GEs also occurred predominantly in clause final position and there were no examples of a GE before single item phrases such as the adverb and verb in Example 6 and Example 7 above. Only in two instances GNNSE moved a GE before an adverbial clause (Example 12) and a prepositional phrase (Example 13).

Example 12: NZE-GNNSE/F-M/8/11:30

Mario: do all the backpacking and stuff when you're younger 


\section{Example 13: NZE-GNNZE/M-M/6/22:00}

Ulf: I mean it's that's not music I listen to it's more like Karneval music and stuff in Germany

The fact that the few occurrences of clause medial GEs feature and stuff in both the NSNZE and GNNSE corpora could be taken as further support for Overstreet's (2005) suggestion that this particular form is becoming more flexible than other GEs. However, bearing in mind the rare occurrence of clause medial and stuff in the corpus it seems premature to take these instances as evidence for Overstreet's claim.

\subsection{Forms and Frequencies}

\subsubsection{New Zealand English}

The NSNZE corpus consists of approximately 5 hours of interactions or 58,869 words of transcription. Since each occurrence of a GE is counted as one token even though GEs are multi word units, all additional GE words were deducted from the overall word count, leaving a corpus of 58,509 words of transcription. This adjusted corpus will be used for the remainder of the study. Table 4 lists all GEs found in the data, the number of their occurrence and overall frequency index. 


\section{General Extenders}

Table 4: Total number of GEs in NSNZE corpus and overall frequency per 100 words

\begin{tabular}{|c|c|c|c|}
\hline \multicolumn{2}{|l|}{ Adjunctive GEs } & \multicolumn{2}{|l|}{ Disjunctive GEs } \\
\hline and all & 1 & or anything & 9 \\
\hline and all of that & 1 & or anything like that & 3 \\
\hline and all of those & 1 & or so & 1 \\
\hline and all sorts of stuff & 1 & or something & 54 \\
\hline and all sorts of things & 1 & or something like that & 18 \\
\hline and all that & 5 & or whatever & 15 \\
\hline and all that kind of stuff & 1 & or whatever it is & 4 \\
\hline and all this other contextual stuff & 1 & or whatever you want to call it & 1 \\
\hline and different things & 1 & & \\
\hline and everything & 8 & & \\
\hline and everything like that & 1 & & \\
\hline and kind of funky stuff like that & 1 & & \\
\hline and other things & 1 & & \\
\hline and shit & 2 & & \\
\hline and something & 1 & & \\
\hline and stuff & 56 & & \\
\hline and stuff like that & 7 & & \\
\hline and that & 3 & & \\
\hline and that kind of stuff & 1 & & \\
\hline and that kind of thing & 2 & & \\
\hline and that sort of stuff & 1 & & \\
\hline and that sort of thing & 4 & & \\
\hline and things & 10 & & \\
\hline and things like that & 3 & & \\
\hline Total & 114 & Total & 105 \\
\hline Forms & 24 & Forms & 8 \\
\hline Frequency per 100 words & 0.194 & Frequency per 100 words & 0.178 \\
\hline Total Frequency per 100 words & & & 0.374 \\
\hline
\end{tabular}

Generally speaking, the NSNZE data indicates that adjunctive extenders are used more frequently than disjunctive GEs. Throughout the corpus the number of disjunctive extender forms is smaller than that of adjunctive ones, thereby displaying less variability. The most frequently used GEs are and stuff and or something with 56 and 54 tokens respectively, followed by or something like that with 18, or whatever with 15, and things with 10 and or anything with 9 tokens.

The data collected in the present research can be compared to the results of Overstreet's (1999: 7) study on the use of GEs in American English. Overstreet's research is based on a 10-hour corpus of informal telephone and face-to-face 


\section{General Extenders}

interactions among familiars. Overall, in the American English corpus disjunctive extenders were used more often than adjunctive ones. Applying Overstreet's (1999) restriction of including only those extenders used three times or more to the NSNZE data, it appears that NSNZE also use disjunctive extenders more often, albeit by a relatively small margin (96 adjunctive GEs and 103 disjunctive GEs). The most frequently used GEs in Overstreet's corpus are also and stuff and or something with 29 and 42 tokens respectively. It is noteworthy that even though Overstreet's corpus features twice as much talk time as the present one it contains fewer occurrences of these tokens (see section 5.2.3 for further discussion). With 12 tokens, the adjunctive extender and everything is also one of the more frequently used forms in Overstreet's corpus. However, other commonly used adjunctive forms in the NZE corpus such as and things (10 tokens) and and stuff like that (7 tokens) only occurred once in Overstreet's data. Similarly, forms frequently used in the American English corpus such as and blah blah blah (4 tokens) and and all that stuff (4 tokens) do not feature in my NZE corpus. The most commonly used disjunctive extenders from the American set can be found in the present corpus; however some of them occur in a different order: or anything $\left(2^{\text {nd }}\right.$ most commonly used extender in Overstreet's data vs. $4^{\text {th }}$ in the NSNZE corpus), or whatever ( $3^{\text {rd }}$ in both corpora) and or something like that $\left(4^{\text {th }}\right.$ vs. $\left.2^{\text {nd }}\right)$. Further research is required to determine whether the differences in frequencies suggest dialectal variation between American and New Zealand English or whether this pattern is related to the topic of conversation, the experimental setting of the recording or personal preferences of the speakers.

The disjunctive extender or what, which occurred 4 times in Overstreet's corpus, has not been included in the present study as all occurrences in the NSNZE corpus were used only affectively to add emphasis to a statement. However, the German translational equivalent form oder was, which can also be used emphatically, has been taken account of in cases where it serves to express referential uncertainty.

Interestingly, Aijmer's (2002) investigation of GEs in the London-Lund Corpus (LLC) yielded quite different results. The LLC comprises approximately 500,000 words that were collected from 5,000 interactions of varying formality. Aijmer (2002) found that native speakers of British English use more adjunctive 
extenders than disjunctive extenders by a large margin. In her investigation Aijmer (2002: 222-3) counted 353 adjunctive and 256 disjunctive extenders. When only those forms are counted that occur three times or more, those numbers change to 328 adjunctive and 247 disjunctive extenders. The most commonly used adjunctive marker is and so on, a form that occurred more often in formal interactions in Overstreet's study (1999: 8), and which does not feature at all in the NZE data. According to Aijmer (2002: 233), 80\% of the tokens of and so on occurred in discussions, i.e. in a more formal conversational situation. Similarly, the disjunctive extender or so is the second most frequently used disjunctive extender in Aijmer's study but it was only used three times by the NSNZE in my data. And all the rest of it is another form that occurs relatively frequently in Aijmer's study but not in the present corpus. On the other hand, the most frequently occurring GE in the NSNZE data and stuff is among the lesser-used extenders in the LLC. Considering that the LLC was collected about 30 years ago, it remains to be seen whether these differences can be related to language change.

\subsubsection{NZE - GE Construction Rules}

The formation of GEs allows for some variation and the creation of new forms. Nevertheless, the options are not unlimited as GEs seem to conform to certain constructional patterns. For example, it seems that adjunctive extenders can only incorporate certain elements between the conjunction and the vague expression. The data from the current study complies with Aijmer's (2002: 223) observation that the modifier sorts of only occurs in conjunction with the universal quantifier all. Moreover, sorts of only occurs with a plural vague expression (things) or mass nouns (stuff), as common grammatical rules such as number agreement also apply to the construction of GEs. This is also true for the patterns relating to the use of anything and everything so that anything only occurs in a GE in negative, nonassertive utterances, together with the disjunctive conjunction or, while everything can only be used in positive and assertive utterances using an adjunctive conjunction (Channell 1994: 132; Aijmer 2002: 223). The data also suggests that the complementary distribution of or anything and or something noted above also applies to NZE GEs. Moreover, the data confirms Aijmer's (2002: 223) observation that all can only occur in adjunctive extenders and variants of some (e.g. something) only in disjunctive ones. Finally, in my data it can be noted that 


\section{General Extenders}

kind of only immediately follows the conjunction when it precedes an adjective (and kind of funky stuff like that).

The present corpus of native-native NZE interactions features only one GE with a demonstrative pronoun this, i.e. and all this other contextual stuff. Other lists (e.g. Overstreet's 1999: 4) of possible GEs also indicate that adjunctive extenders can contain this as in and things like this or and this sort of stuff. However, my data does not include an example where a disjunctive extender contains this. An attempt has been made to represent these rules in form of a flowchart in Figure 2 and Figure 3. The chart is based only on forms that were found in the NSNZE corpus. Bold boxes indicate possible endpoints. Direct arrows indicate that these core elements can occur immediately next to each other to form a basic GE. The elements that are indirectly attached to the arrows such as adjectives are optional and are not required for the GE construction. It should be noted that not all possible combinations of optional elements and vague expressions occurred in the data (e.g. and all sorts of rubbish).

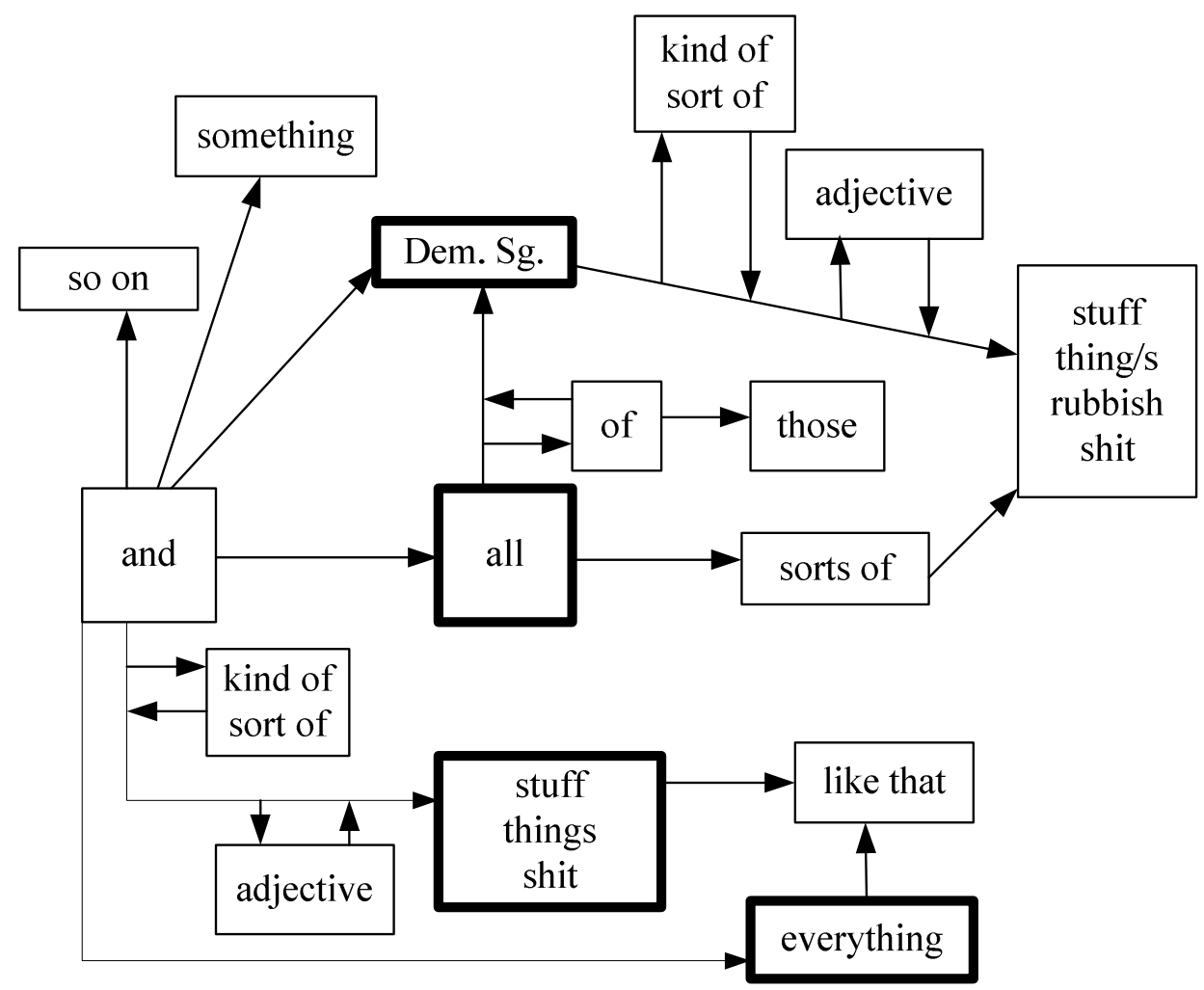

Figure 2: NZE GE Construction Map - And 


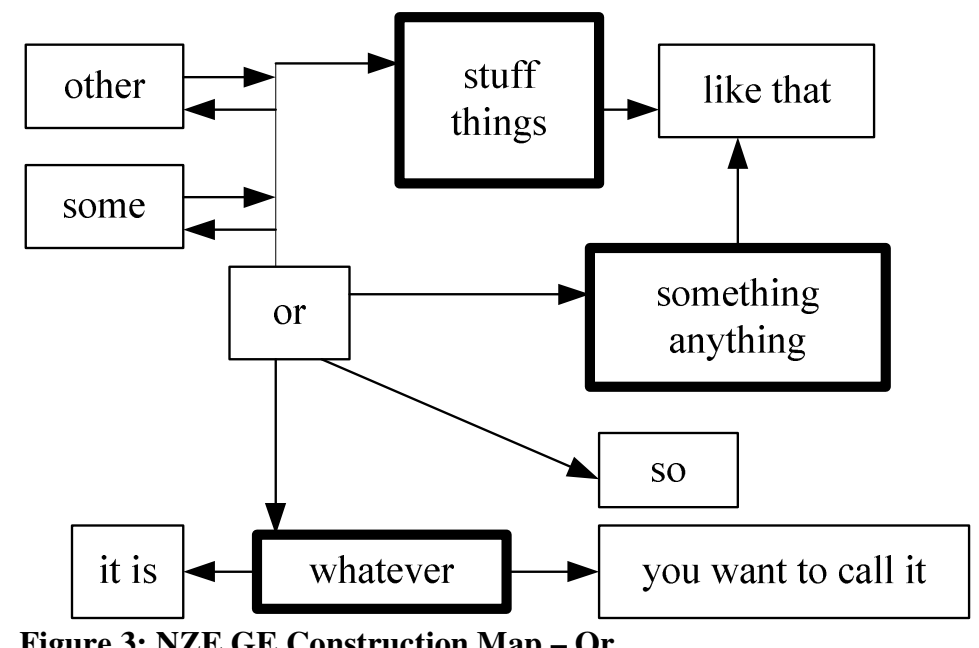

Figure 3: NZE GE Construction Map - Or

\subsubsection{German}

The German corpus is based on 15 German conversations. The corpus is made up of about 4.5 hours of interactions or 59,500 words after adjustments for the words per token ratio. Table 5 indicates that NSG use disjunctive extenders more often than adjunctive ones overall. The most frequently used German GEs, by far, are und so and oder so with 100 and 122 tokens respectively, followed by oder so was (24), und so weiter (10) and und alles (7). Overstreet's (2005) comparative study of American English and German GEs, which bases its analysis of German extenders on 14 hours of interaction, yields similar results. In Overstreet's study, NSG also use more disjunctive than adjunctive extenders, and und so and oder so are also the most frequently used GEs by a large margin, followed by oder so was. These results are also confirmed by a quick search of the Brons-Albert (1984) corpus of informal German, which consists of approximately 45,000 words transcribed from telephone conversations between familiars. Again, the speakers produce more disjunctive than adjunctive extenders with und so (14) and oder so (22) being the most frequently used ones, followed oder so was (5) and und so weiter (4). 
Table 5: Total number of GEs in NSG corpus and overall frequency per 100 words

\begin{tabular}{|c|c|c|c|}
\hline Adjunctive Extenders & & Disjunctive Extenders & \\
\hline und allem & 1 & oder irgend so etwas & 1 \\
\hline und alles & 7 & oder irgend so was & 1 \\
\hline und alles drum und dran & 1 & oder irgend so was in der Richtung & 1 \\
\hline und alles Mögliche & 1 & oder so & 122 \\
\hline und blah & 1 & oder so ähnlich & 1 \\
\hline und böh & 1 & oder so was & 24 \\
\hline $\begin{array}{l}\text { und lauter solche schönen } \\
\text { Sachen }\end{array}$ & 1 & oder so was in der Art & 1 \\
\hline und mhm mhm mhm & 1 & oder so'n Scheiß & 2 \\
\hline und nichts & 1 & oder sonst irgendwas & 1 \\
\hline und so & 100 & $\begin{array}{l}\text { oder sonst irgendwie was in der } \\
\text { Richtung }\end{array}$ & 1 \\
\hline und so Sachen & 2 & oder sonst was & 1 \\
\hline und sowas & 5 & oder sonst wo & 1 \\
\hline und so weiter & 10 & oder was & 6 \\
\hline und so weiter und so fort & 1 & oder was auch immer & 2 \\
\hline und solche ganzen Sachen & 1 & oder was es alles gibt & 1 \\
\hline und solche Sachen & 1 & oder was weiß ich & 1 \\
\hline und so'n Mist & 1 & oder wie auch immer & 2 \\
\hline und so'n Scheiß & 2 & & \\
\hline und so'n Zeug & 2 & & \\
\hline und tralala & 2 & & \\
\hline und was weiß ich & 1 & & \\
\hline Total & 143 & Total & 169 \\
\hline Forms & 22 & Forms & 17 \\
\hline Frequency per 100 words & 0.239 & Frequency per 100 words & 0.282 \\
\hline Total Frequency per 100 words & & & 0.692 \\
\hline
\end{tabular}

However, despite the similarities in results, there are also some differences between the present study and Overstreet's analysis. While the form und alles does not feature at all in Overstreet's data, oder was weiß ich, Overstreet's third most frequent disjunctive extender, only occurred once in the present corpus. Table 5 also indicates that NSG use GEs more frequently than NSNZE, a result that differs from Overstreet's (2005) comparative study.

Interestingly, however, even though Overstreet's German corpus was much larger, the two corpora seem to feature relatively similar numbers of tokens. Overall, in her 14 hours of recorded conversations between familiars Overstreet collected 147 GEs. Overstreet only counted GEs that were used three times or more. The count 
of forms that occurred three times or more for the present corpus of 4.5 hours adds up to 273 tokens. In other words, in about a third of the time, the participants produced approximately twice as many GEs. A similar observation can be made for the English data. Again only counting the forms that occurred three times or more, Overstreet's corpus featured 156 tokens in 10 hours while the speakers in my NSNZE corpus produced 199 tokens in 5 hours, i.e. NSNZE produced slightly more tokens in half the time. One possible explanation for this markedly higher frequency could lie within the different social contexts in which the data was collected. While Overstreet's data comprised conversations between friends, the speakers in my study were speaking to near strangers/semi familiars. This might have had the result that they perceived the recording situation as stressful. In addition, the recording devices could have made them feel more self-conscious, all of this leading to an increased use of hedges and vague language.

Another interpretation of this data is that it offers further support to the notion that GEs serve more interpersonal than referential functions in discourse, and play an integral part in the creation of rapport. Since the interlocutors did not know each other at all or only a little bit, it is possible that the speakers had to engage in more face work to create an amicable communicative situation. An increased use of politeness forms in interactions with semi-familiars would be consistent with the predictions of hypotheses derived from Wolfson's Bulge Theory (1988). In her study on the cultural implications exhibited by people's communicative behaviour Wolfson points out that in western societies, speech behaviour differs depending on the social distance between the speakers. Wolfson (1988: 32-4) notes that speakers use politeness devices more often in interactions with semi-familiars than with strangers or intimates, as the relationship with mere acquaintances is unstable and therefore requires more face work.

Another difference between the German and the NSNZE data can be found with the production of disjunctive extenders. The German data contains 17 different forms as opposed to 8 in the NSNZE corpus. This suggests that German features a greater variability with regard to the creation of disjunctive extenders. Moreover, there also appears to be a higher frequency of GEs in the German data than in the NSNZE data. It is possible that this high frequency use of GEs by NSG could be 


\section{General Extenders}

related to the influence of English on the language of NSG as they were all living in New Zealand at the time. Due to the lack of comparable data it is difficult to assess the extent of the impact of English on the German spoken by the NSG used in this study. However, Overstreet's (2005) German corpus suggests that German speakers in Germany also use GEs relatively frequently, albeit at a lower frequency than native speakers of English. Since both the NSG and NSNZE used GEs a lot more than Overstreet's (2005) participants, it is likely that the high frequency use is a result of the speech situation. In any case, the fact that Germans use substantially more GEs in less time than NSNZE seems remarkable.

\subsubsection{German - GE Construction Rules}

The construction of GEs in German appears to involve a wider range of lexical items than in English. As in English, the patterns in the corpus suggest that German GEs must contain a conjunction and a vague expression. The vague expression is usually a proper noun such as Sachen, the onomatopoeic word tralala or the indefinite pronouns irgendwas and so was. However, the vague expression can also be the adverb so as in oder so and multi-word expressions such as wie auch immer 'how ever that may be' or keine Ahnung 'don't know'. German extenders can take a number of modifiers, among them a string of indefinite determiners such as irgendwelche and solche and the adverbs sonst 'otherwise' and irgendwie 'somehow' that highlight the non-specificity of the referent. German extenders can take adjectives such as lauter 'lots of', ähnlich 'alike' and schöne 'nice/ beautiful' and adverbial expressions such as drum und dran 'bag and baggage'.

Another difference between German and English forms seems to be that, while English extenders mostly contain demonstrative articles, German ones only contain indefinite ones. The rules describing GE constructions in German are represented in the flow charts in Figure 4 and Figure 5. Again, the bold boxes indicate possible endpoints. The symbol * suggests that only the forms und so weiter 'and so on' and und so weiter und so fort 'and so on and so forth' are possible. Further repetitions are not permissible. The symbol `signifies that even though there are two possible slots for inserting irgend or irgendwie, only one slot 


\section{General Extenders}

can be occupied at a time and ${ }^{\circ}$ implies that only the form oder so ähnlich is possible, with an insertion of irgend making the GE ungrammatical.

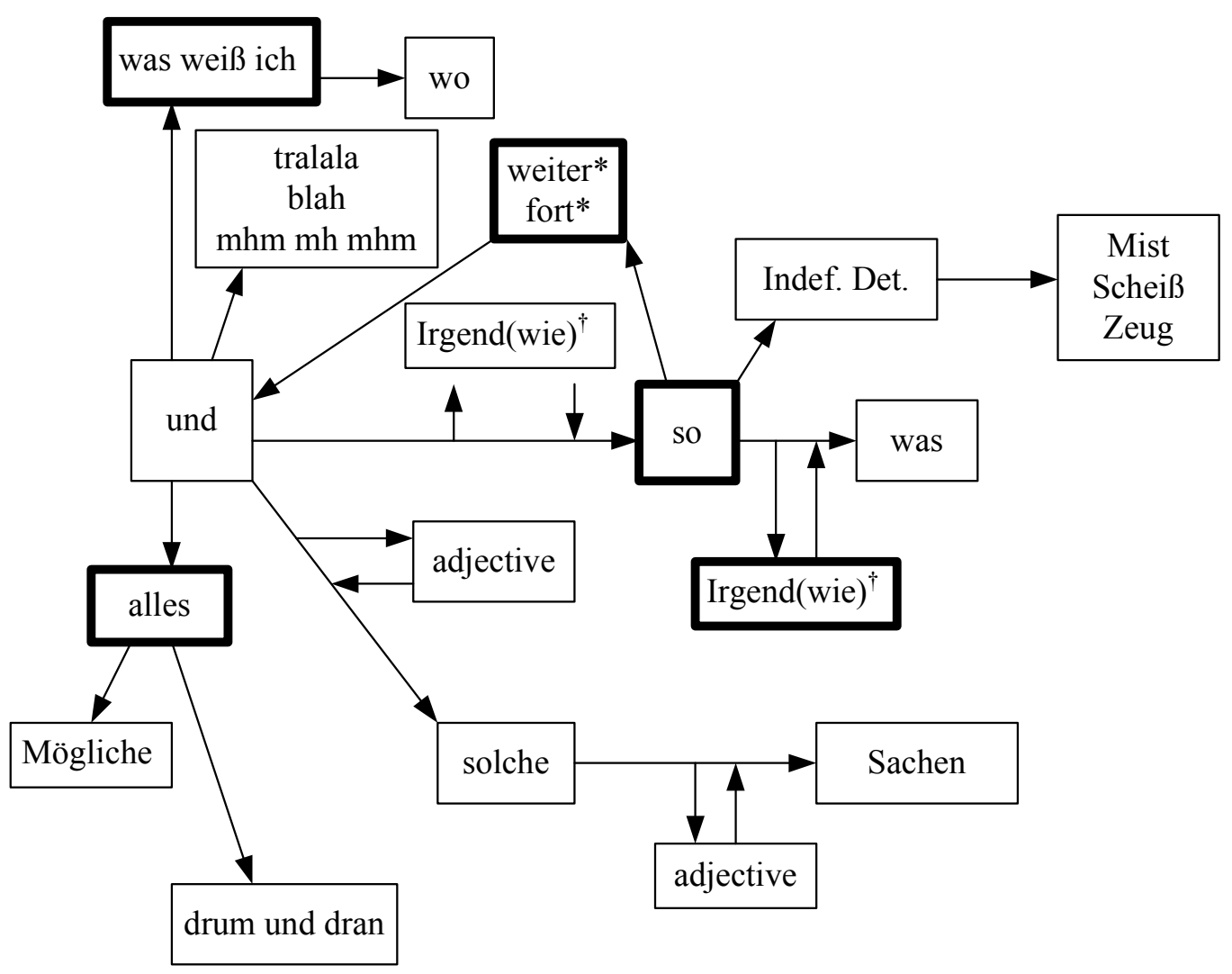

Figure 4: German GE Construction Map - Und 


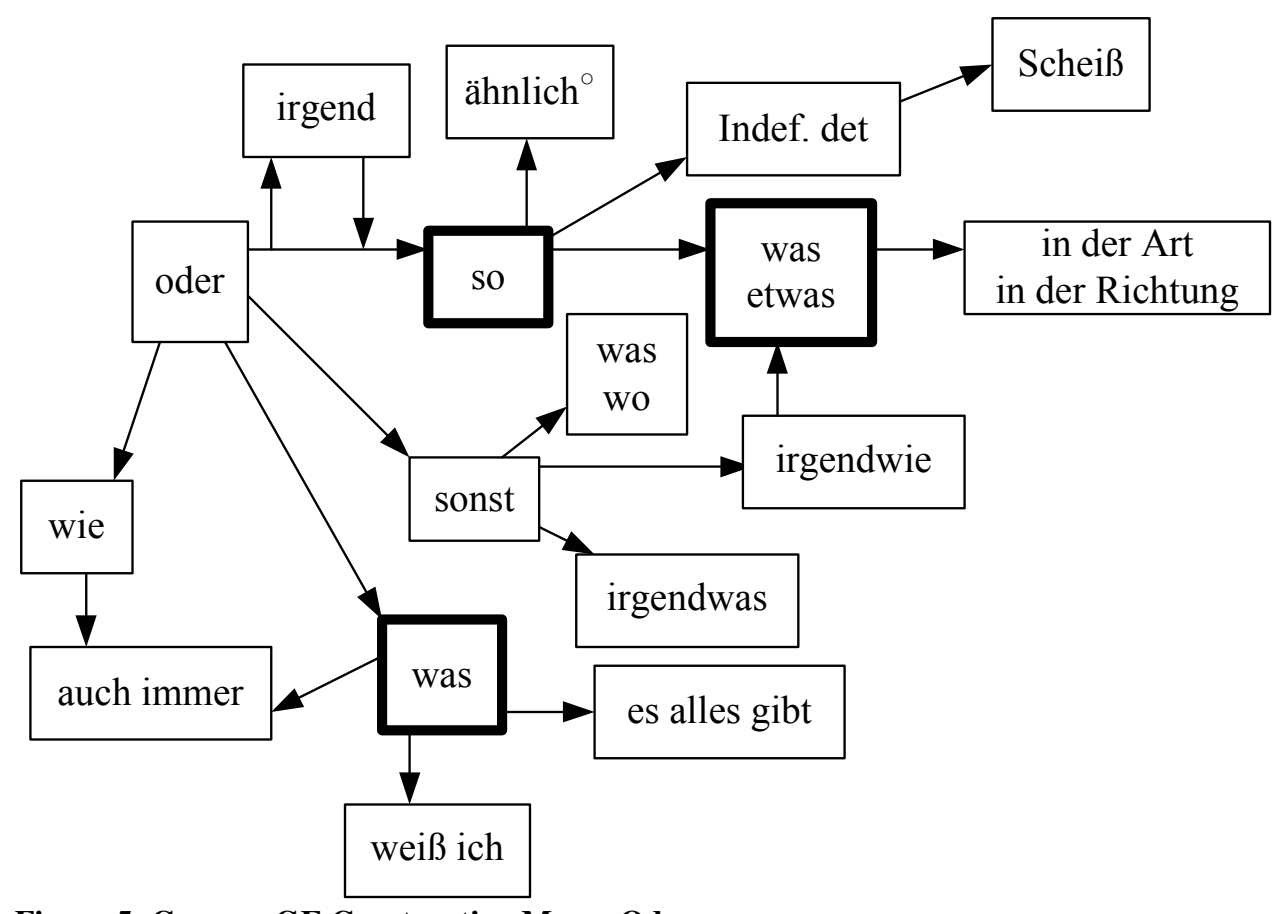

Figure 5: German GE Construction Map - Oder

\subsubsection{Implications for $L 2$ learners and predictions for $L 2$ speaker use}

As described in 2.4.1, the semantic equivalence hypothesis states that learners find it easier to learn an L2 word that covers the concept of an equivalent form in L1 (Ijaz 1986: 443). Since German and NZE GEs appear to have similar structures and functions, it could be expected that GNNSE pick up on the use of English GEs fairly quickly and apply them in a way comparable to NSNZE. However, not all forms are exact formal equivalents of each other, which could result in the construction of a number of non-native GE structures. With regard to the frequency of use it seems likely that, as the large degree of formal and functional overlap between English and German GEs might make the device more accessible, GNNSE will use GEs as often or maybe slightly less than in German.

\subsubsection{Use of GEs by GNNSE and NSNZE in cross-cultural interactions}

The corpus of cross-cultural interactions includes 30 conversations, which add up to approximately 9 hours 10 minutes of speech or 105,583 words of transcriptions. 52,866 words were produced by GNNSE and 52,168 by NSNZE after additional GE words have been deducted from the corpus. This makes the 


\section{General Extenders}

cross-cultural corpus nearly twice as large as either of the native-native corpora.

There are several points of interest in the data presented in Table 6 and Table 7.

Table 6: Total number of GEs used by GNNSE and overall frequency per 100 words

\begin{tabular}{llll}
\hline Adjunctive Extenders & & Disjunctive Extenders & \\
\hline and all of that & 1 & or anything & 4 \\
and all that & 2 & or anything like that & 1 \\
and all that stuff & 3 & or so & 42 \\
and all this & 3 & or some other stuff & 1 \\
and everything & 12 & or something & 35 \\
and really sick stuff & 1 & or something like that & 7 \\
and so & 2 & or something like this & 2 \\
and so on & 7 & or stuff like that & 1 \\
and some smaller stuff & 1 & or things like that & 1 \\
and stuff & 42 & or this & 2 \\
and stuff like that & 4 & or whatever & 11 \\
and the whole stuff & 1 & & \\
and things like that & 3 & & \\
and this stuff & 1 & & 107 \\
and tralala & 3 & & \\
and whatever & 2 & Total & \\
Total & 88 & Forms & 0.201 \\
Forms & 16 & Frequency per 100 words & \\
Frequency per 100 words & 0.165 & & 0.369 \\
Total Frequency per 100 words & & & \\
\hline
\end{tabular}

The GNNSE data in Table 6 shows that, as in the NSNZE corpus, and stuff and or something are also among the GEs most frequently used by non-native speakers. Disjunctive or whatever (11 tokens), or something like that (7 tokens) and or anything (4 tokens) were also used relatively often by GNNSE. Similarly, adjunctive extenders and everything and and stuff like that that were frequently used by NSNZE also occurred relatively often in the GNNSE corpus with 12 and 4 tokens respectively.

The forms and frequencies of GEs produced by GNNSE and NSNZE differ in the sense that GNNSE did not produce a single instance of and things, whereas it was used 10 times by native speakers in the NSNZE corpus and 5 times in the crosscultural conversations. Moreover, there are a number of forms in the GNNSE data that do not occur in the NSNZE sets at all. Most notably, with 42 tokens, GNNSE 


\section{General Extenders}

used the disjunctive form or so more often than any other GE. Native speakers, on the other hand, only produced three tokens of or so overall. Other forms that occurred in the speech of GNNSE but not in the language of NSNZE include and the whole stuff, and all this, and so, and so on, and tralala, or this, or and something like this. The form or so is an interesting example in this context because it is an acceptable English form, albeit one that is restricted in its use to numerical approximation, and directly corresponds to a German construction that can be used in a multitude of contexts. Non-native use of or so will be discussed in greater detail in section 5.5.

The frequency of use suggests that GNNSE use fewer GEs when speaking English than when speaking German. This may mean that they adopted NZE native speaker conventions for GE use, or alternatively that the use of GEs has been restricted by their limited second language proficiency. The results of a paired ttest show that the differences in frequencies of use between GNNSE and NSNZE in cross-cultural interactions are not statistically significant $(p$-value $=.422>.05)$. Nevertheless, it can be noted that GNNSE use slightly more GEs than their NSNZE interlocutors and more disjunctive GEs than NSNZE in both the crosscultural and the native-native interactions. This seems surprising since the quantitative comparison of a range of pragmatic devices used by NSNZE and GNNSE in section 4.3 suggests that GNNSE generally use pragmatic devices less than their NSNZE interactants. It is possible, however, that the referential nature of GEs makes this set of forms more readily accessible to non-native speakers.

Another point of interest is that, although GNNSE produce a greater number of GEs in the cross-cultural interactions, they only use a limited range of forms. In the native-native interactions NSG produced 22 different adjunctive extenders while there were only 17 different forms in the GNNSE data set. Similarly, NSG constructed 17 different disjunctive forms in German but GNNSE only produced 11. One possible explanation for the decrease in the number of GE forms in the GNNSE set could be the reduced linguistic proficiency in the speakers' second language, which might entail a more formulaic use of pragmatic devices. 
Table 7: Total number of GEs in cross-cultural NSNZE data and overall frequency per 100 words compared with NSNZE-NSNZE results

\begin{tabular}{|c|c|c|c|c|c|}
\hline \multicolumn{3}{|l|}{ Adjunctive Extenders } & \multicolumn{3}{|l|}{ Disjunctive Extenders } \\
\hline and all & - & (1) & or anything & 13 & (9) \\
\hline and all of that & - & (1) & or anything like that & 1 & (3) \\
\hline and all of those & - & (1) & or so & 2 & (1) \\
\hline and all sorts of stuff & - & (1) & or something & 43 & $(54)$ \\
\hline and all sorts of things & - & (1) & or something like that & 13 & (18) \\
\hline and all that & 1 & (5) & or things like that & 1 & $(-)$ \\
\hline and all that kind of jazz & 1 & $(-)$ & or whatever & 8 & (15) \\
\hline and all that kind of rubbish & 1 & $(-)$ & or whatever you call it & 1 & $(-)$ \\
\hline and all that kind of stuff & 1 & (1) & & & \\
\hline and all this & 1 & $(-)$ & & & \\
\hline and all this other contextual stuff & - & (1) & & & \\
\hline and all this other shit & 1 & $(-)$ & & & \\
\hline and anything important like that & 1 & $(-)$ & & & \\
\hline and different things & - & (1) & & & \\
\hline and everything & 6 & (8) & & & \\
\hline and everything like that & - & (1) & & & \\
\hline and kind of funky stuff like that & - & (1) & & & \\
\hline and other things & - & (1) & & & \\
\hline and shit & - & (1) & & & \\
\hline and shit like that & 1 & $(-)$ & & & \\
\hline and so on & 2 & $(-)$ & & & \\
\hline and stuff & 56 & $(56)$ & & & \\
\hline and stuff like that & 5 & (7) & & & \\
\hline and that & 2 & (3) & & & \\
\hline and that kind of stuff & 1 & (1) & & & \\
\hline and that kind of thing & 2 & (2) & & & \\
\hline and that sort of stuff & - & (1) & & & \\
\hline and that sort of thing & 6 & (4) & & & \\
\hline and things & 5 & (10) & & & \\
\hline and things like that & 9 & (3) & & & \\
\hline Total & 102 & (114) & Total & 82 & (105) \\
\hline Forms & 18 & (24) & Forms & 8 & (8) \\
\hline Frequency per 100 words & 0.194 & $(0.194)$ & Frequency per 100 words & 0.156 & $(0.178)$ \\
\hline Total Frequency per 100 words & & & & 0.353 & $(0.374)$ \\
\hline
\end{tabular}

Table 7 features the results from the native-native interactions in brackets where appropriate in order to facilitate a direct comparison of the production of GEs by NSNZE in cross-cultural interactions. The table shows that in cross-cultural interactions NSNZE also display less variation of forms. In the native-native interactions overall 24 different adjunctive GEs where used while only 18 


\section{General Extenders}

different ones were found in the cross-cultural data. Moreover, as the frequency indexes suggest, NSNZE also used fewer disjunctive tokens when talking to GNNSE. In terms of the Accommodation Theory framework (Giles, Coupland and Coupland 1991) this slight decline in form variation and frequency might represent convergence by NSNZE towards their non-native interlocutors in the form of the simplification of their language use, which would minimise social differences and emphasise commonalities. Research on accommodation in nativenon-native interactions suggests that native speakers are more likely to accommodate their speech to that of their non-native interlocutor in spontaneous interactions when there is a mutual exchange of ideas (Long 1981; 1983 as cited in Zuengler 1991: 236). If this simplification is a common trend for native speakers when speaking with non-natives then this, in turn, is likely to hinder nonnative speaker's acquisition of native-like norms. However, since the variation is only minimal and not statistically significant ( $\mathrm{p}$-value $=.489>.05$ ), any explanation for the data can only be tentative at this stage.

A comparison between the production of GEs by NSNZE in native-native and in cross-cultural interactions shows that, despite a slight decline of forms and frequency, NSNZE used GEs relatively consistently. Thus, the frequency index for adjunctive extenders is the same for native-native and cross-cultural interactions and NSNZE even produced the same number of and stuff tokens in both settings. Interestingly, though, NSNZE produced more tokens of and things (10 vs. 5) and and all that (5 vs. 1) in the native-native interactions than in the cross-cultural ones, while the opposite is true for and things like that (3 vs. 9). Since the frequency of use for disjunctive extenders was smaller overall for the cross-cultural conversations, it comes as no surprise that there is a drop in the number of tokens of all disjunctive GE with the exception of or anything. All frequently used forms in the native-native conversations also occurred in the cross-cultural ones. The forms that did not occur in one or the other setting were low frequency GEs.

\subsubsection{GNNSE - General Extender Construction}

Generally speaking, GNNSE seem to follow native-speaker conventions of GE construction. However, there are a few forms that do not follow the established 
pattern, namely and so, and the whole stuff, or something like this and or this. The forms and so and and the whole stuff seem to be direct translations of the German GEs und so and und solche ganzen Sachen 'and all those things', which sound unusual by English native norms. The non-native forms or something like this and or this both contain the demonstrative article this, which does not occur in the NZE data. The two forms would be completely acceptable if this was replaced by that. It seems interesting to note that forms containing this were used by only three speakers. Two of these speakers have only lived in an English-speaking context for a short period of time.

Overall, an analysis of the forms used by the different groups showed that there appears to be less variation among the disjunctive forms than the adjunctive ones. One possible explanation for this could be that in both German and NZE disjunctive extenders have become more formulaic or 'automatic' (Aijmer 2002: 223) than the adjunctive forms, allowing for less variation. This could indicate that disjunctive extenders are ahead of adjunctive extenders in the process of grammaticalisation (e.g. Brinton 1996; Andersen 2001). Similarly, the fact that the most frequently used GEs are short forms in both German (oder so, und so) and NZE (or something, and stuff) also suggests that these GEs have become formulaic expressions (Aijmer 2002: 223). It is interesting to note that while German seems to have more elements available for GE construction, NZE seems to have more ways of combining its smaller set of elements to create more forms. A study of GEs across a larger corpus is necessary to determine whether these slight trends prove to be relevant.

\subsubsection{Individual Variation}

The GNNSE and NSNZE data shows that the use of GEs varies greatly from speaker to speaker. This suggests that at least some of the variation might be related to personal preferences. In the GNNSE corpus, frequency of use ranges from 0 by Gudrun and Frauke (F-F) and $0.06 \%$ by Nils (M-M) to $0.79 \%$ by Valena (F-F), $0.91 \%$ by Lotta (F-F) and $0.92 \%$ by Nina (F-M). Among the NSNZE in native-native interactions the frequency varied between 0 by Tom (MM) and Tanya (F-M) to $1.04 \%$ by Pamela, $0.87 \%$ by Carl and $0.77 \%$ by Guy (all F-M). This shows that the high frequency users in the GNNSE and NSNZE 


\section{General Extenders}

groups are producing GEs at very similar rates. This also suggests that high frequency use by non-native speakers does not necessarily equal a high degree of native-like proficiency. This notion is further supported when looking at the language background of the GNNSE. There does not seem to be a correlation between high or low frequency use of GEs and linguistic proficiency. Frequent GE users Lotta and Valena have spent more than six months in New Zealand and Australia before coming to Wellington for their current course of studies, whereas Nina has not. The same can be observed at the other end of the spectrum: for the low frequency user Gudrun this is the first time she has lived in an English speaking country for more than six months; Frauke and Nils, on the other hand, have lived overseas before coming to Wellington.

With regard to their language use in social interactions both Lotta and Valena indicated that they use predominantly English whereas Nina gave a mixed reply. Among the lower frequency group, Gudrun stated that she did not use English for the majority of her social interactions while Frauke claimed that she does (Nils did not fill in this part of the questionnaire). All speakers reported that they started to learn English at school at the age of 9 or 10 and they all stated that they used mainly English in their home in Wellington. The frequency of use of GEs does not seem to reflect the subjectively perceived quality of the interaction as they all indicated that they enjoyed their conversations and thought that they established a good rapport with their respective interlocutor. Finally, it does not seem to be the case that the results for the speaker's frequencies of use were substantially influenced by the length of the individual transcriptions in the sense that speakers might have had more opportunity to produce GEs when the full conversation was considered. However, low frequency users Gudrun and Frauke but also high frequency user Valena belonged to the group that were represented by only 10 minutes of transcriptions.

This lack of a clear correlation between high frequency use of GEs and linguistic proficiency seems to suggest that proficiency is not relevant for the incorporation of GEs into the language of non-native speakers. This notion seems to be further supported by the fact that only Lotta, who lived in New Zealand for a year when she was on a school exchange and continued to keep contact when back in 
Germany, can be considered a highly proficient, near native speaker. The other near-native speakers, such as Ingo, Ulf or Cordula, use GEs at lower frequency rates, namely $0.28 \%, 0.22 \%$ and $0.13 \%$ respectively, while Silke (F-M) uses it at a medium rate with $0.66 \%$. This suggests that other factors, such as personal preference or accommodation to a peer, might be more influential.

Looking at the correlation between the use of GEs in German and English by GNNSE it can be noted that both Lotta and Valena are also high frequency users of GEs in German with frequencies of $1 \%$ and $0.6 \%$. This, however, does not apply to Nina, who uses German GEs only $0.11 \%$ of the time. At the opposite end it turns out that Frauke, Gudrun and Nils are low frequency users of GEs in German as well. This correlation between frequency of use of GEs in German and English applies to about 20 out of 30 interactions. The other 10 GNNSE display a great discrepancy between their frequency of use of GEs in German and English. The correlation between the use of GEs by NSNZE and GNNSE appears to be an equally reliable indicator of the frequency of use of the device. Though there are a number of conversations where a high or low frequency use of GEs by the NSNZE does not coincide with the frequency of GEs by their GNNSE interlocutor, in the majority of interactions (21 of 30) the frequencies do coincide by a margin of about $-/+0.2 \%$. The 21 speakers contained in this group are not necessarily the same ones where an approximate correlation between the frequencies of occurrence in German and English was found. Arne, for example, uses German GEs with a frequency of $1.13 \%$ whereas his frequency for English GEs is $0.27 \%$, which is closer to his interlocutor's $0.29 \%$. These seem to be trends rather than definite inter-relationships. Nevertheless, this result would strengthen the assumption that the language use of NSNZE has a strong influence on the language use of non-native interlocutors.

\subsection{Functions}

As noted above, GEs are multifunctional devices, which can express a wide variety of meanings, ranging from predominantly referential functions, for instance as indicators of imprecision or vagueness, through to affective and interpersonal functions, establishing rapport and reducing social distance. GEs also play an important role in terms of discourse management. However, an 


\section{General Extenders}

analysis of, for example, the turn-taking functions of GEs would be beyond the scope of this study and therefore will not be investigated further in this discussion. Because GEs work on so many different levels simultaneously, it is often impossible to specify the entire range of functions they may serve since these will vary slightly and often subtly from point to point in a conversation. Knowledge of the wider discourse situation, together with an analysis of the use of discourse strategies, phonological cues and other pragmatic devices, can generally help in identifying the potential meanings of an extender in a specific context. Nevertheless, a quantative analysis of the various functions will not be attempted because the referential and affective functions are so closely related and difficult to keep apart. In this section some of the functions or discursive meanings conveyed by GEs in my data set will be illustrated.

\subsubsection{Referential meanings of GEs}

In this study, GEs have been defined as forms whose referential function is to convey imprecision or vagueness, but which also express affective meaning, establishing rapport by appealing to the interlocutors' shared knowledge. These two basic functions characterise both the NZE and the German GEs. For the purpose of this study, two broad meanings of referential imprecision are differentiated. Instances of predominantly referential GEs are categorised depending on whether the GE relates to a specific lexical item or to a proposition. Lexically oriented GEs function as hedges on particular lexical items, indicating that the speaker's choice of a specific item is for some reason imprecise. In this sense they can serve to convey the speaker's degree of (un)certainty towards the accuracy of a number, for example, or the speaker's reservations about the precision of a specific lexical item, or they can indicate that the focus lexical item is just one example of a larger class of potentially relevant items. The second broad category constitutes GEs which convey the speaker's degree of (un)certainty about the validity of a proposition. The following examples illustrate these categories.

An example of a GE functioning as a lexical hedge on a number, conveying approximation, is represented in Example 14. 


\section{General Extenders}

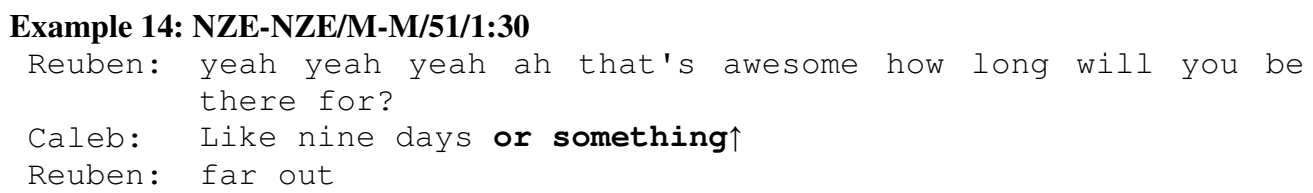

The day before the recording Caleb was offered the opportunity to go to Thailand for a few days. He does not know all the details of the trip yet since he only just found out and has not had the time to organise anything. He uses or something to indicate that the given period of nine days is just an approximation of how long he will be in Thailand.

Among other forms, German can use the form oder was as a numerical hedge as illustrated in Example 15. Like its English translational equivalent or what, German oder was can also serve to add emphasis in certain constructions (Overstreet 2005: 1857); however, the form was not employed in this sense in the present corpus. In Example 15 Rolf talks about the ranking of his favourite team in the German soccer league. He is not entirely sure how many points behind Bremen they are, using oder was to signal numerical vagueness.

\section{Example 15: NSG-NSG/M-M/32/- \\ Rolf: Sechs Punkte hinter Bremen glaub ich sind die oder was \\ Rolf: I think they are six points behind Bremen oder was}

Example 16 illustrates the lexical hedge oder so ähnlich expressing the speaker's uncertainty with regard to the precision of the specific lexical item stickmen, the title of a New Zealand movie. By using the GE, Frauke indicates that she is not entirely sure if the name of the movie is correct.

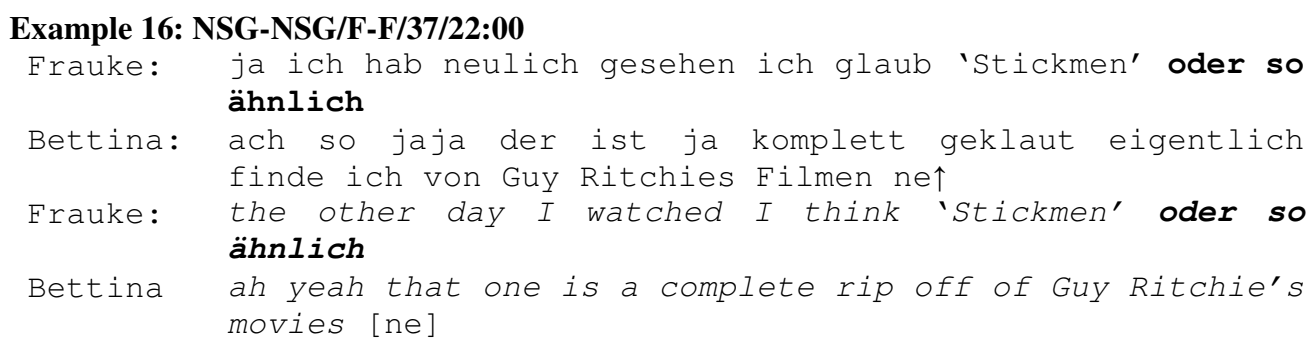

In this example, the interpretation of the GE oder so ähnlich as a lexical hedge is supported by the co-occurrence of the pragmatic device ich glaub 'I think'. 


\section{General Extenders}

Example 17 illustrates a GE which functions as a lexical hedge, signalling that the focus lexical item is just one example of a class and thereby implying that more items could be provided. Overstreet (1999) identifies this referential function of GEs, noting that such hedges orient to Grice's Maxim of Quantity. In the example, Zach talks about his Honours thesis on New Zealand history. In this case, the GE and stuff like that is used to suggest that youth movements and protest movements are just two aspects of what he looked at for his research.

\section{Example 17: NZE-NZE/M-M/58/12:30 \\ Zach: I did a whole lot of . finding out about . em . you know basically youth movements and protest movements and stuff like that from the basically from the sixties}

Example 18 provides an example of a German GE used in the same way: i.e. a lexical hedge signalling that the focus lexical item is just one example of a wider class. Silke and Mario talk about where in Germany they would like to live and work. Silke states that she likes Hamburg, her hometown, because of its vibrant cultural life and its relatively liberal attitude. She goes on to say that, even though she would consider it, she might have a problem with the more conservative mind-set in cities such as Jena, where Silke was thinking of taking up a $\mathrm{PhD}$ position. Channell (1994: 126) suggests that in these cases the chosen item often represents a model example that represents the group in mind. In this instance it seems that, even though Jena could stand in for a number of cities in Germany, it was chosen because of its immediate connection to and importance for the speaker. 


\section{General Extenders}

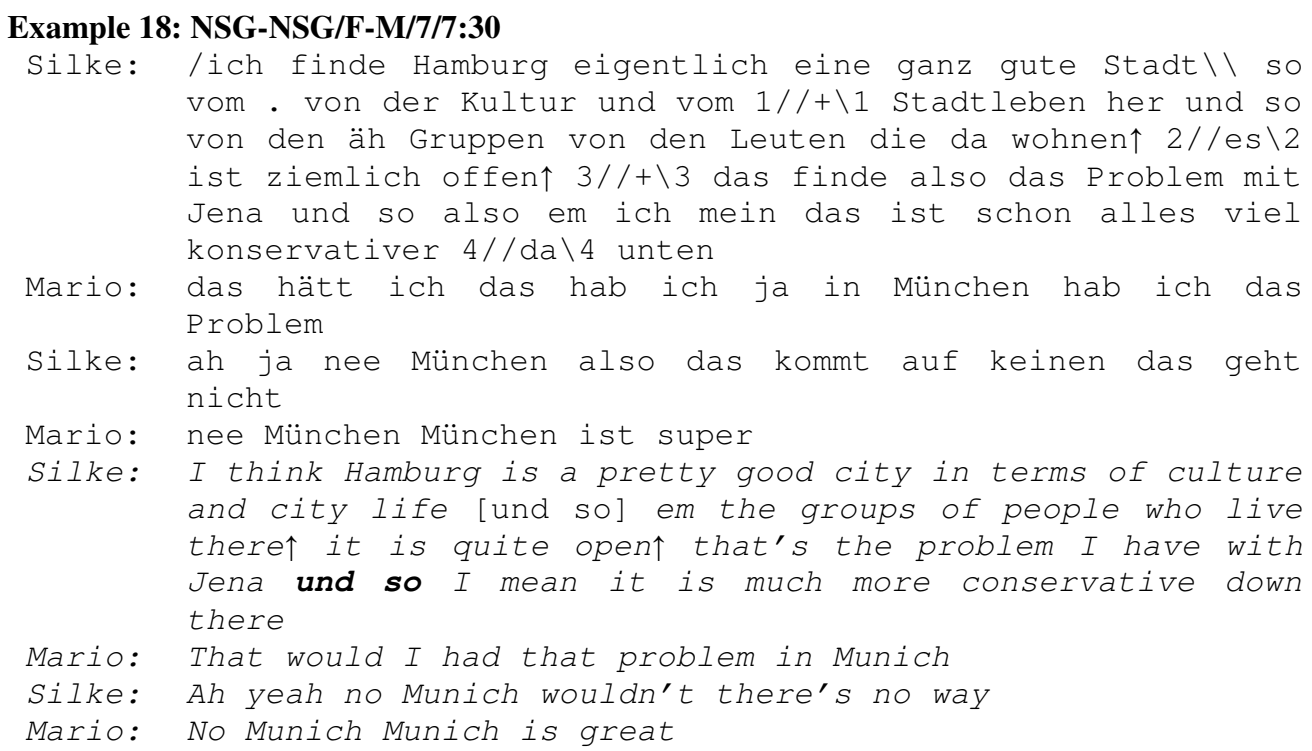

The GE und so indicates that in addition to Jena there are other places in the south of Germany that are more conservative than Hamburg. Incidentally, this example also nicely illustrates the concurrent interpersonal or affective function of GEs, since it appeals to assumed shared background knowledge, pre-supposing that the addressee knows what other cities could be mentioned in this context. In the next turn, Mario responds to this appeal to the interlocutor's shared knowledge by referring to a city that seems to fit Silke's description of a more conservative city in the south where Silke would be hesitant to move. Interestingly, however, Mario's and Silke's ideas of what belongs to the group implied by the und so seem to differ: for Mario Munich belongs to the list of cities he might consider living in while for Silke Munich would not even be an option. The idea that GEs can function as appeals to the interlocutor's shared background knowledge will be taken up below.

Propositional hedges convey the speaker's degree of (un)certainty about the validity of a proposition. One possible explanation of the use of the GE in Example 19 is that of a hedge on the proposition that's how it ends and and then blacking out. Greg tells Nathan about a famous psychological experiment where participants were asked to punish other participants by giving them electric shocks with increasing intensity. The punished participant, a paid actor, did not receive real electric shocks but acted out the appropriate symptoms. The experiment was 


\section{General Extenders}

supposed to test at what stage the participants refuse the researcher's demand to inflict pain on someone else.

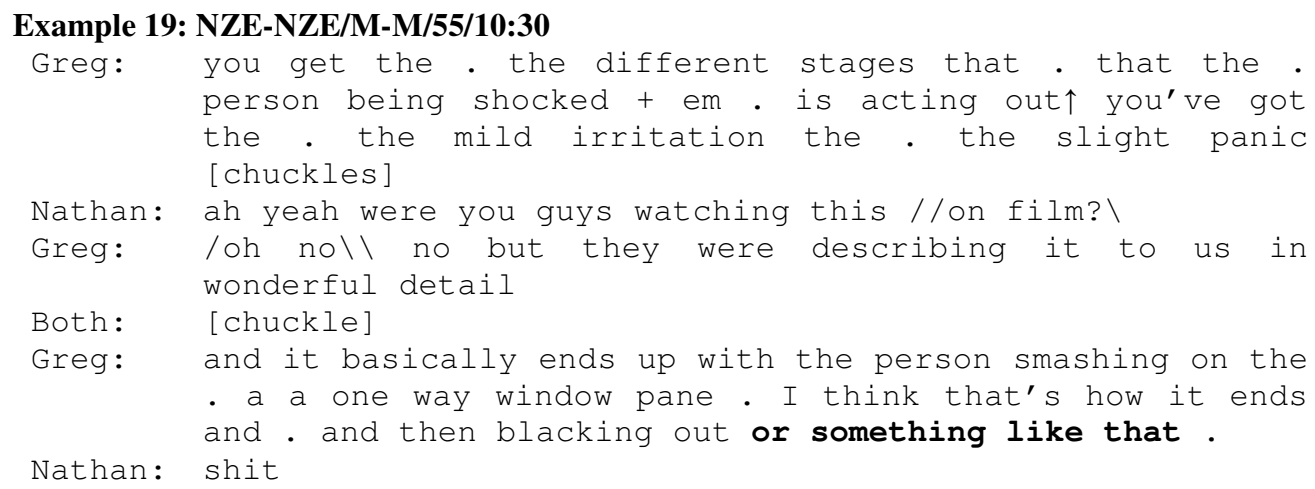

In this context, the GE or something like that seems to indicate that Greg cannot recall the finer details of the experiment, which he has only been told about in class. Alternatively, the GE could also be a hedge on the lexical item blacking out. In this case, the occurrence of the pragmatic device I think in the same turn would strengthen both interpretations regarding Greg's uncertainty towards the correctness of his utterance.

These examples have illustrated that even the referential meanings of GEs are complex as they can serve as hedges that are expressing vagueness in relation to concepts at different levels. Even though different kinds of referential hedges may have been presented as distinctive categories in the present section, it should be noted that the distinctions are not always easily maintained. Overlapping meanings are typical of authentic interpersonal discourse. Even the distinction between lexical and propositional meaning is not always easy to draw (see Example 27 below). Furthermore, in addition to hedging referential aspects of talk, such as quantity and quality, GEs often also serve interpersonal functions by appealing to the interlocutor's shared knowledge (see Example 12). This is also true for the propositional hedge in Example 13. Here a basic knowledge of how the human body reacts to high voltage is required for Nathan to understand Greg's description of blacking out as a feasible reaction to electrocution and to be aware of alternative responses. Such assumptions of shared knowledge help reduce social distance and create interpersonal rapport. The next section will focus more explicitly on such meanings. 


\subsubsection{Affective Meanings of GEs}

The analysis in the previous section indicated that GEs which express some degree of referential uncertainty simultaneously convey affective meanings. In this section, some of these affective meanings are illustrated, and examples where the affective functions are particularly prominent are presented. The focus is on two broad categories: firstly, GEs used as positive politeness or rapport management strategies (Brown and Levinson 1987; Spencer-Oatey 2000) i.e. actively constructing rapport, and secondly GEs used to attenuate negatively affective speech acts, i.e. contributing to rapport indirectly by ameliorating a face threatening act or minimising an infringement on the other's sociality rights.

\subsubsection{Constructing rapport}

Probably the most pervasive interpersonal or affective meaning of GEs is their contribution to the creation and maintenance of rapport, i.e. a sympathetic relationship or understanding (Collins Dictionary: 1286), through their appeal to shared knowledge and assumed common experiences. Example 20 illustrates how the GE and stuff may function in this way. A series of unfortunate circumstances have forced Vivienne to quit a degree at a different university. Her main reason for returning to study was to avoid feeling she had spent a lot of time and money on a university degree with nothing to show for it.

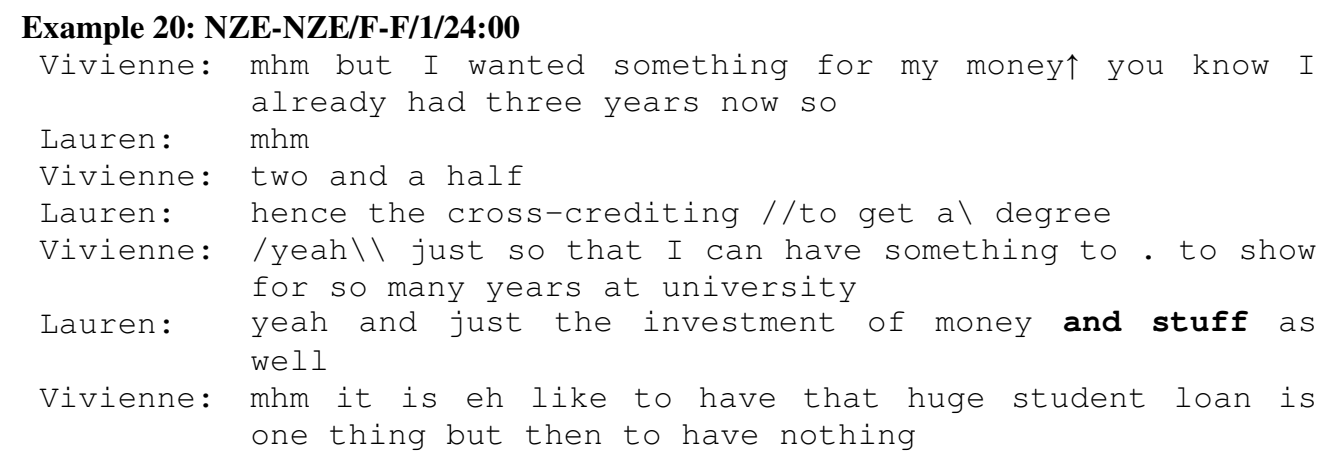

Referentially, the GE and stuff functions here as a lexical hedge, indicating that Lauren understands that the focus lexical item money is just one example of what has been invested. Affectively, this GE can be interpreted as an indication that Lauren is on the same wave-length as Vivienne. She picks up Vivienne's reference to what she has invested and signals that she understands her position. 


\section{General Extenders}

Comparable examples from German can be found in Example 21 and Example 22. In the first excerpt, Knut and Lars exchange stories about their travels in South America. Lars just recounted how he and his friends got tricked out of a lot of money by a doctor. In the present excerpt, Knut commiserates with Lars by relating how something similar happened to him in the same town.

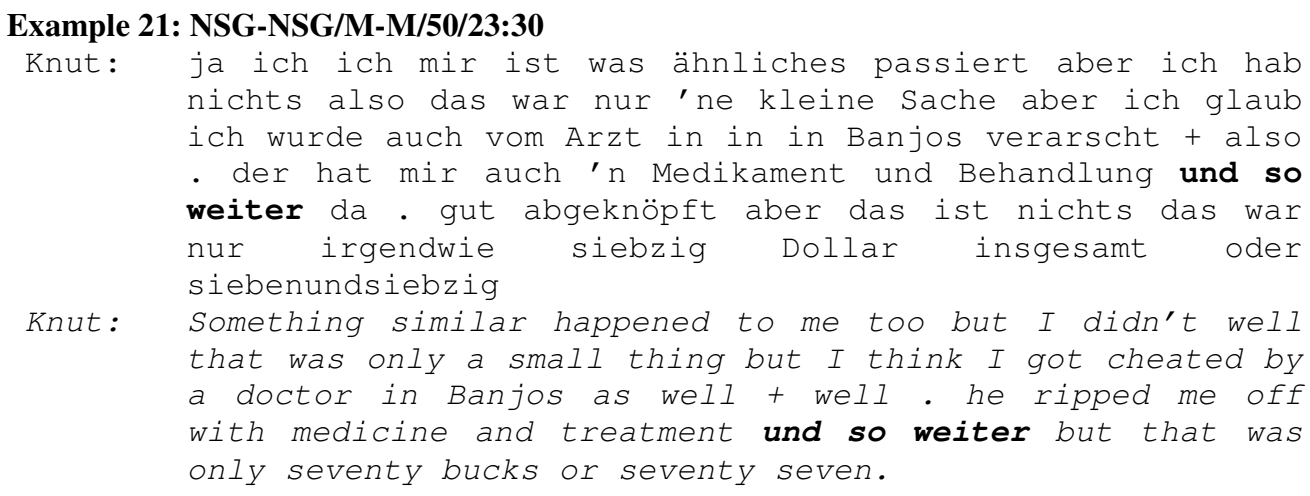

On a referential level, the GE und so weiter modifies the nouns Medikament und Behandlung and seems to indicate that there might have been additional entries on the bill that has not been mentioned. On an interpersonal level, however, the GE seems to strengthen interpersonal rapport by drawing on the similarities of their experiences (I got cheated by a doctor in Banjos as well) and thus seems to signal that Knut fully understands the situation.

In Example 22, Arne tells Frederike about his course of study, which combines English language and literature with business management. While Arne is generally interested in learning about management he does not particularly enjoy studying accounting. The memory alone seems to be enough for him to get worked up. His tone of voice and the negative evaluations in the form of colloquial expressions such as super ätzend and the informal GE und so'n scheiß increase the impression that Arne thoroughly disliked studying accounting. In a later turn he even describes the experiences as horrible. His emotional involvement in a relatively trivial matter in conjunction with the use of slightly coarse and very informal language could be interpreted as the source for the laughter. 


\section{General Extenders}

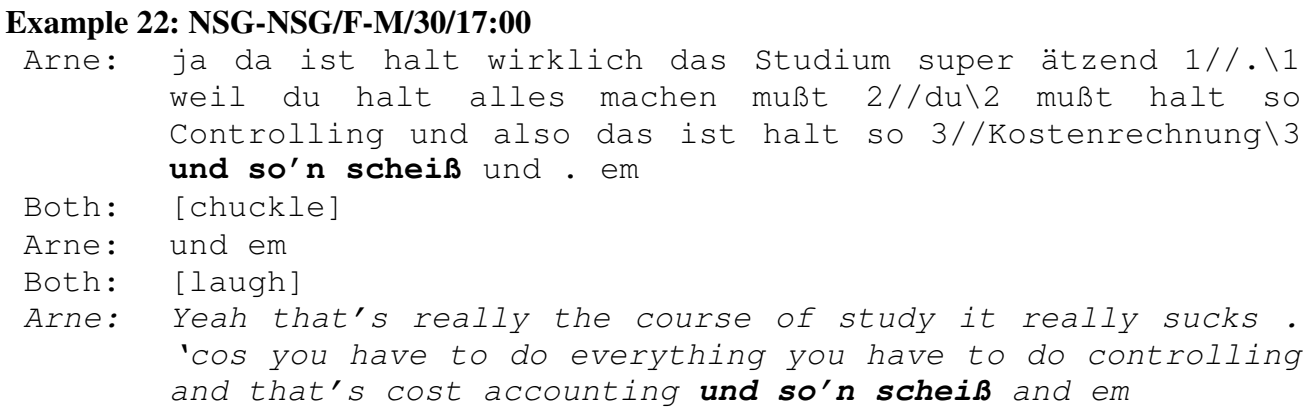

Instead of presenting a balanced criticism of the course Arne reverts to ranting or whingeing, a speech act which has been described in term of its role in the establishment of interpersonal solidarity (Clyne 1994: 62-3). The use of a GE containing an expletive (Schei $\beta$ 'shit') seems to support these affective functions as it emphasises Arne's distress over his accounting paper. Daly, Holmes, Newton and Stubbe (2004: 959) have noted the frequent occurrence of expletives in whinges and conclude that the use of expletives can function as a solidarity enhancing device. A further interpretation of the example could be that the use of the marked GE has the effect that it makes Arne's emotional reaction seem exaggerated and comical rather than serious. In this sense, the use of the GE would serve to attenuate the force of the speech act of whingeing by making light of his annoyance. The following laughter would further support this analysis.

The present corpus contains a number of instances where GEs seem to be used for comedic effects. Overstreet (1999: 120) points out that disjunctive markers lend themselves to be used in jokes since "in these environments, they signal to the hearer that what precedes the general extender is not accurate or real. Instead, it is a purposeful exaggeration, or an analogy, which should not be taken too literally". This is illustrated in Example 23. Carol and Felicity are talking about the fact that tertiary education in France is free for New Zealanders.

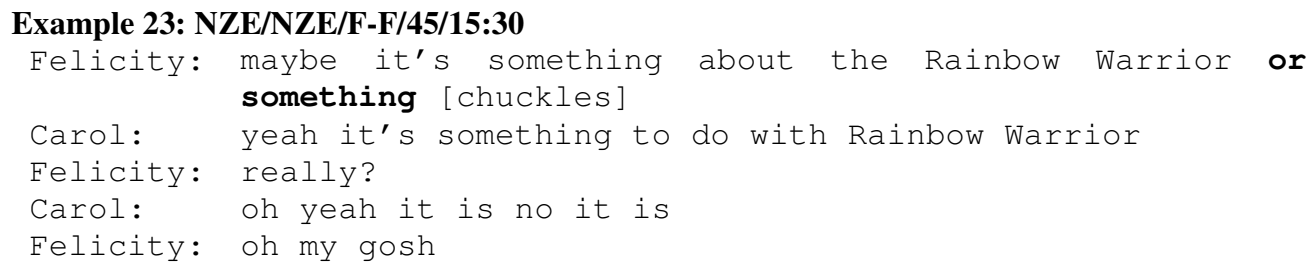




\section{General Extenders}

The Rainbow Warrior was a Greenpeace ship which was illegally blown up in a New Zealand harbour by French secret service agents, killing someone, and causing a major diplomatic furore. Felicity's use of or something here suggests 'something of similar political significance'. However, the context and tone of voice make it clear that Felicity's implicit suggestion (that the political crisis surrounding the illegal sinking of the Rainbow Warrior might account for this preferential treatment) is made in jest. This notion is supported by Felicity's surprised reaction when Carol confirms that her suggestion is correct. In this case the GE or something seems to function as a reinforcement of the non-serious key by expressing vagueness and imprecision, and indicating that she does not mean to be taken too literally.

Similar uses of GEs for comedic effects can be found in the German corpus. In Example 24 Knut talks about how different the university experience in New Zealand is from what he encountered in Germany.

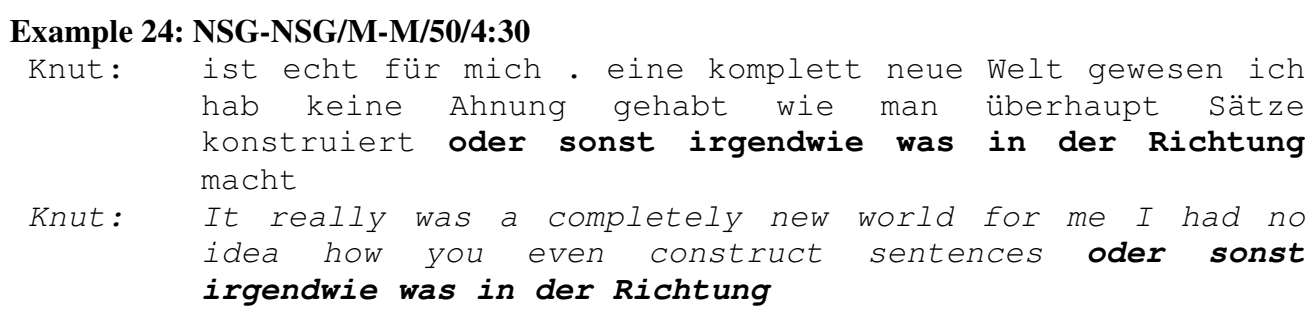

The somewhat extreme claim that he did not know how to write sentences when he first arrived is modified by the GE oder sonst irgendwie was in der Richtung, indicating that the proposition represents an exaggeration of the truth and should not be taken literally. Instead, the GE seems to implicate a whole range of potential problems with academic and writing skills that Knut might have experienced.

\subsubsection{Attenuating negative speech acts}

A second interesting affective meaning expressed by GEs is their function as hedges on the force of negatively affective speech acts, such as criticism and disagreement. Example 25 illustrates this meaning of GEs. Katja claims that New Zealanders are usually nice on an interpersonal level, but that she cannot develop 
a deeper relationship with them since they seem to have more conservative, and in Katja's view, out-dated, beliefs and attitudes.

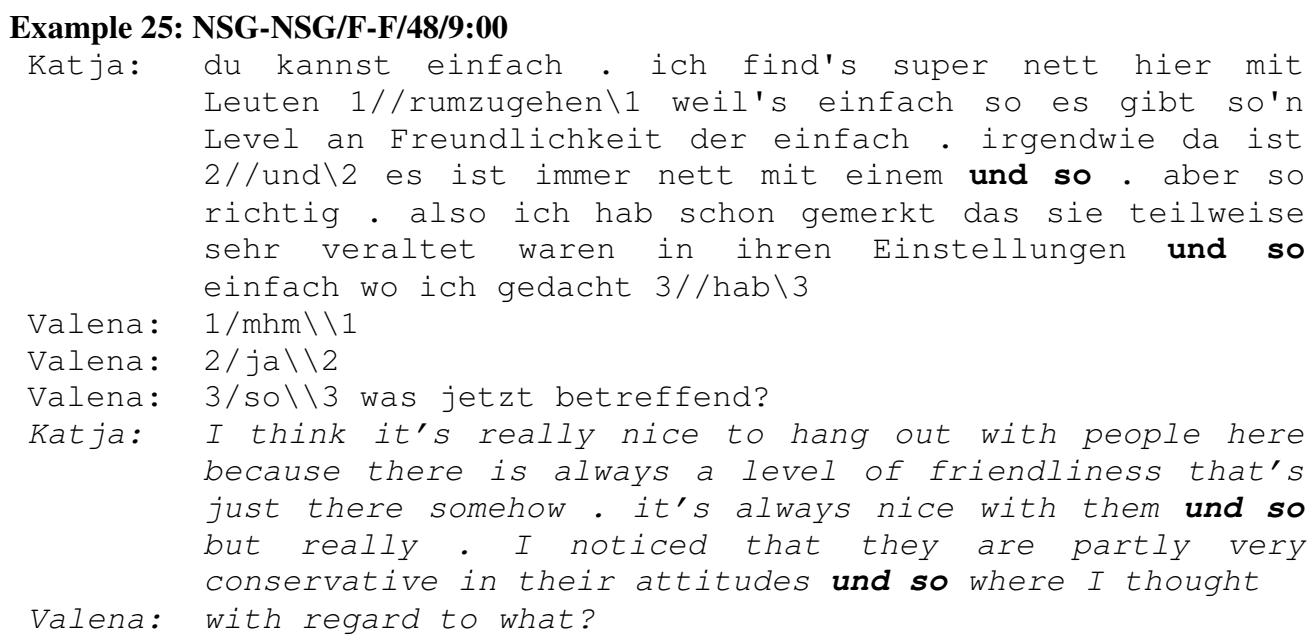

The two instances of und so in this example appear to have very similar referential and affective functions. On a referential level, the devices seem to indicate that there are more ways to be friendly or conservative than those mentioned by Katja. On an affective level, both tokens appear to convey Katja's assumption that the interlocutor shares her knowledge or understands her description of interactions with people who are friendly but have very different values. Interestingly, Valena does not seem to share Katja's understanding of the way some New Zealanders can hold rather conservative beliefs as she requests clarification on that point. At the same time, both tokens appear to function as hedges on the speech act of a criticism as they seem to attenuate Katja's critique of her host nation.

In the present NSNZE corpus only a few instances of hedging a complaint or whingeing were found. Instead, there were a number of instances where NSNZE used GEs when asking questions, as shown in Example 26 below. Nathan's graduation is coming up soon and Greg asks if his family is going to come to attend the ceremony. Referentially, the GE and stuff suggests that it is not only family that might want to attend such a big event but maybe also friends or partners. In terms of politeness, the GE seems to mitigate the rather personal nature of the question, making it sound less intrusive. 


\section{General Extenders}

\section{Example 26: NZE-NZE/M-M/55/16:30}

Greg: got a lot of family and stuff coming? sorry you go

Nathan: em + yeah mum and dad are coming down both my brothers are overseas

Upon a first inspection of the data, it seems as if more instances of whingeing occurred in the NSG interactions than in the NSNZE-NSNZE data. This could mean that there is a cultural difference in the sense that whingeing is more accepted as a strategy to create solidarity among Germans than New Zealanders. However, the results could also be influenced by the peculiarity of the general circumstances of the recordings. All Germans were recorded while living abroad, and the shared experience of being a member of a minority group, of being a foreigner, might have motivated the German participants to try hard to establish a good interpersonal rapport with other Germans when that would not necessarily happen in Germany. Thus, Germans might have been more interested in making friends with their fellow German speakers while New Zealanders might have been more reserved, resulting in NSNZE using more negative politeness strategies such as mitigating questions.

In addition to these more general politeness functions discussed above, GEs may also express a wide range of more subtle and complex affective meaning. Due to space constraints, I here discuss just one example. However, it can be taken as representative of a host of others where the precise meaning of the GE is complex and subtle, as well as very context-dependent. The focus in Example 27 is Barbara's use of the GE or whatever.

\section{Example 27: NZE-NZE/F-F/41/25:00}

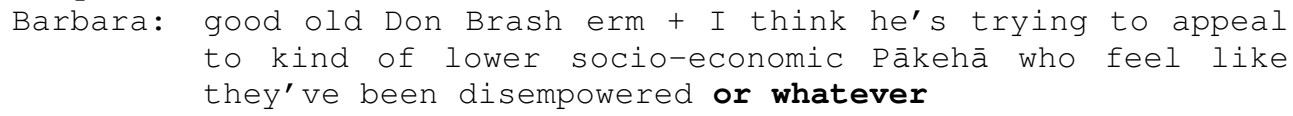

In this context, the GE can be interpreted as conveying the general referential meaning of vagueness or imprecision. The referential focus appears to be the lexical item disempowered, although this is an example where the distinction between lexical and propositional hedge is not very clear-cut, since the proposition appears relatively semantically empty apart from this specific lexical item. 


\section{General Extenders}

Affectively, I consider this a complex example. Clearly the GE can be interpreted as appealing to shared knowledge, i.e. or whatever indicates that the speaker assumes the addressee can construct the relevant kinds of meanings that have been left unspecified. But it also seems possible to interpret the GE in this context as conveying additional components of affective meaning. Overstreet (1999: 123) points out, the lexeme whatever has "a dismissive quality", signalling that the details are not important in the context. This dismissive component of meaning certainly seems relevant to the interpretation of or whatever in Example 27. It is also possible that or whatever functions in this example to indicate that the speaker considers the word disempowered to be a rather pretentious lexical choice, given the informality of the conversational context. One could go even further and suggest that the GE or whatever suggests that Barbara is distancing herself from the kind of Pākehā she is talking about. All in all then, this example illustrates some of the complexities that may be conveyed by GEs in specific contexts, and some of the challenges that face both native and non-native speakers in interpreting their potential meanings.

While this preliminary analysis of the different functions of GEs is far from exhaustive the results nevertheless indicate that in both German and NZE these forms function like GEs in American and British English. My analysis indicates that both between NSNZE and between NSG, GEs express referential and affective or interpersonal meanings. They function to convey vagueness or imprecision as well as to construct and develop rapport. More specific referential functions include those of hedges on specific lexical items, expressing approximation or signalling that more examples could be provided, as well as hedges on the truth conditions of propositions. Affectively, GEs appeal to the speakers' assumed shared background knowledge, thereby constructing rapport and solidarity between the participants, as well as conveying a range of more subtle affective and attitudinal meanings in specific contexts. Considering that German and English are closely related languages these similarities are not necessarily surprising. The following section will discuss how these functions are expressed in cross-cultural encounters. 
General Extenders

\subsection{The functions of GEs as used by non-native speakers in cross-cultural interactions}

\subsubsection{Referential meanings of GEs}

An analysis of the cross-cultural data shows that the non-native speakers made appropriate use of English GEs at the referential end of the continuum, to express vagueness and imprecision. In Example 28, Rolf uses the GE or something to express numerical approximation, indicating that he cannot remember the accurate year when his car was made. While the GE signals that the proposed date cannot be taken too literally, it also implies that the real age of the car is about as old as one built in 1984 .

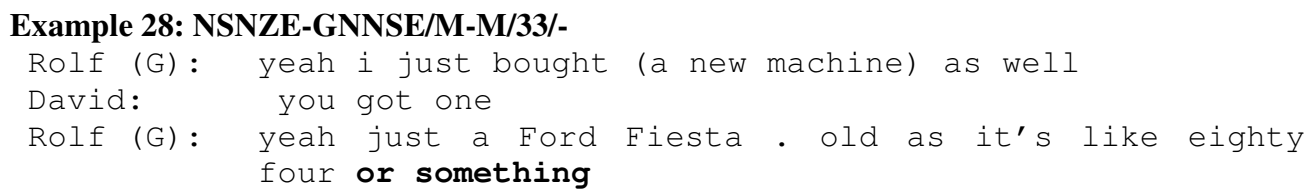

In Example 29, Moritz, the GNNSE, and Xander are talking about slaughtering techniques. Moritz points out that the modern slaughtering practice of shooting the animal in the brain is not always humane since the right spot is often missed, inflicting a lot of pain on the animal. Moritz uses the GE or something to indicate that the word pistol is not necessarily the correct or most appropriate term in this context but that it suffices as an approximation of what he means.

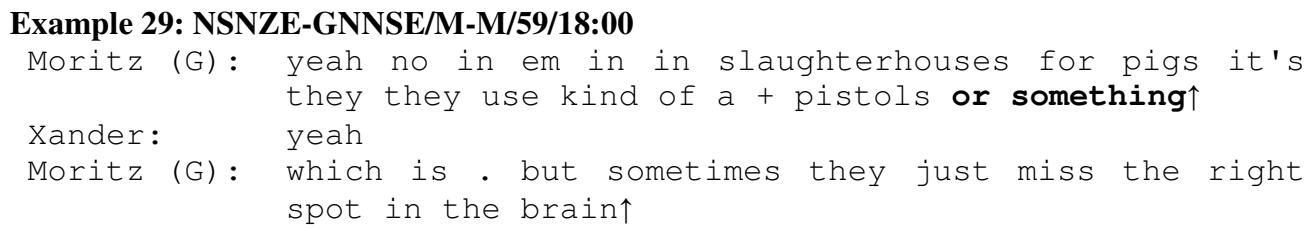

The impression of lexical insecurity is further supported by the use of the hedge kind of, the pause immediately preceding the word pistol and the utterance final HRT.

There are also examples in the GNNSE corpus that illustrate that the German students also use English GEs to indicate that a particular lexical item is just one instance of a more general class and that more options could be specified. 
Example 30 illustrates this usage by Katrin, a German student interacting with Guy, a New Zealander. Katrin's course of study revolves around energy management and the two speakers are having a conversation about the advantages and disadvantages of wind energy.

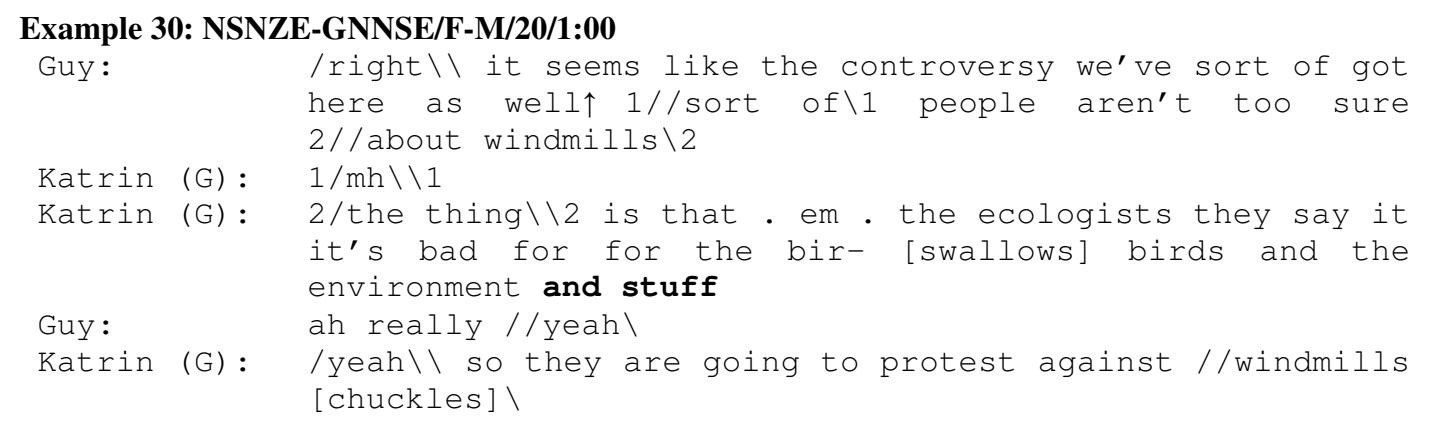

In the excerpt, Katrin recounts arguments against wind energy that were made by ecologists who claim that wind turbines have a negative impact on certain animals and the natural habitats surrounding wind turbine sites. The use of the GE and stuff indicates that birds and the environment are not the only ones potentially affected by wind turbines as the lives of other animals and plants would be influenced as well.

Finally, Example 31 illustrates the use of a GE as a propositional hedge. The excerpt below was taken from a discussion about the rivalry between Auckland and Wellington expressed in this discussion between Frederike and Bobby. Frederike, the German, has not been to Auckland before but she believes that it offers a greater range of entertainment than Wellington.

\section{Example 31: NSNZE-GNNSE/F-M/29/8:30 \\ Frederike: But well I'm . yeah. I believe that there's more to

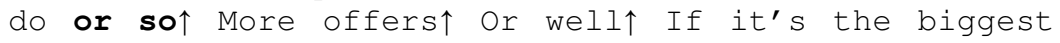 city but I wonder because I'm quite busy here and + I couldn't even do all those things}

The GE or so, in conjunction with the hedges well and I believe and the HRT, appear to be used to express lack of certainty, i.e. to highlight that Frederike's proposition (that there is more to do in Auckland) is only an assumption and that she cannot be sure if it is true since she has not been to Auckland. This effect is 


\section{General Extenders}

achieved even though the GE or so is technically an inappropriate form to use in this context since its use is generally restricted to numerical approximation.

This brief qualitative analysis of the non-native use of GEs in their mainly referential functions indicates that at least some GNNSE do use GEs as lexical hedges, expressing approximation and indicating that additional options remain unspecified, and as propositional hedges. Thus, these GNNSE put GEs to similar uses in English as they do in German and as NSNZE do in New Zealand English. The similarities between the use of referential GEs in German and NZE probably have helped GNNSE to adopt native-like conventions for expression referential uncertainty.

\subsubsection{Politeness - Affective Meanings}

Like native speakers of both German and English, GNNSE also use GEs to express a range of affective meanings, including establishing rapport and reducing the imposition of negatively affective speech acts on the others' face or their sociality rights. One fairly common affective use of GEs among GNNSE is to mark a proposition as a joke. The excerpt below serves as an example of this. Sven explains to Tanya what living in a relatively densely populated country such as Germany feels like as opposed to living in New Zealand. He points out that in New Zealand, you can drive for a long time without passing through a town whereas in Germany that would not be possible.

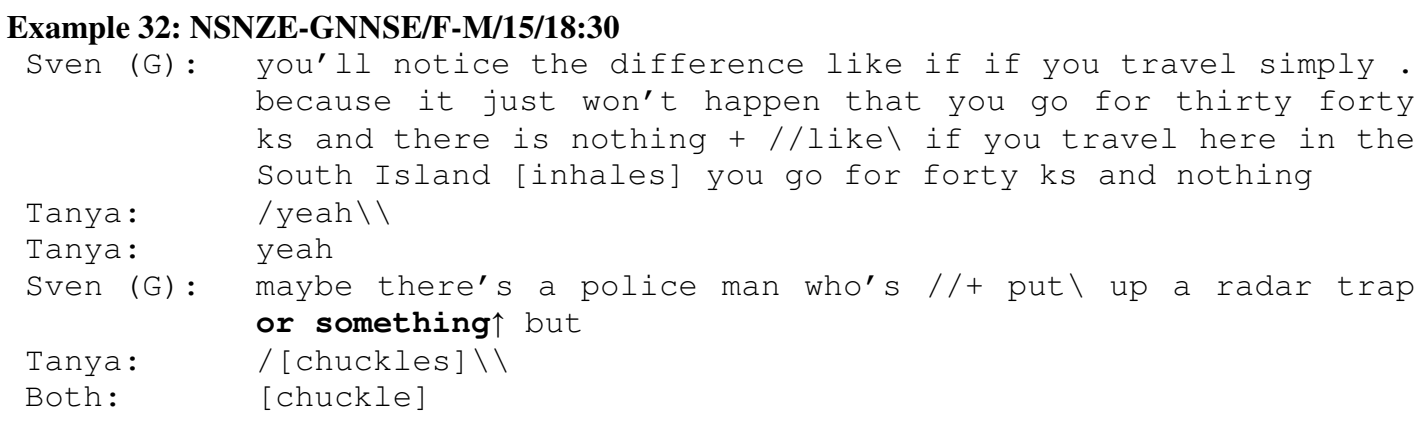

The GE or something modifies the suggestion that there might be a police man with a radar trap somewhere in the middle of New Zealand's countryside. The GE, in conjunction with the HRT, indicates that the proposition is made up and 
intended to be an exaggeration or an extreme example which should not be taken seriously.

A more complex example of GNNSE using GEs to create rapport is given in Example 33. In this excerpt, Ulf gives Tom an account of German music. Specifically, he explains how a certain type of music produced in German speaking countries is very popular in Asian countries.

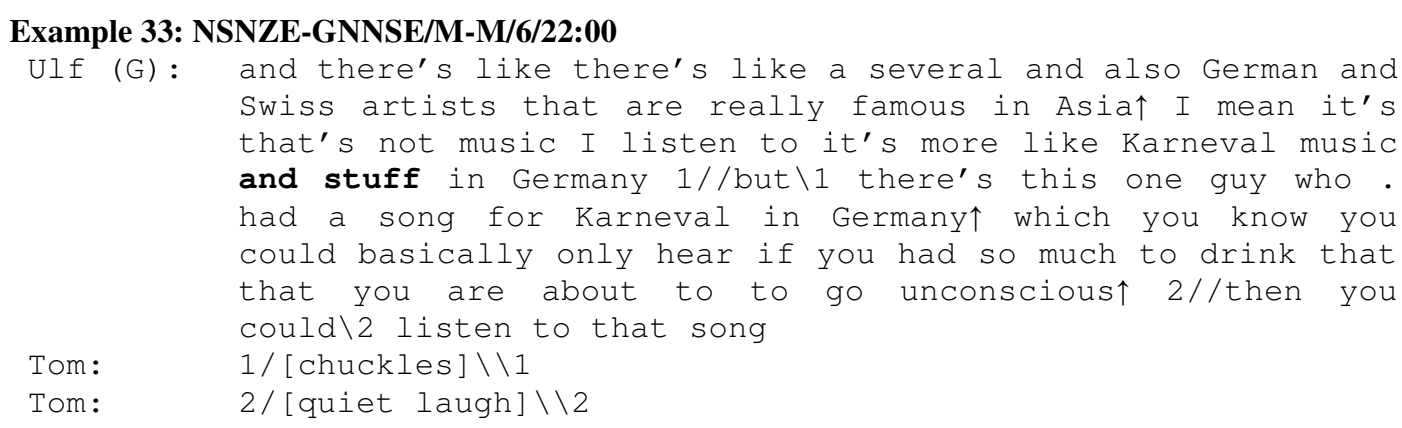

On one level, based on the structure of Ulf's turn, the use of the GE could be interpreted as a joke. The proclamation that he does not listen to the kind of German music that is popular in Asia indicates that Ulf thinks it is bad. The comparison with Karneval music in turn seems to imply that it is even worse, that it is the most extreme example of bad or grotesque music Ulf could think of. German Karneval is a festive period of dressing up during the weeks before the period of Lent that is celebrated in the catholic parts of Germany. Stereotypically, the music played during the German Karneval could be described as folksy with a strong rhythm, easy melody and simple lyrics. Ulf's comparison with this kind of music in turn emphasises how awful he thinks certain kinds of German music can be, marking the comparison as a humorous exaggeration. Tom's chuckle appears to support the notion that Ulf's utterance was intended to be funny. However, Ulf's monotonous intonation and the absence of a pause after the GE do not support this analysis, leaving an interpretation of this example uncertain.

Taking a different approach to analysing this example it can be observed that, referentially, the GE and stuff modifies the comparison to Karneval music, indicating that there are other possible kinds of music that could be mentioned in this context. However, the GE also does affective work, contributing to the 


\section{General Extenders}

construction of rapport and reducing social distance by implying the assumption of shared knowledge. The impression that the GE contributes to the creation of a bond between the speakers is further supported by the co-occurrence of interactive politeness devices such as you know and the high rising terminal intonation, another pragmatic device which has been identified as expressing solidarity (Britain 1998: 232) within the turn.

This is an interesting example of both interlocutors co-constructing rapport. Ulf appears to assume that Tom also knows what German Karneval music is like. However, it is likely that Tom, who might think of carnival fairs and thus have completely different associations with the term, is not familiar with this type of music. Earlier on in their conversation Tom indicates that he does not know much about German music and Ulf acknowledges the relative obscurity of German music on an international level. Nevertheless, both interlocutors seem to treat the background knowledge necessary to understand the comparison with German Karneval music as collective and given; Ulf by mentioning it without further explanation and by the interpersonal use of the GE, Tom by not asking for clarification and by laughing in the appropriate moment, indicating that he understands the comparison. No matter whether Tom's chuckle is in response to his own understanding of carnival music or whether it is a reaction to the structure that strongly suggests a joke, his response indicates that the exchange is effectively contributing to the construction of rapport.

The use of the non-standard GE in Example 34 can also be interpreted as serving various functions simultaneously. Sven gave his partner a voucher for a ring for their anniversary and after a long search they found one based on the Lord of the Rings movies that carries a meaning that they liked. The non-standard GE and tralala seems to be transferred from the German form und tralala. Interestingly, Sven even adopts English phonology when he articulates the extender, pronouncing the $/ \mathrm{r} /$ sound and the vowels in an un-German manner. This might indicate that he is not actually aware that he is using a non-standard form that is the product of L1 transfer. 


\section{General Extenders}

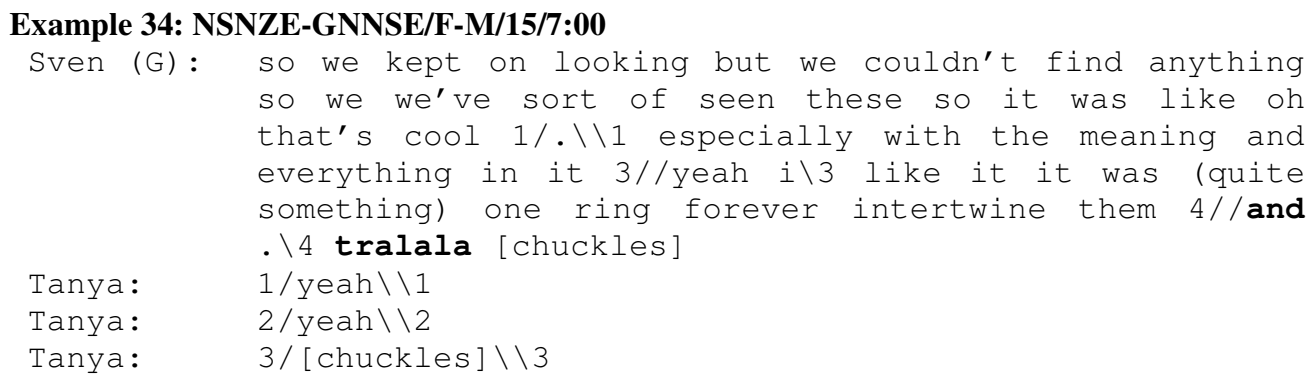

The extender seems to modify the quote of the meaning, indicating either that there is more to the quote or that he could elaborate on it, e.g. by explaining how the meaning relates to their relationship. The GE works affectively in the sense that it implies that Sven wants to protect his privacy and does not want to give any further details on this relationship. At the same time, the GE seems to be used in a jocular manner, making light of the meaning and how important it is for him. The use of an atypical GE does not seem to be problematic for the interactant as its meaning is semantically transparent and can be understood from the context.

In Example 35, Maggie shares with Bettina, a non-native speaker, the fact that she is pleased about having returned to university study after an injury stopped her from becoming a professional musician. Bettina responds with suggestions for further courses Maggie might consider taking.

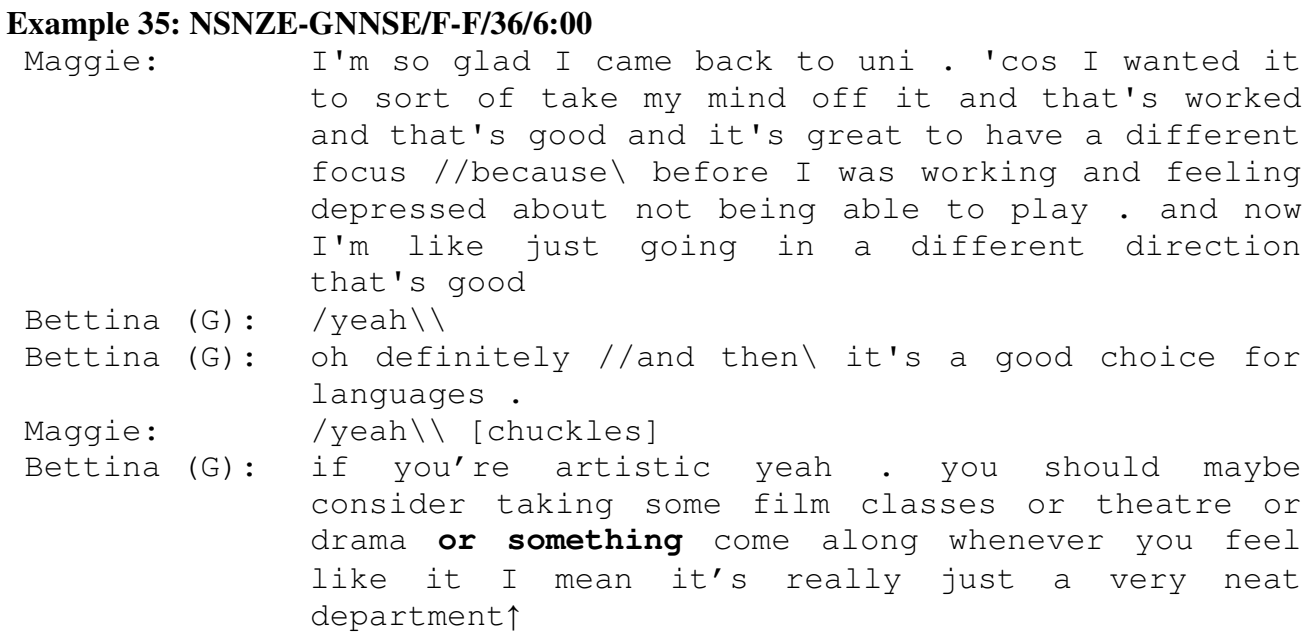

The GE or something expresses referential vagueness in that the film, theatre and drama courses mentioned represent just a small selection of what Maggie could get involved in. The GE also does affective work, however, contributing to the 


\section{General Extenders}

construction of rapport and reducing social distance. In this sense it could be argued that Bettina uses the GE to soften the potentially face threatening or sociality rights infringing act of making a suggestion to Maggie. Bettina's suggestion to get back into arts subjects by taking some film or drama classes could be perceived as inappropriate or pushy. The GE, spoken with a falling intonation, decreases the illocutionary force of the offer. This interpretation is supported by the co-occurrence of the hedge maybe, the non-specific invitation come along whenever you feel like it, the use of the pragmatic particle I mean, and the HRT.

Another relatively complex instance of GNNSE using GEs in potentially problematic speech acts can be seen in Example 36. Here, the German participant uses a GE interactively to construct rapport, in this case appealing to the understanding of her addressee on a sensitive topic. Lotta, the German student, is describing to Barbara, the New Zealander, a difficult living situation that Lotta found herself in.

\section{Example 36: NSNZE-GNNSE/F-F/42/18:00 \\ Barbara: were you having problems with the first one? \\ Lotta (G): yeah like she was em a single mum and she always had her daughter on the weekends. and she used to be an alcoholic and stuff and she like really got attached to me like as if I was her best friend or something $\uparrow$ Barbara: oh no \\ Lotta (G): and then she got like really jealous of my boyfriend and like wouldn't let me see him anymore and stuff $\uparrow$ and that was just just weird yeah}

The two instances of the adjunctive GE and stuff suggest that more could be said to describe the situation, but that Lotta chooses not to get into further details. The disjunctive extender or something suggests that the simile of best friend is approximate, i.e. she is indicating the kind of relationship rather than being precise. Affectively, the GEs clearly serve as affective appeals to Barbara's solidarity and understanding on this sensitive topic. Such an interpretation is supported by the use of HRTs on two of the GEs. The GEs can be interpreted as indicating that Lotta does not want to talk extensively or in detail about her former host mother. Furthermore, it is possible to interpret the GEs as contributing 


\section{General Extenders}

affectively to the softening of a negatively affective speech act of complaint or criticism.

This attenuating or softening function of negatively affective speech acts is also apparent in Example 37. Cordula and Eve are talking about being stressed out by study, and how to cope with the stress.

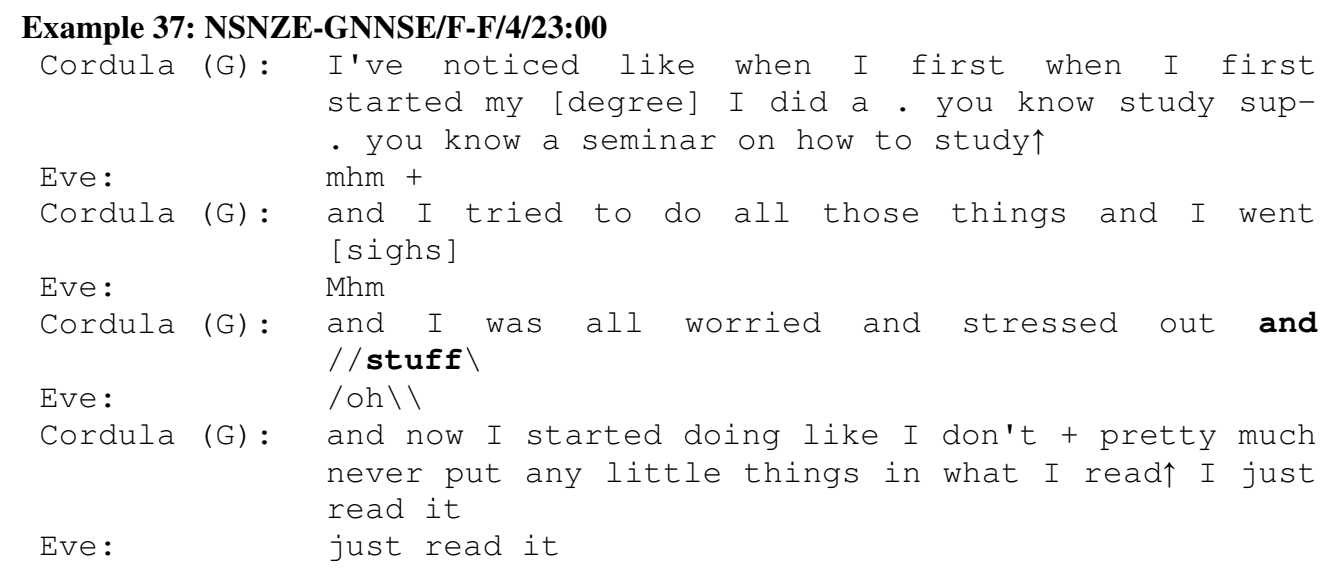

Cordula describes how she used to be really worried about doing all the things she was told to do to help her study, and how things got more relaxed once she stopped worrying so much. The GE and stuff intensifies the message that she was experiencing a lot of stress, and also appeals to Eve's understanding. This short excerpt is another illustration of how a GE may contribute to the joint construction of rapport, since Eve's supportive minimal responses $\mathrm{mhm}$ and $o h$, and her echoing just read it provide further evidence of this process.

Finally, Example 38 provides an example of an English GE used in a question by a German non-native speaker. In this example, the GE seems to function as a hedge on a relatively personal question. In the excerpt Sven, a law student, tries to find out what career options Tanya has with a degree in Japanese and Linguistics.

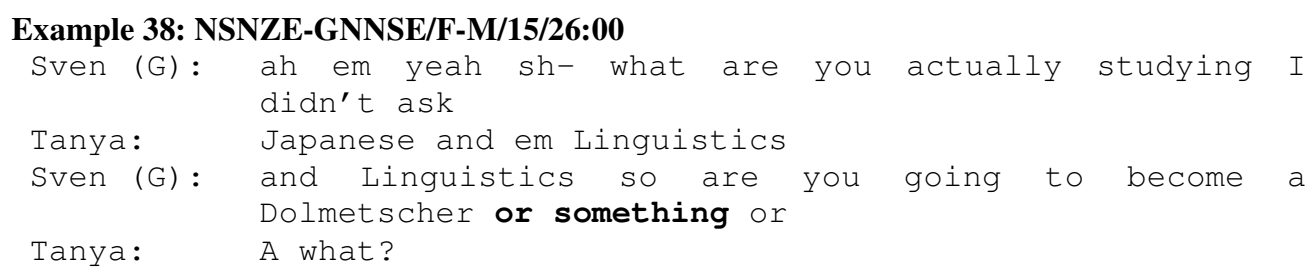




\section{General Extenders}

The GE or something modifies Sven's suggestion that she could become a Dolmetscher, an interpreter. Together with the utterance final open-ended or that invites Tanya to fill in the blanks, the GE indicates that he does not think that interpreting is the only possibility but that there are other job opportunities available. Moreover, the GE also seems to serve as a hedge on the proposition on a politeness level. Making assumptions about someone else's future career can be considered rude, and in this case in seems as if Sven does not have any idea what kind of jobs are available with an Arts degree. Moreover, the proposition that she could be an interpreter may not be deemed the most prestigious job by Tanya. In that sense, the implication that other options exist seems to soften the potential face threat involved in the question.

The qualitative analysis of these examples indicates that overall these GNNSE appear to use English GEs in conversation with native speakers for a variety of interpersonal functions that are comparable to the range of GE functions in both German and NZE conversations. The sample of GNNSE speech did not include any examples where GEs were the cause of communicative breakdown or where they were used inappropriately on the interpersonal level. Even in cases where GNNSE used an incorrect or non-standard GE form for the context, e.g. Frederike in Example 31 or Sven in Example 34, the intended meaning was still transparent enough for the interlocutor to understand or alternatively, the native speaker interactant decided to gloss over these kinds of small conversational problems in order to maintain good interpersonal relations. Obviously, the results of this small study must be treated with caution, but the discussion has established some of the parameters and the groundwork needed for more detailed quantitative and qualitative research comparing native and non-native speaker patterns in the use of GEs.

\subsection{Case Study: Or so}

\subsubsection{Introduction}

The quantitative analysis of the data has shown that GNNSE use the GE or so 42 times - more often than any other disjunctive GE. NSNZE, however, used this form only three times in their interactions. Numerically, this preference for or so 
is the most notable difference between GNNSE and native speakers, and it is a preference that is consistent throughout a large portion of the GNNSE population. Moreover, the form or so is a direct word-for-word translational equivalent of the most commonly used disjunctive GE in German oder so. This transparent formal resemblance suggests that the frequent use of or so by GNNSE is due to L1 transfer. Therefore, the use of the GE by native and non-native speakers deserves closer examination. The following discussion focuses on the use of or so in NZE and oder so in German and compares the results with the data collected from GNNSE.

\subsubsection{Or so}

For the purpose of this study, GEs have been defined as referential markers that serve to create interpersonal rapport and follow a specific structure. Following the GE construction rules as detailed above and conforming to the laws of English grammar, most GEs can be used to modify a large array of grammatical categories such as verbs, nouns, adjectives, adverbs, and even entire clauses. However, the forms and something and or so belong to a more specialised group of GEs that are functionally restricted in their use to numerical approximation (Channell 1994: 59; Aijmer 2002: 223).

The form or so is not included in most studies on GEs due to its restricted applicability as a GE. Overstreet (1999), for example, did not include this extender in her study. Overstreet does not discuss this decision explicitly, but it may have been made because or so is a numerical approximator and therefore does not fulfil the condition of GEs having mostly interpersonal functions. Or so was also not listed in Dines' (1980) study, possibly because the form does not implicate a set or category, and Channell (1994) discusses or so separately from other GEs in her study on vague language in British English. Aijmer (2002: 213) does include or so in her count of GE forms in the LLC, as she believes GEs to have "functions such as uncertainty, approximation and intensity", but does not require them to be able to serve all three purposes.

Channell (1994) provides a detailed discussion on the use of or so in British English. She (Channell 1994: 59) maintains that, in addition to its restriction to 


\section{General Extenders}

numerical approximation, for some speakers the occurrence of or so is also restricted in the sense that it may only occur after "units of measurement or items contextually rendered units of measurement" (Quirk, Greenbaum, Leech and Svartvik 1985: 13.102). In cases where there is no acceptable unit of measurement the GE occurs immediately after the number. However, neither Quirk et al. nor Channell explain what 'contextually rendered units of measurement' are, which makes the test of the applicability of this rule rather difficult. Channell's (1994: 59) table of acceptable and unacceptable forms has been reproduced below.
a. six or so books
b. *six books or so
c. ten pounds or so [weight]
d. *? ten or so pounds

According to this table, the phrases in a) and c), six or so books or ten pounds or $\underline{s o}$, are considered unproblematic. However, the b) construction six books or so is deemed unacceptable by native speaker because it violates the rule that or so may only follow units of measurement. With reference to the structure in d) ten or so pounds, Channell (1994: 59) claims that native speakers do not agree in their judgment of its grammaticality as it seems acceptable for some but unacceptable for others.

In her study on the use of or so in British English, Channell (1994: 60) looked at the Cobuild corpora of spoken and written English. Altogether they provide a corpus of approximately 10.5 million words. Channell found 95 tokens of or so, 53 of them occurred in the spoken corpus of 1.32 million words, 42 in the 9.5 million word corpus of written English. The majority of the or so tokens followed the construction in c) shown above. Channell (1994: 60) also noted that most of the instances of or so occurred with units of time that occur in the singular, i.e. an hour or so. The other constructions were hardly used. The following section looks at the use of or so in NSNZE. 


\section{General Extenders}

\subsubsection{Or so in NZE}

\subsubsection{Quantitative Analysis}

The analysis of the use of or so in New Zealand English is based on the corpus of NSNZE speech of approximately 111,000 words. These include the native-native interactions as well as NSNZE contributions in the cross-cultural conversations. A search of this section of the corpus shows that it only contains 3 tokens of or so, 1 in the native-native and 2 in the cross-cultural data sets. In all three instances, the NSNZE use the form for numerical approximation. One of the tokens is used as a hedge on a guess on how long ago it was that a specific event has taken place (it was about a year and a half or so), one to indicate that a given ranking might not be entirely accurate (we just usually make like top ten or so) and one serves to express imprecision of a year date, as illustrated in Example 39. In the excerpt Zach explains to Xander how youth protests started in New Zealand a few years later than in other western countries. In this case, the GE or so is used to indicate that the year given for the beginning of the hippy movement might not be correct.

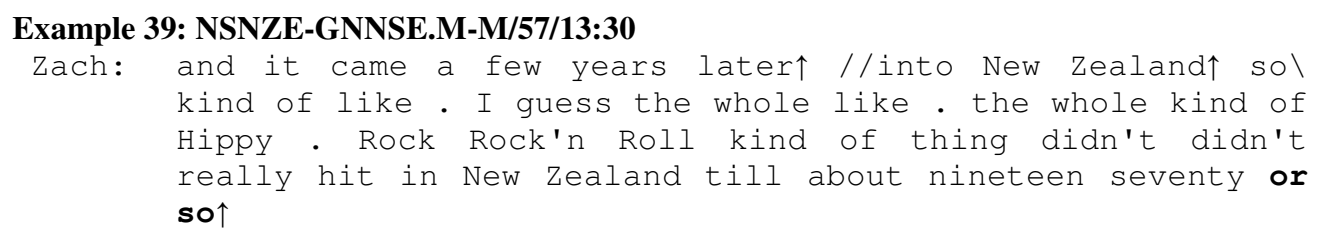

Since 3 examples cannot be considered a sound database to find out whether the only types of noun or so can follow are units of measurement, I also consulted the Wellington Corpus of Written and Spoken New Zealand English (WWC and WSC). The WSC consists of a combination of formal (e.g. broadcast news, lectures, parliamentary debates) and informal speech (e.g. private face-to-face conversations). The informal speech category makes up more than 50 per cent of the corpus. The WWC features 10 different text styles, including fiction, scientific writing and press editorials and reportages.

A comparison of the occurrence of or so in the different corpora can be found in table 8. The WWC and WSC contain 1 million words each. The WSC contained 56 tokens of or so and the WWC featured 34. The same observation can be made for the Cobuild corpora (taken from Channell 1994) where the spoken corpus 


\section{General Extenders}

contains more tokens of or so than the much larger written one. Moreover, in the WSC or so was most frequently used in informal contexts, especially in informal conversations. The use of a number of GEs is sometimes closely associated with a particular mode of communication or level of formality between the interactants. Thus, for example, and so on has been found to be predominantly used in formal speech between non-familiars while and stuff appears to be mainly used in informal contexts between familiars (Overstreet 1999: 8). However, the relatively frequent occurrence of or so in the WSC and the WWC could indicate that, maybe due to its functional restriction to numerical approximation, this form is more universally applicable than most GEs.

Table 8: Frequency of or so across corpora

\begin{tabular}{|c|c|c|c|}
\hline & Cobuild & Wellington Corpus & NSNZE corpus \\
\hline \multirow[t]{3}{*}{ Spoken } & 1.32 million words & 1 million words & 111,000 words \\
\hline & 53 tokens & 56 tokens & 3 tokens \\
\hline & $\begin{array}{l}4.0 \text { tokens per } 100,000 \\
\text { words }\end{array}$ & $\begin{array}{l}5.6 \text { tokens per } 100,000 \\
\text { words }\end{array}$ & $\begin{array}{l}2.7 \text { tokens per } 100,000 \\
\text { words }\end{array}$ \\
\hline \multirow[t]{3}{*}{ Written } & 9.44 million words & 1 million words & - \\
\hline & 42 tokens & 34 tokens & - \\
\hline & $\begin{array}{c}0.4 \text { tokens per } 100,000 \\
\text { words }\end{array}$ & $\begin{array}{c}3.4 \text { tokens per } 100,000 \\
\text { words }\end{array}$ & \\
\hline
\end{tabular}

Interestingly, the overall result of the WSC differs noticeably from the result of my NSNZE corpus in that the WSC seems to have generated twice as many tokens proportionally. The WSC is about 9 times larger than my NSNZE corpus but it contained 18 times more tokens of or so. This difference is still noticeable when taking out the more formal sections of the WSC. With 500,363 words the informal conversation section of the WSC is still about 5 times larger than the NSNZE corpus and with 25 instances of or so contains 8 times more tokens. One possible reason for this difference between the WSC and my NSNZE corpus could be the social relationships between the interactants as the informal section of the WSC is based on conversations between speakers who know each other well. 
Another influential factor might be the topics of conversations. As mentioned above, the WSC includes speech dealing with a large variety of topics of conversation taken from a number of different settings (i.e. broadcast news; debates, face-to-face interactions). The topics of conversation in my corpus, however, were restricted in scope by the uniform setting of the recordings: interactions between status-equal near-strangers. Even though the interactants were free to talk about anything they liked, using the same setting and set up for the recording meant that most conversations dealt with similar topics, such as the personal background of the interactants, their studies, hobbies, travel experiences or plans for the future. In any case, the conditions of the conversations for my study might not have fostered the use of numerical approximation. The NSNZE corpus, which consists of approximately 5 hours of talk time and 59,000 words of transcription, contains only about 13 instances of number hedges.

It is also worth noting that both the WWC and WSC contained proportionally more tokens of or so than the Cobuild (Channell 1994: 60). This is especially prominent in the written corpora: the Cobuild corpus of written British English is about 10 times larger than the WWC, yet it contains only marginally more instances of or so. This result could indicate a dialect difference between British English and NZE or it could be an artefact of the texts selected for the two corpora.

\subsubsection{NZE data from the Wellington Corpus}

Since my NSNZE corpus contained only 3 instances of or so, the subsequent analysis of the use of or so in NZE is based on the WSC. A brief analysis of the corpus shows that, just like speakers of British English, NSNZE predominantly use the c) construction ten pounds or so as shown in Example 40. In this example or so follows the established unit of measurement metre but precedes the qualifier of snow.

\section{Example 40}

WSC\#DGI087:0545:BB half a metre or so of snow 


\section{General Extenders}

The data also contains some cases of what I would consider contextually rendered units of measurement as in Example 41. Here, the idea of a car length is treated as a unit of measurement by the speaker.

\section{Example 41}

WSC\#MUC014:0865:BK those last few laps he was just a car

length or so behind

Like the Cobuild corpus, the NSNZE data includes examples that do not conform to the main c) construction format. Example 42 closely resembles Example 40 in that it contains a unit of measurement and a modifying element. However, in this case or so does not follow the contextually determined unit of measurement trailer load but the modifying element compost.

\section{Example 42}

WSC\#DPC066:0390:CH A trailer load of compost or so

Example 43 is a good illustration of the b) construction, six books or so, which was deemed unacceptable by Channell (1994). Even though it is not entirely clear what contextually rendered units of measurement are, it is safe to say that if books is not a unit of measurement in b) then people is not a unit of measurement in Example 43.

\section{Example 43}

WSC\#DPC250:0390: JC Three hundred people or so

Finally, Example 44 shows how in NZE the GE or so is sometimes inserted before the established units of measurement such as years.

\section{Example 44}

WSC\#DPF078:0360: JA Ten or so years ago you know

Overall, it seems that the rules determining the position of or so within an utterance also apply to NZE as only a few exceptions could be found. It is difficult to tell whether these few aberrant cases are indicative of language change or whether or so was moved to an atypical position for stylistic purposes, allowing the speaker to highlight one element or another. 


\section{General Extenders}

\subsubsection{Oder so: German data}

The German translational equivalent of or so is oder so. The form oder so has been identified as the most frequently used German GE both in the present study and by Overstreet (2005). As mentioned above, German GEs on the whole have not been described in great detail in the literature on German particles. The same applies to oder so, a form which has not analysed beyond being classified as belonging to the group of Etceteraformeln 'etcetera formulas' in Schwitalla's (1997) discussion of spoken German. The best indication of the use of oder so has probably been given by Overstreet (2005). In her comparative study of German and American English GEs Overstreet (2005) uses oder so to exemplify common functions of English and German GEs. Both Overstreet's account and the discussion of the German data below suggest that oder so is not as restricted in its application as its English translational equivalent, since it can be used to express the same referential and affective meanings as other German GEs.

Like English or so, German oder so can be used as a numerical hedge, as shown in Example 45. In this excerpt Nadine talks about her living situation, saying that she and her partner are planning to move closer to university soon. In this case, the GE oder so appears to be used to indicate that no definite plans have been made yet and that it might be longer than two months before they will be able to move.

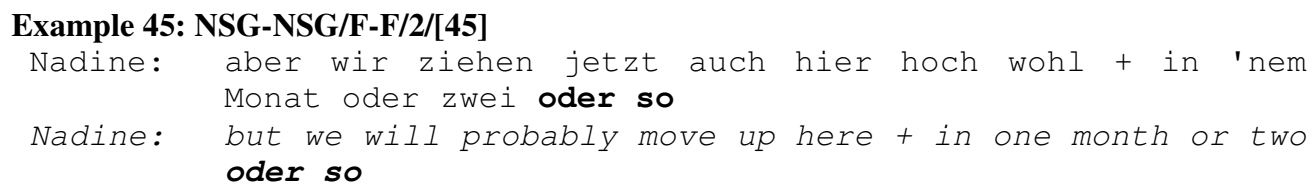

However, unlike its English formal equivalent, oder so can also be used to modify nouns. In Example 46 Bettina recounts her reasons for travelling to New Zealand for postgraduate studies. She points out that, because of an agreement between Germany and New Zealand, it is cheaper for German students to attend university in New Zealand than in the United States of America. 


\section{General Extenders}

\section{Example 46: NSG-NSG/F-F/37/4:30 \\ Bettina: ja genau und deswegen hab ich das jetzt einfach dann mal //weil das \ja erschwinglicher jetzt ist als wenn du in den USA oder so machst \\ Bettina: Yes that's right and that's why I because it's cheaper to do it here than in the states oder so}

Here, oder so seems to be used as a lexical hedge, signalling that the focus lexical item is just one example of a number of possible ones. It indicates that in addition to the States there are other English speaking countries that are more expensive than New Zealand. Incidentally, this example also nicely illustrates the concurrent interpersonal or affective function of GEs, since it also refers to assumed shared background knowledge, pre-supposing that the addressee is aware of the other countries which could be mentioned in this context.

In addition to nouns, it seems that the GE oder so can also be used to modify verbs.

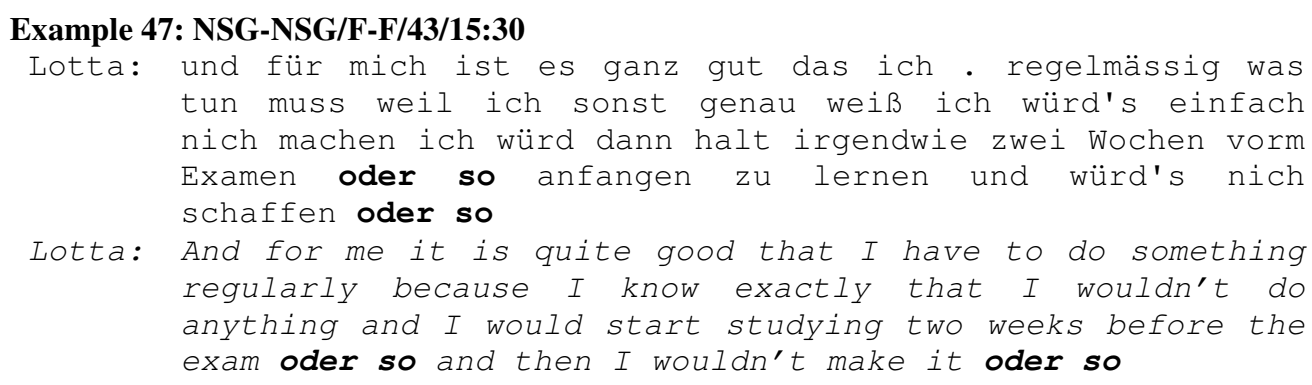

The first oder so in Example 47 works as a numerical approximator of the proposed time of two weeks. This use also demonstrates that in German GEs can modify elements they are not immediately following. The second oder so, however, seems to refer to the verb schaffen, suggesting that failing is not the only possible outcome. Alternative results could be getting a bad mark or panicking so much that she would not even sit the exam. In the example, Lotta explains that she likes the way the assessment is laid out for her law degree. University courses in New Zealand usually base the final grade on relatively small pieces of assessment which have to be handed in on a regular basis, whereas in Germany the course grade is usually based on a final exam. Lotta states that without the constant pressure she would not do the work and might fail the exam because she started studying too late. Taking a different approach, the token could also be analysed as 
modifying the entire proposition, indicating that the described situation is merely hypothetical. In both instances, in addition to its referential functions, this example also works on an affective level as it appeals to the interlocutor's knowledge of the German university system and to her understanding of the stress involved in studying for an exam.

In Example 48, the first oder so modifies the noun Schadstoffuntersuchungen the second oder so is used to modify the adverb ohnmächtig. Mario and Silke are talking about geckos and Mario thinks they are used to test the level of air pollution. In this case the use of the GE seems to predominantly indicate epistemic modality. Silke is the expert on Geckos and Mario is probably not too sure if his information is correct.

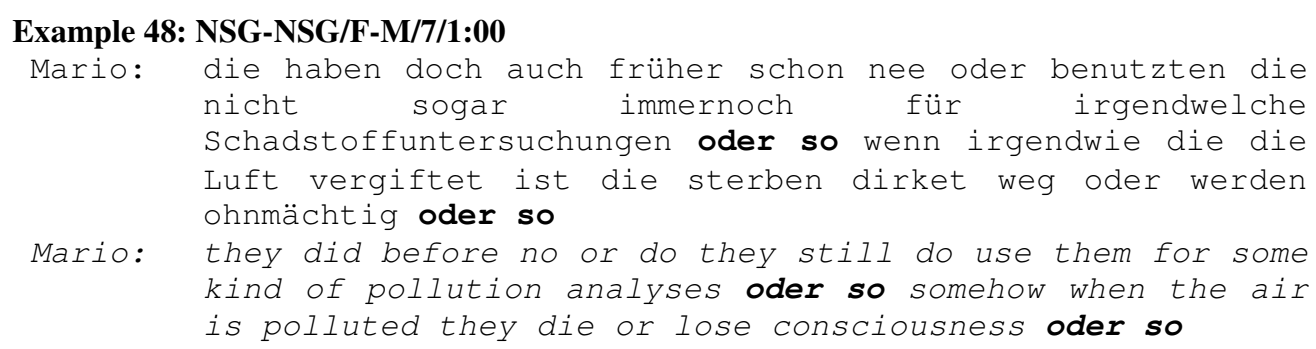

In this section it has been shown that German oder so can be used for a large variety of functions on both a referential and an affective level and also to modify a wide range of grammatical classes. In this sense, oder so works just like any other German GE.

\subsubsection{GNNSE Data}

The GE or so was the most frequently occurring disjunctive extender used by GNNSE in cross-cultural interactions. And as Example 49 shows, GNNSE did employ the GE as a numerical hedge just like their native speaker counterparts. In Example 49, Nina is adding up how many minutes of interaction I collected for my corpus. This is an example of the c) construction where the GE follows the unit of measurement minutes. Here, or so is used as a numerical hedge on time, indicating that the proposed period of twenty minutes is not necessarily accurate.

Example 49: NSNZE-GNNSE/F-M/22/17:00

Nina: when people when we sit here twenty minutes or so it's like sixty times twenty minutes $\uparrow$ 


\section{General Extenders}

When looking at the use of or so by GNNSE for numerical approximation it seem that they adhere to the rules governing or so, with all but one case following pattern c). However, while the GNNSE data set contains a number of examples of correctly constructed utterances containing or so as a numerical hedge, the instances of the GE being used in this sense are more the exception than the rule: in the majority of cases GNNSE use or so to modify elements other than numbers.

In the GNNSE corpus, or so is used to modify a variety of grammatical categories such as verbs (Example 50), nouns (Example 51) and adjectives (Example 52 and Example 53).

\section{Example 50: NSNZE-GNNSE/F-M/29/8:30 \\ Frederike: but well I'm . yeah. I believe that there's more to

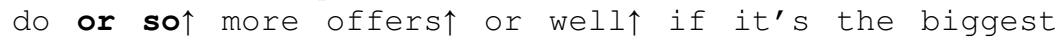 city but I wonder because I'm quite busy here and + I couldn't even do all those things}

In Example 50 (see also Example 31) the GE or so is used to modify both the proposition that there is more to do in Auckland and the immediately preceding verb. In this case, the GE seems to be used for multiple purposes. On one level it seems to serve as a hedge on the entire proposition, emphasising that the notion is entirely based on Frederike's assumptions rather than actual fact. Additionally, it could also be used as a lexical hedge, signalling her acknowledgment that the expression there's more to do is not particularly precise, appealing to the listener's willingness to infer the intended meaning.

Another example of GNNSE using or so for purposes other than numerical approximation can be found in Example 51. Knut tells Caleb about Interrail, a train ticket that allows travellers to tour around Europe for relatively little money. The intonation on the GE goes down and there is a small pause, separating or so from the false start these. 


\section{General Extenders}

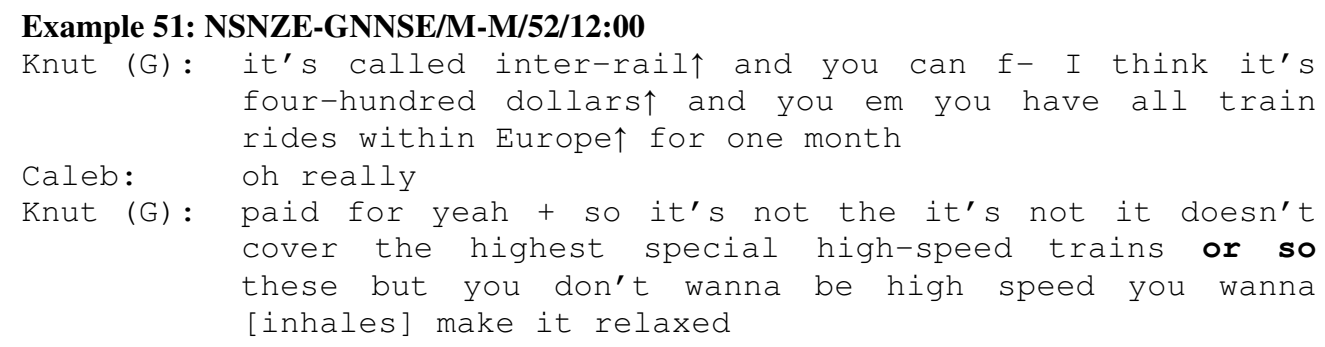

In this example, the main function GE seems to be to modify the noun phrase special high-speed trains, indicating that this might not be the exact technical term Knut is looking for.

The GE in Example 52 is also mainly used as a lexical and propositional hedge. Moreover, it is an illustration of how lexical and propositional approximations are closely interrelated, making it sometimes difficult to tell them apart. After all, when speakers are unsure of the full denotative and connotative meaning of a keyword, they cannot be entirely certain whether the proposition being made is correct. In Example 52 Greg states that he likes the ceremonial aspect of fencing and Veit puts forward the notion that the sport is rather formal. The question intonation on Veit's statement together with the pragmatic devices it's like and or so and the adjective quite seem to attenuate Veit's proposition on a number of different levels.

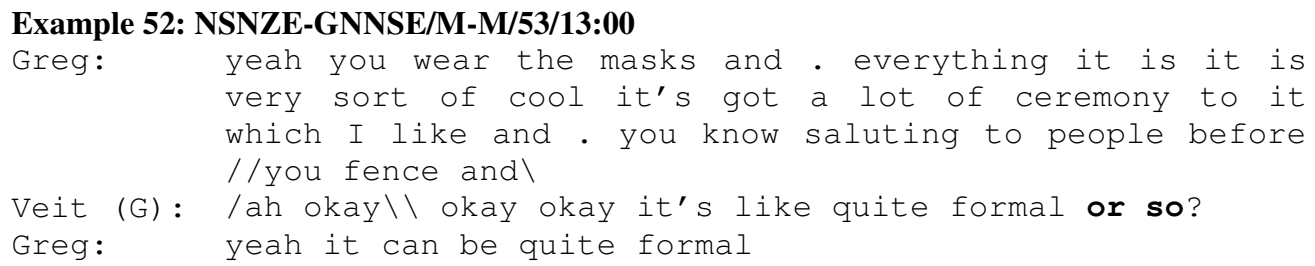

One possible interpretation of this example is that the marker or so is used as a lexical hedge, indicating that the adjective formal might not be the most appropriate word in this context and thus asks to the interlocutor to adopt a more liberal interpretation of the term. At the same time, or so also appears to modify the entire proposition, indicating that Veit is not sure if his evaluation of fencing being formal is a valid one. By mitigating a proposed judgment on an issue Veit is not familiar with and by inviting Greg to confirm or dismiss Veit's assessment, the GE also functions as a politeness device. 


\section{General Extenders}

In the case of Example 53 the GE or so seems to be predominantly used as a propositional hedge, indicating vagueness about the general proposition being considered. Anna confesses to Helen that she tends to buy Australian red wine, and justifies this by claiming that Australian wine is generally less expensive than New Zealand wine. However, when Helen responds "oh too expensive?" Anna retreats from her claim using a GE to convey her vagueness about the relative costs.

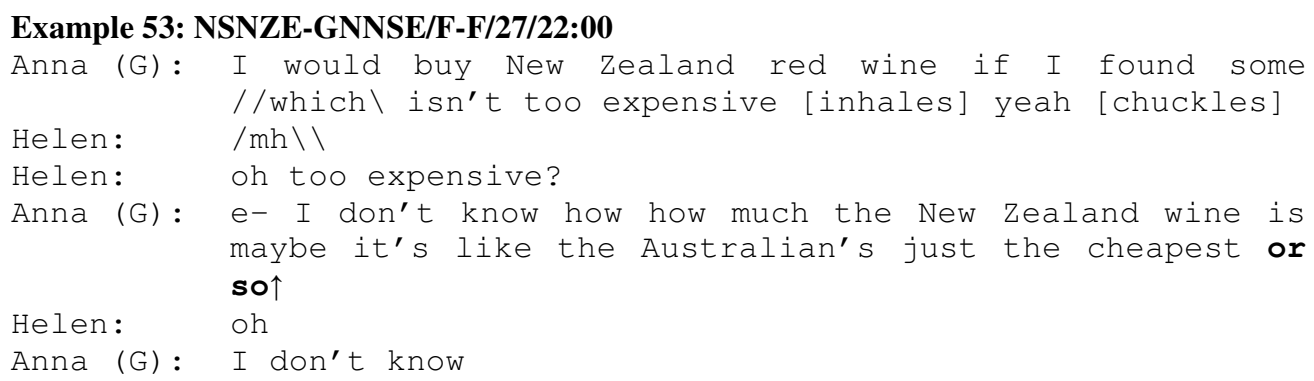

The GE or so conveys a lack of certainty in this context, indicating that Anna is not too sure that her implied proposition, i.e. that Australian wine is cheaper than New Zealand wine, can be sustained, or whether it is just that she has not yet found any affordable New Zealand red wine.

The data presented above has shown that GNNSE do not use the English device or so following English conventions. Instead, they seem to transfer the principles governing the use of German oder so to its literal English translation. As a result, GNNSE use or so for purposes other than numerical approximation and in contexts where its use would not be deemed appropriate by native speaker standards. The data suggests that GNNSE use or so like any other GE, to modify nouns, verbs, or adjectives and to express interpersonal, affective meanings. It seems possible that, rather than transferring their pragmatic knowledge of oder so to or so, GNNSE have merely failed to acquire the restrictions governing the use of this particular form, resulting in the non-standard application of the marker. Nevertheless, their general preference for the form or so appears to be due to direct L1 transfer. 
However that may be, the incorrect use of or so does not seem to lead to a communication breakdown between the interactants. It is possible that the form, syntactic position and context of or so provide the native interlocutor with enough clues to recognise the form as an intended GE and analyse it accordingly. Another potential explanation is that the native speaker interlocutors simply ignored the incorrect use of or so. As pragmatic devices, GEs do not "directly partake in the propositional content of an utterance" (Östman 1982: 153) and therefore their inaccurate use does not have a great impact on the grammaticality and intelligibility of the utterance. If the GNNSE's contribution has been clear otherwise, NSNZE might not pay attention to minor mistakes such as this, either because they do not notice them or in order to maintain the communicative flow.

\subsection{Summary}

The analysis of the average GE frequencies shows noticeable patterns across the three data sets. Overall, it can be observed that the participants produce substantially more GEs in this study than in Overstreet's research. It was suggested that one of the possible reasons for this could be related to the differences in the social contexts in which the data was collected. Whereas Overstreet's data is based on interactions between familiars the present corpus consists of conversations between strangers. Talking to a stranger could be perceived as an awkward and potentially face threatening situation, resulting in an increase in face work and thus an increase in the use of positive politeness devices.

The data presented above shows that Germans use more GEs than native speakers of English. Germans also use more GEs when speaking German than when speaking English. Nevertheless, GNNSE use slightly more GEs than NSNZE in cross-cultural interactions. NSNZE produce approximately the same number of GEs in native-native and in cross-cultural conversations. It has been suggested that Germans use disjunctive extenders more often than adjunctive ones in both German and English, but it seems to be the other way around for NSNZE. This result does not agree with Overstreet's study where both English and German natives favoured disjunctive forms. The difference between the use of GEs by native speakers of New Zealand and American English could be indicative of 


\section{General Extenders}

regional variation. However, the result could also be related to the different interpersonal relationships between the participants in each study.

The comparison between the GEs used by NSNZE and GNNSE in cross-cultural interactions showed that, overall, GNNSE followed native-speaker norms of GE construction. However, a few unusual forms were found that might have been influenced by German conventions. Some GNNSE were found to prefer the deictic this over that in disjunctive extenders such as or something like this. GNNSE also displayed a preference for the disjunctive extender or so, which only occurred once in the NSNZE interactions. A slight decline in the use of GEs by NSNZE both in terms of forms and frequency was noted when they talked to GNNSE. It was suggested that this change in linguistic behaviour by native speakers might be accounted for by accommodation theory and might also have an influence on the learner's adoption of native-like norms.

The analysis of individual variation has suggested that GNNSE accommodate to their native speaker interactant as the frequencies of both female and male GNNSE relatively closely match those of their respective NSNZE interlocutors. The use of GEs by individual GNNSE did not seem to necessarily correlate with the length of exposure to English and therefore with their potential pragmatic proficiency. Instead, it appears to be linked to the individual's use of GEs in German.

The data suggests that NSG, NSNZE and GNNSE all use GEs for similar purposes, even when they use different forms. Thus, while German can use the form oder was to express either emphasis or numerical approximation, English or what seems to exclusively serve emphatic functions. In all three datasets speakers were found to use GEs to convey a number of referential and affective meanings, ranging from expressions of vagueness and approximation to applications for interpersonal politeness and rapport building strategies and mitigations of potentially face threatening or sociality rights encroaching speech acts. It has been suggested that Germans and New Zealanders differ in the functional use of GEs as Germans seem to use GEs more in whinges than New Zealanders do. The GEs used in the speech act of whingeing are often non-standard, marked, low 
frequency forms that can serve to add an element of humour and thus mitigate the force of the speech act, e.g. Arne's use of und so'n Scheiß in Example 22. New Zealanders, on the other hand, appeared to use GEs more often in questions, which could be interpreted as a negative politeness device that can help to soften the possible directness of an interrogative.

The main difference in the use of GEs by NSNZE and GNNSE appears to be the use of the form or so. It was shown that, while in English or so is functionally restricted to numerical approximation, GNNSE use the form synonymously with other disjunctive extenders for the entire range of referential and affective functions. A reason for this could be that, while English or so is functionally restricted to numerical approximation, this does not apply to the German translational equivalent oder so, which is also the most frequently used disjunctive GE. Thus, it seems likely that GNNSE transfer their preference for this form to English without applying its functional restrictions. In other words, they appear to extend their general pragmatic knowledge of GEs to a form these rules do not apply to, which results in the incorrect use of the marker. However, the use of non-standard forms by GNNSE did not seem to result in misunderstandings. Overall, GNNSE's GE construction and use do not seem to differ much from NSNZE. It is possible that this can be explained by the fact that German and English are closely related languages. Further research is needed to establish if similar forms exist in other, non-Germanic languages and to what degree the formal and functional description of GEs in this chapter also applies to them. 


\section{Like}

This chapter focuses on native and non-native use of the pragmatic device like. The chapter includes a discussion of previous accounts of like and establishes a set of functional categories that are used to differentiate between the different meanings of like in context and that form the foundation of a quantitative comparison of native and non-native use. The discussion follows a similar outline to the analysis of General Extenders. First, it examines the different functions of like as used by native speakers of New Zealand English (NSNZE) and discusses possible functional equivalents in German. The results are then compared to the functional distribution of like found in the speech of German non-native speakers of English (GNNSE). Finally, the chapter explores correlations between the linguistic background of GNNSE and their use of the different functions of like.

\subsection{Literature on like}

As the large body of literature on like suggests, this particle can express many different meanings. Broadly speaking, like seems to work on three basic levels: it can serve grammatical or syntactic functions (non-discourse like), pragmatic functions (discourse like), and it can be used a quotative marker (quotative like). For decades researchers have developed new ways of classifying the different functions. However, because of the multifunctional nature of this device, which allows it to express several meanings at the same time, it can still be difficult to distinguish clearly between the numerous usages of like in some contexts. In the following, the uses of discourse and non-discourse like are discussed. 


\subsubsection{Discourse like versus Non-Discourse like}

\subsubsection{Non-discourse like}

The non-discourse functions of like encompass a number of different purposes. According to Collins English Dictionary (1994: 902), like can be used as a noun (Example 54), a verb (Example 55), an adjective (Example 56) and an adverb (Example 57) as illustrated below. Example 56) and Example 57) are taken from Schourup (1985: 37).

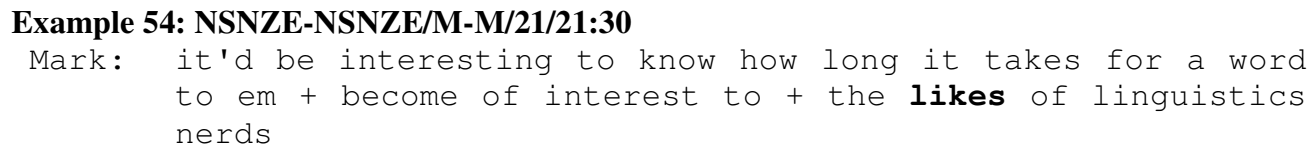

Example 55: NSNZE-GNNSE/F-F/27/19:30

Helen: yeah. it's true fact nobody likes Auckland

Example 56

tables of like color

Example 57

The actual interest is more like two percent

Furthermore, like can also function as a preposition (Example 58), a conjunction (Example 59), and as a suffix (Example 60, taken from Romaine \& Lange 1991: 244). It is these three functions that are most commonly associated with discussions on discourse like (Hasund 2003: 11), such as investigations of the etymological development of the pragmatic device and analyses of its functions (Miller and Weinart 1990: 371; Romaine and Lange 1991: 271).

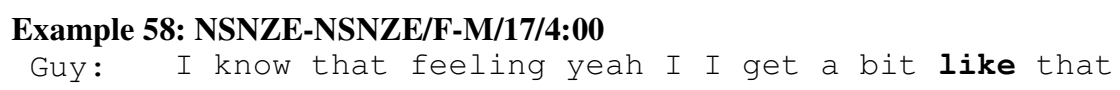




\subsubsection{Discourse like}

Discourse like as illustrated in Example 61 and Example 62 belongs to the large class of pragmatic devices. Rather than simply being intrusive and non-standard (Underhill 1988: 234; Collins 1994: 902), discourse like differs from nondiscourse like in that it is only loosely connected to the syntactic structure. This means that the marker can be omitted without changing the basic meaning of the clause or rendering it ungrammatical (Brinton 1994: 33-35; Hasund 2003: 12).

\section{Example 61: NSNZE-NSNZE/F-M/23/11:30 \\ Pamela: so like if we had an inflation \\ Example 62: NSNZE-NSNZE/F-F/45/20:00 \\ Felicity: like in Germany a lot of towns are em are sort of like + em . they're called like healing places $\uparrow$ and there are sort of different ones for like air and for water like a place that has really clear fresh air is like a - healing place for air}

However, the distinction between discourse and non-discourse like is not always clear-cut. Andersen (2001: 212-3) points out that sometimes it is not easy or even possible to differentiate between the two uses. One example of this problem is the issue surrounding numerical approximation as in I went when I was like ten. While Schourup (1982: 40) considers this use to be a premodifying adverb Andersen (2001: 233) classifies it as a pragmatic device.

One of the reasons for this functional closeness of discourse and non-discourse like could be a result of the development of its discourse functions. Studies taking a diachronic approach and applying a grammaticalisation framework to like have proposed a reconstruction of its chronological development from a functional and grammatical element to a pragmatic device. Thus, Romaine and Lange (1991: 261) suggest that this development started with like as a prepositional like, which takes a pronominal or nominal complement. From there it evolved into the use of like as a conjunction that takes a sentential complement. Finally, the marker was used as discourse like, making it syntactically more and more flexible. The gradual change in the uses of like is often described as a dynamic process that is still ongoing, which allows for overlap and ambiguity between the different functions (Hasund 2003: 13). Romaine and Lange (1991: 246) note that 
conjunctions often tend to serve pragmatic functions and Andersen (2001: 213) comments on the difficulties of distinguishing between like as a conjunction and discourse like in certain contexts. Similarly, in the example below it is impossible to determine whether the instance of like in bold is a preposition or a pragmatic device when judging from the transcription alone. Carl is making a joke about turning screenings of Mel Gibson's The Passion of Christ into a dress-up event not unlike those that take place at showings of the Rocky Horror Picture Show.

\section{Example 63: NSNZE-NSNZE/F-M/14/5:00 \\ Carl: yeah well I was thinking it could be like the new Rocky Horror Show it's like people dress up as Jesus and go see the movie [chuckles] + the movie on Good Friday}

Here, like could be a preposition in the sense of 'similar to', 'in the manner of'. The token could also be a pragmatic device that either highlights the comparison to the Rocky Horror Picture Show or indicates that it is only one possible example and others could be named, e.g. The Sound of Music. Prosody has proven to give useful clues when it comes to determining the main function of a pragmatic device and the same has been noted for like (Andersen 2001: 213). In this case, prosody supports the interpretation that the marker is a preposition as the token is part of the tone group rather than separated from it by a pause. Miller and Weinert (1995: 373) point out that like as a pragmatic device is not necessarily followed or preceded by a pause. Nevertheless, when in doubt prosody was used as a main factor in differentiating between discourse and non-discourse like. Since nondiscourse like, i.e. like as a noun, verb, adjective, adverb, preposition or conjunction, is not of interest for the present study, these functions will not be discussed any further.

Studies considering the sociolinguistic distribution of both discourse and quotative like mostly agree that they are predominantly a feature of the language of younger speakers (Romaine \& Lange 1991; Ferrara \& Bell 1995; Dailey O'Cain 2000; Andersen 2001). However, investigations of gender differences in the use of like show that there is no consistent pattern. Romaine and Lange's (1991) data on quotative like seems to have been predominantly produced by women. Tagliamonte and Hudson (1999) report that women use quotative like more often than men in British English but not in Canadian English. Blyth, 
Recktenwald and Wang's (1990: 221) results for American English, on the other hand, suggest that men use be like more often than women. Research has shown that, regardless of its actual distribution across gender, age and social class, the use of like is stereotypically associated with middle-class young women (Blyth et al. 1990; Romaine and Lange 1991: 255-6).

\subsubsection{Functions of discourse like}

Early studies on the use of like in discourse often classified it as a hesitation marker signalling planning difficulties and used by speakers to buy time (see e.g. Edmondson 1981: 153-4; Schourup 1982: 53). More recent studies (e.g. Schourup 1982; Underhill 1988; Miller and Weinert 1995; Andersen 2001, etc), however, suggest that the marker serves a variety of textual and interpersonal functions.

The two most important concepts used in the literature to describe the functions of discourse like are the notions of focus and hedge. Focus like considers the marker to be an emphasising device, marking new, important or unusual information (e.g. Underhill 1988; Meehan 1991; Miller and Weinert 1995; Dailey-O'Cain 2000). Studies that explore the idea of like as a hedge (e.g. Schourup 1982; Andersen 2001), on the other hand, believe that all realisations of pragmatic like express some form of discrepancy between what the speaker intends to say and what is actually said. These two frameworks differ in their analytical approach and therefore provide different interpretations of the same examples. Hasund (2003: 18) points out that the main difference between these two approaches is their level of analysis. The idea of focus like describes the textual, discourse linking functions of the marker and concentrates on the role of like in creating relations between units. Hedge like, on the other hand, is mostly concerned with how the marker modifies the epistemic impact on an utterance and therefore works on the subjective level. Interestingly, neither approach considers like to be an interpersonal politeness device. The two approaches are described in greater detail below.

\subsubsection{Focus like}

The idea of like as a focus marker is introduced by Underhill (1988). In his description of its use in American English Underhill (1988: 238) notes that like 
seems to be mostly used to indicate the newest and most important aspect of a sentence. Moreover, since new information often occurs sentence finally, like as a marker of new information can be found between constituents that are located towards the end of a sentence as in Example 64 (taken from Underhill 1988: 238).

Example 64

$$
\text { I had a problem like on the second question }
$$

Focus like can be used to mark the main object of a question or of an answer (Example 65, taken from Underhill 1988: 239); it can be used to indicate that an element of a proposition is supposed to be an exaggeration and therefore should not be taken seriously (Example 66, taken from Underhill 1988: 242); and it can be used to introduce what Underhill (1988: 242) calls "stereotyped expressions" (Example 67, taken from Underhill 1988: 242).

\section{Example 65}

Referring to pens: don't you have like a red one?

\section{Example 66}

About a movie: I think that like for those people who haven't seen it we should hold a wake

\section{Example 67}

today I had to ask this girl for a quarter and I mean, like my pride, where is it?!

Some of the examples given to illustrate this last function, however, seem to be closer to the use of like as a quotative or as marking a comment. When describing the scope of its uses, Underhill (1988: 242-3) states that like can serve to modify a noun phrase, a verb phrase (including the auxiliary), an adjective or an adjective phrase, an adverb or an adverb phrase, a subordinate clause or an entire sentence.

A slightly different approach to the notion of focus is taken by Miller and Weinert (1995) in their study on Scottish English. Even though they also refer to like as a "highlighting or focusing device" (Miller and Weinert 1995: 366), they classify like as a focus marker that not only marks new but also given information (Miller and Weinert 1995: 379). Moreover, Miller and Weinert (1995: 375) adopt a more technical definition of focus that considers pitch, syntactic structure and the presence of particles to be potential carriers of focus. They state that, due to 
common pitch patterns, prominence is generally given to the first and last lexical item of an utterance, which are two positions like often occupies in Scottish English. A similar focusing result can be achieved by reordering the syntactic structure of an utterance. Miller and Weinert (1995: 378-9) propose that like constructions can be replaced by WH- and IT-clefts even though the function of "like is not as powerful a focuser as the IT-, WH- and reverse clefts".

In their study, Miller and Weinert (1995: 392) identify two main uses of focus like that are linked to its position within the clause. Their analysis of map task dialogues and spontaneous conversations by native speakers of Scottish English suggests that initial like, in addition to indicating emphasis, can serve as a marker of clarification of previously made comments (Example 68) or to prompt the interlocutor to provide an explanation. In this sense, clause initial like seems to function similarly to I mean, a pragmatic device that has been described as "speaker-oriented repair device which functions to focus the listener's attention on a modification or clarification of the previous utterance, usually the speaker's own" (Stubbe and Holmes 1995: 70). In Example 68 Vivienne talks about how Auckland was the only university to feature in an international university ranking. When adopting the focuser framework, the last like in the excerpt can be interpreted as introducing a specification or elaboration on the preceding comment that the university ranking is based on money.

\section{Example 68: NSNZE-NSNZE/F-F/1/7:00}

Vivienne: and the only university that showed on it was Auckland and it like three hundred and something + but it's all done on like money it seems $\uparrow$ like how much money they have to put into research

Miller and Weinert (1995: 389) suggest that clause-final like can be used to preemptively invalidate possible assumptions of the listener as illustrated in Example 69 (taken from Miller and Weinert 1995: 389). 
With reference to Example 69, Miller and Weinert (1995: 389) propose that clause final like modifies the proposition my wee girl can swim and is used to stop the listener from assuming that the daughter can swim properly without any assistance. This type of clause-final like is a feature characteristic of Scottish English and does not occur in the present NSNZE data. Most of the instances where like occurs in clause final position were cases of cut-off utterances. In these cases, prosodic and syntactic clues suggest that the speakers intended to continue their turn but were interrupted by the interlocutor or lost their train of thought. Other functions of clause-final like in the NSNZE data are discussed in section 6.1.4.1.

Previous investigations of the use of like have often linked the marker with signalling planning difficulties (e.g. Edmondson 1981: 153-4). Miller and Weinert (1995: 372) note that indeed like can be used to bridge over problems with the organisation of a turn. They also note that the few instances of like collocating with pauses do not co-occur with other hesitation markers (1995: 373). They consider that the fact that most of those instances of like that occur with pauses are not phonologically reduced indicates that those tokens do not only function to mark hesitation (Miller and Weinert 1995: 374). Applying the concept of focus to these examples, Miller and Weinert (1995: 374) propose that collocations of like and pauses serve to add focus to an element as a pause can help to attract the listener's attention.

Interestingly, Miller and Weinert (1995: 370) completely reject a hedge interpretation of like. They state that nothing in their map task dialogues data suggests that interlocutors interpret lexical material marked by like as approximations. However, the use of an approximation does not necessarily require a large discrepancy between what is said and what was intended. A small inaccuracy, however, might not have been important enough or might have been disambiguated by the map itself (e.g. it might not have mattered if a given distance was twelve or actually thirteen centimetres to the left) and therefore would not have required the speakers to openly discuss the issue. Another possible alternative interpretation of the use of the data is that the discrepancy suggested by like is not related to the propositional, factual content of the 
utterance but to the way it was phrased, which again might not be an issue that interlocutors would directly address. It is also possible that the marker does not indicate an approximation at all. After all, previous research on the use of pragmatic devices has shown that hedges are multifunctional devices. As such they are not necessarily restricted to mark uncertainty on the speaker's part but can also function as politeness devices in that they soften or strengthen the illocutionary force of a speech act (e.g. Holmes 1985).

One of the main problems of Miller and Weinert's (1995) analysis seems to be that their approach does not take interpersonal politeness into consideration. Even though Miller and Weinert do not directly address the issue, it seems that by choosing to base their study on map task dialogues they believed they were dealing with predominantly goal oriented speech that is not so likely to be affected by interpersonal politeness issues. Assuming that the interlocutors were all status-equal strangers, though, it is likely that the speakers were not only concerned with completing the task as efficiently as possible but also with establishing rapport. Since the use of vague language in order to avoid sounding too assertive has been identified as a common strategy for creating a sense of solidarity and establishing rapport (e.g. Crystal and Davy 1975: 112), it seems negligent to analyse any form of communication without reference to the interpersonal dynamics of the interactants. Furthermore, an additional weakness of the study is the fact that Miller and Weinert restrict their in-depth discussion to clause initial and clause final like. This seems to favour the interpretation of like as a focus marker as opposed to a hedge, as instances of hedge like seem to predominantly occur in clause-medial position.

\subsubsection{Hedge like}

At the other end of the spectrum stands the interpretation of like as a hedge. Schourup's (1982) investigation of the functions of a set of pragmatic devices offers one of the earliest academic discussions of hedge like. Schourup's (1982: 18) analysis is based on the idea that pragmatic devices, or what he refers to as evincives, are expressions that reflect the speaker's thought processes. Furthermore, he believes that even though the precise implications of pragmatic devices are contextually dependent, they still have one basic core meaning. This is 
a common position in studies focussing on the description of pragmatic devices (e.g. Östman 1982; Schourup 1982; Andersen 2001) and has often been discussed in relation to grammaticalisation theory since this approach is often used to link the different realisations of a device to one common etymological source (e.g. Romaine \& Lange 1991; Brinton 1996).

Schourup (1982: 155) describes the basic meaning of like as "a response to the non-equivalence of what is shared and what is privately intended". Andersen (2001) also believes that all uses of like have one core meaning. He states that "in very general terms, then, like can be described as a marker of non-identical resemblance between utterance and underlying thought" (Andersen 2001: 233). Both of these definitions imply that like always carries a degree of vagueness, or, as Andersen (2001: 230) puts it, always expresses a certain degree of 'interpretive resemblance'. Even though Andersen's model for the analysis of pragmatic devices comprises the subjective, textual and interactional level, Andersen believes that like mainly works on the subjective level, i.e. the level that expresses the speaker's stance towards the utterance. He considers interpersonal politeness effects of like, such as avoidance of sounding too assertive and creation of solidarity, to be an "interactional (side-)effect" (Andersen 2001: 248) and therefore does not discuss them in relation to his examples. Schourup's (1982) and Andersen's (2001) very abstract interpretations agree with Östman's (1981: 6) definition of pragmatic devices as items that "implicitly convey the speaker's attitudes and emotions". In this sense, it can be said that like always implicitly conveys some form of imprecision, even though the exact place of the imprecision may vary.

Both Schourup and Andersen believe that this general abstract meaning is applicable to all functions of like, such as its use in approximations, exemplifications, as a quotative and as an interjection or hesitation link. In all these cases the marker indicates that what is to follow is not an ideal or perfect rendering of what is meant and instructs the listener to look for non-literal and interpretative reading of the proposition. In the case of like used synonymously with for example, the marker signals that the following instance is just one possible option that has been selected. Since this is not an inaccurate 
representation of what was intended, Schourup (1982: 50) proposes that it constitutes a discrepancy in that it "is an accurate but selective representation".

The notion of like being a focus marker of new information is challenged by Andersen (2001) in his study on the language of teenagers based on an analysis of the Bergen Corpus of London Teenage Language (COLT) and the British National Corpus (BNC). While Andersen (2001: 247) acknowledges that like often occurs with the most important information of the utterances, he proposes that instead of marking newness the device modifies "lexical material which is from a foreign conceptual domain, sociolinguistically unfitting, stylistically marked, or which appears to involve a relatively high production cost on the part of the speaker". In this function of what Andersen (2001: 241) refers to as 'metalinguistic use', like helps the speakers to distance themselves from the lexical item in question, emphasising that there is, in Schourup's sense, a discrepancy of some sort between what is meant and what is said. This distinction between metalinguistic focus and approximation seems to be rather problematic to me, as it would be very difficult to determine whether the indicated discrepancy is related to the concept implied or to the phrasing itself. This metalinguistic use is illustrated in Example 70 (taken from Andersen 2001: 242). Andersen (2001: 2423) argues that in this case like indicates that the expression ask you out might not be the most appropriate one in the given context.

\section{Example 70}

Did erm, did, Daniel just suddenly like ask you out or did someone get you together?

Andersen's analysis of like as creating metalinguistic focus by functioning as a hedge on the wording of the expression ask you out seems to be one viable interpretation of the data. However, following a different interpretation, in this case like could also indicate that the concept of asking someone out should not be taken too literally. The real question in Example 70 seems to be how did you get together. Since not all relationships start with a formal dating period, though, the use of like could be taken to indicate that other ways of starting a relationship are included in that term, such as drinking too much alcohol one night. 
This example also highlights the limited scope of Andersen's analysis. His focus on the idea that all instances of like have a unified meaning in that the marker "is essentially concerned with the relation that exists between a speaker and the proposition" (Andersen 2001: 230) seems to restrict the analysis to the immediately following lexical material and exclude an examination of its effects on the utterance as a whole, especially of its functions as an interpersonal politeness device. While I agree that the idea of like as a stylistic marker is a viable interpretation of Example 70, I do not consider this to be its main, most salient function in this instance. Instead, I think that in this instance the token predominantly serves as a hedge in the sense that is seems to soften the illocutionary force of a rather personal question. The hesitation marker erm in the clause initial re-start could also be interpreted to support this analysis as it appears to indicate that the speaker is not too sure whether it is an appropriate question to ask as a whole.

With regard to like being a marker of hesitation, Schourup (1985: 53) classifies cases of like occurring in conjunction with pauses as mere 'pausal interjections'. Andersen (2001: 227) also allows that there are cases where like serves to bridge over planning difficulties, false starts and repairs. However, Andersen (2001: 227) points out that occurrences of like are hardly ever accompanied by other signs of planning difficulties in his data, which suggests that its functions as a hesitation device cannot be taken to be the core meaning of the device. Andersen (2001: 228-9) considers the use of like in pauses and reformulations to be an extension of its basic meaning in that it marks the following as an approximate rendering of what the speaker meant so say and "instructs the hearer to opt for a less-thanliteral interpretation of the utterance".

Schourup (1985) and Andersen (2001) both comment on the special use of the collocation it's like. In cases like Example 71Example 71, the pronoun it of the it's like construction does not have a clear anaphoric referent but instead is linked to a "referentially empty item" (Andersen 2001: 214). 
Example 71: NSNZE-NSNZE/F-M/23/9:00

Bobby: I mean people are so demanding about health as well it's

like you know it's not just the government saying hey you

don't smoke it's like other people like hey you know . pay

for my cancer kind of thing so + I don't know

Schourup (1985: 59-60) states that the construction functions similar to hedge like in that it "can be taken to refer to what the speaker has in mind to express" and often co-occurs with hesitations. Andersen (2001: 256) notes that it's like also serves hesitation marking and discourse linking functions. However, he believes that this marker cannot be analysed as analogous to like since the two forms differ in their syntactic properties and the context of their occurrence. While like can occur between clausal elements, Andersen (2001: 257) maintains that it's like is outside of "the propositional clausal structure".This, in turn, has an impact on its functional scope in that it's like cannot be used to express functions such as approximation or exemplification. Moreover, Andersen (2001: 258) notes that it's like only occurs within discourse segments on the same topic. As such, "it's like invariably seems to provide a signal that the speaker not only wants to continue speaking, but that she wants to elaborate on the topic on the floor" (Andersen 2001: 258).

Both Andersen's (2001) and Miller and Weinert's (1995) approaches seem to be limited by their focus on trying to fit the data into their theoretical framework. In this sense, Andersen's insistence that all functions of like can be described as having one basic underlying meaning and his dismissal of the notion that like can serve as a focus marker seems as short-sighted and restricted as Miller and Weinert's rejection of the idea that like can function as a marker of approximation. While both studies provide valuable insights into the workings of the pragmatic device, they only deal with a limited range of its functions, and thereby play down its multifunctional nature.

\subsubsection{Quotative like}

The use of like as a marker of quotation is probably the discourse function that has received the greatest amount of academic attention. Since Butters (1982) first noted the non-standard quotative function of be like constructions in American English, the marker has been discussed and analysed with regard to its discourse 
functions (e.g. Ferrara and Bell 1995; etc.), possible functional restrictions (e.g. Schourup 1985; Blyth et al. 1990; Tagliamonte and D'Arcy 2004 etc.), sociolinguistic distribution (e.g. Ferrara and Bell 1995; Dailey O'Cain 2000; Tagliamonte and D'Arcy 2004 etc.) and its status in terms of grammaticalisation (Romaine and Lange 1991; Brinton 1996; Tagliamonte and D'Arcy 2004). This function of like has been referred to as dialogue introducers (Johnstone 1987; Ferrara and Bell 1995), quotative complementiser (Romaine and Lange 1991) and marker of interpretive use (Andersen 2001). In the following, it is discussed under the label quotative like (Blyth et al. 1990; Meehan 1991; Ferrara and Bell 1995; Hasund 2003).

The majority of the studies dealing with quotative like are based on American English (e.g. Schourup 1985; Meehan 1991; Romaine and Lange 1991; Dailey O'Cain 2000 etc.). However, this use has also been observed in Canadian English (Tagliamonte and Hudson 1999; Tagliamonte and D'Arcy 2004), British English (Andersen 2001; Hasund 2003), and New Zealand English (Baird 2001). Researchers generally agree that quotative like predominantly occurs in informal conversations, particularly in narratives (Blyth et al. 1990: 214) and is used can be used to report "an actual representation of a spoken utterance" (Andersen 2001: 217), as illustrated in Example 72. Moreover, the form can also function to introduce the speaker's inner thought or attitudes. An example of this type of use is given in Example 73.

\section{Example 72: NSNZE-NSNZE/M-M/21/20:00 \\ Stuart: And then they bring in like this um Beatnik Jazz musician he's like. [different voice:] hey man ah what's han- how is it going what's hanging ah huh . to teach you how to speak beatnik which is kind of square you know I wouldn't do it you know um but if you wanna do that um all power to you man}

In Example 72, Stuart recounts a skit about how to speak like a Beatnik and presents a potentially approximate account of what was actually said. The direct speech is introduced by the be like construction he's like and is further highlighted by the use of a clearly different tone of voice. 


\section{Example 73: NSNZE-NSNZE/M-M/51/13:00}

Caleb: I just ran into [name] from [place] eh + far out he plays like he plays rugby every sport imaginable eh and. like ah he's just standing like they're just sitting down stretching and just crouched over and I was like ah yeah . what are they talking about. this guy is not THAT big //. I and then he stood up and I was just like far out

The uses of quotatives in Example 73 are more ambiguous in terms of whether they depict actual utterances or internal thought. Caleb describes how he met a famous New Zealand rugby player who, at first, did not seem quite as tall and strong as he later turned out to be. In this case, the segments of direct speech introduced by a be like construction seem to represent Caleb's comments and attitudes as there is no indication that he was talking to someone else. Moreover, commenting on someone's size might be considered face threatening and rude. This is another reason why it is more likely that the direct speech in the example above illustrates Caleb's thoughts. It is its ability to mark an utterance as the verbalisation of someone's thoughts that distinguishes be like from other verbs of quotation (Blyth et al. 1990).

Schourup (1982) and Andersen (2001: 250-1) maintain that the basic hedge meaning of discourse like, i.e. that it indicates a discrepancy between what is said and what was intended, also applies to quotative like. Miller and Weinert (1995: 370), whose data did not contain any instances of quotative like, also concede that in this particular case the analysis of like as a hedge may be more appropriate than that of a focus marker. On an interactional level "including instances of verbal interchange is one way speakers can heighten the performance value of their stories, thus making them more vivid" (Ferrara and Bell 1995: 265), and in this sense, quotative like can be said to contribute to the conversational flow. Moreover, since quotative like is generally considered to be an informal, nonstandard form, the marker can also be analysed to help create a relaxed interpersonal atmosphere and reduce social distance.

As mentioned before, quotative like is predominantly realised as a be like construction. However, it can also co-occur with other verbs of saying such as $g o$, say, tell, etc, though in these constructions it assumes a different grammatical position and functions more explicitly as a hedge. It has been suggested that 
alternations between different verbs of quotation is related to marking different speakers (Romaine and Lange 1991: 237) and the choice between present and past tense forms has been analysed on connection with the reported speaker's level of authority (Johnstone 1987). Ferrara and Bell (1995: 278) also found that be like and inanimate quotative it's like constructions are used differently in their corpus of Texan American English. According to their study, quotative it's like is used by males to indicate "the collective thoughts of a group" and by both genders to introduce segments that represent characteristic speech or ideas of someone as in Example 74a) and b) (taken from Ferrara and Bell 1995: 279).

\section{Example 74}

a) Jim:

And now it's like, uh you know "Oh man, you know, you guys, you you hippies are nothing." It's like, "Hey, (1) us hippies led the path."

b) Jason: My dad was constantly down on me. It's like, "Get a job."

Another interesting issue related to the analysis of the different uses of discourse like in general and quotative like in particular is the question whether quotative like can be classified as a pragmatic device or not. Quotative like is a borderline case as far as its status as a pragmatic device is concerned. On the one hand, it can be used to indicate that the following quotation is only an approximate rendering of what was said or that something that is presented as direct speech is a vocalisation of thoughts. Romaine and Lange (1991: 263) point out that, similar to the pragmatic effects of the indirect mode, the use of quotative like allows the speaker to stand "in a relation of reduced responsibility and commitment to the truth of the report". In this sense, quotative like carries the approximation and politeness meanings of hedge like. Some definitions of pragmatic devices, however, require them to have no clearly defined semantic content and syntactic function as they are often outside the syntactic structure of a clause (e.g. Östman 1981; Erman 1987; Brinton 1996; Nikula 1996). Quotative like, however, has both. It carries semantic meaning in that it serves as a marker of quotation that is replaceable by other quotative verbs such as say, which makes it an integral part of the clausal structure. Nevertheless, most researchers consider the quotative use of like to be a more grammaticalised and more specialised extension of its discourse uses rather than a fully lexicalised verb of quotation (Meehan 1991: 46; Romaine and Lange 1991: 266). The present research follows this approach and 
discusses quotative like together with hedge and discourse link like as a pragmatic device.

\subsubsection{An integrated approach}

Even though the notions of focuser like and hedge like can be regarded as fundamentally different, most researchers do not treat them as polar opposites. Underhill (1988: 241) acknowledges that like can also be used as an approximator, and notes that in some cases, especially in requests, like can function as both a focus marker and a hedge. In these instances it can be said that "the like not only functions to highlight the new information but also allows the speaker to pull back from the assertion in a rather non-committal fashion" (Meehan 1991: 50).

Similarly, even though Andersen (2001: 259) considers like to have predominantly subjective functions, i.e. to enable speakers to express their stance towards the proposition or choice of words in one way or another (Andersen 2001: 66), he notes that it can also be used for a number of textual functions. Andersen proposes that like can function as a hesitation device marking false starts, self-repairs and incomplete utterances. Moreover, it can be used to provide a "discourse link between syntactically distinct units of discourse" (Andersen 2001: 259). The same observation can be made with regard to Müller's (2005) investigation of the use of pragmatic devices by native speakers of American and British English and GNNSE. In her investigation of the uses of like, Müller maintains that all the functions of like she identified in her study work exclusively on a textual level and this appears to be easily applicable to a function such as 'introducing an explanation', which involves creating discourse links between different units of conversation. However, her category lablled 'lexical focus' includes functions such as approximation and intensification, which are expressions of the speaker's stance towards the proposition and therefore also function on a subjective level. In other words, even though Müller does not explicitly state the notion that like can serve both textual and subjective functions, this notion can be detected when analysing her categories. 
Another study that seeks to provide a thorough picture of the different functions of like can be found in Hasund's (2003) comparative study of English like and Norwegian liksom. In her study Hasund (2003) applies Andersen's (2001) three tier model for analysing pragmatic devices and looks at the subjective, textual and interpersonal functions of like. According to Hasund (2003:91), like can not only be used to express imprecision and approximation but also to signify sameness as in $x$ is (exactly) like $y$. Hasund proposes that on the subjective level like can function both as a hedge and an intensifier, serving to either stress discrepancy between or the sameness of units. In this sense, like serves to express the speaker's epistemic stance towards the utterance. Moreover, unlike Andersen (2001), Hasund also discusses the function of the marker as an interpersonal politeness device in greater detail. When used as a hedge, like can convey negative politeness functions by softening the illocutionary force of potentially problematic speech acts. When used as a booster, like can serve to emphasise the precision of a comparison. In turn, this function can mark an utterance as usual or express positive politeness functions by emphasising the speakers' shared background and establishing common ground.

On the textual level, Hasund (2003: 90) follows Miller and Weinert's (1995: 366) notion that like establishes connections between discourse units. In this function, like often precedes explanations, elaborations or clarifications. With regard to the interpersonal functions of like, Hasund (2003: 94-95) believes them to be sideeffects of textual and subjective stance like that have been conventionalised to the degree that they can serve as the main function in some contexts. In cases where the interpersonal functions of like take on the dominant role, the device can serve as an expression of concern towards the listener, making sure that the listener understands the utterance the way the speaker intended. Furthermore, by explicitly marking the main point of the utterance, the speaker seeks to involve the listener in the conversation (Hasund 2003: 94-5). Hasund (2003: 177) notes that this interpersonal use seems particularly salient when like occurs clause medially in a position equivalent to the "middle-field modal particle slot" of other Germanic languages such as Norwegian or German. In these languages, the clause medial position is closely associated with interpersonal functions. According to Hasund's description, interpersonal like seems to function similarly to focus or even 
intensifier like in that it marks and highlights the most salient information of an utterance.

Unfortunately, although Hasund discusses the interpersonal functions of like to some extent, few examples are given; and those examples that are used to exemplify her claims are not discussed in any detail. This does not strengthen Hasund's claim of the existence of an interpersonal sub-category of like. Hasund (2003: 179) presents Example 75 as an instance where the interpersonal function of like does seem to be dominant.

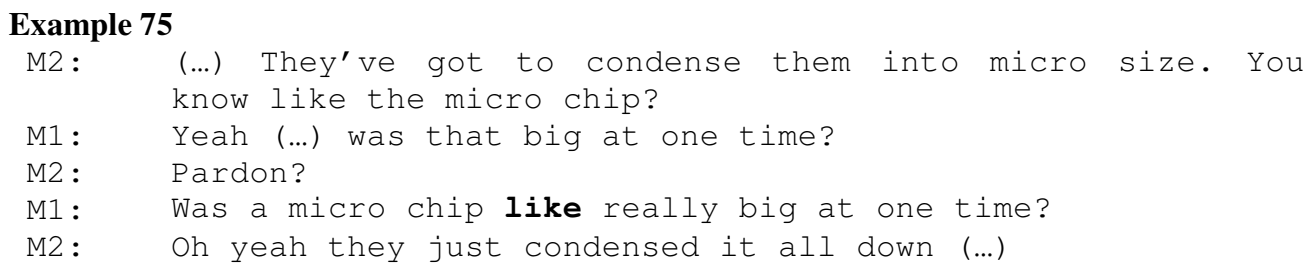

According to Hasund (2003: 180), the highlighted instance of like "serves a primarily interpersonal and involving function which is a conventionalised or routinised side effect of like's potential for expressing a subjective intensifying stance”. While I agree with Hasund's point that in the example like seems to serve as an intensifier or focus marker, I do not agree with her reasoning that in this case the marker takes on predominantly interpersonal functions that are used to involve the speaker. The interpersonal functions of like seem to be intrinsically linked to its textual and subjective functions, i.e. in the example, the use of like seems to boost the proposition that micro chips were big at one time which in turn might have an involving politeness effect. The interpersonal functions of like seem to depend on its use in conjunction with one of the other functions, which makes it impossible to differentiate between them. Therefore, I do not regard this feature to be one of the main functions of like. Instead, I consider this functional by-product to be an underlying implicit function of like that is part of the textual and subjective manifestations of the marker. However, Hasund's approach of analysing both the textual and subjective functions of the marker as well as examining the interpersonal politeness effects seems to be a worthwhile line of attack, because it thoroughly covers all levels. Therefore, I propose to adopt this method for the analysis of like in my study. 


\subsubsection{Like categories: A quantitative approach}

Because pragmatic devices can serve multiple purposes at the same time on both the textual, subjective and interpersonal level, it could seem impossible to determine one single meaning of a marker in a given context. However, it has been argued that, based on phonological and contextual clues, it is often possible to determine the most salient function of a pragmatic device (e.g. Holmes 1984). In each of her studies on the use of pragmatic devices in New Zealand English Holmes (e.g. 1982, 1984, 1985, 1986, 1988) identifies a number of distinct categories, ranging from four different types of tag questions (epistemic modal, challenging, facilitative and softening tags) (Holmes 1982) to a more basic hedge/intensifier distinction for I think (Holmes 1985). Differences in the functions of individual pragmatic devices notwithstanding, the most fundamental distinctions are seen between a marker's referential and affective functions.

Most research to date that deals with the use of like has focused either on describing its different meanings within discourse or on documenting its sociolinguistic distribution, without attempting a quantitative analysis of the functions. For her comparative study of English like and Norwegian liksom Hasund (2003) explicitly rejects a quantitative analysis of the pragmatic functions of like due to the difficulty of the coding. Instead she uses the position of like within a clause as a quantifiable basis for the comparison. This approach seems promising in that it would likely be easier to determine the position of like within a clause than to identify its dominant function. But since the main aim of this research is the investigation of functional differences in the uses of pragmatic devices by native and non-native speakers, a quantitative approach focusing on the different functions of like would be more valuable. However, the two approaches could be combined for the analysis as some correlations between the positions of like within a clausal unit and its dominant function have been noted. Miller and Weinert (1995) comment that like in clause initial position is predominantly used as a marker of clarification, elaboration and exemplification and therefore can be said to function as a discourse link. Hasund (2003: 26-7) points out that clause medial like is often described as modifying the immediately following item by indicating exemplification or expressing epistemic modality, 
thereby serving as a hedge. D'Arcy (2005: 218) also maintains that in clause initial position like functions as a discourse maker whereas in clause-medial position it works as a particle. These studies suggest that, in addition to contextual and phonological clues the position of like within the clausal unit can be taken as a useful functional indicator that can help pinpoint the most salient meaning of a token.

Andersen's (2001) and Müller's (2005) studies are attempts at a quantitative analysis of the various like functions. Andersen uses five distinct categories in his study: approximation, exemplification, metalinguistic focus, quotative and hesitation/discourse link. These categories are further subdivided into more narrowly defined classes. While these categories certainly provide a thorough account of the possible functions of like, they also seem to be rather difficult to code for due to the large degree of functional overlap. Andersen (2001: 237) also notes that approximation and exemplification basically belong to the same group as "their common denominator is that they involve non-identical resemblance between the encoded and the communicated concepts". This also applies to Andersen's class of like as indicating metalinguistic focus; in these instances, like is analysed as a modifier of stylistically marked items that also allows speakers to distance themselves from what has been said (Andersen 2001: 247). Moreover, Andersen's classification does not seem to include the use of like as an intensifier or focus marker, nor does it appropriately account for its textual functions.

Similarly, in her quantitative investigation of like in the language of native and non-native speakers of English, Müller (2005) distinguishes between seven different discourse like categories: searching for the appropriate expression, approximate number, introducing an example, introducing an explanation, lexical focus, various functions and quotative like. The function of lexical focus seems to include cases where the device serves both to highlight certain elements and to indicate imprecision. As with Andersen's classification system, the difference between the categories of lexical focus and introducing an example is not quite clear. Some of the extracts given to illustrate the category of exemplification could feasibly be interpreted as marking lexical focus. For example, the underlined token in so you need like dialog there [...] even like ... subtitles will 
work but (Müller 2005: 214) could also serve to emphasise the idea that, if you cannot have sound, even subtitles would be better than a silent movie. In this case, like could also indicate that the speaker is not sure if the word subtitles is accurate in this context. At the same time, some instances of numerical approximation such as I guess it was like a silver dollar on the floor (Müller 2005: 211) could also be classified as exemplifications or marking lexical focus. These issues of functional overlap suggest that having too many narrowly defined categories can make the classification process more complicated than necessary and could make a replication of the study using different data challenging. In an attempt to simplify the categorisation process I use relatively broad categories for the quantitative analysis part of the current study. In order to balance this rather crude approach to a pragmatic device that is as multifunctional as like, a detailed description of the different functions that have been collapsed into categories is also provided.

It may seem contradictory that a quantitative analysis of the different functions of GEs was not attempted in the current study (see section 5.3), while this approach was chosen for the investigation of the different communicative roles of like. However, since GEs and like are inherently different pragmatic devices that vary as regards their form, their syntactic position within a clause and their textual and pragmatic functions, their analyses require different approaches. GEs are a varied set of forms and the differences in their realisation proved to constitute a sound basis for comparison between the two groups. Like, on the other hand, is a nonvariant form, which is why a comparison of forms is not a feasible option.

With regard to the functions of the pragmatic devices, it has been noted in section 5.3. that GEs serve a range of referential and affective meanings, which were shown to be closely related to one another. This made it impossible at times to identify one dominant meaning. Like as a pragmatic device, however, can be used for four relatively distinct functions: as a discourse link, a subjective stance marker, a quotative and a hesitation marker. Unlike the referential and the affective meanings of GEs, these four functions of like are comparatively easy to distinguish from one another based on context, phonology and position of like within the clause. In other words, while the formal variation of GEs suggested an analysis of the different realisations, the dissimilar nature of the four main uses of 
like makes a quantitative analysis of the functions the most feasible and worthwhile approach to the data.

\subsubsection{Definitions of Categories}

For the purpose of my analysis and in order to make the coding as simple as possible I adopt a modified version of Andersen's (2001) and Müller's (2005) like categories following a basic textual/subjective division. The relatively broad categories are: subjective stance like (which includes hedge like and intensifier like), discourse link like, quotative like and like as a hesitation marker. The categories have been identified by analysing NSNZE interactions to establish native speaker norms. The following section defines and describes these four categories, and discusses potential problems such as functional overlap and classification difficulties. The different functions are illustrated with examples taken from the NSNZE corpus. This qualitative study of like in the NSNZE data is then followed by a discussion of the quantitative results. The description of the functional scope of the four groups serves to provide a detailed definition so that the categories can be successfully applied to other data. Moreover, since the discussion represents what can be considered the baseline of NZE uses of like in this context, it serves as a basis for the subsequent comparison with previous studies on like in other varieties of English as well as with the GNNSE data.

\subsubsection{Subjective stance like}

The class of subjective stance like consists of all items that seem to function as an expression of the speaker's evaluation of the accuracy of the utterance. This includes, for example, instances of like that function as markers of epistemic modality in that they convey the speaker's degree of certainty towards a particular element of the clause or the propositional content of the utterance. Since the expression of epistemic modality is not restricted to its use as a marker of doubt or vagueness, this group also includes cases where the speaker's degree of certainty is high. In this sense, the class of subjective stance like consists of two subcategories: hedges and intensifiers, or what Andersen (2001: 243) refers to as "metalinguistic focus". Instances of like that belong to the subjective stance category often serve as politeness devices in that they help to soften or emphasize the illocutionary force of speech acts. More specifically, one part of subjective 
stance like includes all instances where like seems to add emphasis to a proposition or highlight certain elements of an utterance as in Example 76.

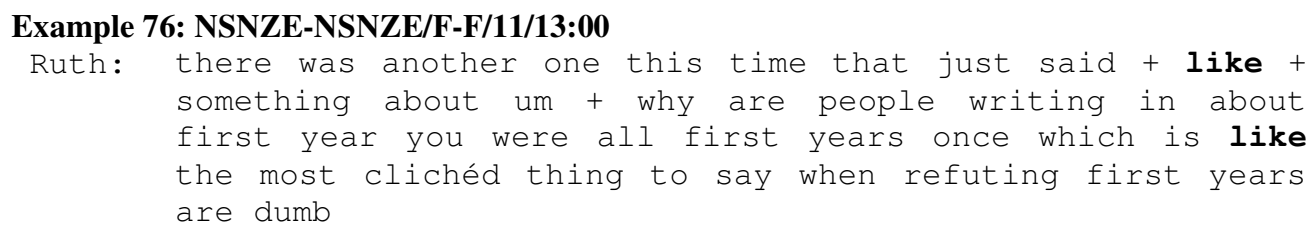

Ruth's comment refers to a letter that was sent to the university student newspaper in which the writer complains about older students not taking first year students seriously. The first like seems to function as a hesitation marker that serves to hold the floor. At the same time it indicates that what follows is only an approximate rendering of the content of the letter. The second like, however, seems to serve as an intensifier or focus marker, emphasising the proposition that the argument that she describes must be considered irrelevant in this context. In this context like could be glossed with 'one must admit' or 'it must be said'.

The subcategory of subjective stance like includes all cases where a token serves to express lexical, numerical and propositional approximation, or signals that the utterance is stylistically marked. An example of like as a marker of approximation is given in Example 77. Caleb is not a good cricket player and uses the statistics of one of his games to underline that fact.

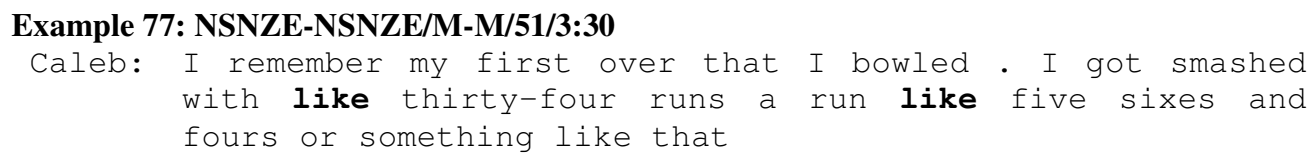

Here, the two instances of like seem to express that the scores given are only estimates that serve to highlight that Caleb is not very good at cricket, and thus do not necessarily represent the real results.

While this example might seem to be a fairly straight-forward case of hedging, it also serves to highlight the difficulty of differentiating between the different subcategories. Bearing in mind that Caleb is using the story of the cricket game to self-deprecatingly emphasise that he is bad at cricket, the use of like in this context can also be interpreted as an intensifier, drawing attention to and 
highlighting the lowness of the score. In this sense, the use of like could serve as an indication that the given score is an exaggeration. Taking an alternative view, the token could also be interpreted to serve as a politeness strategy to protect the speaker's face by minimising the illocutionary force of the self-deprecation.

The category of hedge like also includes cases of lexical or propositional approximation as illustrated in Example 78. Vivienne is talking about the possible professional interests of a friend and cannot be certain about her proposition that he was interested in sports law.

\section{Example 78: NSNZE-NSNZE/F-F/1/12:30}

Vivienne: yeah I think he was really keen on doing like sports law things like that

In this context, like seems to predominantly function as a hedge on the proposition (i.e. that it is sports law that the friend was keen on doing) and/or the lexical item sports law (i.e. the term sports law might not be the correct word or it might be considered too technical for the current context and therefore stylistically marked). The interpretation of like as a hedge in this case is supported by its cooccurrence with other pragmatic devices such as I think and the specific extender things like that.

Even though the primary function of like in Example 78 has been identified as indicating uncertainty about the accuracy of the following proposition, the token could also be interpreted as serving other purposes. One feasible alternative analysis of like could be that it marks the lexical item sports law as an exemplification of the type of thing her friend might be interested in. In this sense, hedging and exemplification can serve similar purposes. After all, there is not much difference between saying that 'I am not too sure about this' and 'this is just a representation of what is true'.

The use of like to introduce examples has been frequently commented on in the literature, with a number of researchers pointing out that in these cases like seems to take on the meaning of for example (Schourup 1985; Miller and Weinert 1995; Andersen 2001; Müller 2005). In their investigations of the functional uses of like 
in British and American English, both Andersen (2001) and Müller (2005) consider its use in exemplifications to be separate from like in approximations and as discourse links. In the present study, however, the function of exemplification is not treated as a distinct class, but instead cases of exemplification are analysed to determine whether they serve as a subjective stance indicator or a discourse link. According to the proposed classification system, exemplification like can operate as an epistemic indicator when it functions as an interpersonal device by marking the following example as random. However, it can also be classified as a discourse link when the main function of the example is to clarify a previous point.

An instance of exemplification like as an interpersonal device can be found in Example 79. In this case, Tom lists a number of animated Disney movies that he enjoyed, introducing the second example with like.

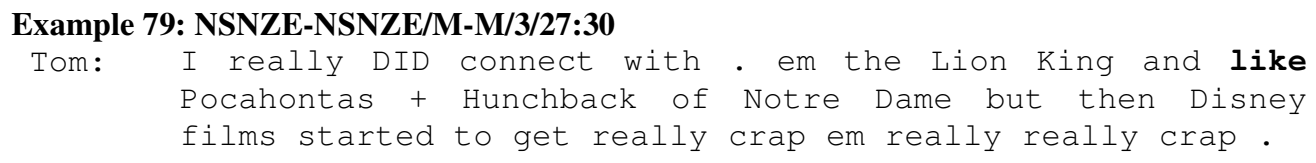

As Tom appears to know the titles of the movies rather well and seems confident in his proposition, the marker does not appear to function as a hedge. Moreover, the level intonation does not indicate that this is a case of like being used as an intensifier. Instead, the marker appears to introduce additional examples of movies Tom connected with, indicating that these are possibly salient but haphazardly chosen ones and that other movies could be listed in their place.

In addition to expressing varying degrees of epistemic modality, instances of subjective stance indicator like can also be analysed in terms of their affective meanings. Its functions as a politeness device can be seen as analogous to GEs: by being vague the speaker implies that the interlocutor is able to understand or infer the intended meaning, thereby appealing to listener's understanding and establishing a common ground. This kind of use can often be found in descriptive segments where speakers seem to struggle to convey what they mean. For instance, in Example 77 Caleb relies on Reuben's knowledge of cricket to understand that his score is a representation of a score that is not very good. In this sense the token functions as an appeal to their assumed shared background 
knowledge. In Example 78 Vivienne's use of like as a lexical hedge can be seen to serve as an appeal to her interlocutor's willingness to cooperate and use her knowledge of the judicial system to infer the branch of law Vivienne is referring to. Another example of this type of use of like as a politeness device can be found in Example 80 where Nora is not too sure which character from the Smurfs is called Gargamel.

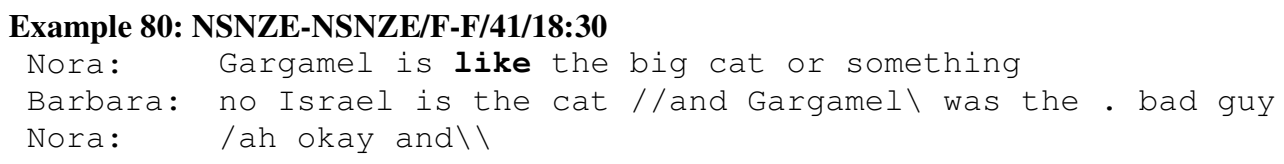

The highlighted like serves as a hedge on the entire proposition, indicating that Nora is not sure if Gargamel is the name of the cat or of another character. Additionally, the marker also conveys that the expression the big cat might not be the best and clearest way to describe the character she has in mind. This impression of lexical and propositional imprecision is supported by the use of the GE or something. However, even though Nora cannot recall the names of all the characters, she knows enough about the show to be able to describe or understand a description of them, e.g. the big cat or the bad guy. By providing only a vague description of the character she is thinking of, Nora has to rely on her interlocutor to understand her and thereby draws on what she believes to be the limited amount of background knowledge they share of cartoon show and its characters.

The functions of subjective stance like as a politeness device are relatively clear: hedges can serve to mitigate potentially negatively affective speech acts, and intensifiers can be used to express positive politeness functions by emphasising or strengthening a positively affective speech act. One example of the use of like as a hedge can be seen in the few instances where like occurs in clause-final position where the utterance does not appear to be cut-off. In these cases like does not seem to fit Miller and Weinert's (1995) description of clause-final like in Scottish English. Instead, the tokens appear to function as hedges on potentially rather personal questions as illustrated in Example 81. Vivienne states that she feels somewhat overwhelmed by the workload that is required for some of her courses and Lauren asks if she manages to keep up with the mandatory reading. 


\section{Example 81: NSNZE-NSNZE/F-F/1/13:30}

Vivienne: I'm feeling really swamped

Lauren: are you doing all the reading that is required? Like

Vivienne: I'm about two weeks behind at the moment in all of my papers yeah

Because the instance of like in the example is not part of the question itself but appears as an afterthought, it seems to serve as a prompt that is used to encourage the interlocutor to clarify a point by continuing the sentence and filling in the blank. This impression is supported by the use of a level intonation on the item, which suggests that it is the beginning of a sentence. At the same time, the highlighted like appears to soften the illocutionary force of the potentially face threatening or sociality rights impinging question. Since Lauren has already completed a university degree, the question could be easily interpreted as suggesting that Vivienne is not working hard enough or is not smart enough for her course of studies. The use of the token in this context seems to suggest that the question is not meant to be an affront to the interlocutor and that Lauren does not expect an exact answer.

Andersen (2001: 237-8) comments on the use of like in connection with hyperboles and metaphors and there are a number of instances in the present corpus where the device is put to similar use. In this way like can also be used in jokes where the form can be used to emphasise an exaggerated description and indicate that the following material is not supposed to be taken seriously. One typical example for this type of use of like occurs in conjunction with exaggerated numbers such as there's like zillions of people in there. Another illustration is given in Example 82 where Carl and Tanya discuss capital punishment.

\section{Example 82: NSNZE-NSNZE/F-M/14/16:00}

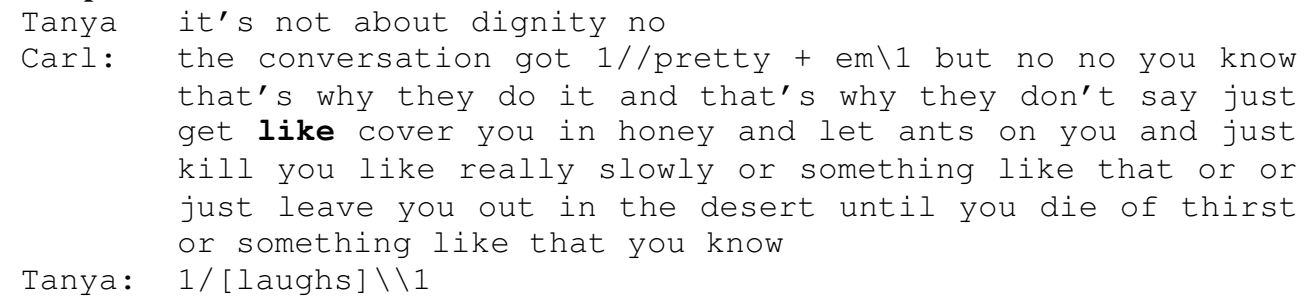

One interpretation of the highlighted like indicates that the following example is just one possible one that has been chosen at random. Moreover, bearing in mind 
the extreme nature of the example, the token also serves to underline that the example is intentionally exaggerated and extreme and therefore should not be taken too seriously. This interpretation is further strengthened by the presence of the GE or something like that, which can also be used in conjunction with humorous exaggerations (Overstreet 1999).

\subsubsection{Discourse link like}

Discourse link like is the second category of like that requires a closer definition. This serves to provide an impression of the scope of functions contained in this group in order to facilitate a qualitative and quantitative comparison with the GNNSE data. The discourse link category incorporates all instances of like which predominantly establish links between units or mark the discourse function of certain elements. Instances of discourse link like primarily introduce additional information that relates to a previously made comment. As such like appears to introduce clarifications of one form or another. In other words, all instances of like that serve as signifiers of clarifications and its sub-groups of specifications, explanations, elaborations or descriptions are included in this group. Example 83 serves to illustrate the use of like as a marker of specification. In these cases, the main function of like seems to be to signal to the listener that what is to follow is supposed to be interpreted as a specification or explanation of a potentially ambiguous or not quite accurate statements which is added to avoid or pre-empt misunderstandings. Guy comments that he is trying to learn French at the moment and he modifies this by making clear that he is just learning casually rather than attending classes at university.

\section{Example 83: NSNZE-NSNZE/F-M/17/15:00 \\ Guy: I'm trying I'm trying to learn. French . like cazh [short for 'casual']}

In this case, like can also be interpreted as a hedge on the rather unusual nonstandard form cazh for 'casual', however, the pause preceding like indicates that this segment is an afterthought relating to his previous statement and therefore is interpreted as mainly serving as a discourse link introducing a clarification.

As mentioned above, like in exemplifications can also function as a discourse link. An example for this function is given in Example 84 below. Steven is talking 
about the subjects that he enjoyed during his degree in philosophy. Steven states that he liked the areas dealing with political aspects the most.

\section{Example 84: NSNZE-NSNZE/F-M/34/14:30}

Steven: I did kind of like the politics stuff. like political philosophy and stuff. but that's one of the I mean that's one of the good things about going to the states

Since the connection between politics and philosophy is not necessarily evident to everyone he modifies this statement by providing the technical term of the philosophical sub-discipline political philosophy as an example of how politics fits in with philosophy. In other words, the purpose of the use of the example is to clarify the previous assertion. In this sense, this form of exemplification functions as a discourse link in that it establishes a connection between the previous statement and the following segment.

Just as in the previous example, the use of like can also be interpreted as a hedge on political philosophy rather than an exemplification. However, again, the pause before and after the modifying sub-clause introduced by like suggests that this entire segment serves as a modification. Moreover, the use of the GE and stuff also supports the interpretation of this exemplification as a discourse link as it seems to indicate that there might be other disciplines that could be mentioned in this context and that political philosophy is just one illustrative example.

Another sub-category that is closely related to the function of clarification is that of elaboration. Most of the discourse link categories could be regarded as elaborations in one way or another and the difference between this sub-class and the other ones is very fine. For the purpose of this study I consider instances of elaboration like to serve to introduce segments that add more detailed information to a topic. Unlike with clarification like, this additional information does not necessarily disambiguate or illustrate a previously made point. One type of this kind of elaboration could be a description of a place or a situation as illustrated in Example 85. The example contains five instances of like overall, with one of them taking the past tense form of the construction it's like. 


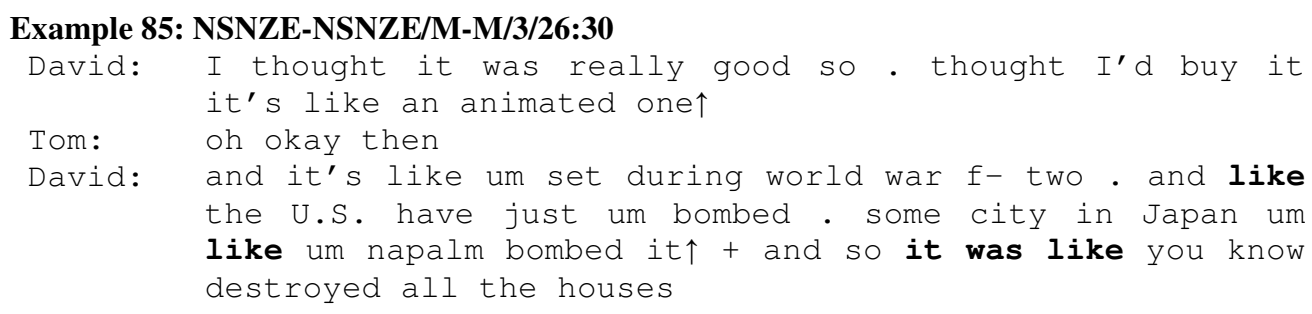

The main function of the first highlighted like seems to be to link the subsequent segment to the preceding one, indicating that it is a continuation of or elaboration on the description of the setting of the movie David just bought. In other words, David provides a clarification of the exact moment in time when the story of the movie takes place. While it is also possible that the token serves as a hedge on the propositional content of the statement (i.e. that the U.S. have bombed a city in Japan) the intonation pattern and the fact that it occurs in initial position strongly suggests that the token predominantly functions as a discourse link.

In the analysis of the it's like construction, Andersen (2001: 258) points out it "seems to provide a signal that the speaker not only wants to continue speaking, but that she wants to elaborate on the topic on the floor". Following this analysis, the function of it was like could be read as leading into an elaboration on or description of the state of Japan after the bombings and consequently a further elaboration on the setting of the movie. In both cases, the additional information does not seem to be meant to prevent misunderstanding or disambiguate a comment but to offer detailed description of the backdrop of the movie. The first two occurrences of it's like in the example have been coded as cases of subjective stance like because the pronoun does have an anaphoric referent (i.e. the movie). The co-occurrence of the second token with the hesitation marker um, further suggests that is serves to indicate propositional or lexical approximation. The second highlighted like has been coded as a clarifying discourse link like as it specifies the exact nature of the bombing that took place.

Differentiating between discourse link it's like and interpersonal like in an it's like construction proved to be fairly difficult at times. In cases such as the highlighted token in Example 86, like appears to serve discourse linking functions in that it 
introduces an elaboration in the form of a comment on a situation. In the example, Guy recounts how a friend of his left to go overseas.

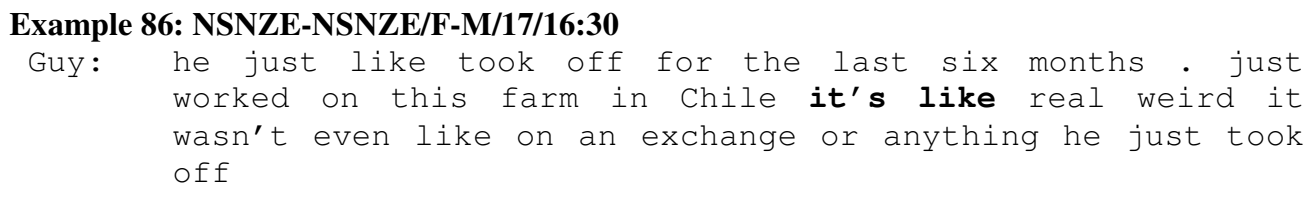

One interpretation of the example could consider the form it's like to introduce a new but related segment. In this case the token could be taken as an elaboration on the topic in the form of conveying the speaker's comment about his friend's spontaneous decision to go to Chile, saying that it was real weird. Cases like these could be taken to function similarly to the use of quotative like to introduce comments (see 6.1.4.3), with the only difference being that Guy does not use a different tone of voice for his remark and therefore does not present it as an exclamation. However, the status of it's like in this example is not entirely clear since the pronoun appears to have a vague anaphoric referent, namely the friend's action. Moreover, the form it's like does not seem to be completely outside of "the propositional clausal structure" (Andersen 2001: 257) as the pronoun plus verb construction it's cannot be left out without rendering the sentence ungrammatical or unacceptable. This would suggest that it is an instance of hedge like in an it's like structure. Based on these structural constraints, such instances were classified as hedge like, even though the main function and the intonation pattern of the form seems to indicate that it is an instance of discourse link it's like.

The use of like as a discourse link can also be interpreted as serving interpersonal functions. Like as a discourse link has been defined as often introducing clarifications in that a speaker can use it "to enlarge their own explanations or check the information they have been given by another speaker" (Miller and Weinert 1995: 366). Thus, it can be regarded as serving the Maxim of Manner: by providing or requesting clarification of a statement the speaker seeks to be clear and avoid misunderstandings. Moreover, like as a discourse link also seems to carry some characteristics of interpersonal like. Underhill (1988: 244) points out that modifying questions with clause initial like, the syntactic position often associated with like as a discourse link, "the speaker is also distancing himself in 
case the proposition fails, and from the implied requests". In other words, like can be interpreted as introducing a modification of a speech act by clarifying the speaker's main point or intention, as shown in Example 87. This type of use can be classified as a negative politeness redress strategy that aims to minimise the illocutionary force of a face or sociality rights threatening speech act for both interlocutors.

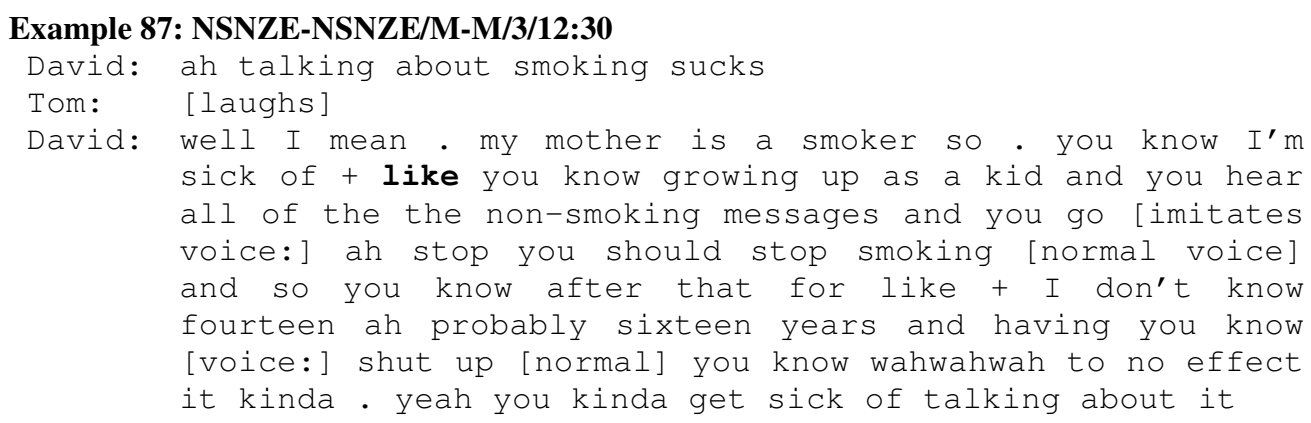

David makes two rather dismissive comments about the topic suggestion relating to smoking, saying that talking about smoking sucks and that he is sick of the topic. He then offers a long explanation for why he has this attitude, saying that he had to deal with this topic all of his life when unsuccessfully trying to convince his mother to quit smoking. This modification segment, which is introduced by a discourse link like, seems to soften the illocutionary force of his initial negative statement as the explanation helps to put his reaction into perspective. This impression is supported by the fact that the justification also contains a large number of pragmatic devices such as you know and kind of which seem to function as an appeal to the interlocutor's understanding.

\subsubsection{Quotative like}

The category of quotative like consists of all instances where the marker seems to introduce reported speech of either actual conversations or internal monologues. When like is used in this function it occurs either on its own or in the collocation be like. The direct speech segment is also often highlighted by the use of a different tone of voice. An example for quotative like is given in Example 88.

\section{Example 88: NSNZE-NSNZE/F-M/34/11:00}

Lana: and em I didn't feel a thing. at first the doctor came out and was just like oh you're done I was like oh okay. 
Lana gives an account of how she got her wisdom teeth removed. She states that she was not in pain and re-enacts how her doctor even had to tell her that he is finished to highlight that she really did not feel anything. Lana uses a combination of the appropriate personal pronoun or proper noun plus a be like collocation and a change of the tone of her voice to mark certain segments as direct speech. Since I was not there when Lana had her wisdom teeth removed it is impossible for me to tell whether this rendering of her conversation with her doctor is accurate or just a representation of what happened and the same is true for Lana's interlocutor. The fact that this ambiguity does not get addressed in the subsequent conversation suggests that in this context this issue is relatively unimportant. It is possible that the doctor really told her that the operation was over. However, bearing in mind that Lana just had major dental surgery and that her mouth was probably still under the influence of anaesthetic when the conversation took place, it can be assumed that she was not able to actually speak. In this sense it is possible that Lana's comment oh okay is a representation of her inner thoughts that is supposed to signify her surprise.

The direct speech introduced by quotative like is not always attributed to a specific person, but can be preceded by a version of the neutral form it's like, as shown in Example 89. David was thinking about visiting a friend in China. In the excerpt he recounts a conversation he had with a friend about China to show how different from New Zealand things seem to be over there.

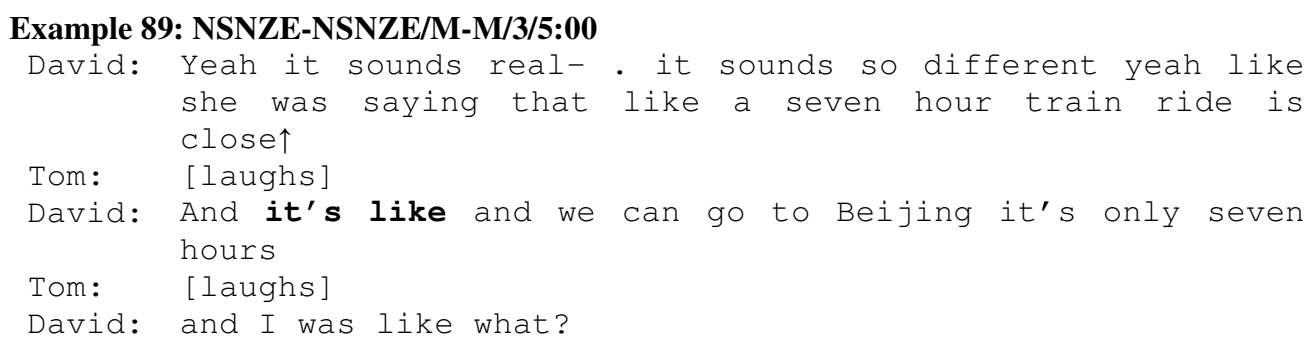

One interpretation of the highlighted it's like construction in David's second turn could be that the quotation is implicitly attributed to David's friend, the she referred to in his first turn. However, it is also possible that the direct speech is not meant to be taken as a representation of a real conversation. Instead, in this case the use of direct speech might be a stylistic choice that serves to engage the 
interlocutor and helps to illustrate or clarify David's point that the geographical dimensions in China are very different from New Zealand. Neither the interlocutor nor the researcher know whether this reported speech is a rendering of an actual conversation or merely an illustration of a point. This is why it is difficult to tell if the choice of the type of pronoun, i.e. gendered personal pronoun or neutral $i t$, gives any indication of accuracy of the quote.

Direct speech as a stylistic choice can be used for a number of conversational purposes, some of which seem to be closely related to the functions of discourse links. This suggests a relatively high degree of functional overlap between the two categories. In Example 90, for instance, the direct speech introduced by it's like is an enactment of a reaction to a situation and functions as a descriptive clarification or illustration of the statement this is where the science student is different.

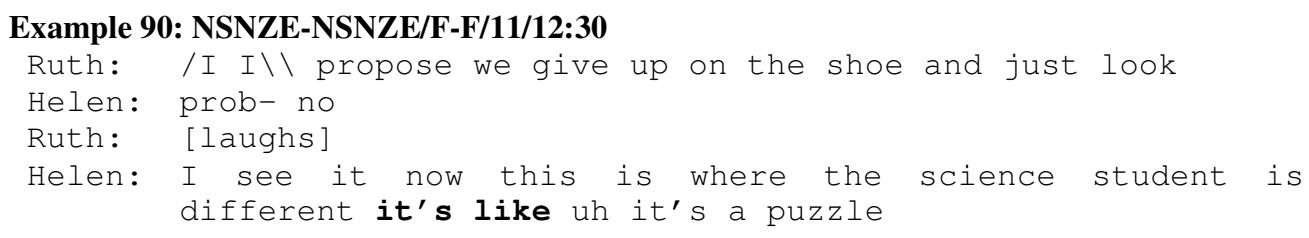

The main difference between this type of quotative use and the functions of discourse link like is that Helen uses a different voice for the direct speech part, which sets the segment apart from the rest of the utterance. In both this case and the previous example, like does not function as a discourse marker as it does not constitute a separate tone group. Instead, it must be analysed as a part of the it's like construction where the pronoun does not have a clear referent. The it's like construction is often used to indicate an elaboration or continuation of the previous topic.

The last quotative sub-type is like functioning to introduce a comment or the expression of an opinion. This variety, which is also related to the clarification function of like as a discourse link, is illustrated in Example 91. 
Example 91: NSNZE-NSNZE/M-M/58/16:30

Zach: but but. just going onto the field and in front of like thirty thousand. rugby fans . and stopping their game it's like. fuck man

Zach is talking about the protests surrounding the Springbok tour protest movement of 1981. He seems to want to express his respect for the protestors who tried to stop the rugby games by marching unto the pitch with the emphatic and stretched fuck man. In this context the direct speech is an enactment of a reaction which seems to be used to make an evaluative comment and thereby to clarify the speaker's stance towards the previously described situation.

The quotation segment introduced by like or one of its variant collocations does not necessarily have to be spoken but can also be made non-verbally by using facial expressions or gestures. This use is illustrated in Example 92 where Xander recounts his reaction when his flatmate shaved his beard off.

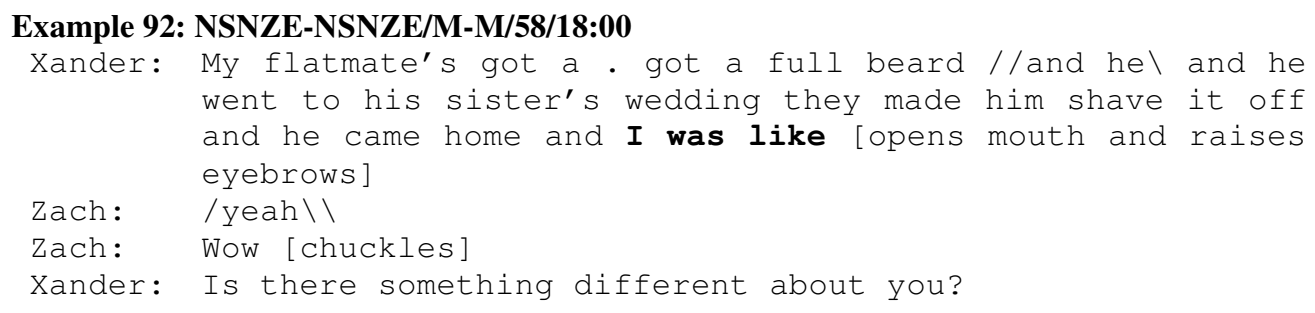

The re-enactment of his expression of surprise is represented by opening his mouth wide and raising his eyebrows. That the facial expression is an important part of the story becomes clear when Xander interrupts the activity he is currently engaged in (pouring juice for Zach and himself) and establishes eye contact with Zach. The very pronounced facial expression is introduced by the quotative marker I was like and seems to function as an integral part of the story.

Generally speaking, cases where the forms like or it's like are used to introduce clarifications or comments have been classified as quotatives when the speaker assumes a distinctly different tone of voice for the introduced segment, thereby clearly indicating that it is supposed to be interpreted as direct speech. Instances where the segment preceded by like or it's like is not differentiated by the use of a different voice are categorised as a discourse link or hedge like accordingly. This 
decision is not always easy to make. Judging from the transcription alone cases such as Example 93 could be interpreted as an instance of quotative use.

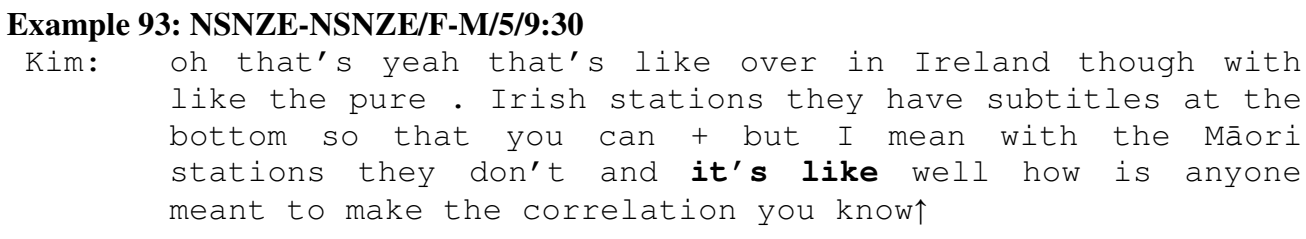

It is only upon repeated listening that the token was classified as a discourse link introducing a clarifying elaboration in the form of the speaker's stance towards the topic.

In a few cases, like occurred together with other verbs of quotation such as to say, to tell or to go as shown in Example 94. These cases were not included in the quotative like category.

\section{Example 94: NSNZE-NSNZE/M-M/3/24:00}

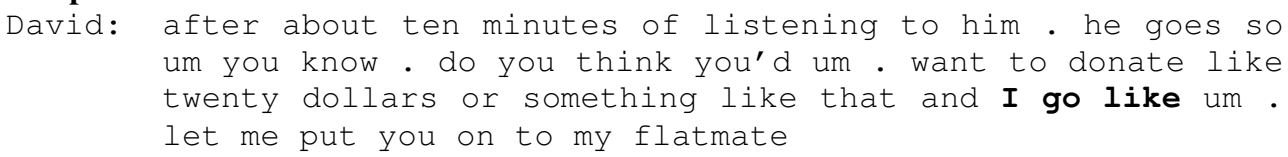

Even though like occurs immediately before the direct speech element it does not seem to introduce the quotation. Instead, the form of to go appears to function as the main quotative marker. Andersen (1999: 249) points out that in these cases like is "a non-obligatory pragmatic marker" and as such can be left out without rendering the sentence ungrammatical or changing the status of the quotative to a zero-quotative form. In these cases like seems to serve to create focus on the quote by marking its start and to indicate that the quote may not be an exact reproduction of what has been said, which is why instances of like in conjunction with verbs of quotation have been grouped in the subjective stance like category.

\subsubsection{Hesitation Marker}

Hesitation markers are instances of like that occur in false starts, self-repairs, repetitions, or before pauses. In its capacity as a marker of hesitation, like seems to serve as a floor-holding device in that it indicates to the interlocutor that more is to follow but that the speaker has some difficulty finding the right words 
(Andersen 2001: 256). Example 76 above illustrates this function of like as a mainly floor-holding device. The highlighted instance of like is used to bridge a rather long pause, suggesting that the speaker is busy finding the right words. Example 95 is similar; where Zach talks about some events surrounding the Springbok tour protests.

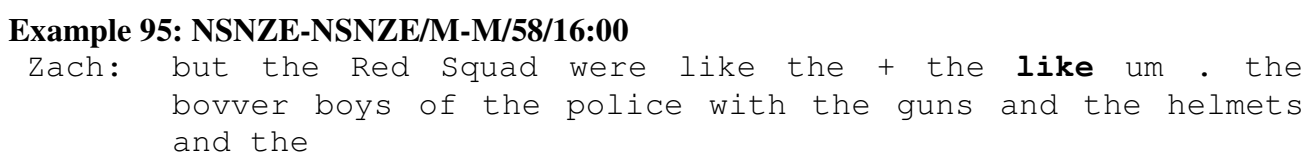

Zach seems to struggle with finding the right words for describing the Red Squad, a unit of the New Zealand police force that was famous for its forthright use of violence to break up protests. This example also highlights the issue of functional overlap with other categories since an alternative interpretation of the token could be that it functions as hedge, marking lexical approximation or metalinguistic focus. The difference between this example and other instances of hedge like are the numerous pauses and the hesitation marker um.

A case of the use of hesitation like in repetitions is given in Example 96.

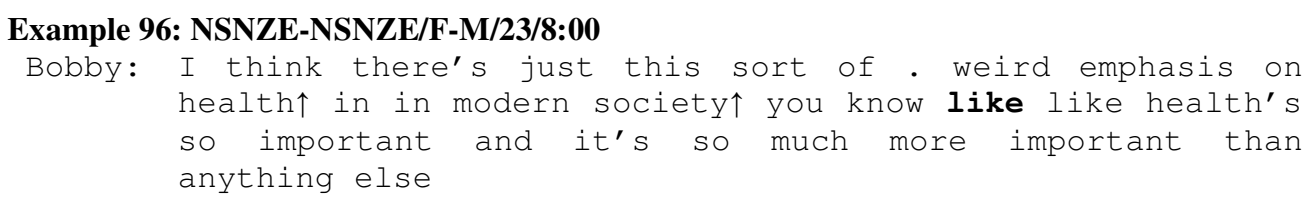

One interpretation of the example could be that the repetitions of in and like, together with the occurrences of pragmatic devices such as I think, sort of, you know and the HRTs in the first part of the utterance, indicate that Bobby has some problems finding an appropriate way of expressing his ideas and organising his turn. In this sense the pragmatic devices could be used to buy some time to plan the next part of the utterance. The highlighted like could be taken as a signal to the listener that he is nearly ready to state the proposition and helps to delay the beginning of the turn a little bit longer. Alternatively, the repetition of the discourse link might add emphasis to the following proposition, indicating that what is to follow is a particularly salient point. Either way, for the purpose of this study, when like or a like construction is repeated the first realisation of the 
marker is counted as a hesitation marker while the second realisation is classified according to its most prominent discourse function in the utterance.

Example 97 shows the use of like in false starts.

Example 97: NSNZE-NSNZE/F-F/41/24:30

Nora: yeah but people like that don't make me proud to be a white eh they don't it's all like so now I kind of go through this whole like culture shame of and that's probably where this stigma of living in Newlands comes from

In this case, Nora starts a proposition with it's all like but does not finish her thought. Instead, she cuts off her original utterance and starts with a new syntactic structure.

\subsubsection{The Classification Process}

The following examination of the use of like by NSNZE and GNNSE includes all occurrences of the word form that did not appear to serve non-discourse functions. All instances where the speaker's turn was cut off after the like either by the speaker or the interlocutor were also excluded from the analysis as it was impossible to determine the meaning of the device in this context. This use is illustrated in Example 98 where Zach sums up an event related to the Springbok riots.

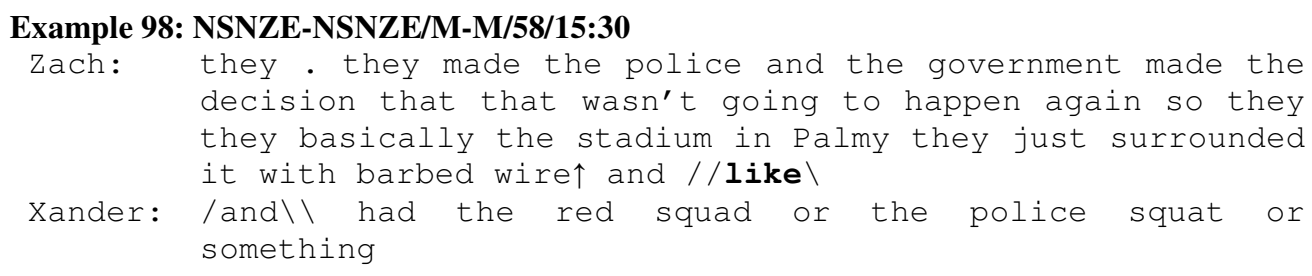

The remaining tokens of discourse like were grouped according to the categories defined above. For the purpose of this study it was decided to code all instances of discourse like using broad categories. After the categories were simplified, a number of tokens had to be relabelled and only a few more were changed upon listening to the recordings of the examples. Overall, it can be said that the decision to use broadly defined categories has made the classification process much easier and at the same time it yielded useful results that can be used for a comparison 
with other datasets. Nevertheless, despite the advantages of this simplified classification system, a few cases remained difficult to code. This encompasses a relatively large degree of functional overlap between the different categories which results in ambiguous examples that could feasibly be assigned to several categories (see sections 6.1.4.1. to 6.1.4.4. for a discussion of common classification problems).

The differentiation of the various sub-categories turned out to be equally difficult. While in some cases it is relatively straightforward to discriminate between different potential subcategories, e.g. numerical approximation and hyperbolic use, in other cases it is nearly impossible to decide which one of the many possible meanings is the dominant function (see Example 81 or Example 87). Distinguishing between cases of elaboration and clarification can be a rather subjective matter and it is difficult to code tokens consistently. But even the identification of supposedly more clear-cut cases such as numerical approximation can be problematic. The difficulty of differentiating between lexical and propositional approximation has been discussed in relation to GEs in Example 27. Due to this functional overlap between the different meanings and the difficulty of identifying one dominant function I decided to refrain from providing a quantitative analysis of the different subcategories. The quantitative comparison between the different speaker groups will therefore be restricted to the four main categories.

\subsection{NSNZE like}

Overall, the 58,509 word NSNZE corpus contained 1,307 tokens of like. Of these 1,307 instances of like, 239 were identified as instances of non-discourse like. The data also included 16 instances of cut-off like, which were excluded from the analysis. The remaining instances of discourse like have been categorised using the proposed categories. Table 9 summarises the functional distribution. Apart from the few cases where interpersonal like occurred clause finally in questions, like occurred exclusively clause initially or medially. No instances of the type of final like characteristic of Scottish English (Miller and Weinert 1995) were identified in the data. 
Table 9: Functional distribution of like in the NSNZE corpus

\begin{tabular}{llll}
\hline Function & N & \% & \% of total corpus \\
\hline Discourse Link & 395 & 37.6 & 0.67 \\
Subjective Stance like & 382 & 36.3 & 0.65 \\
Quotative & 179 & 17.0 & 0.31 \\
Hesitation & 96 & 9.1 & 0.16 \\
Total & 1,052 & 100 & 1.79 \\
\hline
\end{tabular}

Even though their quantitative analysis of the varying functions is based on different categories, the overall figures presented in Andersen's (2001) investigation of like in COLT and Müller's (2005) study of the use of like in the GLBCC provide a good comparison for the present data. When comparing the overall occurrence of discourse and non-discourse like in COLT and my NSNZE data some interesting differences can be noted.

Table 10: Discourse like vs non-discourse like ratio across corpora

\begin{tabular}{|c|c|c|}
\hline COLT & GLBCC & NSNZE \\
\hline Approx. 500,000 words & 53,028 words & 58,869 words \\
\hline $\begin{array}{l}3,484 \text { tokens of like overall } \\
\text { (ca. } 0.7 \% \text { of COLT) }\end{array}$ & $\begin{array}{ll}\text { ca. } 1.76 \% \text { of } & \text { GLBCC } \\
& \text { (excluding } \\
\text { like) } & \text { verb }\end{array}$ & $\begin{array}{r}1,307 \text { tokens of like overall (ca. } \\
2.2 \% \text { of NSNZE corpus) }\end{array}$ \\
\hline $\begin{array}{r}1,347 \text { tokens of discourse like } \\
(38.7 \% \text { of all tokens } \\
\text { or } 0.27 \% \text { of COLT) }\end{array}$ & ca. $1.47 \%$ of GLBCC & $\begin{array}{c}1,052 \text { tokens of discourse like } \\
\text { (ca. } 80 \% \text { of all tokens or } \\
1.78 \% \text { of NSNZE) }\end{array}$ \\
\hline
\end{tabular}

As illustrated in Table 10, the ratio between the absolute number of tokens and instances of discourse like in Andersen's (2001) study is remarkably lower than in the present research. While Andersen considered only $38.7 \%$ of the overall number of tokens for inclusion in his study, the proportion included in the present analysis of discourse like is closer to 80\%. Even Andersen's (1997) suggestion that this relative amount might be so low because of his strict exclusion of any token that might not be a discourse like and that the real ratio between discourse and non-discourse like lies around about 50\% does not seem to explain the NSNZE results. 
With regard to Müller's (2005) investigation of American English, it must be pointed out that, even though she discusses the use of like as prepositions and conjunctions and like in GEs, she does not mention the ratio between all instances of non-discourse like and discourse like. Moreover, she does not present her results in numbers or percentages but in the form of a graph illustrating the frequency of occurrence per 100 words, which makes it difficult to get an exact reading of the numbers. A rough estimate of her data suggests that the GLBCC includes ca. $1.76 \%$ of like-occurrences and the instances of discourse like make up approximately $1.47 \%$ of the corpus. This figure is similar to, albeit slightly lower than, the results of the present study where the NSNZE corpus was found to contain $1.78 \%$ tokens of discourse like. In comparison, the number of tokens Andersen classified as discourse like add up to only about $0.27 \%$ of the corpus.

It is possible that this difference between the studies is related to the fact that Müller's and my studies are based on more recent data. This would suggest that the use of like is spreading. Other interpretations of the data could be that it is dialectal variation, or related to the topic of conversation, the social classes of the speakers involved or the experimental set-up of two of the corpora. However, it is also possible that the different proportions are related to the nature of the corpora being used. While COLT is based on interactions between familiars, both Müller's GLBCC and my NSNZE corpus mostly contain interactions between strangers (the GLBCC also includes interactions between familiars). As with the results for GEs, the differences in the frequency of occurrence of discourse like in Andersen's data on the one hand and Müller's and the present study on the other, could be related to Wolfson's Bulge Theory (1988). It is possible that, when talking to familiars, speakers do not feel as much need to hedge or emphasise their statements and give explanations or exemplifications for their points as they do when talking to semi-intimates or acquaintances.

The varying proportions of the different discourse like categories in the three studies (see table 11) could also be taken to reflect the degree of artificiality of the interactions. In terms of the amount of structure artificially imposed on the conversations, COLT represents naturally occurring, spontaneous talk. Müller's and the present study, on the other hand, are based on data collected from a rather 
unnatural setting. This potentially uncomfortable or even face threatening situation might have promoted the use of face-saving strategies such as the use of vague language and thereby fostered the production of discourse like. The slightly lower frequency of discourse like in Müller's data could be the result of the communicative task participants were asked to perform. In Müller's study participants watched an excerpt from a movie, which they were then asked to retell, discuss and give their opinions on. This content oriented task might have slightly diminished the face threat of conversing with a near stranger in that it gave the conversation a purpose. In the NSNZE corpus, where the only task was to talk, the absence of an assignment might have increased the degree of potential face threat embedded in the interaction. This might have increased the need to engage in more face-saving and rapport building discursive strategies.

Table 11: Comparison of functional distribution of like between Andersen (2001), Müller (2005) and the present study

\begin{tabular}{|c|c|c|c|c|c|}
\hline Andersen (2001) & $\%$ & Müller (2005) & $\%$ & The present study & $\%$ \\
\hline Approximation & 20.6 & Approximation & 3.55 & \multirow{3}{*}{$\begin{array}{l}\text { Subjective Stance } \\
\text { like }\end{array}$} & \multirow{3}{*}{36.3} \\
\hline Metalinguistic Focus & 18.5 & Lexical Focus & 36.3 & & \\
\hline \multirow{2}{*}{ Exemplification } & \multirow{2}{*}{18.9} & \multirow{2}{*}{$\begin{array}{l}\text { Introducing an } \\
\text { example }\end{array}$} & \multirow{2}{*}{6.3} & & \\
\hline & & & & \multirow{3}{*}{ Discourse Link like } & \multirow{3}{*}{37.6} \\
\hline \multirow{3}{*}{ Discourse Link } & \multirow[t]{2}{*}{24.9} & $\begin{array}{l}\text { Introducing an } \\
\text { explanation }\end{array}$ & 11.2 & & \\
\hline & & Various & 355 & & \\
\hline & \multirow[b]{2}{*}{10.1} & Functions & & \multirow[b]{2}{*}{ Hesitation marker } & \multirow[b]{2}{*}{9.1} \\
\hline Hesitational Link & & $\begin{array}{l}\text { Searching for the } \\
\text { appropriate } \\
\text { expression }\end{array}$ & 7 & & \\
\hline Quotative & 7 & Quotative & 32.1 & Quotative & 17 \\
\hline
\end{tabular}


The impact of the communicative task can also be seen in the different functional distributions in Müller's and my NSNZE data. A comparison of the functional distribution is a complicated task due to the different categories that are applied to the data. However, some categories seem to have fairly similar definitions and therefore can be thought of as compatible. The approximate correspondences and overlaps between the categories in the three studies have been illustrated in Table 11. Andersen's metalinguistic focus and approximation and Müller's lexical focus and approximate number categories, for example, can be considered to be relatively equivalent to my subjective stance like class. The most problematic category to compare with my system is that of exemplification since Andersen and Müller use it as a distinct category whereas I differentiate between exemplifications that serve as interpersonal devices and discourse links. In order to facilitate the comparison I decided to assume that Müller's (and Andersen's) categories of exemplification contain even amounts of subjective stance and discourse link like, so that the overall percentage has been split in half. With $36.3 \%$ of lexical focus and $3.55 \%$ of numerical approximation alone, subjective stance like is the most frequently occurring function in Müller's study, even without the addition of half of the exemplification category. The second most frequently used category is quotative like $32.1 \%$. The category that seems most closely related to my discourse link function is that of like introducing explanations, which makes up $11.2 \%$ of the corpus. Even in the ideal case where all instances included in the categories exemplifications and various functions (which consists of what Müller refers to as discourse links and tokens that precede restarts) are counted as instances of discourse links like, this category would add up to merely $21 \%$. This result differs noticeably from the distribution in the NSNZE corpus: first of all, the most frequently used category in the NSNZE data is discourse link like. Moreover, the proportional difference between discourse link and interpersonal like is much more pronounced in Müller's study.

Another noticeable difference between the two studies is the higher frequency of quotative like in Müller's corpus. This could be a result of the narrative task of retelling a scene from a movie, which might have promoted the use of a more engaging discourse tool such as quotatives. The high occurrence of lexical focus like in Müller's study could be a result of speakers trying to voice their degree of 
certainty towards the accuracy of their summary of the movie segment. At the same time, they might have tried to avoid sounding too assertive in order to facilitate interpersonal rapport. In the NSNZE data, on the other hand, speakers might not have been primarily concerned with the accuracy of the propositional content of their messages. Instead, it seems that they were equally focused on explaining and elaborating on their thoughts and ideas, possibly to ensure their interlocutor understands what they mean. This might explain the relatively equal amounts of discourse link and interpersonal like in the NSNZE corpus.

These results are similar to the GE data in that my corpus seems to contain proportionally more pragmatic devices than others. Again, one possible explanation for this discrepancy could be the relationship between participants in the different studies. As noted for the high occurrence of GEs in section 5.2.1, talking to a stranger might have been perceived as uncomfortable, imposing on their sociality rights or even face threatening by the interactants, which could have led to an increased use of vague language. The frequent use of discourse like could also be analysed as a positive politeness strategy and in this sense could be indicative of a greater need of the speakers to establish solidarity.

\subsection{German like-devices}

\subsubsection{Like-like Devices in Other Languages}

The use of devices for similar purposes to English like has been observed in other languages. It has been suggested that Swedish $b a$ 'just' can serve both focussing and quotative functions (Eriksson 1995). Some languages also seem to use words with similar meanings to like for similar functions. Another example for languages that seem to have a relatively close one-to-one form-functional equivalent to English like is Norwegian. A detailed cross-linguistic comparison of English like and Norwegian liksom is provided by Hasund (2003). She (2003: 1-2) claims that the two forms are corresponding words since they seem to be etymologically related. They can also both be used as a preposition or conjunction marking similarity and comparison, they have similar discourse marker functions and they assume corresponding syntactic positions in each language. Hasund (2003) uses the syntactic positions of like in order to compare data of spoken 
British English and spoken Norwegian from two corpora (COLT and UNO/Oslo, a corpus from the research project 'Språkkontakt och Ungdomsspråk i Norden'). She found that, despite a number of distributional differences, both markers serve very similar functions expressing comparison and similarity on a textual, subjective and interpersonal level (Hasund 2003: 2).

\subsubsection{Like equivalents in German: so and also}

In order to determine the degree of L1 interference in the use of like by GNNSE, the existence of a German like-equivalent as well as the degree of its functional overlap with English like needs to be established. As the previous section

suggests, some languages such as Swedish and Norwegian seem to have words that work as a nearly one-to-one form-functional equivalent to English like, i.e. a word that means something similar to like and is used for comparable purposes. In the case of German, however, things do not seem to be quite as straightforward. German, like English, has a range of words that can express either one or several like functions. It has been suggested, though, that so is a particularly close functional equivalent form (e.g. Lovik 1990; Golato 2000). Thus, German so can be used to cover the functions of a hedge (Lütten 1977; Lovik 1990), intensifier or focus marker (Ehlich 1987) and it is part of the German non-standard quotative form und ich so (Golato 2000).

The hedge function of German so and English like belongs to their colloquial uses in the respective languages. However, the two forms differ in their intensifier function: for like this use is generally considered to be non-standard whereas for German so it belongs to the word's adverbial non-discourse meanings (Duden 2002: 825). In addition to these functions, Ehlich (1987: 285) proposes that so can also serve as a focus marker, drawing the interlocutor's attention to non-verbal segments of the utterance. The use of so as a focus marker is also noted by Golato (2000: 50) who states that it "introduces words, phrases, or even clauses and marks them as new and noteworthy information". Moreover, so carries comparable non-discourse meanings to English like since it can be used in the sense of 'in this manner' to mark similarity and comparison (Duden 2002: 825; Golato 2000: 45), e.g. du bist gerad mal so alt wie ich 'you are just as old as I am'. Thus, in terms of its functional variability, so seems to be a close, if not the 
closest, equivalent to English like (Lovik 1990: 126). As Golato (2000: 49) notes, "although English like and German so are not etymologically related, both seem to perform similar interactional functions and for both a similar path of grammaticalization can be suggested".

Even though German so appears to be a good equivalent of subjective stance and quotative like, it does not seem to cover all discourse linking functions. According to Duden (2002: 825) additional functions of German so are its use as a particle and its meaning similar to like that when it indicates that a process took place without something usually associated with it happening, e.g. I didn't have a ticket but they let me in like that. As a particle, so is described as adding emphasis to an order or a request, encouraging the interlocutor to confirm a statement and indicating the end of a discourse topic. None of these functions are congruent with the functions of English discourse link like. Instead, based on my native speaker intuition, it seems that German also could be considered as a potential equivalent to English discourse link like. According to Duden (2002: 78) also can be used as an adverb to indicate that the following proposition is a conclusion of the preceding dialogue in the sense of 'consequently'. As a particle, also serves to mark that the following utterance is connected to some aspect of the preceding conversation and it can function to signal that the speaker wishes to close a topic. Lütten (1977: 371) points out that also can be used to introduce clarifications, explanations and elaborations. Incidentally, however, also is etymologically related to so (Duden 2001: 30), which might further strengthen the notion that also could be a close German equivalent to discourse link like.

Even though German so and also seem to be close equivalents to English like, it still remains to be seen whether they are the two words most closely associated with like by GNNSE. As mentioned above, there are a number of alternative German items able to express some like functions and which therefore might be the closest equivalent for a particular function. Moreover, the functions of German so and also might have a greater impact on the uses of English so and also by GNNSE, rather than on like. Müller (2005: 91) noted that German speakers use English so for marking result or consequence, summarising and sequential so far less frequently than native speakers, possibly because these 
functions are not necessarily associated with German so. Due to this lack of a clear one-to-one equivalent I will not provide a detailed comparison of the functions of English like and German so and also as this does not seem necessary or even useful. For the purpose of this study it suffices to say that German is able to express similar meanings to English like so that GNNSE should be familiar with the different functions. Future research would be needed the establish the uses of English so and also by GNNSE as it might provide valuable information on whether GNNSE transfer their pragmatic knowledge of these forms in German to English, using them in contexts where English like might be more appropriate.

\subsection{Implications for L2 learners}

With regard to L1 interference, the absence of a single one-to-one formal and functional German equivalent to English like is likely to have an effect on the use of like by GNNSE. Since German has a number of alternative words that cover certain like functions, it seems possible that the functional properties of other potential equivalents might have a substantial influence on the uses of like by GNNSE. Thus, it seems possible that GNNSE prefer using words other than like, potentially resulting in an overall lower frequency use. This could be especially true for the use of quotative like by GNNSE. A preliminary analysis of the use of quotatives by GNNSE suggested that this discursive strategy is generally used less in German than in English (Terraschke 2006b). If this communicative habit was transferred into English, it could have the effect that quotative like is used substantially less frequently by GNNSE than by NSNZE.

Another issue that could have an effect on non-native uses of like is that of the form being associated with a different function. One of the main non-discourse marker meanings of like can be glossed with 'similar to'. This could suggest that like is more closely associated with expressing approximation or epistemic modality than with preceding clarifications or quotations. This could lead to differences in the functional distribution between NSNZE and GNNSE, with GNNSE using like more often as a subjective stance marker rather than a discourse link. Finally, since quotative like is the most recent functional development of like and as such can be considered as non-standard, and bearing in mind that NSG do not seem to use the German non-standard quotative form und 
ich so very often, it could also be expected that GNNSE use like less often in this function than their native interactants.

\subsection{The use of like by GNNSE}

\subsubsection{Quantitative analysis of the use of like by GNNSE and NSNZE in cross-cultural interactions}

The GNNSE corpus, which consists of 52,866 words, contains 865 tokens of like, 167 of which were cases of non-discourse like where the item is used as a verb, conjunction or a preposition. Of the 698 remaining instances of like, 29 occur at the end of a cut-off utterance and were therefore excluded from the analysis. The final set of 672 cases of like has been classified according to the same categories detailed for the NSNZE data. The results of the functional distribution in the GNNSE corpus are summarised in Table 12.

Table 12: Functional distribution of like in GNNSE corpus compared with NSNZE data

\begin{tabular}{llllll}
\hline Function & $\mathbf{N}$ & $\mathbf{\%}$ & \% in corpus & NZE \% & \% in NZE corpus \\
\hline Discourse Link & 268 & 40.1 & 0.51 & $(37.6)$ & $(0.67)$ \\
Subjective stance like & 245 & 36.6 & 0.46 & $(36.3)$ & $(0.65)$ \\
Quotative & 74 & 11.1 & 0.14 & $(17)$ & $(0.31)$ \\
Hesitation & 82 & 12.2 & 0.15 & $(9.1)$ & $(0.16)$ \\
Total & 669 & 100 & 1.26 & $(100)$ & $(1.79)$ \\
\hline
\end{tabular}

All instances of like in the GNNSE data were clear cases of either clause initial or medial like. The results confirm the prediction that GNNSE would use like less often than NSNZE: GNNSE used consistently fewer tokens of like in all categories. The functional distribution is fairly similar for the two data sets. Discourse link like is used the most followed by subjective stance like. However, the two datasets appear to differ in the distribution between quotative and hesitation like. While NSNZE speakers use quotative like substantially more often than hesitation marker like, it is the other way around for GNNSE. Moreover, the difference between the two categories is not as pronounced as in the native speaker data. The two groups also differ slightly in the proportional distribution 
across the categories. That GNNSE use like more often as a hesitation marker than NSNZE may not be a great surprise since it is relatively likely that non-native speakers have more problems with lexical retrieval and ad hoc construction of coherent utterances. Moreover, as expected, GNNSE use like as a quotative marker less often than NSNZE. When we look at the distribution of the numbers of tokens in each category in the entire corpus, though, the distribution appears to be proportionally relatively similar in the two groups. In both cases, discourse link like is used $0.06 \%$ more often than subjective stance like, which in turn is used $0.32 \%$ more often than quotative like.

The results of Müller's (2005) study are similar to the present investigation in that non-native speakers use discourse like less often than native speakers. However, with an overall frequency of $0.24 \%$, the Germans in Müller's study use noticeably fewer tokens of discourse like than the GNNSE in my study. Moreover, Müller's results seem to differ in the functional distribution of like in the language of GNNSE. In order to be able to compare Müller's data with mine, I combined her subcategories according to my categorisation system and the category of exemplification was split up equally between discourse link and subjective stance like. The result shows that the most frequently used like function in Müller's study is subjective stance like and not discourse link like as in my data. Another difference between the two studies is the comparatively high frequency of quotative like in Müller's data. It is very likely that these different results are related to the different social contexts in which the talk was recorded in both studies. Müller's corpus consists of task-based and therefore mainly content oriented communication, which might explain the overall lower frequency of discourse like and the relatively higher use of hedge like in the data. The narrative element of the task could have yielded the comparatively high use of quotative like.

In a trend similar to the results for GEs, NSNZE used like less often in crosscultural interactions. The corpus of NSNZE in cross-cultural conversations contains 52,168 words which include 1,001 tokens of like. Of these, 245 were identified as cases of non-discourse like and 26 tokens were excluded from the 
analysis because they occurred at the end of a cut-off utterance. The results of the functional distribution of the remaining tokens is summarised in

Table 13.

Table 13: Functional distribution of like in the cross-cultural NSNZE corpus, compared with NSNZE results

\begin{tabular}{llllll}
\hline Function & $\mathbf{n}$ & $\%$ & Overall \% & NZE \% & Overall NZE \% \\
\hline Discourse Link & 311 & 42.6 & 0.60 & $(37.6)$ & $(0.67)$ \\
Subjective stance like & 241 & 33 & 0.46 & $(36.3)$ & $(0.65)$ \\
Quotative & 114 & 15.6 & 0.22 & $(17)$ & $(0.31)$ \\
Hesitation & 64 & 8.8 & 0.12 & $(9.1)$ & $(0.16)$ \\
Total & 730 & 100 & 1.40 & $(100)$ & $(1.79)$ \\
\hline
\end{tabular}

The results of the functional distribution suggest that there is an overall decline in the use of the marker when NSNZE talk to non-native speakers. A paired t-test comparing the use of like by NSNZE in native-native and cross-cultural interactions shows that this decline is statistically significant ( $\mathrm{p}$-value $=.02<.05)$. However, the difference between NSNZE and GNNSE in cross-cultural interactions is not $(\mathrm{p}$-value $=.11>.05)$. This could be indicative of NSNZE accommodating to their non-native interactants by somewhat simplifying their language and making their language more like their interlocutor's in order to facilitate communication. Again, this tendency to accommodate could be responsible for the differences in the use of the marker by GNNSE in that it impedes the adoption of native-like use. The data also suggests that NSNZE use discourse link like proportionally more often and hedge like less often in crosscultural conversations than when talking to another native speaker. One explanation for the more frequent use of discourse link like could be that the NSNZE perceive an increased need to clarify or explain statements that their nonnative interactant might not seem to have understood in order to prevent confusion. 


\subsubsection{Functional analysis of the use of like by GNNSE}

\subsubsection{Subjective stance like}

The data suggests that GNNSE use interpersonal like in the same way and for the same functions as noted in the speech of their native speaker interactants. This might not be a surprise considering that German so covers most functions of like as a hedge and an intensifier, which might potentially allow non-native speakers to directly transfer their pragmatic L1 knowledge to English. In a number of cases GNNSE employed like as a booster that adds emphasis to a proposition or a lexical item. One illustration of this is given in Example 99, where Arne tries to explain what he likes about Wellington.

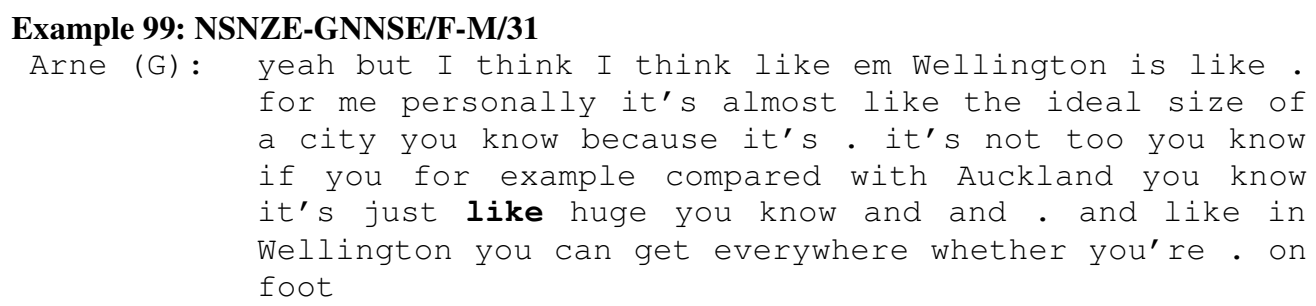

In this case the highlighted token appears to add emphasis to the lexical item huge, indicating that Arne considers Auckland to be exceptionally big. Moreover, the word huge is phonologically marked by being pronounced with a slightly lengthened vowel. This draws attention to the word and adds further stress to the proposition.

The cross-cultural data suggests that a common way for GNNSE to express numerical approximation is by using like as in Example 100. In the passage Steven and Nina are commenting on the size of New Zealand.

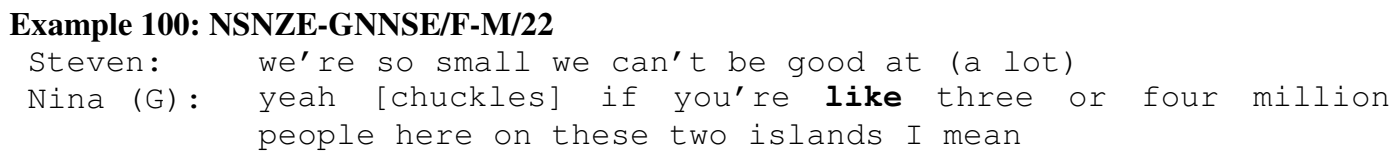

The main function of the highlighted like seems to be to indicate that Nina does not know exactly how many people are living in New Zealand and that the following figures are to be taken as approximations. The offer of an alternative amount in an $n$ or $m$ construction also serves to highlight the approximate nature of the proposed numbers (Channell 1994: 57). 
In the GNNSE corpus like was also frequently used to indicate lexical approximation. In Example 101, Veit states that young Kiwis who go overseas have greater chances to find a job once they return than those who stay in New Zealand.

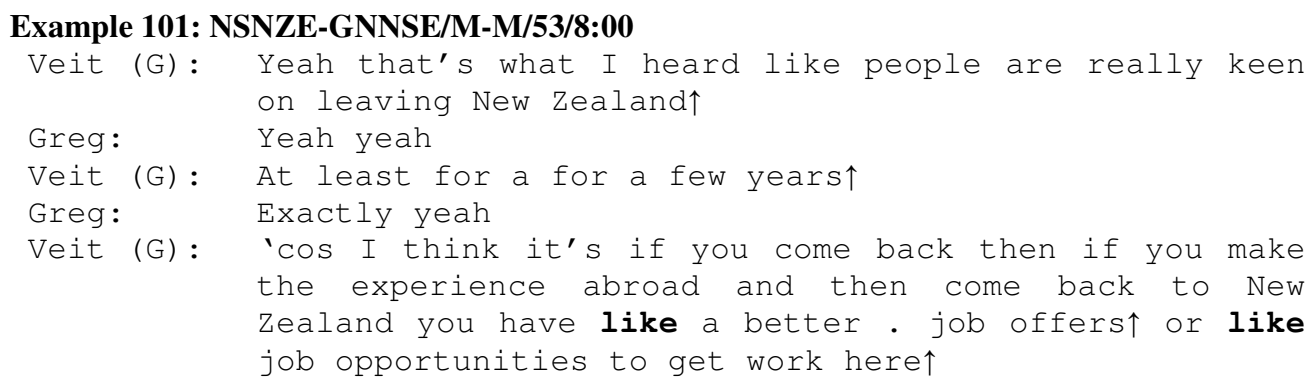

The two cases of like in Veit's turn appear to indicate that the following lexical items, job offers and job opportunities, might not be the correct or most appropriate expressions in this context. Again, the notion of epistemic modality towards the accuracy of an expression is further supported by an $n$ or $m$ construction. It is also possible that the first highlighted like serves as a hedge on the proposition as a whole, i.e. that overseas experience does increase one's chances on the job market. This interpretation could be supported by the use of a tentative I think at the beginning of the turn. Moreover, Veit's statement is based on something that he has heard from someone else, which would suggest that he cannot be too sure about the validity of the claim. However, the use of the $n$ or $m$ approximation and the occurrence of two restarts towards the beginning of Veit's last turn, which seem to indicate that Veit has some problems organising his thoughts, could be seen to shift the focus of the approximation to the lexical rather than the propositional level. The GNNSE corpus did not seem to contain any clear examples of the use of like as a propositional hedge. It is difficult to say at this stage whether this means that GNNSE, including the near-native speakers, have not adopted like as a means to express propositional approximation at all or whether the type of interactions or the topics discussed did not encourage the use of such a construction.

The use of subjective stance like in exemplifications also seems to have been adopted into the pragmatic repertoire of GNNSE. The exemplification that is 
featured in Example 102 is a randomly chosen illustration of how difficult it can be to detect a mistake in a computer programme.

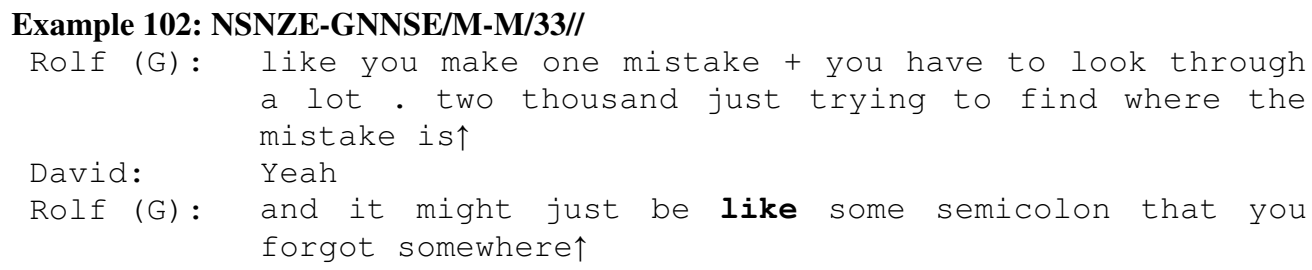

In this context it seems unlikely that the highlighted token serves as a hedge on the lexical item some semicolon or on the proposition that sometimes the mistake in a computer programme is just one semicolon. Rolf has been studying IT and he knows about programming and the possible mistakes that occur. In this case, the token seems to indicate that a missing semicolon is just one possible example of how sometimes a small and tiny symbol can be a problem in programming and that other examples could have been mentioned in this context.

The non-native speaker data also includes some instances where like appears to serve predominantly interpersonal purposes. In Example 103, Anna admits to being homesick and describes what it feels like to Helen.

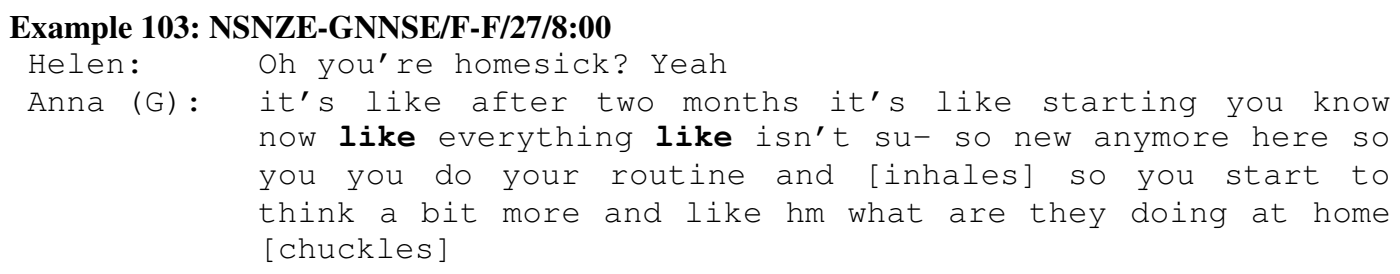

The first two non-highlighted occurrences of like in Anna's utterance seem to be instances of discourse link like that are used to introduce descriptions or clarifications while the last case of like belongs to the category of quotative like, and are functions that will be looked at in subsequent sections. However, the two highlighted cases of like appear to serve predominantly as a lexical hedge on the following statement, indicating that the expression now everything isn't so new anymore here may be not be the most elegant or precise way to express her feelings. The impression of insecurity with regard to finding the right words to convey her thoughts is further supported by the numerous occurrences of false starts and stuttering repetitions in Anna's turn. By marking her explanation as not 
necessarily accurate Anna treats Helen like someone who understands her and her situation well enough to be able to know what she means despite her use of vague language. In this sense Anna appeals to Helen's understanding and their shared background knowledge of what homesickness feels like and when you start feeling it (i.e. when the novelty factor of a new situation has worn off).

Another instance where like could be taken to serve mainly as a politeness device is given in Example 104 where like occurs in a question. Eve and Cordula are talking about working while studying and Eve mentions that she worked more or less full time the year before.

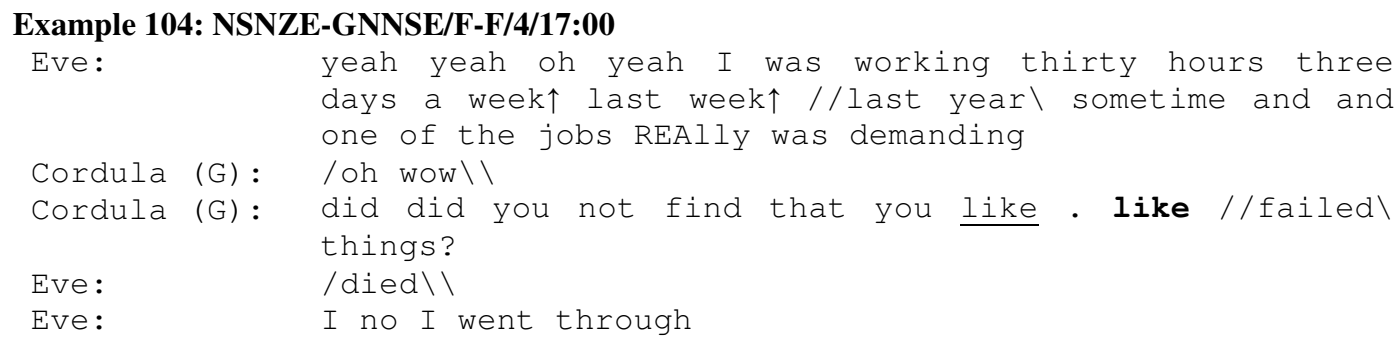

The highlighted like in Cordula's turn seems to function as a hedge on the lexical item failed, indicating that this term might not be the most appropriate in the situation. The highlighted token of like could be taken as an instance of hesitation marker like, which could suggest lexical retrieval problems. Moreover, the two repeated words did and like add further evidence to the analysis that Cordula is not sure how to phrase her question appropriately. By hedging the validity or suitability of the term Cordula automatically softens the illocutionary force of the question. After all, asking someone if she failed university courses could be taken as relatively face threatening and offensive. An alternative interpretation of the example could be that the highlighted token serves to mark the following segment as a humorous exaggeration. However, the comparatively level intonation and the lack of emphasis on the lexical item failed seems to favour the lexical approximation analysis.

The GNNSE corpus did not contain many instances of like in questions and no clear occurrence of like as a marker of hyperboles and metaphors was found. This 
could suggest that GNNSE use different strategies to soften the illocutionary force of a personal question or mark a proposition as a humorous exaggeration.

\subsubsection{Discourse Link like}

As the figures in Table 12 suggest, GNNSE, like their native speaker peers, used discourse link like more often than any other like-function. One of the more commonly used sub-categories of discourse link like employed by non-native speakers is clarification like as shown in Example 105 where Katrin talks about when children used to start learning English at school in Germany.

\section{Example 105: NSNZE-GNNSE/F-M/20/14:30}

Katrin (G): but when I was little we started learning English in fifth grade like when we're when you're ten. because we start u- um school with six.

Katrin comments that she started learning English when she was in fifth grade and then immediately gives an exact age. Since in Germany school starts later than in New Zealand giving a school year for a reference for when children start learning languages could be ambiguous and misleading. The clarification of what age fifth grade is associated with in Germany is introduced by like.

The use of like to introduce examples that serve to clarify or back-up a point or comment also seems to be part of the pragmatic repertoire of GNNSE. Nils uses this word in Example 106 for his comparison of the price of food in Germany and New Zealand.

Example 106: NSNZE-GNNSE/M-M/26/12:30

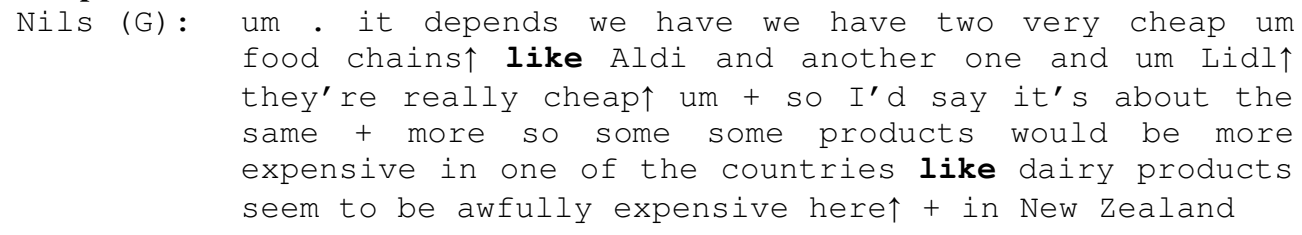

Nils uses the first highlighted token of discourse link like to specify which German supermarkets he considers to be cheap. In a way it could be said that he is exemplifying his point by giving Aldi as an example even though this probably does not mean anything to his interlocutor - the added Lidl seems to be more of an afterthought that might not necessarily be within the scope of the highlighted 
like. However that may be, the second highlighted token seems to provide a clearer example for the use of discourse link like in exemplifications. In this case, like is used to introduce the example of dairy as a way to illustrate Nils's point that some products are more expensive in one of the countries.

The data suggests that GNNSE also employ like to introduce elaborations of a previously made point. In Example 107 Gudrun explains to Nora why she chose to come to study in Wellington.

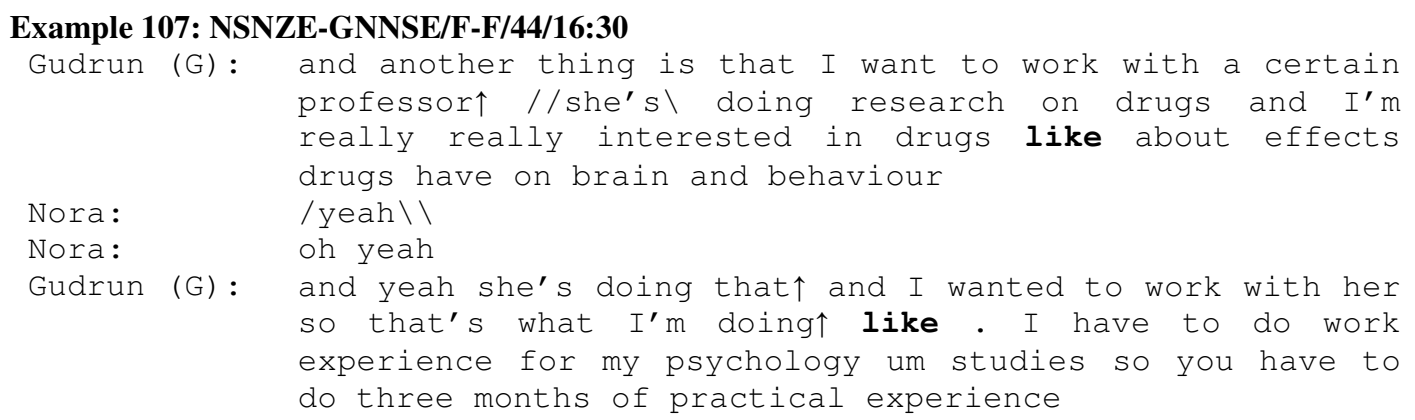

Gudrun, a psychology student, states that she came to Wellington to work with one particular lecturer who is working with drugs. The first highlighted token shows how difficult it is to tell the different sub-categories apart and as such gives further support for my decision not to attempt a quantitative analysis of the different sub-functions. On the one hand, the token could be taken as an example of clarification like which introduces a specification of what was meant by the preceding comment. After all, the statement I'm really interested in drugs could be misinterpreted quite easily. Alternatively, however, the first like could also be interpreted as a case of exemplification like where the proposed area of interest being effects drugs have on brain and behaviour is to be taken as only one possible way to describe her research interests. Finally, the token could be analysed as an elaboration like that serves to hold the floor and offer the Gudrun the opportunity to expand on her research interests. The second highlighted like, on the other hand, seems to me a clearer case of elaboration like as Gudrun offers a more detailed explanation for why she wanted to work with the lecturer (i.e. she had to do a certain amount of work experience for her German degree) even though the original explanation would have sufficed and not caused confusion or misunderstandings on Nora's side. 


\subsubsection{Quotative like}

The GNNSE data suggests that non-native speakers use like in quotatives far less frequently than native-speakers and they use them less often than hesitation marker like. Nevertheless, the data suggests that GNNSE still cover a similar range to non-native speakers, in that they use quotative like to introduce potentially real quotations, enactments of imagined situations, comments and nonverbal segments. In Example 108, Bettina uses like to introduce what is presented as a verbatim repetition of a conversation that took place between her and someone who did not know who Renoir was.

\section{Example 108: NSNZE-GNNSE/F-F/36/8:00}

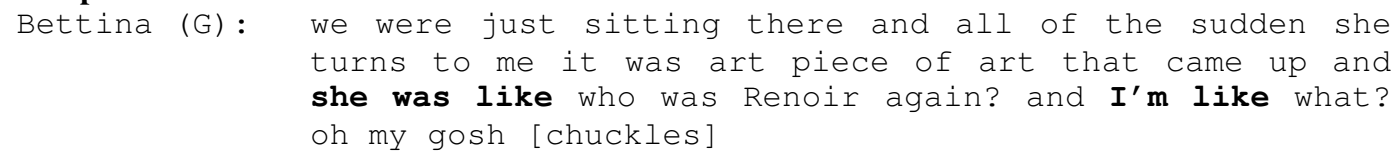

The direct speech segments that are introduced by be-like quotative variants are further marked as representations of dialogue that actually took place by the use of different tones of voice. Bettina uses her rendition of an American accent for the first segment and the second one is spoken with strong emphasis, indicating her level of surprise.

While it is impossible to know for sure whether the direct speech segments in the example above are verbatim quotes or not, it can be claimed that be-like quotatives introduce segments that are presented as such. However, this form can also be used to represent dialogue that is imagined or spoken by an unidentified speaker. An example of a direct speech segment that is supposed to be a representation of an imagined reaction to a situation is given in Example 109 where Sven demonstrates a typical non-native reaction when talking to a New Zealander.

\section{Example 109: NSNZE-GNNSE/F-M/15/11:00}

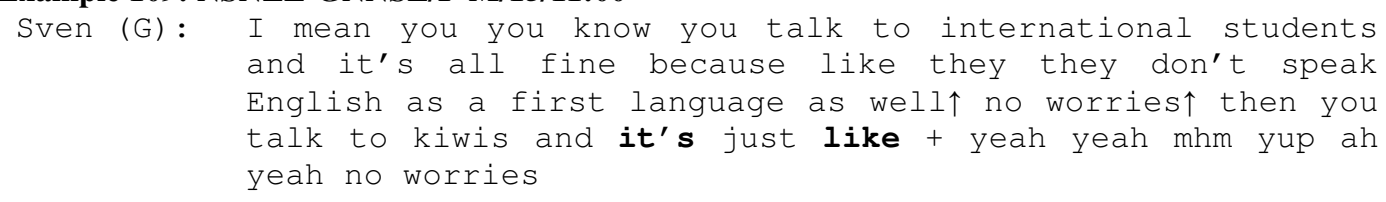


The segment Sven introduces with the quotative it's like is not attributed to a particular speaker nor is it presented as a rendition of actual dialogue even though it is spoken with a different tone of voice. Instead it seems that the quote is supposed to represent the attitude or feeling of non-native speakers when they are not able to understand their interlocutor but do not want to admit it. In this sense, Sven is enacting a situation and a reaction that he might or might not have experienced personally in this way but that is presented as representative of this type of situation in general.

GNNSE also use quotative like to introduce comments to thereby illustrate and clarify their stance towards the proposition. In Example 110 Ingo describes the stress involved having to switch languages from one moment to the next.

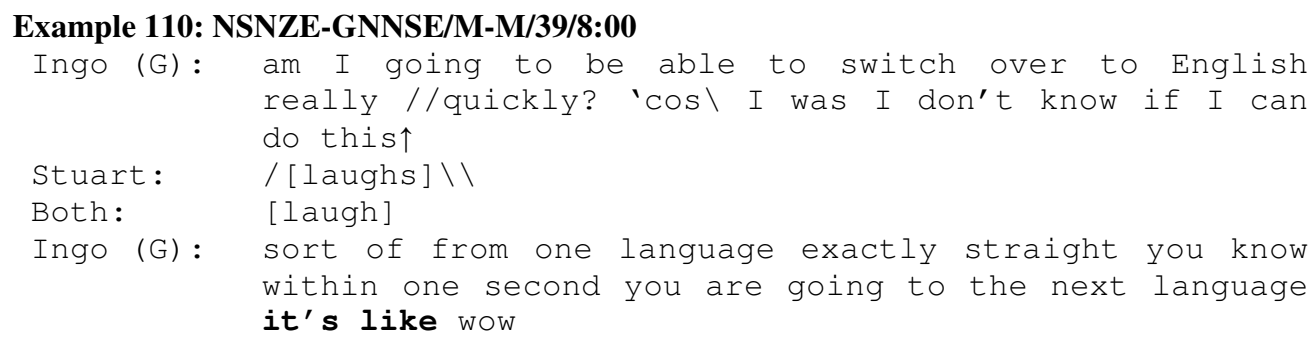

The main difference between the use of quotative and discourse link like to make comments is the use of a different tone of voice on the wow. In a sense, however, the marker it's like still introduces an elaboration of a topic in that it provides a description of the speaker's attitude towards the described situation.

Non-verbal comments on situations were also introduced by quotative like in the GNNSE data as illustrated in Example 111, where Nina compares the cold weather in Germany to the cold weather in New Zealand.

\section{Example 111: NSNZE-GNNSE/F-M/22/14:30}

Nina (G): but the difference is that it's cold but its dry and over here it's like [whimper]

Nina uses a whimpering-like sound effect to illustrate what kind of cold weather can be found in New Zealand. Instead of using words to describe the weather like she did for German cold weather, Nina uses a sound to represent not necessarily the level of dryness or absolute temperature, but the effect the weather has on her, 
implying that the cold weather feels worse in New Zealand than in Germany. The oral enactment of being cold is introduced by the quotative it's like.

\subsubsection{Hesitation Marker}

The use of like as a hesitation marker appears to be part of the non-native speakers' repertoire. As noted above, Example 104 contains an example of the use of like in a repetition that could be taken as a marker of hesitation which suggests that the speaker, Cordula, is experiencing some turn planning problems and is trying to buy herself some time. In the GNNSE data like also occurred in false starts as illustrated in Example 112. In the excerpt Ulf is trying to find out his interlocutor's ethnic identity.

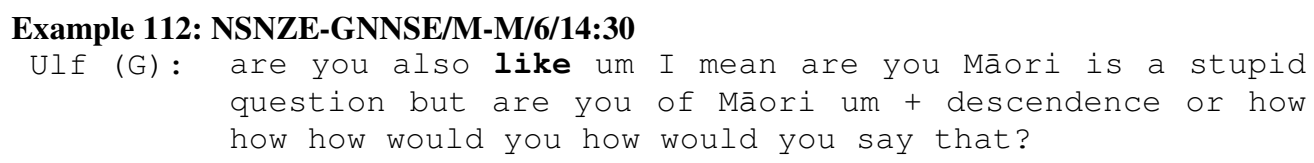

The highlighted token occurs at the end of a false start where the original sentence is terminated midway in favour of a different sentence or, in this case, a modification. The token appears to work in conjunction with the hesitation marker um, suggesting that Ulf is not too sure how to formulate his question appropriately. In this sense the example also shows the use of hesitation marker like as a negative politeness strategy, indicating uncertainty and hesitation which, in turn, could be taken as a softening device on a potentially critical speech act.

\subsubsection{Individual Variation}

In the GNNSE corpus speakers displayed quite a large amount of individual variation in the use of like in its different functions. Frequencies of use of like by individual speakers range from 0 by Ute (F-F), Felix and Boris (M-M) to $4.62 \%$ by Arne (F-M), $3.57 \%$ by Lars (M-M) and $3.46 \%$ by Lotta (F-F). Ute, Felix and Boris indicated that they have not lived in an English speaking country before coming to New Zealand and English does not seem to have played a dominant role in their course of studies in Germany. All three report using mainly English (Felix) or a mix of German and English (Ute and Boris) at their temporary home in Wellington, however, Felix seems to use mainly English for his social interactions in general while Boris indicates that he does not (Ute did not fill in 
this part of the questionnaire). Interestingly, among the high frequency users it is only Lotta who has spent an extended period of time in an English speaking country before coming to Wellington for her course of studies. English seems to play an important role in their degrees in international business, English and business and New Zealand law. All three report English to be the main language of their home in Wellington. However, Arne states that English is not the language he predominantly uses for social interactions. Again, Lotta is the only high frequency user of like who has been exposed to English more than the average GNNSE and who can probably be considered a high proficiency if not a near-native speaker, whereas the other near-native GNNSE can be found in the lower to medium range.

There does not seem to be much of a correlation between the frequency of use of like and GEs. Ute and Boris are among the low frequency users of GEs with $0.29 \%$ and $0.08 \%$ respectively. However, with $0.27 \%$ the same is true for Arne. Lars can be found in the medium range for GEs, while both Felix and especially Lotta are high frequency users of GEs. Indeed, a comparison between the use of GEs and like suggests that while there is some overlap between proportionately similar frequency uses of both pragmatic devices, there are also a number of cases where the reverse is true.

Interestingly, unlike with GEs, when comparing the GNNSE data with the frequencies of like by NSNZE in cross-cultural conversations, there does not appear to be a strong correlation. For example, Arne's interactant Lana employed like with an average frequency of $2.01 \%$ and Ute's conversation partner produced the device at a rate of $2.26 \%$, both of which values greatly differ from the GNNSE's in question. Overall, there are merely 5 conversations out of 30 where the frequencies of GNNSE and NSNZE are relatively close to one another. While this does not necessarily rule out the possibility that some form of relative accommodation takes place, the margins are too big to draw any conclusions from.

This individual variation of use in terms of frequency, functional distribution and use of other pragmatic devices makes it difficult to identify a clear pattern 
concerning the linguistic and pragmatic background of who uses these devices in general. Since a similar variation can be found in native speaker interactions, it seems that the use of like and other pragmatic devices by non-native speakers is to a large degree dependent on the speaker's personal preferences. When considering the use of quotative like, it seems that pragmatic competence and exposure to colloquial everyday communication are important factors that favour the use of this device. The frequent users of quotative like from the GNNSE group, Sven, Bettina and Cordula, are all speakers who have spent at least a year or more living in an English speaking context before the data collection started. The exception to this is Katja, who has never lived overseas before. However, she does live in an English speaking flat and socialises mainly in English, with one of her best friends in Wellington being an American. She also states that at the start of her stay in New Zealand she made a point of not socialising with Germans for a while, resulting in a period of total immersion. This does not mean that spending a year in an English speaking country or living with English speakers appears to be a guarantee for non-natives to pick up quotative like - after all, other GNNSE who have lived overseas or live with native speakers of English do not use it very often. Nevertheless, the data indicates that the use of quotative like goes together with a relatively large amount of pragmatic competence and exposure to everyday language use.

Another possibility is that the use of like and other English pragmatic devices is influenced by the speakers' use of similar or corresponding forms in German. Since the quantitative use of like-equivalent German forms has not been investigated in-depth, the overall frequencies of use of like by GNNSE cannot be compared to German patterns. However, a preliminary analysis of the use of quotatives in female-female interactions suggests that the use of quotatives by NSG has an influence on their use of English quotatives (Terraschke 2006a). Those speakers that frequently use German quotatives such as denken, meinen, sagen, zero quotative and the und ich so construction, are also the ones who use English quotatives such as be like, say, go, think and zero quotative more often than the other speakers. The use of quotatives is not only a narrative strategy that serves to create interest and heighten the dramatic effect of a story (Romaine and Lange 1991). Its use can also be regarded as a stylistic marker and a positive 
politeness device, and as such it could be argued that this observation of pragmatic transfer can be extended to the use of pragmatic devices in general.

\subsection{Summary}

This chapter compared the use of discourse like by NSNZE and GNNSE in terms of its discourse functions and their frequency of occurrence. In order to simplify classification of the different functions of like the tokens were grouped into four broadly defined categories: discourse link like, subjective stance like, quotative like and hesitation marker like. Generally speaking, instances of discourse link like are cases where the token occurs clause initially and serves to introduce a clarification of or elaboration on a previously made point. Items belonging to the category of subjective stance like convey the degree of the speaker's commitment to the utterance, either in the form of a softener expressing uncertainty or a booster or focus marker, adding emphasis to the proposition. The group of quotative like incorporates all instances where the marker is used to introduce non-verbal elements or direct speech segments of real or imagined dialogue. Cases of like co-occurring with pauses or interrupted syntactic structures in false starts were classified as instances of hesitation marker like.

It was proposed that German so is not only able to indicate similarity and resemblance but also serve most of the subjective stance and quotative like functions while German also can express meanings of discourse link like. A quantitative analysis of these forms was not attempted, however due to the absence of a close form-functional equivalence it was hypothesised that GNNSE would use fewer instances of discourse like overall. In particular, it was assumed that GNNSE would use fewer instances of discourse link like as they might favour the use of alternative forms instead. Moreover, since it appears that NSG use quotatives less often than in NZE, it was suggested that GNNSE would also produce fewer tokens of quotative like in English.

The quantitative analysis suggests that the proportion between discourse like and non-discourse like is substantially higher in my NSNZE than in Andersen's (2001) investigation of British English. While in Andersen's study merely 38.7\% of all instances of like were counted as cases of discourse like, the proportion was closer to $80 \%$ in my NSNZE data. Moreover, NSNZE seem to use discourse like 
more frequently than speakers of American or British English (Andersen 2001; Müller 2005). The only function where speakers of American English produced more tokens is the category of quotative like. This is interesting in the sense that American English is often considered the source of discourse like, in particular quotative like (e.g. Romaine and Lange 1991; Tagliamonte and Hudson 1999; Andersen 2001). It was suggested that the overall higher use of discourse like by NSNZE might be related to the differences in the research methodology as the present data is based on interactions between strangers with no set topic. This possibly requires more face work and therefore generates more pragmatic devices. The higher use of quotative like in the American English data might be a product of the communicative task of retelling a story.

The hypotheses for the uses of discourse like by GNNSE turned out to be partially true. While discourse like makes up approximately $1.79 \%$ of the NSNZE corpus, the device makes up only about $1.25 \%$ of the GNNSE data. Nevertheless, GNNSE did not use discourse link like less than NSNZE. Instead they used it proportionally more often. The hypothesis regarding the use of quotative like by GNNSE, on the other hand, proved correct as they use this function of the marker about half as often overall as NSNZE. Indeed, the data suggests that GNNSE, unlike NSNZE, use like in its quotative function less than hesitation marker like. The GNNSE who were high frequency users of discourse like were found to have either spent substantial amounts of time in an English speaking context prior to the recording or have close or regular contact with NSNZE. Therefore these speakers can be considered to have acquired a relatively high degree of pragmatic competence. The analysis of functional application of the word suggests that GNNSE use like for a similar range of purposes than their native-speaker interlocutors. NSNZE in cross-cultural interactions were found to use discourse like less often than when speaking to a fellow NSNZE. They also appear to use discourse link like more often when talking with a non-native which could be taken as an indication that they felt a greater need to clarify their comments in order to facilitate communication. This tendency to use pragmatic devices less often when talking to non-native speakers might have an effect on the use of these devices by GNNSE. This might explain the generally lower use of pragmatic 
devices by GNNSE as the non-native speakers accommodate to their NSNZE conversant.

Future research looking at the use of discourse like by GNNSE could take a closer look at the frequency of occurrence and the functions of German so and also. In particular it might be worthwhile investigating if the uses of German so have been extended so that it can also be used for discourse link like functions, introducing clarifications or explanations. Furthermore, an investigation into the influence of German so and also on English so, also and like could prove an interesting line of research as it might help establish if the proposed German forms do represent the closest translational equivalents. Another area of interest could be an investigation of the full quotative inventory of German and NZE and how that affects the use of quotatives by GNNSE. 



\section{Eh}

The final analysis chapter investigates the use of the pragmatic device $e h$, which is often considered to be a distinctive feature of New Zealand English. NZE $e h$ is phonologically, and to a degree syntactically, similar to German ey (/e1/). However, German ne appears to be a closer functional equivalent. This discrepancy of functional and phonological similarity could potentially result in faulty pragmatic transfer, and thus presents an interesting device for analysis. Bearing in mind the close association of $e h$ with NZE, the adoption of this form by GNNSE could also serve as an indicator of pragmatic acculturation (cf Sankoff et al. 1997). The investigation of the functional application and frequency of use of $e h$ in the NSNZE data and German $e y$ and $n e$ in the NSG corpus is preceded by a discussion of the relevant literature. The English and German devices are compared and predictions regarding the use of $e h$ by GNNSE are made. In the final section, the use of English $e h$ by GNNSE is analysed and the results are contrasted with the observed NSNZE norms. The data is also discussed in terms of the linguistic background of those GNNSE who use $e h$.

\subsection{NSNZE}

Originally, the use of $e h$ was mostly associated with Canadian English, which is why early descriptions of its discourse functions focused on its occurrence in this variety of English. Still, one of the first accounts of the marker investigates novels, newspapers and other written material from several countries in order to prove that $e h$ is not only used in Canadian English but can also be found in American, British, Australian and South African English (Avis 1972). Avis (1972: 95) acknowledges that, even though $e h$ might not be a form unique to Canada, its use differs from that of other varieties of English as it "has been pressed into service in contexts where it would be unfamiliar elsewhere". In his discussion of 
the different functions of $e h$, Avis (1972: 95) differentiates between eight interrogative and one non-interrogative realisations. All instances of the interrogative form can be described as an "articulated question mark" (Avis 1972: 96), whereas non-interrogative $e h$ is considered to "represent ejaculations of sorrow or disgust" (Avis 1972: 95).

The different functions of the interrogative $e h$ identified by Avis (1972) are: requests for repetitions, prompting agreement (similar to tag questions) of both positive and negative statements, reinforcements of exclamations, imperatives and interrogatives in both utterance medial and final position and narrative $e h$. This last function is illustrated in Example 113 (taken from Avis 1972: 103).

\section{Example 113 \\ That was when we almost intercepted a pass, eh? And stu Falkner bumped into him, eh?}

While Avis's (1972: 101) description of the function of narrative eh does not go beyond saying that it occurs in extended stretches of discourse and is often used with a high frequency in spoken language, it is this particular use that Avis considers to be characteristic of Canadian English. In terms of the sociolinguistic distribution of eh, Gibson (1977) notes a correlation between the use of the marker and the speaker's social background. The use of narrative or anecdotal $e h$ especially appears to be closely connected with the speech of lower socioeconomic classes (Gibson 1977: 30).

A similarly close association between the device and a particular group was also found for NZE. In one of the first studies to look at the functions and sociolinguistic distribution of $e h$ in NZE, Meyerhoff (1992: 413) points out that the device is mainly used by Māori men and, to a lesser degree, Māori women. She proposes that it serves as an ethnic in-group marker of solidarity and a positive politeness device for this particular group. Meyerhoff (1994: 375-376) suggests that male speakers might use the device more often than female speakers because they have a smaller repertoire of interpersonal politeness devices. Age was also found to be a relevant variable as younger speakers of all groups consistently produced the highest frequencies of eh. Among the Pākehā speakers, 
young women in particular seemed to have adopted the marker. Many of the women who used it were found to have Māori partners. Their use of $e h$ was therefore taken as an indicator of "affective speech accommodation" and is used as a positive politeness strategy in that it signals "affiliative desires and their identification with an aspect of their partner's identity that they believe to be salient" (Meyerhoff 1994: 375).

Stubbe and Holmes (1995: 74-75) also found that eh mainly occurs in the language of working class speakers, particularly among younger speakers, which seems to highlight its status as a feature of vernacular NZE. However, in their study of the WSC, which includes speakers from a range of different ethnic backgrounds, they found that is was the working class men who use eh more frequently. This result would be more in line with previous studies that suggest male speakers lead in instances of change from below by using more extreme variants that carry covert prestige (Stubbe and Holmes 1995: 76; 81). Stubbe and Holmes (1995: 81) suggest that the different results are related to the type of data recorded: while Meyerhoff's (1992) corpus is based on sociolinguistic interviews, the WSC mainly includes interactions between familiars. The notion that eh functions as a solidarity marker is further supported by Bell's (2001) study of NZE interview data. Based on data where the interviewer and interviewee are involved in three interviews each, Bell (2001: 153-156) shows that the use of $e h$ appears to be dependent on the interlocutor, with male Māori interviewees using more tokens of $e h$ with other Māori males than with Pākehā, and a male Pākehā interviewer using it more when talking to Māori males than with any other participant.

With regard to the functions of $e h$ in discourse, Meyerhoff (1994: 369) dismisses Avis' (1972) and Gibson's (1977) analysis of the device as a verbalised question mark and with it the interpretation of $e h$ as a request for verification of the proposition and an indicator of propositional insecurity. Meyerhoff (1992: 416) notes that speakers usually do not use $e h$ together with the rising intonation pattern commonly associated with questions, but with a falling intonation. The notion that $e h$ does not invariably function as an interrogative marker is also supported by the absence of minimal feedback. Instead, Meyerhoff (1992: 414- 
417) proposes that the form can serve a variety of functions, ranging from strengthening, establishing and re-checking common ground and interpersonal solidarity, to marking narrative focus and requesting confirmation. In this sense, eh serves a similar function to tag questions. Stubbe and Holmes (1995: 74-75) suggest that the two devices might even occur in complementary distribution. Based on its function as an addressee-oriented device that serves to mark solidarity and indicate shared knowledge, eh can also be compared to you know.

For the qualitative analysis of $e h$ in the present NZE corpus I chose not to use Meyerhoff's (1992: 414-416) functional typology. The main reason for this was that Meyerhoff's (1992) functional categories proved to be difficult to apply to the present data because of the large degree of functional overlap between the various categories. Distinguishing between $e h$ as a request for confirmation and its use in establishing or negotiating common ground between the speakers is relatively straightforward. On the other hand, the distinction between asserting, establishing and re-establishing assumed common ground was difficult as it would have required me as a non-native to make judgements about what are valid truisms or commonly held beliefs in New Zealand. Moreover, determining whether an occurrence of $e h$ represents an instance of establishing or re-establishing common ground requires in-depth knowledge of the information state between the speakers, which would have involved time-consuming re-reading of the transcripts and was therefore deemed beyond the time-frame of the present study.

The difference between establishing common ground and marking a genuine question on the one hand and the category of marking the focus of a narrative function on the other also seems rather subtle and difficult to apply to my data. According to Meyerhoff (1992: 415), Example 114 illustrates the use of $e h$ to create narrative focus on the idea of granite panels that are attached to buildings and to "attend to the interlocutor's continued involvement in and understanding of the narrative".

Example 114

Jeez, they're freaky man + unreal + it's not stuck on with much eh 


\section{Example 115}

I'm afraid to walk in the house eh they might have a three-oh-three pointing at me.

Example 116

[Bunny was born] nineteen forty-two so he's he's um forty

eight + eh Bunny

Example 115, on the other hand, is considered to represent an instance where $e h$ signals an attempt to negotiate common ground between the interactants.

Meyerhoff (1992: 415) argues that its placement immediately after the evaluative comment indicates that the speaker is trying to find out whether the interlocutor agrees with the assessment. However, the two interpretations appear to be somewhat interchangeable, as the use of eh in Example 114 could feasibly be read as an attempt to find out the interlocutor's opinion on the proposition that the concrete blocks are not attached with much and therefore as an effort to establish common ground. Conversely, the token in

Example 115 could be analysed as creating narrative focus on the fact that the speaker is scared of the neighbours. Similarly, Meyerhoff (1992: 416) considers the use of $e h$ in Example 116 to be a signal of "genuine epistemic uncertainty". However, the example could also be interpreted as the creation of narrative focus, reasserting that it is Bunny the speaker is talking about. Since this lack of a clear distinction between Meyerhoff's categories rendered their application to my NSNZE corpus ineffective, the subsequent discussion of the different functions of $e h$ will be based on a simplified categorisation system derived from an analysis of the data itself.

\subsubsection{Functions of $e h$}

Establishing distinct functional categories for $e h$ proved to be rather difficult. Nevertheless, when focussing on the most prevalent function of the marker in a particular context, two broad functional categories can be identified: referential and affective $e h$. Cases of referential $e h$ are those instances where the marker generally expresses the speaker's uncertainty towards the propositional content of the utterance or serves as a request for confirmation of the correctness of the preceding statement. Tokens considered to belong to this category predominantly function on a textual level. The category of affective $e h$, on the other hand, 
comprises all occurrences of the device that seem to work mainly on an interpersonal level and serve important politeness functions.

\subsubsection{Referential eh}

Even though I have described Meyerhoff's (1992: 416) example for referential $e h$ as overlapping with other functions, there are a number of cases where indicating propositional insecurity or requesting confirmation appears to be the main function of $e h$. Admittedly, the discursive strategy of asking for verification could also implicitly serve politeness functions in that it aims to involve the interlocutor in the conversation and puts them into a position of authority. Nevertheless, in these cases the central function of referential eh appears to be located on the textual level. The identification of cases of referential eh does not rely on linguistic clues such as prosody or grammar. In accordance with Meyerhoff's (1992: 416) observations, instances of referential $e h$ are not spoken with a rising, question-like intonation. But like other question markers they mostly occur at the end of statements. The sense of uncertainty towards the propositional content of the utterance is usually conveyed by the speaker's tone of voice and the context of their occurrence.

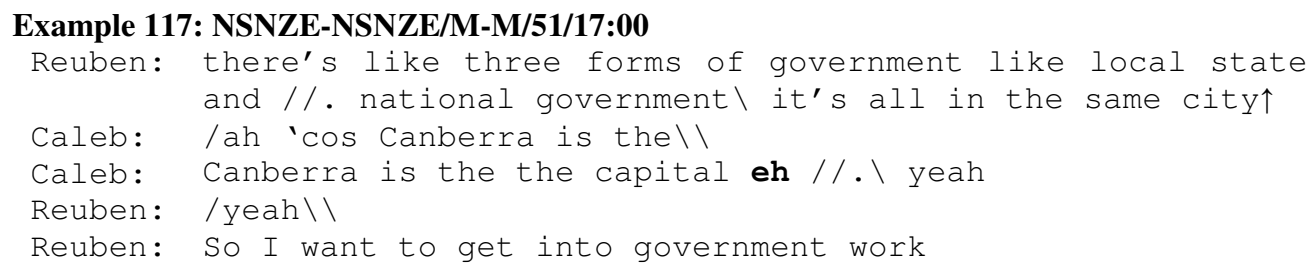

In Example 117, Reuben talks about his future plans, saying that he would like to get a government job in Canberra, where three different levels of governmental representations are located. Caleb, in turn, asserts that Canberra is the capital of Australia and modifies his statement with $e$ h. Interpreting Caleb's utterance as an informative statement for Reuben's benefit with $e h$ functioning as a focus marker seems unreasonable since Reuben appears to know a lot about the governmental organisation of Australia, which in all likelihood includes the fact that Canberra is the capital of Australia. However, if Caleb expected Reuben to be aware of the political status of Canberra, stating an obvious fact about a tangential aspect of the 
main focus of the conversation would be a rather counterproductive discursive strategy.

Instead, the use of $e h$ in Caleb's statement appears to create an impression of propositional insecurity. Caleb has mentioned before that he has never been overseas and therefore might not be entirely certain with regards to the capital of Australia. However, Caleb is certain enough about the validity of his proposition that he formulates it in the form of a statement rather than that of a question, merely adding $e h$ as a request for confirmation of his assumption. The presence of verbal minimal feedback from Reuben and the fact that Reuben does not expand on the issue but continues with the original conversation can be taken as additional evidence for this analysis.

\subsubsection{Affective eh}

The category of affective $e h$ includes all instances where the main function of the device appears to be of an interpersonal nature, for example asserting and establishing common ground between interlocutors or appealing to the interlocutor's understanding. A frequently occurring function of affective $e h$ in the NSNZE corpus was its use in conjunction with evaluative comments about certain aspects related to the topic of conversation. In these instances, eh appears to be used to negotiate a common ground between the interlocutors by encouraging or prompting the interactant to either agree or disagree with the often only moderately evaluative opinion proposed by the speaker.

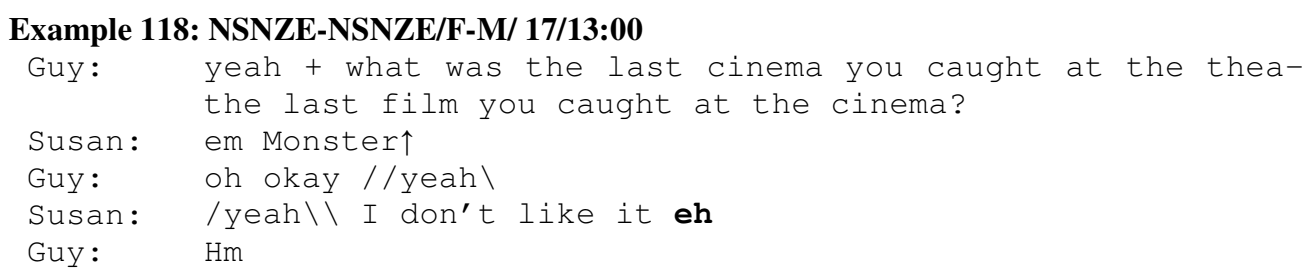

In the example, Susan recounts that the last movie she saw in a cinema was Monster, and then goes on to comment that she did not like it, modifying her assessment with $e h$. Even though the main function of the marker in Example 118 could be interpreted as an appeal for feedback, it does not seem to request verification of the accuracy of the proposition as it contains Susan's personal 
assessment of the movie. After all, while Guy might have his own opinion about the movie, he does not know Susan's thoughts any better than she does and therefore does not have the authority to verify the truthfulness of her opinion. In this case, eh appears to work on a more interpersonal level in that it seems to invite Guy to agree or disagree with the assessment and express his own opinions on the matter. In this sense, by inquiring about Guy's opinion, Susan is trying to check whether the two of them agree on the subject. The use of $e h$ in the example can therefore be interpreted as indicating the desire to negotiate, and consequently establish, common ground between the interactants. This interpretation is further supported by the general nature of Susan's comment: since at this stage she does not know whether Guy has seen the movie or whether he liked it or not, her rather non-specific expression of dislike leaves plenty of room for negotiations and attenuations of the criticisms.

This use of affective $e h$ together with evaluative comments can also mark a comment to be a humorous exaggeration that is not to be taken too literally. In these cases, it does not seem to be intended as a genuine request for feedback. This function is illustrated in Example 119 where Maggie and Eve share stories of being mature students at university.

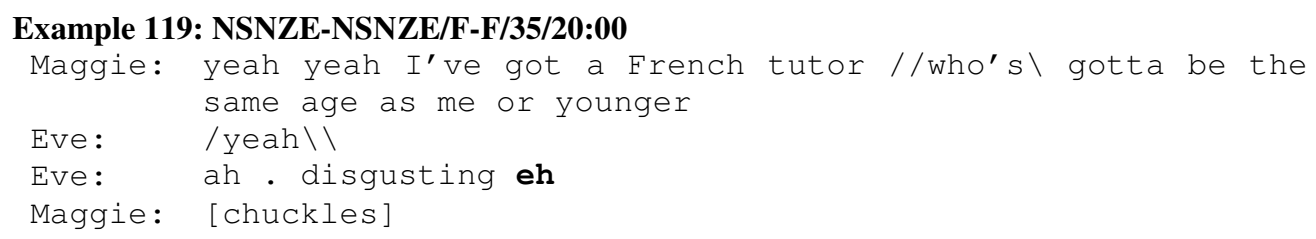

Eve comments that it is disgusting that Maggie's French tutor is probably younger than she is. This statement is then modified with $e h$. On the one hand, the token appears to serve to negotiate a common ground between the speakers by checking Maggie's stance on the matter. At the same time, the use of the marker also appears to indicate that Eve's comment is over the top and should not be taken literally. With her statement, Eve, who is a mature student herself, seems to express solidarity with Maggie's situation of having tutors at university who are younger than her. By voicing the underlying sentiment of Maggie's comment, Eve conveys that she understands the strangeness of the situation. However, the evaluation that having younger tutors is disgusting appears to be an intentional 
exaggeration as assessments such as strange, awkward or somewhat demeaning might seem more appropriate in this context. Thus, the use of $e h$ seems to draw to their common ground and shared knowledge that disgusting is an exaggerated estimation of the situation.

Another relatively common function of affective $e h$ seems to be that of an intensifier or a hedge. In addition to indicating the speaker's assumption of shared knowledge, the device can also be said to function on a textual level as a focus marker as it draws attention to certain elements of an utterance.

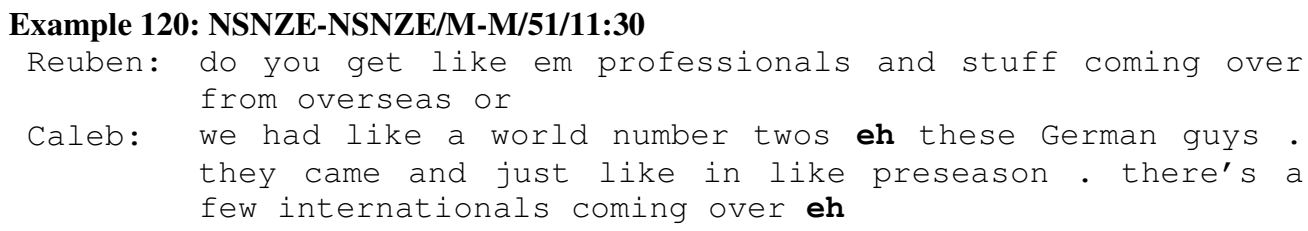

In Example 120 Reuben and Caleb are talking about beach volleyball in New Zealand and whether international players come over to play. Caleb states that the second best team in the international ranking came and that generally a number of international players are coming to New Zealand. Both of these statements are modified by $e h$. Again, interpreting the tokens as requests for verification would not make sense as Caleb is the expert on beach volleyball in New Zealand and Reuben does not know the answer to his question. It also seems unlikely that the markers are intended to check the interlocutor's position on the matter in order to establish common ground as the statements are more of an informative nature rather than expressions of personal values and beliefs. Instead, the two ehs seem to highlight the factual content of the proposition, thereby checking if the listener heard and understood the statement on a textual level and whether the listener understood and agrees with the implied evaluation of the presented information on an affective level. In this case it seems that Caleb considers the fact that international players are coming to New Zealand to be impressive and exciting and, judging from his question, so does Reuben. By emphasising the propositions using eh, Caleb seems to confirm that the two of them know how important it is for the sport to have ranked players from overseas coming to New Zealand. In this sense, the tokens serve to indicate shared knowledge and consequently assert common ground. 
Example 121 serves to illustrate the function of $e h$ as an appeal for the interlocutor's understanding more clearly. In the excerpt Kim is talking about the greyness of winter in Europe.

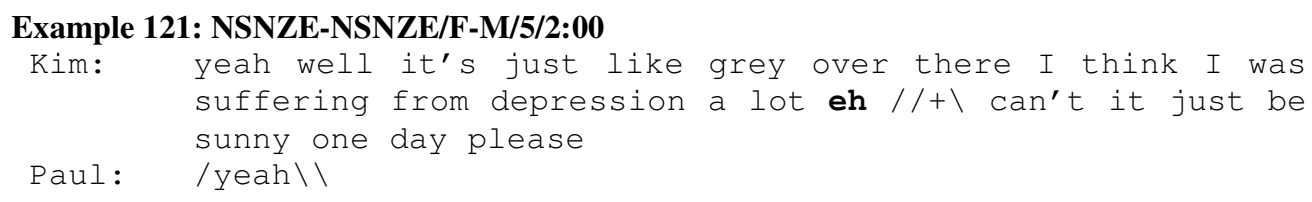

Kim attenuates her statement that she suffered from depression because of the lack of sun with $e h$. However, instead of marking the proposition as a humorous exaggeration, the token appears to serve as an appeal for understanding. While she might not have suffered from an actual, clinical depression at the time, the lack of sun might still have had a serious impact on her. At this point in the conversation, Kim is aware that her interlocutor, Paul, has lived in Europe for a long period of time and consequently might be familiar with this feeling of winter melancholy. The marker seems to function as an appeal for his understanding of what was meant, a plea for him to not take her comment literally but to remember what it is like in Europe in winter and to be willing to interpret her statement accordingly.

A more specialised sub-category of this emphatic function of $e h$ is its occurrence with agreements where the speaker stresses his or her agreement with the interlocutor's comment.

\section{Example 122: NSNZE-NSNZE/M-M/58/15:00}

Xander: we haven't really seen anything like it since

Zach: ah totally not eh nothing nothing like it at all

In Example 122, Zach and Xander are talking about the Springbok tour riots and Xander points out that this type of political resistance has been unique in New Zealand's history. Zach, who studied the Springbok tour protest movement in greater detail, agrees with Xander's evaluation of New Zealand's history. In this case, an interpretation of the token as a marker of insecurity or a request for feedback or verification of the proposition seems unreasonable. After all, at the point of his utterance Zach is already aware of Xander's assessment of the situation, rendering any attempts at negotiating or establishing a common ground unnecessary. Instead, the use of eh appears to add emphasis to Zach's statement, 
indicating that he wholeheartedly agrees with Xander's proposition. In this sense, the token could be interpreted as asserting and reinforcing the speakers' shared ideas and values and consequently as confirming their common ground. Zach further strengthens the force of his agreement with the boosters totally and at all and by repeating Xander's original proposition that New Zealand has seen nothing like it again.

\subsubsection{Functional overlap}

In the subsequent quantitative analysis of $e h$ I will only differentiate between referential and affective $e h$. The tokens were not divided into the different subcategories and counted mainly because it is not always possible to clearly distinguish between the subcategories as some of the functions seem to be overlapping. After all, checking if someone agrees with your assessment and appealing to their willingness to understand what you mean are not necessarily mutually exclusive. Thus, the material is often difficult to summarise and interpret as there are many potentially relevant contextual and personal variables that come into play. The proximity of the two main subcategories of affective eh is illustrated in Example 123, where Susan and Guy talk about playing the guitar and being in bands.

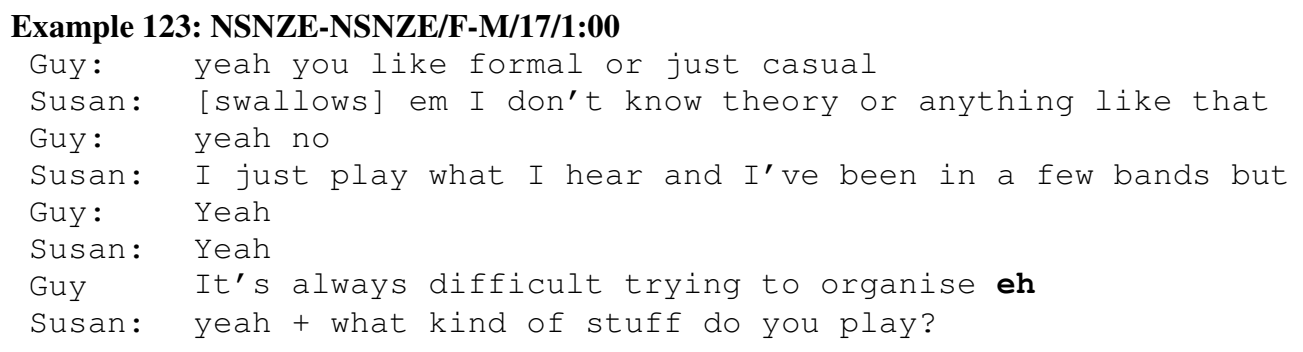

The instance of $e h$ in the example seems to serve several purposes simultaneously. On one level it appears to be used as a prompt for Susan, asking her to agree or disagree with Guy's comment. However, Guy's remark seems a bit disjointed from the rest of the conversation and it is not entirely clear what exactly it is that he considers difficult trying to organise. Based on the immediate context he could have referred to learning music theory or starting a band and only when looking at a longer stretch of conversation it becomes obvious that he is referring to the latter. Since Susan responds to Guy's comment with a non-committal and non- 
specific yeah followed by a pause and a change of topic, it seems that she is not completely sure what he intended either. Bearing in mind the potentially ambiguous nature of Guy's remark, another feasible function of $e h$ in this example could be that of an appeal to Susan to decipher his remark in order to understand what he meant. Moreover, since at that point both speakers have established that they have played in bands, this instance of $e h$ also appears to serve to assert common ground between the speakers in that it suggests that Guy believes Susan to have experienced the difficulty of organising a band and know what issues are involved. Based on the multifunctional nature of $e h$ the approach of using broad categories was considered to be the most appropriate and useful one.

\subsubsection{Functional distribution of $e h$}

A quantitative analysis of $e h$ in the NSNZE corpus shows that the 58,509 words produced by native speakers contained 179 tokens. It is worth pointing out that the use of the device differs noticeably among NZE speakers: while like and GEs were used by all participants and all but two respectively, eh is used by only 19 out of 30 NSNZE. Moreover, about half of all tokens were produced by only two speakers: Caleb is the most prominent user of $e h$ with an overall frequency of 2.66 $\mathrm{pd} / \mathrm{cw}$ or 64 tokens, followed by Guy with $1.01 \mathrm{pd} / \mathrm{cw}$ or 29 tokens. This seems to suggest that the use of $e h$ is somewhat more non-standard than the other pragmatic devices analysed in this study. The analysis of the functional distribution of $e h$ found that of the 179 tokens, only 8 could be classified as instances of referential $e h$. The results for the functional distribution of $e h$ in the NSNZE corpus are summarised in Table 14.

Table 14: Functional distribution of $e h$ in the NSNZE corpus

\begin{tabular}{llll}
\hline Function & $\mathbf{N}$ & $\mathbf{\%}$ & Overall \% \\
\hline Referential $e h$ & 8 & 4.5 & 0.01 \\
Affective $e h$ & 171 & 95.5 & 0.29 \\
Total & 179 & 100 & 0.3 \\
\hline
\end{tabular}

A comparison of the frequencies of occurrence of $e h$ in my NSNZE corpus with Meyerhoff's $(1992 ; 1994)$ study proves to be somewhat difficult as she used a 
different measurement for representing the proportional use of $e h$ in her corpus. Rather than calculating the frequency of use in relation to the number of words spoken by each speaker, Meyerhoff uses the minutes of free speech as a measuring unit. However, when comparing the proportional distribution of eh across the different functions, it can be seen that in both Meyerhoff's and my study speakers hardly used its referential function. This seems to further support the notion that this pragmatic device mainly functions as an affective marker of solidarity that serves the establishment of common ground.

Stubbe and Holmes (1995) and Bell (2001), on the other hand, provide sufficient information to allow for a direct comparison with my results. In a corpus of 75,000 words consisting of radio and TV interviews and informal conversations taken from the WSC, Stubbe and Holmes (1995) found 51 tokens of eh. This translates into a proportion of $0.06 \%$ of the entire data set. The WSC frequency turns out to be lower than the one in the present study, even if those tokens produced by the most frequent users of $e h$ were removed from the data. One of the reasons for the substantially higher frequency of occurrence in the present study could be, once again, related to difference between using mainly informal conversations between familiars (WSC) and interactions between un-familiars (present study). At the other end of the spectrum, Bell's (2001) corpus of 150,000 words of interview data contained 4,830 tokens of eh or a frequency of 3.22 $\mathrm{pd} / \mathrm{cw}$, which is much higher than in the other two studies. Again it seems possible to explain this difference with reference to the types of data used. Bell's corpus is based on a series of one hour interviews between non-familiars which were recorded at the interviewee's house. The relatively formal setting of the interaction in conjunction with the inherently uneven and fixed speaker roles of an interview might have fostered an increased use of politeness strategies in order to establish a good interpersonal rapport. Incidentally, the interviewers produced a greater number of ehs than the informants, which might be taken as an additional indication that pragmatic devices like eh serve important rapport building functions and help facilitate the conversational flow. 


\subsection{NSG}

Forms phonologically similar but usually not functionally identical to English eh can be found in a number of different languages such as French, Spanish or Italian. Here the form often functions as an interjection, e.g. in eh bien. Among these similar forms, German ey is not only a close match in terms of phonological composition but the two forms are also similar in terms of their sociolinguistic distribution and, to some degree, their syntactic position. Both devices can occur in clause final position as a tag. German ey, however, can also occur clause initially. Even though German ey is lacking a close association with one ethnic group, both markers can be said to be features of vernacular varieties that are commonly associated with younger speakers and speakers from lower socioeconomic classes (Schlobinski 1995: 333; see also Meyerhoff 1994). Schlobinski (1995: 333) also notes that while ey appears to be an exclusive marker of youth talk, young speakers themselves express a negative attitude towards its use due to its close association with the lower working class.

Despite these similarities, German ey differs from NZE $e h$ with regard to its functions. It has been suggested that the functions of German ey can be linked to its position within the clause (Schlobinski 1995: 333). The following discussion of the uses of ey identified in the literature and in my NSG corpus also follows this division.

\subsubsection{Final ey}

German clause-final ey has been found to function to close a topic and as a booster on the illocutionary force of a proposition (Henne 1986: 105; Schlobinski 1995: 333). By highlighting important parts of the utterance, ey also works as a discourse structuring signal in that it creates focus and thereby helps organise the content of a turn (Henne 1986: 150; Schlobinski 1995: 333). This use is illustrated in Example 124 where Ulf and Ingo are expressing their dislike of a controversial German TV personality. 


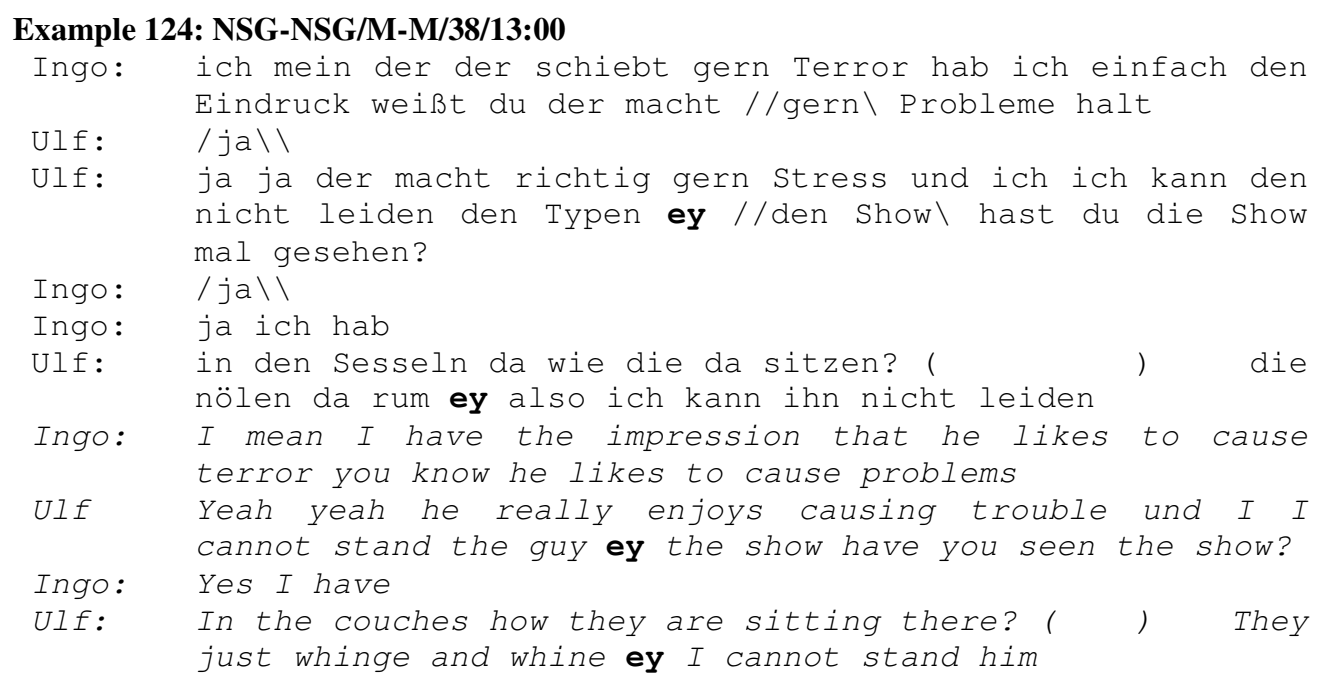

Ulf has taken a real dislike to this TV presenter and vents his annoyance about him. His exclamation I cannot stand the guy and the complaint that they just whinge and whine are both modified by ey. Unlike NZE $e h$, these two instances do not seem to function as interactive devices that serve to invite feedback from the interlocutor to negotiating common ground. Instead, these tokens appear to emphasize the propositions, adding extra strength to the force of the complaints. Ey often occurs in conjunction with whingeing, complaining, raving about something or other expressions of extreme positive or negative sentiments. However, it can also be used as a positive politeness strategy for commiserations as in Example 125.

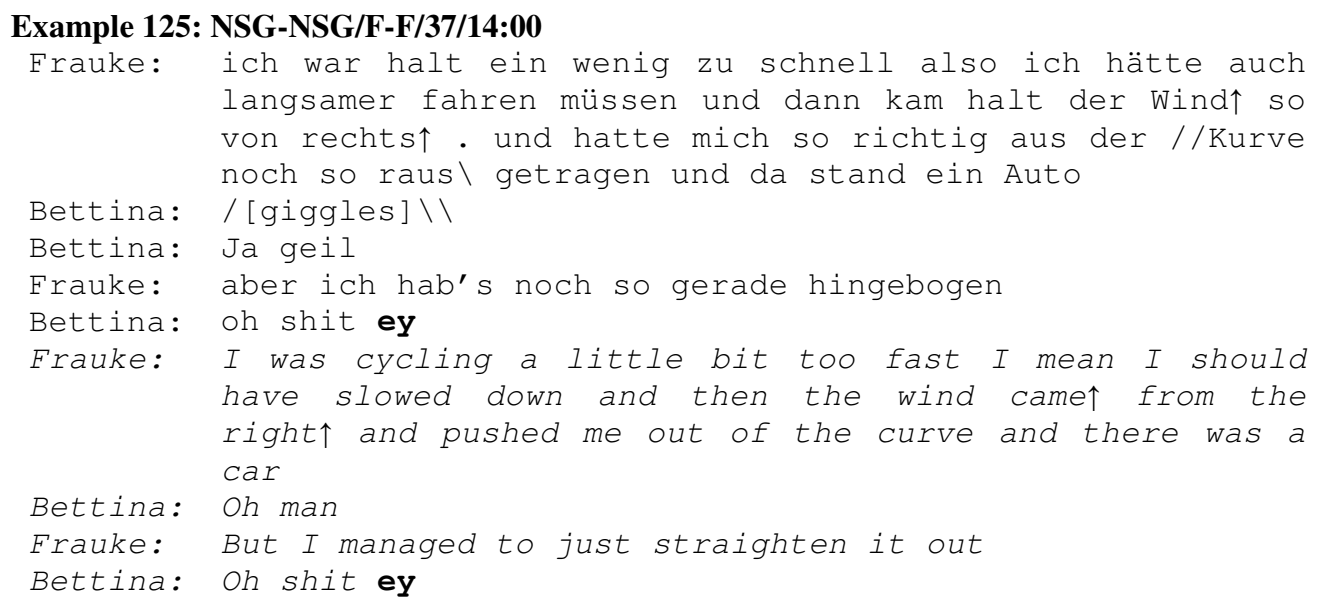

Frauke tells Bettina about a scary moment when she was cycling around Wellington and nearly crashed into a parked car. Bettina uses the English 
exclamation oh shit to express her sympathies with this scary and potentially dangerous experience. The use of ey in this context seems to amplify her emotional involvement in and understanding of Frauke's story, signalling that she knows what it must have been like and that she understands how bad it could have ended if Frauke smashed into the parked car. This use of German ey to portray sympathy and understanding is similar to the function of NZE $e h$ as described in Example 122. Nevertheless, even though the function may be similar, the tone of the marker is different. When providing a translation of the form in context, German ey could potentially be replaced with this is what I think or can you believe it!, whereas this particular function of NZE $e h$ carries the connotation of wouldn't you agree?.

\subsubsection{Initial ey}

Androutsopoulos (1998: 495) and Schlobinski (1995: 333) point out that utterance initial ey can be used as a dialogue starter when it occurs in conjunction with a direct form of address. The present data does not contain any clear and direct examples of this use, possibly due to the dyadic nature of the corpus which did not require the interactants to directly address each other. However, in a few cases, this type of ey was used in the initial part of the direct speech as illustrated in Example 126.

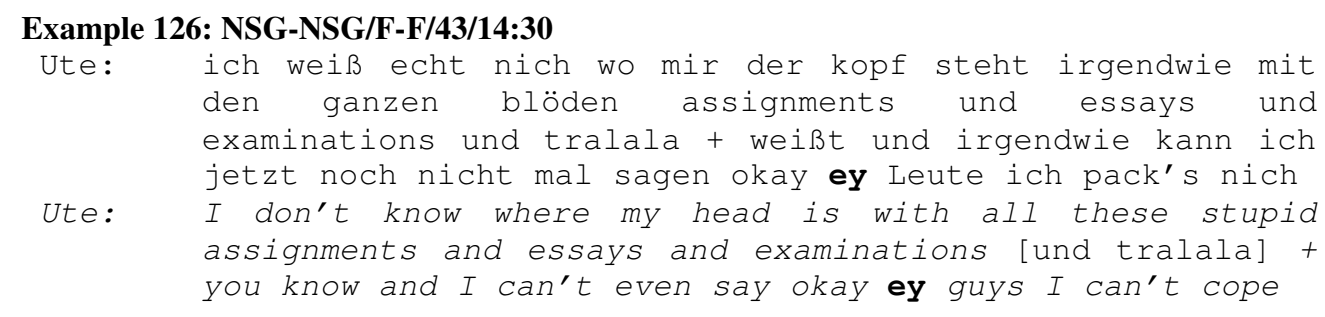

Ute is somewhat overwhelmed by the workload of her courses. However, it is too late for her drop a course. The direct speech of the hypothetical conversation that would be required for changing her courses is introduced by ey. While it is somewhat difficult to discern the exact function of ey in this context as it is used in a hypothetical statement, it still seems to work as an attention grabber by initialising the fictional dialogue and drawing attention before identifying the intended referent of the address. Moreover, the non-standard nature of $e y$ together with the colloquial term of address Leute 'guys' appears to represent an attempt to 
create a sense of informality between the interactants and thereby serves as an appeal for understanding, either for the benefit of Ute's actual interlocutor at the time of the recording or the imaginary administrative assistant.

When instances of initial ey do not function as conversation initiators they can also serve as a general attention getter (Schlobinski 1995: 333) and to introduce a new topic (Androutsopoulos 1998: 495). This type of use could not be identified in the current corpus. However, instances of non-dialogue initiating initial ey were found to be used as a focus marker to indicate that the following proposition is particularly important in the current context. This pattern is shown in Example 127, where Olaf recounts one summer when he had to do excessive amounts of lab work to fulfil the requirements of his degree.

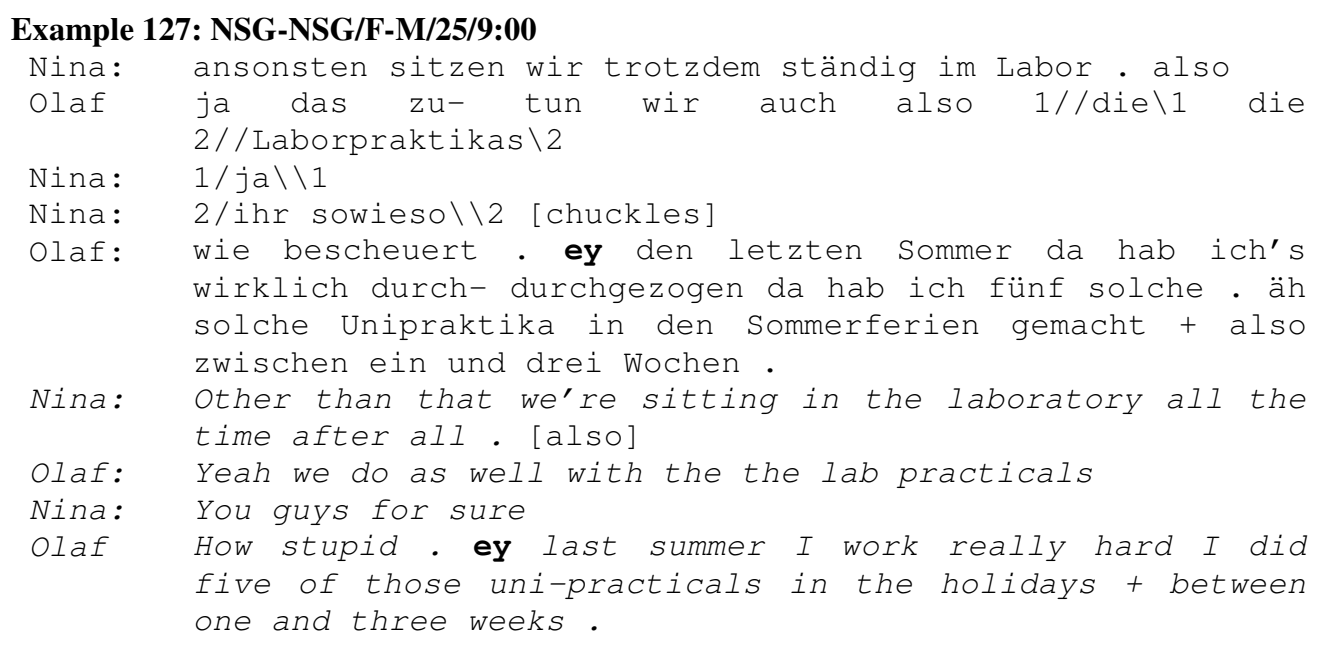

Since Nina and Olaf are talking about working in laboratories for their studies before and after this occurrence of $e y$, the function of the marker does not seem to be to introduce a new topic as such. Instead, as Olaf continues on the theme of lab work, the token appears to introduce important and related information on the same or a related subject matter. In this context, the use of clause initial ey seems to indicate that the following information is an extreme illustration of just how much time Olaf had to spend in laboratories at one time. In other words, the token conveys the speaker's stance towards the proposition, which in turn indicates to the listener how to interpret what is being said and thereby helps structure the information transmission. Even though NZE $e h$ was also described as creating focus, it does so more in the sense that it checks up on the listener's understanding 
of the facts and indicates supposed shared common ground on an interpersonal level. German ey, on the other hand, appears to be more speaker-oriented in that it conveys the speaker's position towards the topic.

\subsubsection{German ne}

While German ey might be the closest phonological equivalent form to NZE eh, other German devices are a closer functional match. The closest example for a functionally similar form is the clause final vernacular marker $n e$, and its regional variations such as gell, gelle, nich, net, oder, wa, woll, etc. These alternative forms are not investigated in this section because they did either not occur at all in my NSG corpus or only marginally (gell occurred 6 times). The device oder, which occurred about 76 times in clause final position, is not analysed here. Similar to German so and English like, oder has a close English translational equivalent $o r$ which can be used to serve related functions. This seems to make it more likely that the use of oder would influence the use of English or rather than eh. Additionally, oder appears to be more of a standard form, while ne seems to be a closer equivalent to the non-standard nature of NZE $e h$.

In one of the earlier accounts of German ne, Jefferson (1981: 53) noted that the device functions as a response solicitation device similar to a tag question that occurred after the speaker's turn was finished and often in midst of, and therefore potentially interrupting, the interactant's turn. Referring to this use of the device as the 'abominable $n e$ ', Jefferson considers the marker to be a somewhat rude and aggressive device that serves to force the interlocutor to acknowledge that the preceding proposition has been heard and understood (Jefferson 1981: 85). This strategy, however, did not seem to be very effective as it often does not elicit the desired response (Jefferson 1981: 67). Weber (1986: 397), on the other hand, analyses the marker as a 'socio-centric sequence' that serves to check the interlocutor's understanding and agreement of what has been said and to establish common ground. Similarly, in their project investigating regional varieties in Germany, Elspaß and Möller (2006) found that in the North of Germany ne can be used as a Versicherungsfrage or assurance question both as a request for verification of the proposition and to mark propositions or assessments the 
speaker believes everyone to agree with. As such, the marker appears to function similarly to you know or eh.

One of the reasons why Jefferson and Weber came to such opposing conclusions in their analyses of ne could lie in the nature of their data. While Weber (1986) used a large corpus of instruction dialogues relating to pottery, Jefferson based her assumptions mainly on an interaction between a psychiatrist, a potential patient and her husband (Jefferson 1981: 53) taken from an interview to determine whether the woman should be admitted to a psychiatric hospital. All instances of this aggressive abominable ne and related forms were used to the woman who the other two speakers appear to consider mentally sick. Power and status differences such as these in addition to the apparent goal of the interaction (i.e. getting the woman admitted to the hospital), which the potential patient might not agree with, will have an effect on how the doctor and the husband talk to the woman and as such it will have an effect on how pragmatic devices including $n e$ are used. This notion that Jefferson's (1981) analysis cannot be applied to all interactions is supported by the fact that in the current corpus of 134 tokens of ne, only four instances of this particular type of the ne could be found where the marker occurred after the end of the original turn and after the interlocutor began to speak. However, in all of these cases the interlocutor has finished the turn and therefore was not interrupted by the speaker. In the remainder of the corpus the marker occurs 52 times in utterance final and 78 times in utterance medial position. Jefferson's comment that $n e$ is not a very effective response elicitor seems to be confirmed by the observation that the marker frequently occurs in utterance medial position and therefore often gets no response. Moreover, in a number of cases, utterance final tokens also go without explicit verbal feedback. This indicates that the speaker often does not require, expect or demand a response from the interlocutor, which suggests that marker serves not only as a prompt for verification but also other interpersonal pragmatic functions.

As noted by Weber (1986) and Elspaß and Möller (2006), German ne can be used as an interrogative particle asking the listener to verify the accuracy of the proposition. As such, analogous to NZE $e h$, it can serve to negotiate and assert 
common ground between the speakers by encouraging the interlocutor to provide feedback and therefore to engage in the conversation.

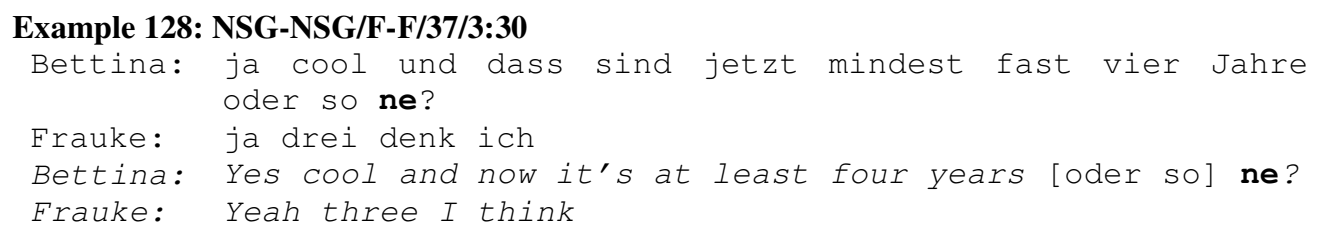

In Example 128 Bettina asks Frauke about her $\mathrm{PhD}$ and inquires about the length of the programme. Her statement that it takes four years to complete the $\mathrm{PhD}$ is modified by $n e$, which appears to serve as a prompt for Frauke to verify or correct the proposition. This sense of $n e$ being used on a referential level to check the correctness of an assertion is further supported by the use of ne with a rising question-like intonation and the general extender oder so.

The use of ne to establish common ground and appeal for the interlocutor's understanding is illustrated by Nina's complaint about how hard it is to keep up with the accent and speech rate of her supervisor in Example 129.

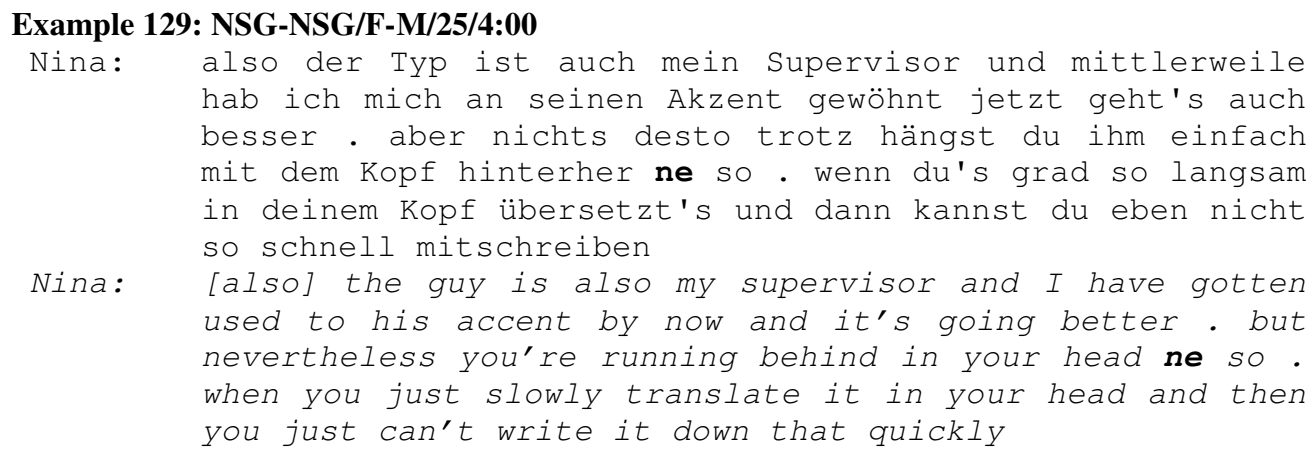

Since it is Nina's story, interpreting the marker as an interrogative tag asking for confirmation does not seem plausible. Instead, the token appears to help establish whether Nina's interlocutor knows what she means by running behind in your head in this context. Similar to NZE $e h$, this use of German ne serves to negotiate common ground between the speakers and at the same time functions as a politeness device creating interpersonal rapport by suggesting that the speaker considers the listener to be in the know. 
When German ne is used with propositions that the speaker is certain about and which do not require negotiation, the marker can also be used to add emphasis to important parts of the utterance. Felix describes the bike he uses in his university town in Germany, where bicycling is the preferred method of transportation.

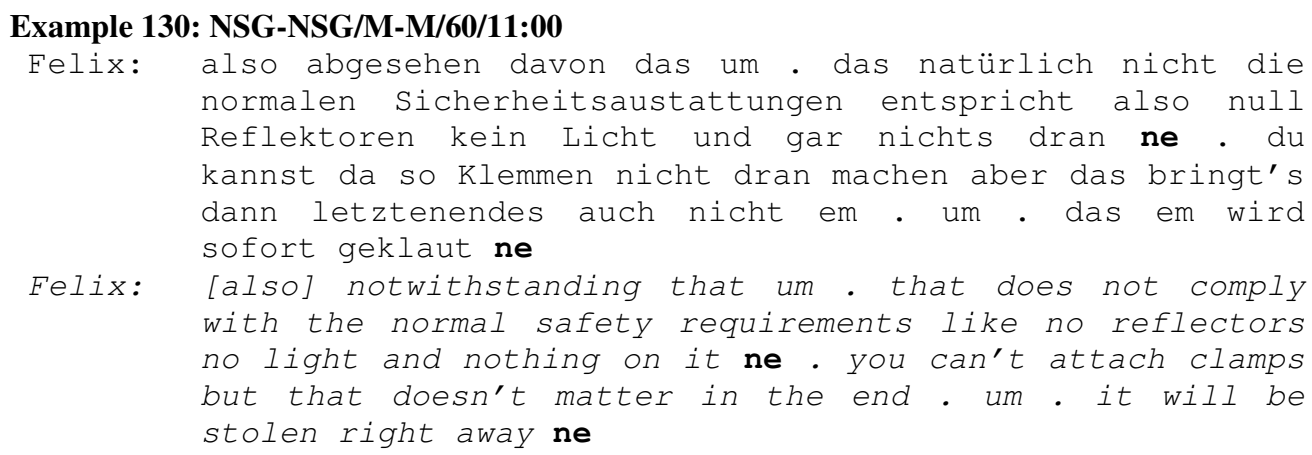

The two tokens of ne seem to draw attention to the implications of the proposition they modify, highlighting that his bike is really basic and that even that type of bike will be stolen quickly. In this sense, they could be glossed with can you believe it or I'm not kidding. The marker creates both focus on the proposition and emphasises the illocutionary force of the proposition. Like its English counterpart, German ne as a booster and focus marker can be used to serve a number of positive and negative politeness strategies.

\subsubsection{Functional distribution of NSG ey and ne}

In the 59,500 word corpus of the German-German interactions, 27 tokens of ey and 134 tokens of ne were found. German ey was used by 13 of 30 speakers, with 1 to 4 tokens per participant. German $n e$, on the other hand, was used by 17 of 30 speakers with a large variability in the individual frequency of use. Bettina has the greatest frequency of German ne with $1.42 \%$ or 61 tokens, followed by Felix with $0.54 \%$ ( 11 tokens) and Mario with $0.53 \%$ (16 tokens). This shows that German $n e$ has a greater distribution than $e y$ and therefore ne might be more comparable to the use of NZE $e h$ by NSNZE. The distribution of the tokens according to their position within the clause or their functions is presented in Table 15 and Table 16. 
Table 15: Functional distribution of $e y$ in the NSG corpus

\begin{tabular}{llll}
\hline Position of $\boldsymbol{e y}$ & $\mathbf{N}$ & $\boldsymbol{\%}$ & Overall \% \\
\hline Initial $e y$ & 10 & 37 & 0.02 \\
Final $e y$ & 17 & 63 & 0.03 \\
Total & 27 & 100 & 0.05 \\
\hline
\end{tabular}

Table 16: Functional distribution of $n e$ in the NSG corpus

\begin{tabular}{llll}
\hline Functions of $\boldsymbol{n} \boldsymbol{e}$ & $\mathbf{N}$ & $\boldsymbol{\%}$ & Overall \% \\
\hline Referential $n \boldsymbol{e}$ & 10 & 7.5 & 0.02 \\
Affective $n e$ & 124 & 92.5 & 0.21 \\
Total & 134 & 100 & 0.23 \\
\hline
\end{tabular}

From the tables it can be seen that both functions are used at a lower frequency than NZE eh, with German ne being closest to NZE $e h$ in terms of overall frequency and functional distribution. The main difference between NSNZE and NSG is that German speakers use ne slightly more often as a referential marker to ask for verification. German $e y$ is used notably less than $n e$, which could be taken as an indication that its use is considered to be more non-standard.

\subsection{Implications for L2 learners}

Since German ne can be considered to be functionally equivalent to NZE $e h$, it could be expected that GNNSE are familiar with the uses and applications of $e h$ and are able to use it appropriately. However, German also has a phonological equivalent form, German ey, which carries different interpersonal connotations and serves somewhat different functions from NZE eh. This might lead to functional L1 transfer, resulting in NZE eh being used like German ey by GNNSE. Thus, GNNSE might use NZE eh for referential purposes and to emphasise or highlight an opinion, but not employ its common ground building functions. Based on this overlap of functional and formal properties between German and NZE markers, it seems likely that the appropriate use of NZE $e h$ would require a relatively high sociopragmatic knowledge of non-native speakers. 
Consequently, it could be expected that GNNSE use the forms less often than NSNZE and possibly L1 transfer can be detected.

\subsection{GNNSE}

\subsubsection{Functional distribution of $e h$ in cross-cultural interactions}

Overall, the GNNSE corpus of 52,866 words contained 12 tokens of $e h$, produced by 5 of 30 speakers. Three of these tokens were categorised as referential $e h$ and 9 as affective $e h$ as summarised in Table 17.

Table 17: Functional distribution of $e h$ in the GNNSE corpus compared with NSNZE data

\begin{tabular}{lcclll}
\hline Functions of $\boldsymbol{e h}$ & $\mathbf{N}$ & $\boldsymbol{\%}$ & Overall \% & NSNZE\% & NSNZE Overall \% \\
\hline Referential $e h$ & 3 & 25 & 0.006 & $(4.5)$ & $(0.01)$ \\
Affective $e h$ & 9 & 75 & 0.017 & $(95.5)$ & $(0.29)$ \\
Total & 12 & 100 & 0.023 & $(100)$ & $(0.3)$ \\
\hline
\end{tabular}

As predicted, GNNSE produce noticeably fewer tokens of $e h$ than NSNZE in native-native interactions. With NSNZE using eh about 13 times more often than GNNSE this is the most pronounced difference between native and non-native speakers found in this study. Moreover, GNNSE appear to use the device proportionally more often as a referential marker than native speakers. As this finding is similar to what has been noted for German $n e$, this could be taken as an indication of L1 transfer. It could also support the notion that for non-native speakers the referential functions of pragmatic devices are more accessible. However, since these observations are based on a very small sample size, these results must be considered tentative. In any case, the adoption of a device as idiosyncratic as NZE $e h$ into their repertoire suggests a form of affective speech accommodation (Meyerhoff 1994: 375). This strategy could be seen as an attempt to minimise social distance by proclaiming affiliation to New Zealand and NZE norms and therefore could be taken as an attempt to build interpersonal rapport. The notion of accommodation is further supported by the paired t-test, which suggests that the difference between GNNSE and NSNZE in cross-cultural interaction is not statistically significant ( $p$-value $=.773>.05)$. 
Table 18: Functional distribution of $e h$ in the cross-cultural NSNZE corpus compared with NSNZE data

\begin{tabular}{llllll}
\hline Functions of $\boldsymbol{e h}$ & $\mathbf{N}$ & $\boldsymbol{\%}$ & Overall \% & NSNZE\% & NSNZE Overall \% \\
\hline Referential $e h$ & 0 & 0 & 0.0 & $(4.5)$ & $(0.01)$ \\
Affective $e h$ & 73 & 100 & 0.14 & $(95.5)$ & $(0.29)$ \\
Total & 73 & 100 & 0.14 & $(100)$ & $(0.3)$ \\
\hline
\end{tabular}

With 73 instances of $e h$ in the 52,168 word corpus, NSNZE in cross-cultural conversations also used the marker about half as much as NSNZE in native-native interactions. The paired t-test shows that this decrease in use is only marginally statistically significant ( $\mathrm{p}$-value $=.068>.05$ but $<.10)$. With 13 out of 30 speakers who used the marker, the overall smaller number of tokens also correlates with a smaller number of participants who used them. This might further strengthen the assumption that $e h$ functions as an in-group solidarity marker for New Zealanders, so that the drop in use with non-natives would signify that they are not part of this particular group. Moreover, this tendency to use fewer devices with non-natives is similar to the observations made for like and, to a much lesser extent, GEs. Therefore, the data could be taken to support the notion that NSNZE simplify and possibly accommodate their language when talking to non-native speakers. Since other aspects of language use by NSNZE with GNNSE have not been examined it is impossible to state at this stage whether this simplification is a general tendency or whether the level of accommodation is restricted to a decrease in the use of interpersonal vernacular features such as the devices analysed in this study.

Interestingly, no case of referential $e h$ could be identified in the cross-cultural NSNZE data. This seems unexpected as it is the opposite of what was observed for GNNSE, which challenges the notion of NSNZE accommodating to their nonnative interlocutor. It also seems surprising as the referential function of a pragmatic device often appears to be the more accessible one. Thus, this would not comply with the proposition that NSNZE simplify their language in crosscultural interactions by employing pragmatic devices more often in their referential functions. However, since the mere use of any function of $e h$ by GNNSE could be interpreted as affective speech accommodation and an 
expression of positive politeness, it may be possible that NSNZE in cross-cultural interactions are mainly responding to this aspect of the marker's function. Moreover, bearing in mind the overall low frequency of $e h$, it is also possible that NSNZE opted to employ more straightforward and explicit strategies to prompt their interlocutor to verify a proposition, such as the use of proper questions or tag questions, while reserving the use of $e h$ for expressing its interpersonal politeness functions.

It should be acknowledged that the results of the functional distribution consistently showed a large gap between the affective and referential $e h$. In the native speaker data, this difference is so large that the referential function does not appear to be relevant at all. This seems to suggest that the proposed categorisation system was not useful since it does not differentiate between the various functions of the main affective $e h$ group. Future research on $e h$ would need to either use more narrowly defined categories or not attempt a quantitative functional analysis. It might seem more worthwhile for future research to treat this device similarly to the analysis of GEs in this study: to use the overall frequency as a means for comparison and to provide a general description of the functions.

\subsubsection{Functional use of $e h$ by GNNSE}

\subsubsection{Referential eh}

As suggested above, the GNNSE data shows that non-native speakers use $e h$ proportionally more often in its referential function than native speakers. Even though German ey does not serve this function, the use of $e h$ by GNNSE to ask the interlocutor for verification might not be very surprising as German ne can be used for a similar purpose. This referential use is illustrated in Example 131 where Carl and Silke are discussing whether the video camera in the room is on or not.

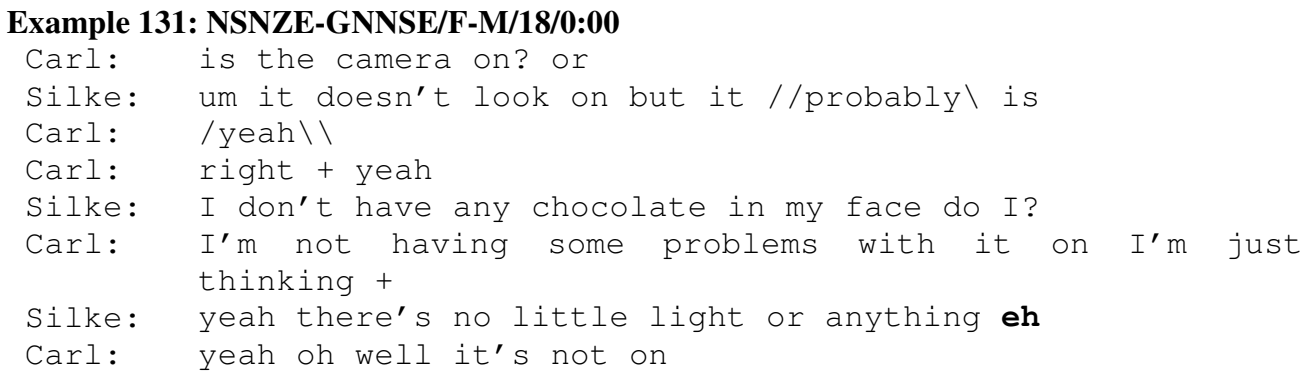


The GNNSE Silke modifies her proposition that the camera cannot be on because there is no light with $e h$. This use of referential $e h$ seems to serve two functions in this context. On the one hand, Silke seems to ask Carl to validate her assumption that a light indicates that the camera is on. At the same time, the token seems to function as a prompt for Carl to confirm Silke's assessment that there really is no light turned on somewhere on the camera.

\subsubsection{Affective eh}

The majority of tokens of affective $e h$ in the GNNSE corpus can be classified as serving the establishment, negotiation or reassertion of common ground. Thus, eh can be used to modify an expression of the speaker's opinion or evaluation of a given subject, inviting the interlocutor to agree or disagree with the presented stance and thereby testing the compatibility of the interactants' values and beliefs as shown in Example 132.

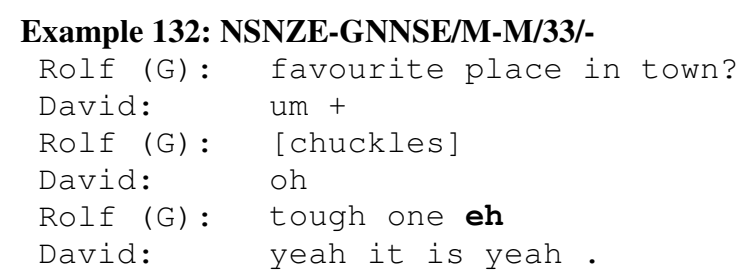

Rolf interrogates David about where he likes to go on a night out in town. David, however, does not have a ready answer to that question and needs some time to think about it. After a few moments Rolf helps him out, commenting that it is a difficult question. He modifies this evaluation of his query with $e h$, which, in this context, seems to serve to negotiate and at the same time emphasise their common ground. While David's hesitation to answer the question implicitly suggests that he considers it difficult to answer, Rolf does not know for sure that this is the problem. Another possible explanation for the delay could be that David does not want to say where he likes to go for some reason. By commenting on the question and presenting the evaluation as his own, Rolf puts forward a reason for David's seeming reluctance to answer and allows him to accept or reject the explanation. By agreeing with the proposed explanation, David asserts Rolf's assumption of a shared assessment of the question and thus strengthens the notion of a shared common ground. Moreover, Rolf's provision of an explanation for David's 
avoidance in conjunction with $e h$ that marks it as a shared opinion suggests that the device could be used as a positive politeness strategy. In this sense, the device would serve to express Rolf's agreement with David's implicitly conveyed opinion regarding the quality of the question and his sympathy and understanding for David's current dilemma. At the same time, the use of a marker idiosyncratic for NZE could also be seen as affective speech accommodation that serves to proclaim affiliation with David's cultural background as a whole and his current problem in particular, which would help to minimise social distance and further enhance interpersonal rapport.

The small data set also contained one example of affective $e h$ used to mark a comment as an exaggeration in order to suggest to the listener that the speaker believes the opposite to be true. This instance occurred when Tanya tells Sven about how different the various Japanese dialects are from what you learn in the classroom as shown in Example 133.

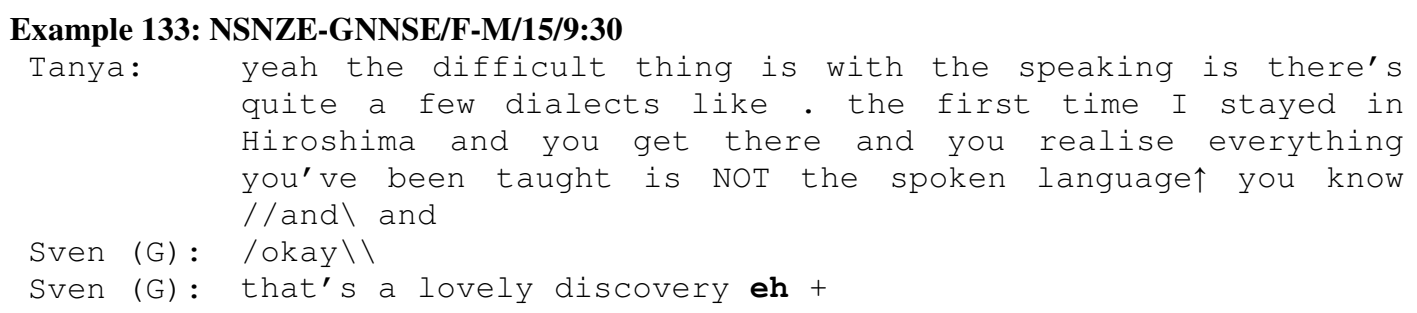

Judging from the context and Sven's tone of voice, his comment that realising that what you have learned is useless is a lovely discovery is meant sarcastically. By marking the comment with $e h$, Sven does not require verification of his remark but he seems to be negotiating with Tanya whether she understands the implicit meaning of his utterance and whether she agrees with his assessment. Based on Tanya's description of going to Japan, it seems likely that she will agree with his comment. As such, the function of the marker could be not only that of negotiating agreement but also of ascertaining understanding and solidarity. After all, as a non-native speaker it can be expected that Sven has had a similar experience when coming to New Zealand. This use of expressing solidarity and understanding can also be analysed as a form of agreement. 
Rolf was also the only speaker to use affective $e h$ in its focus marking function. In Example 134 David and Rolf are talking about doing a degree in programming and Rolf disagrees with David's suggestion that a Polytechnic might provide a better education in this particular field.

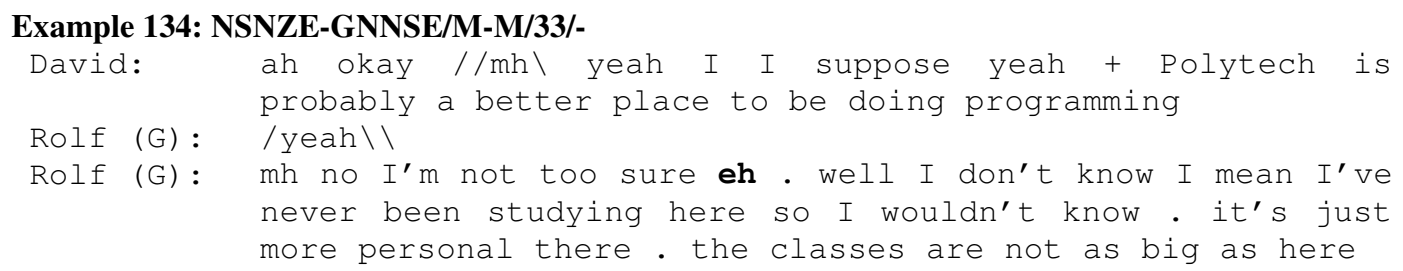

Rolf's tentative proposition I'm not too sure is an expression of his doubts regarding the correctness of David's suggestion and as such does not require verification by David. The statement that he is not sure whether it is better to learn about programming at a Polytechnic is also not an opinion or stance towards the matter on hand that can be debated in order to negotiate common ground. Instead, the instance of $e h$ seems to draw attention to Rolf's doubts, marking his utterance as an important part of his following proposition. In this context, however, the marker does not seem to work as a booster that is meant to strengthen his proposition, but as a hedge that serves to attenuate the force of the disagreement. In addition, the use of $e h$ appears to function as an appeal to David's understanding and willingness to accept the rejection of his proposition and to listen to Rolf's alternative view on the matter.

It is quite remarkable that, despite the small size of the number of $e h$ tokens produced by non-natives, GNNSE display a similar range of functional variation in the use of the device as their native speaker interlocutors. It also seems rather surprising that the data does not contain an instance of L1 transfer of German ey features. In this sense it seems that those GNNSE that chose to use the marker do not blindly rely on form but are very well aware of its pragmatic functions.

\subsubsection{Individual Variation}

Due to the small number of tokens, the variation in the frequency of use of $e h$ is not as great as that of the other pragmatic devices. The majority of the participants (25 out of 30) did not use the marker at all and the frequency of use by the 
remaining 5 ranges from $0.026 \%$ by Cordula, $0.031 \%$ by Sven and $0.074 \%$ by Mario (all 1 token each) to $0.263 \%$ by Silke ( 4 tokens) and $0.52 \%$ by Rolf (5 tokens). All five participants have lived in New Zealand and other English speaking countries for extended periods of time before the recordings and as such can be counted among the socio-pragmatically more proficient speakers. Since other speakers with prior overseas experience such as Lotta or Bettina did not use the form at all, exposure to the spoken language alone does not automatically lead to the adoption and use of $e h$. A number of other factors are likely to influence the choice of pragmatic devices chosen by these high-proficiency speakers, for example personal preferences, topic, rapport with the interlocutor or perceived formality of the interaction. Nevertheless, it seems that long-term interpersonal contact with native speakers makes the use of $e h$ into and its native-like application more probable.

The use of $e h$ by GNNSE also does not seem to correlate with high frequency use of other pragmatic devices. All of the 5 participants who used $e h$ have frequencies in the middle ranges for like and GEs. However, there might be a slight link between the use of English eh and similar forms in German. While only Sven, Mario and Silke used German ey, all five speakers used German ne with a comparable range of frequencies, albeit not in the same order of speakers. Again, other high frequency users of German $n e$ such as Bettina and Felix do not produce a single token of English $e h$. However, the data seems to suggest that the use of English $e h$ by GNNSE is connected to a speaker's use of the functionally similar German $n e$.

The use of the device by their native speaker interlocutors did not seem to have an influence on the use of $e h$ by GNNSE. Kim and Tanya, who spoke with Mario and Sven respectively, used the marker as often as their non-native interactants. Silke's conversation partner Carl used the device only twice, half as often as Silke. Most notably, even though Rolf produced the highest number and highest frequency of $e h$ among the GNNSE group, his native-speaker interlocutor David did not use the device at all. Conversely, the German interactant of Caleb, the NSNZE with the highest $e h$ frequency, did not produce a single token of the marker. When looking at the native-native interactions, however, it seems that 
interlocutors have an important influence on the use of $e h$. Out of the 19 NSNZE who used $e h$ at all, only 3 speakers used the device while their partner did not. Similarly, only 5 out of the 17 GNNSE users of German ne had an interactant who did not use the device. This could be taken as a sign of speaker accommodation where speakers try to adapt their speech to one another in order to minimise differences and establish good rapport.

\subsection{Summary}

The uses of NZE $e h$ have been divided into its referential and affective functions. In its referential application, $e h$ serves as an interrogative marker, requesting verification of the preceding proposition from the listener. The affective functions were described as negotiating and establishing common ground between the speakers, inviting the listener to give feedback regarding the subject matter and voice his or her opinion. This type of $e h$ is usually used to modify comments but it also occurs in conjunction with irony and exaggerations. In cases where affective $e h$ is used to mark a proposition that neither requires verification nor gives room to negotiate opinions, the device seems to work as a booster that highlights important segments of the utterance. By emphasising certain elements of the proposition, the speaker presents these segments as shared knowledge and in this sense the device appears to serve as an appeal to the listener's understanding and willingness to cooperate. The German phonologically similar marker ey proved to work mostly as a booster, either to gain the listener's attention or to mark the following proposition as extreme or surprising. In a few cases it also seemed to serve to express solidarity and understanding. However, the German device ne appears to be a closer functional equivalent to NZE $e h$ as it was found to serve similar referential and affective functions as $e h$. Even though the phonologically similar but functionally different device seems to present a potential for L1 transfer and possibly miscommunication in cross-cultural interaction, no instance of transfer of German ey properties could be found in the GNNSE data.

The frequencies of use of $e h$, ey and ne were collectively low in all pairings. German ne was used more often than German $e y$, which was taken to suggest that ey is more closely associated with non-standard, lower class youth speak than ne and therefore avoided in certain situations. As noted before, NSNZE used the 
device more frequently in native-native interactions than in cross-cultural ones, suggesting that they tried to simplify and clean up their language. GNNSE were found to hardly use the marker at all, as the data contains only 12 tokens produced by 5 speakers. All GNNSE who used $e h$ can be counted as highly proficient speakers who have lived in New Zealand for an extended period of time prior to the recording. Nonetheless, long term exposure to the language can not be taken as a guarantee that the marker will be adopted and applied since many other high proficiency speakers did not employ the token at all. Further research is required to determine whether the use of $e h$ by GNNSE can be linked to a high degree of affiliation and identification with New Zealand society and culture and thus whether it can serve as an indicator of cultural assimilation. Moreover, it has been noted that the use of $e h$ as a pragmatic device seems to be more likely if the speaker also uses the functionally similar German $n e$. In this case, the use of $e h$ by the native speaker interactant seems to have only little effect on the language use of GNNSE.

Despite the small sample size, this investigation of the use of $e h$ by GNNSE proved to be worthwhile as it provided useful insights into the adoption of the pragmatic devices by non-native speakers. The suggested correlation between the use of German ne and NZE $e h$ could indicate that the use of a device is facilitated if the non-native's L1 features a form with similar functions, since this would guarantee an awareness and understanding of the pragmatic functions of the marker. This idea would agree with Ijaz's (1986: 443) suggestion that it is easier for L2 speakers to learn a word if they have to merely re-label a familiar L1 concept. The data also shows that the pragmatic functions of the device are more important than the form as GNNSE did not transfer the functional properties of German ey to NZE eh. However, it is possible that this phonological similarity deterred the use of NZE $e h$ as GNNSE might have tried to consciously avoid L1 transfer. This would also imply that transfer of the formal properties of a marker could only occur if the forms serve similar pragmatic functions, as seems to be the case with the use of the GEs oder so and or so by GNNSE. Further research investigating non-native use of forms that are either similar in form but different in function or different in form but similar in function is required to test this assumption. 



\section{Discussion}

This chapter describes the overall findings of this research study, both in relation to the main research questions of the study as well as observations made throughout the investigation. These research results are then discussed in light of theories and concepts proposed in previous studies in order to determine how the current results compare to the established literature.

\subsection{Research Findings}

This study examines differences in sociopragmatics of language use between native and non-native speakers of English as manifested in the use of particular linguistic forms and considers non-native use with regard to L1 influences. More specifically, the main aim of this research is to investigate differences in the use of pragmatic devices by GNNSE and NSNZE in terms of frequency and function. Furthermore, the study seeks to identify potential factors that influence non-native patterns of use, in particular the effect of speakers' first language on their second language performance. For this purpose, a sizable corpus of dyadic interactions was compiled, consisting of sets of German and NZE native-native conversations as well as a set of conversations between Germans and New Zealanders.

The overall research findings of this study can be grouped into three sections; these are discussed in 8.2. - 8.4. below. The first of these sections is concerned with the methodological design used in this study. The next segment describes differences in the ways in which GNNSE and NSNZE use pragmatic devices in cross-cultural interactions. The third section compares the cross-cultural data with the patterns observed in the native-native interactions.This also includes an examination of differences in the language use of NSNZE in native-native and cross-cultural interactions. Areas of L1 interference on the uses of pragmatic 


\section{Discussion}

devices by GNNSE are discussed and factors that might influence the use of these devices by non-native speakers are identified.

\subsection{Methodological Design}

Methodologies used in studies on the functions of pragmatic devices include DCT (Hentschel and Weydt 1983), task-based interactions (Meyerhoff 1994; Müller 2005) and conversational data (e.g. Holmes 1988). The more controlled methods of DCT and task-based interactions, despite being artificial, have the advantage of producing highly comparable data as all responses represent a speaker's linguistic behaviour in a specific setting with a predetermined goal. Naturalistic conversational data, on the other hand, might be difficult to collect but has the advantage of better representing speakers' actual language use. The methodological design adopted for this study combines these approaches, drawing on the benefits of goal-oriented interaction and free conversation. Thus, participants were given the option to solve a picture description task, talk about suggested topics or engage in a conversation on a subject of their choice. By offering participants a range of interactive alternatives speakers were free to do whatever they felt most comfortable with. It was assumed that giving them the freedom of choice would help create a more relaxed conversational atmosphere and make participants less self-aware of the recording situation and their language use.

\subsubsection{Evaluation of the methodology}

Looking at the results of the study for the number of pragmatic devices used in the interactions, it appears that the approach chosen was effective and therefore recommendable for future investigations in this area. From a quantitative perspective alone, the data of this study consistently contained proportionately more of the pragmatic device under investigation than other studies. It has been suggested that the high frequency use of pragmatic devices is a result of the potentially sociality rights imposing or even face threatening nature of the data collection that was created by the artificial setting of the recordings. However, regardless of the artificial nature of the setting, the interactants still experienced the pressure of having to talk to a stranger for a certain amount of time and they genuinely tried to establish interpersonal rapport with their interlocutors. The face 


\section{Discussion}

work participants engaged in to ease the situation and create rapport is similar to what speakers would do in a comparable situation, for example at a dinner party where people do not know each other well. In other words, while the recording situation might have been artificial, similar situations can arise naturally. The high frequency use of pragmatic devices appears to be a result of the speakers trying to establish a relationship, negotiate common ground and create interpersonal rapport while protecting their own face needs, to keep the conversation going without being too assertive. For the purpose of studying the use of pragmatic devices in establishing and negotiating new relationships this approach seems to be very effective as it fosters the use of these forms for a range of interpersonal and affective goals.

\subsubsection{Use of broad categories}

Another aspect of the methodology of this study that proved to be valuable was the establishment of very broad functional categories for the analysis of like. In their descriptions of the different functions of the pragmatic devices under investigation, both Andersen (2001) and Müller (2005) opted for the creation of relatively narrow categories. On the one hand, this approach allows for a more differentiated quantitative analysis and a detailed comparison between groups. On the other hand, it makes the categorisation process more complicated as pragmatic devices often fit more than one function. Moreover, the differences between the categories tend to be small at best. For example, as argued in section 6.1.3, exemplification like can serve as both a discourse link and a subjective stance marker. Keeping the groupings relatively broad not only simplifies the categorisation process, it also makes the categorisation more comprehensible and easier to reproduce. A closer description of the sub-categories contained within the broad functional classes still allows for a qualitative comparison between the functional uses of specific forms by native and non-native speakers. In this sense, the current approach combines the thoroughness of the detailed description with the straightforwardness of grouping tokens into easily identifiable categories. It was found, though, that this approach is not applicable to all pragmatic devices as the results it generated for $e h$ showed that the device is hardly ever used in its referential function, making the distinction between affective and referential $e h$ not very useful. 


\subsection{Differences in the use of pragmatic devices between GNNSE and NSNZE}

One of the main foci of this study was a consideration of the differences in the use of pragmatic devices by native and non-native speakers of English. When looking at the results for frequencies of use it can be seen that, even though GNNSE use all of the forms under investigation, they generally use them less often than their native speaker interactants. With the exception of GEs (chapter 5) and I mean (chapter 4), GNNSE consistently use the devices at a lower frequency than New Zealanders in both the native-native and cross-cultural interactions. This result of an overall lower use of pragmatic devices agrees with previous studies on nonnative use of such devices; Nikula (1996), Overstreet (2005), Cheng and Warren (2001) and Müller (2005) have all noted a similar, if slightly less pronounced, trend.

\subsubsection{Possible effects on perception of non-native speakers}

It seems to be nearly impossible to measure the effect of the use of any one particular linguistic item or structure on how speakers are being perceived, both in terms of personality and linguistic proficiency. Based on this assumption, this study does not attempt to make claims in that regard. Generally, it has been noted that the use of pragmatic devices alone does not guarantee a smooth conversational flow and a good interpersonal rapport between the speakers. In other words, a proportionately lower use of these forms by non-native speakers does not necessarily result in less amicable interactions or even cross-cultural misunderstandings. Nevertheless, this quantitative difference has the potential to have an adverse effect on how non-native speakers are perceived by native speakers. The use of pragmatic devices serves to make propositions sound less assertive which helps create a sense of informality and establish interpersonal rapport. Thus, by not regularly integrating pragmatic devices into their speech non-native speakers may come across as more direct, opinionated or even rude as they might appear to present their points as absolute certainties and nonnegotiable facts. This impression could be even further increased by a proportionately higher use of speaker-oriented or egocentric devices such as $I$ think in Aijmer's (2001) study or, as was the case for GNNSE in the preliminary 


\section{Discussion}

analysis, I mean. For this reason alone, i.e. to avoid unintentionally giving the impression of being overly direct, it might be important to raise learners' awareness of the existence of the forms and functions of a range of pragmatic devices in the language they are studying. However, the effects of these devices on the interlocutor's perception are still unknown.

\subsubsection{Overall results of the functional analysis}

The data has also been analysed with regard to the functions of the pragmatic devices in the NSNZE and GNNSE corpora. The functions of GEs, like and eh have been described in terms of their affective and textual properties and effects in the specific contexts they occur in. Individual tokens have then been grouped into broadly defined categories which contain a range of un-quantified sub-groups. The comparisons of the functional applications of these forms by GNNSE and NSNZE are based on the results of this broad categorisation. On the whole, the results suggest that GNNSE use pragmatic devices for the same functions as native speakers, including most of the range of sub-functions identified for each category. This suggests that GNNSE are aware of the different functional applications of the forms in context and are able to use them accordingly. This awareness could be related to the fact that German and English are closely related languages of the same language family and therefore may have a number of pragmatic properties in common. In this sense, the results might support Færch and Kasper's (1989: 244-5) claim that learners of a language that is closely related to their own often use linguistic politeness strategies that are very similar to native norms.

\subsubsection{Eh and like}

The main difference between the functional distributions of GNNSE and NSNZE was a proportionally higher frequency use of referential $e h$ and a proportionately lower use of quotative like by GNNSE. Bearing in mind that GNNSE did not use $e h$ very often overall, this proportional preference for its referential meaning appears rather irrelevant and may not have any impact on the cross-cultural interaction at all. On the other hand, the relatively sparse use of quotative like by GNNSE as compared to NSNZE could have an effect on how they are being perceived by their native speaker interlocutors. The use of quotatives in general is 


\section{Discussion}

associated with the telling of engaging narratives (Ferrara and Bell 1995: 265) and the be like form in particular has been found mostly in informal interactions (Blyth et al. 1990). As a preliminary analysis of all lexicalised quotatives in the corpus suggests, GNNSE generally do not use this narrative strategy very often in cross-cultural interactions (Terraschke 2006b). The analysis shows that be like constructions are still the most frequently used quotatives by GNNSE. However, GNNSE use proportionally more explicit quotative verbs such as go, say or tell than native speakers. The relatively high use of these forms in conjunction with the overall low frequency use of quotatives in general may be perceived as a more correct and stilted way of talking, deterring the creation of an informal conversational setting and the establishment of interpersonal rapport. More research in this area is required to establish the interpersonal effects of such pragmatic differences between GNNSE and NSNZE.

\subsection{Connections with native-native data}

\subsubsection{Differences in the language used by NSNZE in native-native and cross-cultural interactions}

\subsubsection{Differences in frequencies}

The collection of not only cross-cultural interactions but also native-native conversations between Germans and New Zealanders allowed for a direct comparison between native norms and uses in cross-cultural or L2 settings. The data suggests that NSNZE in cross-cultural conversations generally use pragmatic devices more often than their GNNSE conversants but that NSNZE use consistently fewer instances of pragmatic devices when talking to GNNSE than when speaking to another native speaker.

This is a valuable finding because native speaker interlocutors are likely to have an impact on the non-native speakers' adoption to the underlying pragmatic norms of spoken English. This notion is supported by observations made of speakers' use of GEs. For this device the frequencies of use by GNNSE and NSNZE were relatively similar across the dyads, as were the frequencies in most of the samesex native English interactions. This suggests a degree of accommodation to the 
interlocutor, with speakers matching their language use close to each other in a trend similar to that observed by Bell (2001) for $e h$. Moreover, while the NSNZE in cross-cultural interactions used $e h$ and like significantly less compared to native-native interactions, the differences between GNNSE and their NSNZE interlocutors were not statistically significant. This could indicate that non-native speakers accommodate their use of pragmatic devices to their native interlocutors, using the reduced frequency as a baseline.

That NSNZE use fewer instances of pragmatic devices in cross-cultural conversations could be indicative of native speakers trying to simplify their language in order to facilitate communication and understanding. Another possible interpretation of this pattern is that native speakers try to accommodate their language to non-native speakers' speech, or to what they believe non-native speech to be. Whatever the reason, this overall decrease in use could actually have adverse effects on the learners' use of these forms by preventing them from acquiring the native norms of application.

\subsubsection{Different uses of discourse functions}

In addition to this quantitative adjustment of native speaker's use of pragmatic devices in cross-cultural conversations, a slight change in the functional applications of these forms by native speakers has also been noted. The most prominent example of this is that native NZE speakers use like proportionally more often as a discourse marker when engaged in cross-cultural interactions. This could be a result of native speakers perceiving a greater need to clarify and explain their utterances in order to avoid misunderstandings. Similar to the overall lower frequency of use of pragmatic devices, this slight change in the use of the different discourse functions of specific devices could have an impact on the language use of their non-native interlocutors.

\subsubsection{Influence of L1 on the use of pragmatic devices by GNNSE}

It has been noted that the language use of non-native speakers, especially advanced speakers, is influenced by a large range of factors including the nature of the class-room instruction, unguided acquisition through native-speaker contact and L1 transfer (Odlin 1989). Since considering all possible aspects in the 


\section{Discussion}

analysis of GNNSE language use was beyond the scope of this thesis, the present study has focused on investigating the possible correlations between L1 forms and L2 uses.

\subsubsection{General Extenders}

The issue of L1 interference for language learners has been one of the main foci of interlanguage pragmatics (Kasper and Blum-Kulka 1993). Interestingly, Nikula reported that she did not "find any clear evidence of the non-native speakers transferring incorrect forms from their native language" (1996: 227) and that instead there appeared to be more instances of non-transfer. However, the data of the current study contained some relative straightforward cases where German appears to have influenced the language of GNNSE. The clearest examples of interference of German on the forms used by GNNSE can be found in the GE data where the extender and tralala was identified as a direct translation of the German form und tralala. Another notable correlation between the German and the GNNSE data was the preference of GNNSE for the disjunctive extender or so, which featured only marginally in the NSNZE data. It was suggested that this is a case of L1 interference because English or so is a close translation of the most frequently used disjunctive German extender oder so. The most noticeable feature of the use of or so by GNNSE was that they used it as in German: like any other disjunctive extender that can modify a range of grammatical categories and entire propositions. GNNSE, therefore, appear to be unaware that English or so is restricted in its use for numerical approximation. This pattern of use may simply be to a lack of awareness and subsequent non-acquisition of the exceptions to the rules rather than the result of L1 transfer. Nevertheless, it still represents a clear case of non-native use of this particular form.

\subsubsection{Be like quotative}

Another case of L1 interference on the non-native speakers language use can be found in the use of quotatives by GNNSE. The data suggests that the low frequency of quotatives in general and particularly the be like quotative corresponds to the low frequency use of quotatives in German. The German close translational and functional equivalent of the be like construction und ich/er/sie so occured rarely in the native-native German conversations. These very specific 


\section{Discussion}

instances of L1 transfer provide clear suggestions for potentially problematic areas that may be useful for second language teaching. Further research looking at a wider range of quotative forms, including the zero quotative, would be needed to confirm this suggestion.

\subsubsection{Patterns of L1 interference: GEs and be like}

In addition to highlighting areas of potential L1 transfer, the results of the uses of GEs and the be like quotative also help us further understand underlying L1 influences on the uses of pragmatic devices and the semantic equivalence hypothesis (Ijaz 1986). The comparatively high frequency use of GEs by GNNSE, which was also remarkably close to the use of this set of devices by NSNZE, could be related to the similarity of the English GE forms to the German ones. A correlation between L1 and L2 in terms of frequency might explain the high frequency use of I think in Ajimer's (2002) study and it might also be the reason for the high frequency use of I mean by GNNSE in chapter 4. The low frequency use of quotative like and quotative so by GNNSE and NSG would suggest that L1 norms can also affect the frequency of use. Further research is required to determine to what degree the frequency of use of the L2 forms reflects L1 usage.

Generally speaking, the fact that German and English GEs serve similar textual and interpersonal functions as well as sharing certain syntactic properties and following similar internal construction rules appears to have facilitated the process of their use and correct application by GNNSE. However, it seems to be this close resemblance of form and functions that has led to direct translations such as and tralala and to the German-like uses of or so. Similarly, Cheng and Warren (2001: 1428) observated that the use of tag questions as invariant forms by Hong Kong Chinese speakers of English could be related to the prevalence of invariant forms in Cantonese. They also suggested that the high frequency use of tag questions by Hong Kong Chinese in asking for confirmation could be due to the fact that Cantonese invariant tags mostly function as question markers (Cheng and Warren 2001: 1436-7). These results would further support the assumption that a high degree of form-functional similarity of pragmatic device in L1 and L2 might increase the likelihood of L1 interference. 


\section{Discussion}

Conversely, the relative unfamiliarity of German speakers with the interpersonal effects of the use of quotatives as a narrative strategy may have made it more difficult for GNNSE to learn and adopt English quotatives such as be like into their repertoire. These results appear to support the semantic equivalence hypothesis (Ijaz 1986) in that the existence of the pragmatic concepts underlying GEs and quotatives in German together with similarity of forms and functions seems to have an influence on their use by GNNSE.

\subsubsection{L1 transfer: eh}

Due to the small sample size, the influence of L1 transfer of the uses of $e h$ by GNNSE is more difficult to interpret and thus mostly speculative. One possible explanation for the remarkably low use of NZE eh by GNNSE may be that they perceived the recording situation as more formal than New Zealanders and were trying to avoid using too many colloquialisms. Another possibility is that GNNSE consciously tried to not use a device that is so closely associated with NZE in order to avoid sounding like they were mimicking NZE, thereby potentially offending their interactant. This could be supported by the use of the marker by the GNNSE Knut: even though Knut himself commented at some point before the recording that he uses $e h$ a lot and even though his NSNZE interactant Caleb was among the more frequent users of $e h$, Knut did not use the device at all.

It is also feasible that the amount of exposure to certain English pragmatic devices had an impact on their use by GNNSE. Thus, GNNSE may have been familiar with the use of GEs and like through American and British television stations that are available in Germany, e.g. MTV, BBC or CNN. However, they may not have been exposed to NZE eh due to a limited access to New Zealand media and personal contacts and thus may not have been fully aware of the range of its functions. Finally, bearing in mind that German features a phonologically similar form, it seems likely that GNNSE do not consider $e h$ to be a distinctive English form and avoid it altogether to steer clear of potential L1 transfer. This would be an opposite trend to Müller's (2005) observation regarding the use of well by German non-native speakers. Müller (2005: 251) notes that GNNSE use well more than native speakers of English, because they consider the form to be a 


\section{Discussion}

typical English device and so believe "that the usage of well is related to 'good English"”.

Generally speaking, the results suggest that, despite the phonological similarity of German ey and NZE eh, GNNSE rarely used NZE $e h$ in cross-cultural conversations. Moreover, those speakers who did use NZE $e h$ appeared to use it according to NSNZE norms as no clear case of transfer of German ey functions could be found. This suggests that non-native speakers do not blindly transfer similar forms from their first to their second language, even when those forms function on a more sub-conscious and pragmatic level. Furthermore, those GNNSE who used eh according to NSNZE conventions did not only have to realise that German $e y$ and NZE $e h$ are not the same, they also had to understand the interpersonal functions of NZE $e h$. This means that, even though non-native speakers may not learn much about the uses of pragmatic devices in a second language classroom, advanced learners appear to be able to recognise the interpersonal functions of such devices. In accordance with the semantic equivalence theory, this seems to suggest that for non-native speakers to use a pragmatic device, it is more important that the L2 form corresponds to a L1 marker in terms of the pragmatic meanings than its phonological or other structural features. On the one hand, this might suggest that GNNSE would be able to use their pragmatic knowledge of German ne to adopt the functionally similar NZE $e h$. However, it seems likely that the phonological similarity between German ey and NZE eh interfered with this process as GNNSE might have associated the marker more closely with German than with English. The fact that NZE eh was only used by GNNSE who have lived in New Zealand for an extended period of time seems to support this notion. After all, it might require a greater amount of pragmatic awareness to overcome the potential confusion caused by the phonologically similar forms. 



\section{Conclusion}

\subsection{Summary of research results and implications}

This research study set out to investigate differences in frequency and function in the use of a small set of pragmatic devices by German non-native speakers of English (GNNSE) in interactions with native speakers of New Zealand English (NSNZE). The use of pragmatic devices by NSNZE in cross-cultural conversations was contrasted with the use of the same set of pragmatic devices in intra-cultural interactions between NSNZE. This helped to determine whether NSNZE change their patterns of speech when talking to non-native speakers. Moreover, close German functional equivalents of the chosen devices were identified and the forms, frequencies and functional scopes of these forms were examined in a corpus of conversations between those native speakers of German (NSG) involved in the cross-cultural interactions. A comparison between the GNNSE and NSG data allowed for an investigation of the extent to which linguistic behaviour in L1 influences speech production in L2. More specifically, this study set out to answer two sets of research questions; the first focusing on the similarities in the use of pragmatic devices by NSNZE and NSG, and the second examining differences in their use by GNNSE.

1. a) Which English pragmatic devices in the corpus most clearly deserve close examination? What are their German counterparts?

b) Do these selected English pragmatic devices and their German equivalents serve comparable sociopragmatic functions?

The selection of pragmatic devices for close investigation in the main body of the thesis was based on a preliminary analysis of a sub-set of the corpus examining a wider range of pragmatic devices. The devices chosen for a detailed analysis in the complete corpus were General Extenders (GEs), and the devices like and $e h$. 
These markers were selected based on a range of factors including frequency in the preliminary analysis, relevance to non-native speakers in New Zealand and the potential for interference from corresponding L1 forms for GNNSE. By selecting devices based on the possibility of transfer, the present research differs from other studies looking at non-native use of pragmatic devices (e.g. Müller 2005) which often chose forms for examination based on frequency and functional variability alone.

The German close equivalents of these devices identified as most suitable for a comparison with the NZE markers were German GEs for NZE GEs, German so and also for NZE like, and German ey and ne for NZE $e h$. The German markers identified were either phonologically or functionally similar to the NZE forms. They were selected based on suggestions made in previous research (e.g. Overstreet 1999), my native speaker intuitions, and description of the functions found in the corpora (GEs and $e h$ ).

\section{Are there differences in the use of English pragmatic devices between} NSNZE and GNNSE in terms of frequency and function?

The analysis identified a number of differences in the use of the selected pragmatic devices by NSNZE and GNNSE. Overall, in accordance with previous research (e.g. Nikula 1996; Overstreet 1999; Cheng and Warren 2001; Müller 2005), GNNSE appear to use pragmatic devices less often than native speakers. The only exceptions to this general tendency appear to be the speaker-oriented device I mean and content-oriented GEs. A closer investigation of the use of GEs shows GNNSE differ from NSNZE in that they use or so more often, and they use this phrase to modify a wider range of grammatical classes. Generally speaking, GNNSE were found to use the same range of pragmatic devices as their native speaker interlocutors, including a few instances of NZE $e h$. NSNZE and GNNSE differed in their use of NZE $e h$ in that GNNSE used $e h$ proportionally more in its referential function than NSNZE, who used it more in its affective sense. However, since GNNSE used the token only 12 times, the sample size is too small to make any firm claims. The data for like suggests that the main difference between NSNZE and GNNSE was the use of quotative like, as GNNSE used like noticeably less in this function than the native speakers. 
3. Can L1 transfer be observed in the use of pragmatic devices by GNNSE?

The language use of GNNSE in the present corpus suggests that a speaker's mother tongue has an influence of their L2 production. The clearest case of L1 transfer was found in the GE data where the German GE form und tralala was directly adapted into English and tralala. The preference for the disjunctive marker or so by GNNSE also seems to be influenced by their native language as the most frequently occurring disjunctive GE in German is oder so. The use of this form is also influenced by German norms as GNNSE use it like any other GE, and not solely for numerical approximation as is the case in English. It was suggested that this might not be due to L1 transfer but instead to a lack of awareness of this exception, and a failure to acquire the functional restrictions associated with or so. With regard to like, the GNNSE data did not appear to contain any cases where the device was used in unusual and non-native contexts. However, one correlation that was found between the German corpus and the GNNSE data was between the use of quotative like and German quotative so. Thus, the low frequency use of non-standard quotative so in the NSG corpus corresponds to the relatively low frequency use of quotative like in the GNNSE corpus

The most notable issue regarding the use of $e h$ by GNNSE is the lack of L1 transfer of the pragmatic functions of the phonological German equivalent ey. Despite the similarity in form, GNNSE did not produce a clear single instance where they use English $e h$ in a German ey context. This suggests that formal similarity is not enough to cause L1 transfer and that non-native speakers do not blindly transfer L1 forms to L2 contexts. The data also suggests that the use of NZE $e h$ could be an indication of the level of pragmalinguistic awareness and identification with New Zealand culture as it was only used by GNNSE who have lived long term in New Zealand or other English speaking countries. Finally, it has been suggested that, to a certain degree, L1 can have an influence on the frequency of use of equivalent English forms. In the majority of cases a high frequency of use of English GEs by GNNSE appears to correspond to a high frequency of German GEs and the use of NZE $e h$ seems to be more likely if the 
GNNSE uses $n e$ in German conversations.

\section{Do NSNZE modify their discourse strategies and use of pragmatic devices when talking to GNNSE?}

Overall, NSNZE in cross-cultural conversations consistently produced a lower frequency of pragmatic devices than when talking to a fellow native speaker. There also appears to be a functional difference in how NSNZE use pragmatic devices when talking to non-native speakers. The functional distribution of the uses of like by NSNZE suggests that in cross-cultural conversations native speakers use like more often in its discourse linking function, which matches a proportionally high frequency of discourse link like among GNNSE. It was suggested that NSNZE might have perceived an increased need to provide additional explanations or modification in order to grant understanding and a good communicative flow. In terms of GEs, NSNZE were found to not only use fewer tokens overall but also to display somewhat less variation in form. This general trend of using pragmatic devices at a lower frequency in cross-cultural conversations could be a sign of NSNZE accommodating to their non-native interactants by simplifying their language and reducing their use of more nonstandard language features. This tendency is likely to have an influence on the learner's use of non-standard linguistic features and might therefore impede the expansion of their pragmatic competence.

\section{5. a) What are the implications of the findings for cross-cultural communication? \\ b) Is the use of pragmatic devices in conversations a source of potential miscommunication?}

Pragmatic devices are often considered to be a feature of spoken language which help create an informal atmosphere, minimise social distance and establish interpersonal rapport. Nevertheless, their use does not seem to guarantee a friendly and personal conversation and conversely their absence does not appear to make the interaction stilted and forced. With regard to pragmatic devices being a potential source of miscommunication it was noted that the data did not contain any clear examples where this seemed to have been the case. Speakers appear either to not notice or gloss over non-native like uses of pragmatic devices. 


\section{Conclusion}

Generally speaking, since pragmatic devices mainly function on a subtle interpersonal level, it seems their non-native-like use would not lead to miscommunication as such but instead have interpersonal consequences on how the non-native speaker is being perceived.

\subsection{Limitations of the study}

When evaluating the relevance and applicability of any research to its field it is important to bear in mind the limitations of the approach taken by the study. Though the methodological approach was efficient in that it appears to have encouraged the use of pragmatic devices by the participants, the data was nevertheless collected in a relatively artificial setting. It is plausible that any attempts to create a relaxed conversational atmosphere, such as minimising the amount of instructions and guidelines for how to conduct the conversation, were outweighed by the artificiality of the situation and the presence of the recording devices. Consenting to being filmed and audio-recorded may have made participants more aware of the artificial nature of the situation, which likely had an effect on their language use. Since all participants have been exposed to the same conditions, the research results are still valid within themselves. However, the circumstances under which the conversations have been recorded should be kept in mind when comparing the data to interactions taken from other contexts as different conversational situations are likely to result in the use of different conversational strategies.

It should also noted that the fact that all participants are self-selected volunteers means that the sample is not necessarily representative of even the German student population. Apart from those speakers who were recruited from my circle of personal acquaintances, most participants were proactive about being involved in this project by emailing me and asking questions about my poster advertisement or getting in touch upon the referral of a friend. All participants knew before the recording started what would be expected of them and thus those who participated knew they would be involved in a linguistic study on communication. As a result, the data cannot be considered to represent the average German or New Zealand English speaker. 
Furthermore, the interpretation of pragmatic devices, and particularly the description of their interactive functions, is a subjective process that mostly rests with the researcher. As has been argued above, it is usually possible to determine the most salient function of a pragmatic device based on the immediate context, the general tone of the interaction and the intonation used by the speakers. Nevertheless, it would have been beneficial to supplement this informed interpretation by confirming the results with the speakers themselves, as they might have been able to offer further insights into their interactional intentions and how these were connected to the use of certain devices, thus providing their own interpretations. In the early stages of creating the methodological design for this study, the use of retrospective interviews was considered for this purpose. However, it was decided that it would not be feasible to conduct retrospective interviews straight after the recording, when the conversation was still fresh in the speakers' minds, due to constraints in time and difficulty with obtaining the special and technical equipment required for such an undertaking. Asking participants to come back at a later stage to comment on their conversation was also dismissed as an option as it would have been unlikely that speakers would remember the interactive goals of a very specific context after a few days or weeks. Instead, my readings of individual examples and my classification systems for the functional analyses were checked and discussed with my supervisors and other linguistics students. This procedure added an extra level of confidence to my interpretation as it prompted me to reject or tone down readings others did not agree with and keep those others found plausible.

Related to this issue is the problem of identifying functionally equivalent German forms to the English devices. As was pointed out in the discussion of possible equivalents to NZE like, just as there are different ways of expressing the same or similar functions of English pragmatic devices, there is usually more than one German form that could be used to express the similar meaning. Nikula (1995: 233) points out that "it is, as yet, far from clear whether it is possible to consider features across languages as fully equivalent pragmatically". Therefore, the particular German forms identified as the closest equivalents to the English markers and the correlations drawn between the NSG and GNNSE data can only be tentative at best and the area merits further research. The selection of the 
devices that were identified as the closest equivalent forms was based on native speaker intuition in conjunction with a literature-based survey of the functions of the selected forms. Thus, even though it might be debatable whether the forms are exact equivalents, the chosen forms, as well as the comparisons between the German and the GNNSE uses, can be considered valid and relevant within the context of this study.

Another limitation of the methodology is the restriction to only a few pragmatic devices; this had to be applied due to the timeframe of the study. This relates to the preliminary analysis of the data in chapter 4 , where the three devices were selected from a predetermined range of potential forms. Similarly, it also applies to the conclusions drawn from the analyses of $e$, like and GEs. With regard to the preliminary analysis it might have been worthwhile to use a broader range of devices for the quantitative analysis as this would have given a better picture of the different uses of pragmatic devices by native and non-native speakers. After all, it is possible that GNNSE preferred the use of pragmatic devices that were not included in the selection. And even if this were not the case, comparing the frequencies of a larger number of tokens would have been able to confirm the finding that GNNSE generally use the same pragmatic devices as NSNZE at roughly the same relative frequencies. In this sense, this restricted view makes it impossible to determine if, for example, GNNSE balance out their comparatively low use of NZE $e h$ with a high frequency use of another interactional device, certain prosodic features or non-verbal elements. While the conclusions drawn from each of the three analyses are valid within the framework of the thesis, it seems difficult to make any wide-reaching generalisations based on this data. Nevertheless, the in-depth analysis of a small set of devices that was provided in this study was able to capture the range of functions used by GNNSE and NSNZE and pinpoint differences in their uses of pragmatic devices.

\subsection{Possible directions for future research}

Throughout the analysis of the pragmatic devices and during the review of the limitations of the study, potential avenues for further research were highlighted. As this study has focused on the analysis of the uses of only a very small selection of forms by native and non-native speakers, many aspects of native/non-native 
interactions remain to be investigated. As an extension of the present study, it would be worthwhile to conduct a closer examination of all the pragmatic devices used by native and non-native speakers in the present corpus. This would help to establish the range of pragmatic devices in the repertoire of both groups and it would ascertain whether GNNSE prefer using devices other than those used by native speakers. In addition to giving a better overview of the forms that have been learned and are being used by non-native speakers, such an analysis would help determine the relative importance of those devices investigated in the present study.

Due to the restriction of the thesis to the investigation of a small number of pragmatic particles it was not possible to consider the use of other paralinguistic means for modifications. The inclusion of such paralinguistic features (e.g. High Rising Terminals) in a close analysis of modification strategies used by nonnative speakers would provide an even more detailed picture of their pragmatic repertoire. Furthermore, such a study could establish whether non-native speakers do in fact use fewer lexical pragmatic devices than native speakers or whether they compensate their smaller range of lexical devices with strategic use of prosodic features and non-verbal communication.

Another issue that deserves further attention is the question of identifying equivalent forms in two languages. As mentioned above, this is a problematic procedure as it is unlikely that two forms or features are perfectly equivalent on all levels. The German forms used for comparisons in this research were only tentatively identified as equivalent devices. Their selection would beyond doubt require closer analyses of possible German forms both in terms of their pragmatic functions as well as the frequency of their occurrence and other relevant factors. This would help determine the extent to which German and English forms can actually be considered equivalent. Moreover, such a study would require the establishment of relevant factors to determine the degree of equivalence between forms, which would facilitate the search of these items in the future.

The analysis of the results has also suggested the need for a more detailed study of individual devices. These features include the differences in native and non-native 


\section{Conclusion}

uses of quotatives, you know/weißt Du and English so and also. In particular, the potential impact of L1 from German markers other than so and also on the uses of like deserves further attention. In the present study German so and also were only tentatively identified as corresponding forms, which is why a more in-depth examination of these and other potential candidates would be necessary to verify the selection of the closest German counterpart to NZE like. The identified devices would then be used for an analysis of the German sub-corpus in terms of frequency and function.

In the preliminary analysis, the most noticeable difference was the use of the speaker-oriented device I mean by native and non-native speakers. The results of chapter 4 showed that, unlike most other devices, GNNSE use I mean at a much higher frequency than NSNZE. Further research is needed to identify differences in the functional applications of the marker by native and non-native speakers. This would help determine whether the use of I mean by GNNSE merely mirrors the frequency of use of German ich meine or whether it is also a case of functional L1 transfer. Bearing in mind that correlating non-native use of pragmatic devices with their use of corresponding forms in their mother tongue is a relatively novel approach, it may be worthwhile conducting more research in this area, including different languages. A closer analysis of the degree to which functional and/or formal similarity facilitates or impedes use of pragmatic devices by non-native speakers in conjunction with an assessment of which factors are the most influential would facilitate the identification of potential areas of transfer.

In addition to the uses of pragmatic devices by native and non-native speakers, an investigation into how much impact non-native use of pragmatic devices actually has on interpersonal relations also promises to be an interesting avenue for further research. For the purpose of the thesis it was assumed that the use of pragmatic devices is important for the creation of interpersonal rapport. It remains to be seen, though, if the use of pragmatic devices by non-native speakers actually has an effect on how they are viewed by their native interlocutors and if so, whether it has a positive or a negative effect. Bearing in mind the large degree of individual variation in terms of frequency of use among native speakers, it seems unlikely that it would be an important factor for non-native speakers. On the other hand, 


\section{Conclusion}

non-native language use is sometimes evaluated differently, and the use of colloquial forms by foreigners could sound odd or even presumptuous to native ears. Once the effect of non-native use of pragmatic devices has been established, recommendations regarding the teaching of these items in EFL or ESL classrooms can be made.

Since non-native use of pragmatic devices is usually the product of unguided acquisition by language learners, an investigation into how well non-native speakers adapt to the norms of use of the various societal sub-groups might prove worthwhile. Some of the variables that could be studied in this regard are the influences of gender, social class and the degree of formality of the interaction on non-native speakers' use of pragmatic devices. It would be interesting to see if

non-native speakers conform to patterns that have been observed for native speakers, if they follow their L1 patterns or whether their use of pragmatic devices is dependent on the language use of their interlocutor.

There is clearly a great deal more research which needs to be undertaken in the area of interlanguage pragmatics. This study has hopefully made a useful contribution to the area, by providing a thorough and detailed examination of native and non-native uses of a number of pragmatic devices, as well as a close investigation of L1 influence on the language of second language speakers. The research entailed compiling a unique corpus of carefully matched speaker conversations, involving interactions between native speakers of German and English and between German and English speakers. The analysis suggested that the form, function and frequency of use of pragmatic devices in the first language have an influence on the use of comparable forms in the second language. The results of this study highlight areas of L1 transfer that may help to advance our understanding of the second language acquisition process. This research has also identified a wide and exciting range of areas for further exploration: study of the interrelations between L1 and L2 forms which serve as interpersonal politeness strategies is clearly a promising avenue for future research. 


\section{Appendices}

\section{Appendix 1: Background Information Sheet and Retrospective Conversation Ranking Sheet \\ Background Information Sheet}

1. Gender:

Female

Male

2. Circle your age group: 16-19

$20-24$

$25-29$

$30-34$

3. What are you studying?

4. What is your highest educational qualification?

5. Which ethnic group do you identify with?

6. What $\quad$ is $\quad$ your country of
birth?

7. Have you lived in a country other than your country of birth for more than 6 Months?

Please specify:

8. What is the language of your family-home?

9. What is the language of your home now in Wellington?

10. Where did you grow up (city, region, etc)?

11. Have any of your flat-mates or close friends volunteered to participate in this research? If so, please name them

12. At the end of your recordings would you prefer to receive a $\$ 15$
$\square$ book voucher or
CD voucher 
Appendices

\section{German-speakers only:}

14. Wann bist Du in Neuseeland angekommen?

15. Wie alt warst Du, als Du mit Englisch Lernen angefangen hast?

16.Seit wann benutzt Du Englisch für Gespräche mit Freunden

17. Welche Rolle spielte und spielt Englisch in Deinem Studium in Deutschland? (ist es Unterrichtssprache, Dein Hauptfach, die Sprache der Unterrichtstexte, etc)?

18. Benutzt Du hauptsächlich Englisch für Deine sozialen Interaktionen in Neuseeland?

19. Mit ungefähr wievielen Neuseeländischen Englischen Muttersprachlern hast $\mathrm{Du}$

regelmäßigen sozialen Kontakt?

$\square$ 1-5 $\square$ 6-10 $\square 11-15 \quad \square 16+$


Appendices

\section{Retrospective Interview Schedule}

\section{Ranking sheet}

Please read the questions and rank them according to your experiences during the recording, with 1 indicating a low and 5 a high ranking. Under each question there is some space for you to elaborate.

On the whole, did you enjoy the conversation?

$\begin{array}{lllll}1 & 2 & 3 & 4 & 5\end{array}$

How intrusive did you find the tape recorder?

$\begin{array}{lllll}1 & 2 & 3 & 4 & 5\end{array}$

How did you like the room?

$\begin{array}{lllll}1 & 2 & 3 & 4 & 5\end{array}$

Did you establish a good rapport/ relationship?

$\begin{array}{lllll}1 & 2 & 3 & 4 & 5\end{array}$

Did you have any problems understanding each other?

$\begin{array}{lllll}1 & 2 & 3 & 4 & 5\end{array}$

How would you rate the natural flow of the conversation?

$\begin{array}{lllll}1 & 2 & 3 & 4 & 5\end{array}$




\section{Appendices}

How would you rate your relationship with your interlocutor during the conversation? (ranging from distant (1) to close (5))

$\begin{array}{lllll}1 & 2 & 3 & 4 & 5\end{array}$

Were there any misunderstandings during the course of your conversation? If yes, please specify:

Do you have any further comments on the conversations? 
Appendices

\section{Appendix 2: Information sheet and Consent form}

\section{Informal conversations between native New Zealanders and German non- native speakers of English}

Researcher: Agnes Terraschke, School of Linguistics and Applied Language Studies, Victoria University of Wellington.

Email: agnes.terraschke@vuw.ac.nz

Phone: 4759351

I am a $\mathrm{PhD}$ student in Linguistics at Victoria University of Wellington. In my thesis I will be looking at informal conversations between native new Zealanders and German non-native speakers of English. The university requires that ethics approval be obtained for research projects involving human participants.

If you decide to volunteer for my project I will group you with a partner and ask you to engage in a conversation while recording and videotaping yourselves. Since the study looks at informal conversations you are free to talk about anything you want. However, suggested topics will be provided. You will be asked to engage in two conversations, each with a different partner and different suggested topics. After the recording is finished I will ask you a few questions about the conversation. As soon as transcripts of the interactions are available, you will be asked to return again to answer some questions about specific speech situations. Each conversation will take approximately 25-30 minutes, which will be followed by a 10 minutes debrief.

If you should feel the need to withdraw from the project or if you want to recall disclosed information from being used in the paper, you may do so without further questions. Just let me know at the time.

The collected information will be used anonymously for the written report of the research project. It will not be possible to identify you personally. All disclosed information will be kept secure and confidential. No other person than my supervisors, Prof Laurie Bauer and Prof Janet Holmes, and I will have access to the conversation-recordings. The paper will be submitted for marking to the School of Linguistics and Applied Language Studies and a copy of paper will be lodged in the University Library. The data will also be used for conference and journal papers. All data will be destroyed within two years after the research is completed.

If you have any questions or would like to receive further information about the project, please do not hesitate to contact me. My primary supervisor, Dr Laurie Bauer, can be contacted at the School of Linguistics and Applied Language Studies at Victoria University of Wellington, P.O. Box 600, Wellington, phone 4635619.

Agnes Terraschke 


\section{Victoria University of Wellington}

\section{Consent to participation in research}

\section{Title:}

INFORMAL CONVERSATIONS BETWEEN NATIVE NEW ZEALANDERS AND GERMAN NON-NATIVE SPEAKERS OF ENGLISH

I have been given and have understood an explanation of this research project. I have had an opportunity to ask questions and have them answered to my satisfaction. I understand that I may withdraw myself or any information I have provided from this project before September $15^{\text {th }} 2004$, when the data collection and analysis is complete, without having to give any reasons.

I understand that any information I provide will be kept confidential to the researcher and the supervisor. The written report will not use my name, however any demographical data I have provided will be disclosed and used for the analysis. I understand that the tape recordings of the conversations will be electronically wiped at the end of the project unless I indicate that I would like them returned to me.

I understand that the data I provide will not be used for any other purpose or released to others without my written consent.

I would like to receive a summary of the results of this research when it is completed.

I agree to take part in this research

Signed:

Print full name:

Date: 
Appendices

\section{Appendix 3: English Version of the letter used to find participants}

Hello:

\section{Are you a New Zealander? Do you study at VUW? Are you 22-28 years old? Do you like to talk? And, most important of all: do you have $11 / 2$ hours to spare?}

If you answered these questions with yes then I need you to participate in my research project.

My name is Agnes Terraschke and I am currently conducting research for my $\mathrm{PhD}$ thesis at the School of Linguistics and Applied Language Studies. My study is concerned with informal cross-cultural communication.

And that's why I need you! Participating would involve recording two conversations of about 30 minutes in two sessions: one with another native speaker and one with a German non-native speaker of English. Afterwards I will ask you to fill in a short questionnaire. Overall it should take approximately 1hour. In return, you will be provided with soft drinks during the recordings and you will receive a $\$ 15$ book voucher.

If you would like to participate I would love to hear from you as soon as possible.

Best wishes

Agnes Terraschke 
Appendix 4: Contents of attached CD

\begin{tabular}{|c|c|c|c|c|c|c|}
\hline Nr. & Interactant 1 & Sex & Group & Interactant 2 & Sex & Group \\
\hline 1. & Lauren & $\mathrm{F}$ & NSNZE & Vivienne & $\mathrm{F}$ & NSNZE \\
\hline 2. & Cordula & $\mathrm{F}$ & NSG & Nadine & $\mathrm{F}$ & NSG \\
\hline 3. & Tom & M & NSNZE & David & M & NSNZE \\
\hline 4. & Cordula & $\mathrm{F}$ & GNNSE & Eve & M & NSNZE \\
\hline 5. & Paul & M & NSNZE & Kim & $\mathrm{F}$ & NSNZE \\
\hline 6. & Tom & M & NSNZE & Ulf & M & GNNSE \\
\hline 7. & Silke & $\mathrm{F}$ & NSG & Mario & M & NSG \\
\hline 8. & Kim & $\mathrm{F}$ & NSNZE & Mario & M & GNNSE \\
\hline 9. & Lauren & $\mathrm{F}$ & NSNZE & Nadine & $\mathrm{F}$ & GNNSE \\
\hline 10. & Ute & $\mathrm{F}$ & GNNSE & Vivienne & $\mathrm{F}$ & NSNZE \\
\hline 11. & Ruth & $\mathrm{F}$ & NSNZE & Helen & $\mathrm{F}$ & NSNZE \\
\hline 12. & Paul & M & NSNZE & Carmen & $\mathrm{F}$ & GNNSE \\
\hline 13. & Holger & M & NSG & Carmen & $\mathrm{F}$ & NSG \\
\hline 14. & Carl & M & NSNZE & Tanya & $\mathrm{F}$ & NSNZE \\
\hline 15. & Sven & M & GNNSE & Tanya & $\mathrm{F}$ & NSNZE \\
\hline 16. & Sven & M & NSG & Katrin & $\mathrm{F}$ & NSG \\
\hline 17. & Susan & $\mathrm{F}$ & NSNZE & Guy & M & NSNZE \\
\hline 18. & Silke & $\mathrm{F}$ & GNNSE & Carl & M & NSNZE \\
\hline 19. & Susan & F & NSNZE & Holger & M & GNNSE \\
\hline 20. & Katrin & $\mathrm{F}$ & GNNSE & Guy & M & NSNZE \\
\hline 21. & Mark & M & NSNZE & Stuart & M & NSNZE \\
\hline 22. & Steven & M & NSNZE & Nina & $\mathrm{F}$ & GNNSE \\
\hline 23. & Bobby & M & NSNZE & Pamela & $\mathrm{F}$ & NSNZE \\
\hline 24. & Olaf & M & GNNSE & Pamela & $\mathrm{F}$ & NSNZE \\
\hline 25. & Olaf & M & NSG & Nina & $\mathrm{F}$ & NSG \\
\hline 26. & Nils & $\mathrm{M}$ & GNNSE & Mark & M & NSNZE \\
\hline 27. & Anna & $\mathrm{F}$ & GNNSE & Helen & $\mathrm{F}$ & NSNZE \\
\hline 28. & Anna & $\mathrm{F}$ & NSG & Gudrun & F & NSG \\
\hline 29. & Bobby & M & NSNZE & Frederike & F & GNNSE \\
\hline 30. & Arne & M & NSG & Frederike & $\mathrm{F}$ & NSG \\
\hline 31. & Arne & M & GNNSE & Lana & $\mathrm{F}$ & NSNZE \\
\hline 32. & Rolf & M & NSG & Nils & M & NSG \\
\hline 33. & Rolf & M & GNNSE & David & M & NSNZE \\
\hline 34. & Steven & M & NSNZE & Lana & $\mathrm{F}$ & NSNZE \\
\hline 35. & Maggie & $\mathrm{F}$ & NSNZE & Eve & F & NSNZE \\
\hline 36. & Maggie & F & NSNZE & Bettina & $\mathrm{F}$ & GNNSE \\
\hline 37. & Bettina & $\mathrm{F}$ & NSG & Frauke & $\mathrm{F}$ & NSG \\
\hline 38. & Ingo & M & NSG & Ulf & M & NSG \\
\hline 39. & Ingo & M & GNNSE & Stuart & M & NSNZE \\
\hline 40. & Frauke & $\mathrm{F}$ & GNNSE & Ruth & $\mathrm{F}$ & NSNZE \\
\hline
\end{tabular}


Appendices

$\begin{array}{lllllll}\text { 41. } & \text { Nora } & \text { F } & \text { NSNZE } & \text { Barbara } & \text { F } & \text { NSNZE } \\ \text { 42. } & \text { Barbara } & \text { F } & \text { NSNZE } & \text { Lotta } & \text { F } & \text { GNNSE } \\ \text { 43. } & \text { Lotta } & \text { F } & \text { NSNZE } & \text { Ute } & \text { F } & \text { GNNSE } \\ \text { 44. } & \text { Nora } & \text { F } & \text { NSNZE } & \text { Gudrun } & \text { F } & \text { GNNSE } \\ \text { 45. } & \text { Carol } & \text { F } & \text { NSNZE } & \text { Felicity } & \text { F } & \text { NSNZE } \\ \text { 46. } & \text { Valena } & \text { F } & \text { GNNSE } & \text { Felicity } & \text { F } & \text { NSNZE } \\ \text { 47. } & \text { Carol } & \text { F } & \text { NSNZE } & \text { Katja } & \text { F } & \text { GNNSE } \\ \text { 48. } & \text { Valena } & \text { F } & \text { NSG } & \text { Katja } & \text { F } & \text { NSG } \\ \text { 49. } & \text { Reuben } & \text { M } & \text { NSNZE } & \text { Lars } & \text { M } & \text { GNNSE } \\ \text { 50. } & \text { Knut } & \text { M } & \text { NSG } & \text { Lars } & \text { M } & \text { NSG } \\ \text { 51. } & \text { Reuben } & \text { M } & \text { NSNZE } & \text { Caleb } & \text { M } & \text { NSNZE } \\ \text { 52. } & \text { Knut } & \text { M } & \text { GNNSE } & \text { Caleb } & \text { M } & \text { NSNZE } \\ \text { 53. } & \text { Greg } & \text { M } & \text { NSNZE } & \text { Veit } & \text { M } & \text { GNNSE } \\ \text { 54. } & \text { Boris } & \text { M } & \text { NSG } & \text { Veit } & \text { M } & \text { NSG } \\ \text { 55. } & \text { Greg } & \text { M } & \text { NSNZE } & \text { Nathan } & \text { M } & \text { NSNZE } \\ \text { 56. } & \text { Boris } & \text { M } & \text { GNNSE } & \text { Nathan } & \text { M } & \text { NSNZE } \\ \text { 57. } & \text { Zach } & \text { M } & \text { NSNZE } & \text { Felix } & \text { M } & \text { GNNSE } \\ \text { 58. } & \text { Zach } & \text { M } & \text { NSNZE } & \text { Xander } & \text { M } & \text { NSNZE } \\ \text { 59. } & \text { Xander } & \text { M } & \text { NSNZE } & \text { Moritz } & \text { M } & \text { GNNSE } \\ \text { 60. } & \text { Felix } & \text { M } & \text { NSG } & \text { Moritz } & \text { M } & \text { NSG }\end{array}$





\section{References}

Abraham, Werner 1991. Introduction. In Werner Abraham (ed.) Discourse Particles. Amsterdam/ Philadelphia: John Benjamins. 1-10.

Aijmer, Karin 2001. I think as a marker of discourse style in argumentative student writing. In Katrin Aijmner (ed.) A Wealth of English - Studies in Honour of Göran Kjellmer. Goteborg: Acta Universitatis Gothoburgensis. 247-258.

Aijmer, Karin 2002. English Discourse Particles: Evidence from a Corpus. Amsterdam/ Philadelphia: John Benjamins.

Allan, Scott 1990. The rise of New Zealand intonation. In Allan Bell; Janet Holmes (eds.) New Zealand Ways of Speaking English. Wellington: Victoria University Press. 115-128.

Andersen, Gisle 2001. Pragmatic Markers and Sociolinguistic Variation: A Relevance-Theoretical Approach to the Language of Adolescents. Amsterdam/ Philadelphia: John Benjamins.

Androutsopoulos, Jannis K. (1998). Deutsche Jugendsprache. Untersuchungen zu ihren Strukturen und Funktionen. Frankfurt am Main: Peter Lang.

Ariel, Mira 1996. Pragmatic Operators. In R.E. Asher (ed.) Encyclopedia of Languages and Linguistics. Oxford: Pergamon and Aberdeen University Press. 3250-3253.

Auer, Peter and Susanne Günthner 2003. Die Entstehung von Diskursmarkern im Deutschen - ein Fall von Grammatikalisierung? InLiSt - Interaction and Linguistic Structures 38.

Avis, Walter 1972. So eh? Is Canadian eh? Canadian Journal of Linguistics: La Revue Canadienne de Linguistique 17: 89-104.

Baird, Sarah 2001. How 'to be like' a Kiwi: Verbs of quotation in New Zealand English. New Zealand English Journal 15: 6-19.

Beebe, Leslie M. and Martha Clark Cummings 1996. Natural speech act data versus written questionnaire data: How data collection method affects speech act performance. In Susan M. Gass and Joyce Neu (eds.) Speech 


\section{References}

Acts across Cultures: Challenges to Communication in a Second Language. Berlin/ New York: Mouton de Gruyter. 65-86.

Bell, Allan 2001. Back in style: Reworking audience design. In Penelope Eckert and John R. Rickford (eds.) Style and Sociolinguistic Variation. Cambridge: Cambridge University Press. 139-169.

Betten, Anne 1976. Ellipsen, Anakoluthe und Parenthesen. Deutsche Sprache 4: 207-230.

Blum-Kulka, Shoshana; Juliane House and Gabriele Kasper 1989. Investigating cross-cultural pragmatics: An introductory overview. In Shoshana BlumKulka, Juliana House and Gabriele Kasper (eds.) Cross-Cultural Pragmatics: Requests and Apologies. Norwood, New Jersey: Ablex. 1-36.

Blyth, Carl Jr., Sigrid Recktenwald and Jenny Wang 1990. I'm like, "Say What?!": A new quotative in American oral narrative. American Speech 65: 215-227.

Brinton, Laurel J. 1996. Pragmatic Markers in English: Grammaticalization and Discourse Functions. Berlin/ New York: Mounton de Gruyter.

Britain, David 1998. Linguistic change in the intonation: The use of high-rising terminals in New Zealand English. In Peter Trudgill and Jenny Cheshire (eds.) The Sociolinguistic Reader. Volume 1: Multilingualism and Variation. London/New York: Arnold. 213-239.

Brown, Penelope and Stephen Levinson 1987. Politeness: Some Universals on Language Use. Cambridge/ London/ New York: Cambridge University Press.

Bublitz, Wolfram 1978. Ausdrucksweise der Sprechereinstellung im Deutschen und Englischen: Untersuchungen zur Syntax, Semantik und Pragmatik der deutschen Modalpartikeln und Vergewisserungsfragen und ihrer englischen Entsprechungen. Tübingen: Max Niemeyer.

Butters, Ronald R. 1982. Editor's Note. American Speech 57: 149.

Cárdenes Melián, José 1997. Aber, denn, doch, eben und ihre spanischen Entsprechungen: eine funktional-pragmatische Studie zur Übersetzung deutscher Partikeln. Münster/ NewYork: Waxmann.

Channell, Joanna 1994. Vague Language. Oxford/ New York/ Toronto: Oxford University Press.

Cheng, Winnie and Martin Warren 2001. 'She knows more about Hong Kong than you do isn't it': Tags in Hong Kong conversational English. Journal of Pragmatics 33: 1419-1439. 


\section{References}

Clyne, Michael 1994. Intercultural Communication at Work. Cultural Values in Discourse. Cambridge: Cambridge University Press.

Collins English Dictionary (3 ${ }^{\text {rd }}$ Ed.). 1994. J. M. Sinclair (ed.). Glasgow: Harper Collins Publishers.

Corder, S. Pit (1992). A role for the mother tongue. In Susan M. Gass and Larry Selinker (eds.) Language Transfer in Language Learning. Amsterdam/ Philadelphia: John Benjamins. 18-31.

Crystal, David and Derek Davy 1975. Advanced Conversational English. London: Longman.

Dagut, Menachem 1977. Incongruencies in lexical "gridding" - An application of contrastive semantic analysis to language teaching. International Review of Applied Linguistics 15: 221-229.

Dailey-O'Cain, Jennifer 2000. The sociolinguistic distribution of and attitudes toward focuser like and quotative like. Journal of Sociolinguistics 4: 6080 .

Daly, Nicola; Janet Holmes, Jonathan Newton and Maria Stubbe 2004. Expletives as solidarity signals in FTAs on the factory floor. Journal of Pragmatics 36: $945-964$.

D'Arcy, Alexandra 2005. Like: Syntax and Development. Unpublished PhD thesis, University of Toronto, Canada.

Dines, Elizabeth R. 1980. Variation in discourse - "and stuff like that". Language in Society 9: 13-31.

Duden: Das Bedeutungswörterbuch (3rd Ed.). 2002. Dudenredaktion (eds.). Mannheim: Dudenverlag.

Duden: Herkunftswörterbuch, Etymologie der deutschen Sprache (3rd Ed.). 2001. Dudenredaktion (eds.). Mannheim: Dudenverlag.

Durrell, Martin 1996. Hammer's German Grammar and Use. London/ Sydney/ Auckland: Arnold.

Edmondson, Willis 1981. Spoken Discourse: A Model for Analysis. London/ New York: Longman.

Ehlich, Konrad 1986. So: Überlegungen zum Verhältnis sprachlicher Formen und sprachlichen Handelns, allgemein und an einem widerspenstigen Beispiel. Ludar Germanistische Forschungen 55: 279-298.

Elspaß, Stephan and Robert Möller 2006. Atlas zur deutschen Alltagssprache. Philologisch-Historische Fakultät, Universität Augsburg. (24/11/2006) 
http://www.philhist.uniaugsburg.de/de/lehrstuehle/germanistik/sprachwissenschaft/ada/

Eriksson, Mats 1995. A case of grammaticalization in modern Swedish: The use of $B a$ in adolescent speech. Language Sciences 17: 19-48.

Erman, Britt 1987. Pragmatic Expressions in English: A Study of You know, You see and I mean in Face-to-Face Conversation. Vol. LXVIV: Stockholm Studies in English. Stockholm: Almqvist \& Wiksell International.

Færch, Claus and Gabriele Kasper 1989. Internal and external modification in interlanguage request realization. In Shoshana Blum-Kulka, Juliana House and Gabriele Kasper (eds.) Cross-Cultural Pragmatics: Request and Apologies. Norwood: Ablex. 221-247.

Ferrara, Kathleen and Barbara Bell 1995. Sociolinguistic variation and discourse function of constructed dialogue introducers: The case of be + like. American Speech 70: 265-290.

Fischer, Kerstin 2007. Grounding and common ground: Modal particles and their translation equivalents. In Anita Fetzer and Kerstin Fischer (eds.) Lexical Markers of Common Grounds. Amsterdam: Elsevier. 47-66.

Fleischer, Wolfgang; Gerhard Helbig and Gotthard Lerchner (eds) 2001. Kleine Enzyklopädie, deutsche Sprache. Frankfurt am Main: Peter Lang.

Fraser, Bruce 1999. What are discourse markers? Journal of Pragmatics 31: 931952.

Gass, Susan and Noel Houck 1999. Interlanguage Refusals: A Cross-Cultural Study of Japanese-English. Berlin/ New York: Mouton de Gruyter.

Gibson, Deborah 1977. Eight types of Eh. Sociolinguistics Newsletter 8: 30-31.

Golato, Andrea 2000. An innovative German quotative for reporting on embodied actions: Und ich so/und er so 'and I'm like/and he's like '. Journal of Pragmatics 32: 29-54.

Greaves, Chris 2005. ConcApp Concordance and Word Profiler Version 4. Hong Kong: edict Virtual Language Centre. (http://www.edict.com.hk/default.htm).

Grice, Paul H. 1975. Logic and Conversation. In Peter Cole and Jerry Morgan (eds.) Syntax and Semantics, Volume 3: Speech Acts. New York: Academic Press. 41-58.

Günthner, Susanne and Wolfgang Imo 2003. Die Reanalyse von Matrixsätzen als Diskursmarker: ich mein-Konstruktionen im gesprochenen Deutsch. In Magdolna Orosz and Andreas Herzog (eds.) Jahrbuch der Ungarischen Germanistik. Budapest/Bonn: DAAD. 181-216. 
Hasund, Ingrid Kristine 2003. The Discourse Markers like in English and liksom in Norwegian Teenage Language: A Corpus-Based, Cross-Linguistic Study. Unpublished $\mathrm{PhD}$ Thesis, University of Bergen and Agder University College, Norway.

Henne, Helmut 1986. Jugend und ihre Sprache: Darstellungen, Materialien, Kritik. Berlin/ New York: Walter de Gruyter.

Hentschel, Elke und Harald Weydt 1983. Der pragmatische Mechanismus: Denn und Eigentlich. In Harald Weydt (ed.) Partikeln und Interaktion. Tübingen: Max Niemeyer Verlag. 263-273.

Hinkel, Eli 1997. Appropriateness of advice: DCT and multiple choice data. Applied Linguistics 18: 1-26.

Holmes, Janet 1982. The functions of tag questions. English Language Research Journal. 3: 40-65.

Holmes, Janet 1984. Modifying illocutionary force. Journal of Pragmatics 8(3): 345-365.

Holmes, Janet 1985. Sex differences and miscommunication: Some data from New Zealand. In J.B. Pride (ed.) Cross-Cultural Encounters: Communication and Miscommunication. Melbourne: River Seine. 24-43.

Holmes, Janet 1986. Functions of you know in women's and men's speech. Language in Society 15: 1-22.

Holmes, Janet 1988. Paying compliments: A sex-preferential politeness strategy. Journal of Pragmatics 12: 445-465.

Holmes, Janet 1995. Women, Men and Politeness. London/New York: Longman.

Holmes, Janet 2003. On Transcriptions, Personal communication. Agnes Terraschke. Wellington.

Horst, Ilka and Kathrin Rump 1989. Gambits - Stiefkinder des Englischunterrichts? Fremdsprachenunterricht 33/ 42: 231-235.

House, Juliane 2000. Understanding misunderstanding: A pragmatic-discourse approach to analysing mismanaged rapport in talk across cultures. In Helen Spencer-Oatey (ed.) Culturally Speaking: Managing Rapport through Talk across Cultures. London/ New York: Continuum. 145-164.

Ijaz, Helen 1986. Linguistic and cognitive determinants of lexical acquisition in a second language. Language Learning 36: 401-451.

Jefferson, Gail 1981. The abominable ne? An exploration of post-response pursuit of response. In Peter Schröder and Hugo Steger (eds.) Dialogforschung. Düsseldorf: Pädagogischer Verlag Schwann. 53-88. 


\section{References}

Jefferson, Gail 1990. List-construction as a task and resource. In George Psathas (ed.) Interaction Competence. London/ Washington D.C: International Institute for Ethnomethodology and Conversation Analysis/ University Press of America. 63-92.

Johnstone, Barbara 1987. 'He says ... so I said': Verb tense alternation and narrative depiction of authority in American English. Linguistics 25: 3352.

Jucker, Andreas H. and Yael Ziv 1998. Discourse markers: Introduction. In Andreas H. Jucker and Yael Ziv (eds.) Discourse Markers: Descriptions and Theory. Amsterdam/ Philadelphia: John Benjamins. 1-12.

Kasper, Gabriele 1998. Interlanguage pragmatics. In Heidi Byrnes (ed.) Learning Foreign and Second Languages: Perspectives in Research and Scholarship. New York: Modern Language Association of America. 183208.

Kasper, Gabriele and Merete Dahl 1991. Research methods in interlanguage pragmatics. Studies in Second Language Acquisition June 13: 215-247.

Kärna, Aino 1983. Abtönung im Finnischen und im Deutschen. In Harald Weydt (ed.) Partikeln und Interaktion. Tübingen: Max Niemeyer Verlag. 85-95.

Labov, William 1966. The Social Stratification of English in New York City. Washington, D.C.: Center for Applied Linguistics.

Lakoff, Robin 1975. Language and Woman's Place. New York: Harper Colphon Books.

Laufer, Batia 1990a. Ease and difficulty in vocabulary learning: Some teaching implications. Foreign Language Annals 23: 147-156.

Laufer, Batia 1990b. Why are some words more difficult than others? - Some intralexical factors that affect the learning of words. International Journal of Applied Linguistic 18: 293-307.

Lee, Hikyoung 2004. Discourse marker use in native and non-native English speakers In Carol Lynn Moder and Aida Martinovic-Zic (eds.) Discourse Across Languages and Cultures. Amsterdam/ Philadelphia: John Benjamins. 117-127.

Lenk, Uta 1996. Marking Discourse Coherence: Functions of Discourse Markers in Spoken English. Tübingen: Gunter Narr Verlag.

Lerner, Gene H. 1994. Responsive list construction: A conversational resource for accomplishing multifaceted social action. Journal of Language and Social Psychology 13: 20-33. 
Lindner, Katrin 1991. 'Wir sind ja doch alte Bekannte': The Use of German ja and doch as Modal Particles. In Werner Abraham (ed.) Discourse Particles: Descriptive and Theoretical Investigations on the Logical, Syntactic and Pragmatic Properties of Discourse Particles in German. Amsterdam/ Philadelphia: John Benjamins. 163-201.

Long, Michael H. 1981. Questions in foreigner talk discourse. Language Learning 31: $135-57$.

Long, Michael H. 1983. Linguistic and conversational adjustments to non-native speakers. Studies in Second Language Acquisition 5: 177-93.

Lovik, Thomas A. 1990. Geben Sie mir so'n Streuselapfel: Hedging in authentic speech situations. Die Unterrichtspraxis/ Teaching German 23: 121-128.

Lütten, Jutta 1977. Untersuchungen zur Leistung der Partikeln in der gesprochenen deutschen Sprache. Göppingen: Verlag Alfred Kümmerle.

Maeshiba, Naoko, Naoko Yoshinaga, Gabriele Kasper and Steven Ross 1996. Transfer and proficiency in interlanguage apologizing. In Joyce Neu and Susan Gass (eds.) Speech Acts Across Cultures. Berlin: Mouton de Gruyter. 155-187.

Meehan, Teresa 1991. It's like, 'what's happening in the evolution of like?': A theory of grammaticalization Kansas Working Papers in Linguistics 16: $37-51$.

Meyerhoff, Miriam 1986. A study of Sex Differences in New Zealand English. Unpublished MA thesis, Victoria University of Wellington, New Zealand.

Meyerhoff, Miriam 1992. "We've all got to go one day, eh": Powerlessness and solidarity in the functions of a New Zealand tag. In Kira Hall, Mary Bucholtz, Birch Moonwoman (eds.) Locating Power: Proceedings of the Second Berkeley Women and Language Conference. Berkeley: Berkeley Women and Language Group. 409-419.

Meyerhoff, Miriam 1994. Sounds pretty ethnic, eh?: A pragmatic particle in New Zealand English. Language in Society 23: 367-388.

Miller, Jim and Regina Weinert 1995. The function of LIKE in dialogue. Journal of Pragmatics 23: 365-393.

Möllering, Martina 2001. Teaching German modal particles: A corpus-based approach. Language Learning \& Technology 5: 130-151.

Morrison, Anthea 2005. Refusals: Discovering how People Say 'No' - A Methodological and Cross-Cultural Approach. Unpublished MA thesis, Victoria University of Wellington, New Zealand. 
Morrison, Anthea and Janet Holmes 2005. Eliciting refusals: A methodological challenge. Te Reo 46: 47-66.

Müller, Simone 2005. Discourse Markers in Native and Non-native English Discourse. Amsterdam/ Philadelphia: John Benjamins.

Nelson, Gayle L., Mahmoud Al Batal and Erin Echols 1996. Arabic and English compliment responses: Potential for pragmatic failure. Applied Linguistics 17: $411-432$.

Nikula, Tarja 1996. Pragmatic Force Modifiers: A Study in Interlanguage Pragmatics. Jyväskylä: University of Jyväskylä.

Östman, Jan-Ola 1982. The symbiotic relationship between pragmatic particles and impromptu speech. In Nils Erik Enkvist (ed.) Impromtu Speech: A Symposium. Åbo: Åbo Akademi. 147-177.

Östman, Jan-Ola 1991. On the language-internal interaction of prosody and pragmatic particles. In Jef Verschueren (ed.) Levels of Linguistic Adaptation: Selected Papers of the International Pragmatics Conference, Antwerp, August 17-22, 1987, Volume 2. Amsterdam: John Benjamins. 203-221.

Overstreet, Maryann 1999. Whales, Candlelight, and Stuff Like That: General Extenders in English Discourse. New York/ Oxford: Oxford University Press.

Overstreet, Maryann 2005. And stuff Und so: Investigating pragmatic expressions in English and German. Journal of Pragmatics 37: 1845-1864.

Quirk, Randolf, Sidney Greenbaum, Geoffrey Leech and Jan Svartvik 1985. A Comprehensive Grammar of the English Language. Harlow: Longman.

Rathmayr, Renate 1989. Zur Frage der Lehr- und Lernbarkeit von Partikeln. In Harald Weydt (ed.) Sprechen mit Partikeln. Berlin/ New York: Walter de Gruyter. 623-633.

Romaine, Suzanne and Deborah Lange 1991. The use of like as a marker of reported speech and thought: A case of grammaticalization in progress. American Speech 66: 227-279.

Sankoff, Gillian, Pierrette Thibault, Naomi Nagy, Hélène Blondeau, Marie-Odile Fonollosa and Lucie Gagnon 1997. Variation in the use of discourse markers in language contact situation. Language Variation and Change 9: 191-217.

Scott, Mike 1999. Wordsmith Tools Version 3. Oxford: Oxford University Press.

Schiffrin, Deborah 1987. Discourse Markers. London/New York: Cambridge University Press. 
Schlobinski, Peter 1995. Jungendsprache: Speech styles of youth subcultures. In Patrick Stevenson (ed.) The German Language and the Real World. Oxford: ClareNdon Press. 315-338.

Schmidt, Claudia 1988. Typisch weiblich - typisch Männlich: Geschlechtstypisches Kommunikationsverhalten in studentischen Kleingruppen. Tübingen: Max Niemeyer Verlag.

Schmidt, Richard W. 1990. The role of consciousness in second language learning. Applied Linguistics 11: 129-158.

Schourup, Lawrence C. 1982. Common Discourse Particles in English Conversation. New York/ London: Garland Publishing.

Schwitalla, Johannes 1997. Gesprochenes Deutsch: Eine Einführung. Berlin: Erich Schmidt Verlag.

Spencer-Oatey, Helen 2000. Rapport management: A framework for analysis. In Helen Spencer-Oatey (ed.) Culturally Speaking: Managing Rapport through Talk across Cultures. London/ New York: Continuum. 11-46.

Sperber, Dan and Deirdre Wilson 1995. Relevance: Communication and Cognition. Oxford/ Cambridge: Blackwell.

Stubbe, Maria and Janet Holmes 1995. You know, eh and other 'exasperating expressions': An analysis of social and stylistic variation in the use of pragmatic devices in a sample of New Zealand English. Language and Communication 15: 63-88.

Svartvik, Jan 1980. Well in conversation. In Geoffrey Leech S. Greenbaum, and Jan Svartvik (eds.) Studies in English Linguistics for Randolph Quirk. London: Longman. 167-177.

Tagliamonte, Sali and Rachel Hudson 1999. Be like et al. beyond America: The quotative system in British and Canadian youth. Journal of Sociolinguistics 3: 147-172.

Tagliamonte, Sali and Alex D'Arcy 2004. He's like, she's like: The quotative system in Canadian youth. Journal of Sociolinguistics 8: 493-514.

Terraschke, Agnes 2006a. To be like or to say: A preliminary analysis of the use of quotative verbs by German non-native speakers of English. Paper presented at the 3rd International Postgraduate Linguistics Conference at Victoria University of Wellington, Wellington.

Terraschke, Agnes. 2006b. Und er so: And she's like - Non-native use of quotatives. Paper presented at the Language and Society Conference, University of Christchurch, Christchurch. 


\section{References}

Thomas, Jenny 1995. Meaning in Interaction: Introduction to Pragmatics. London/ New York: Longman.

Underhill, Robert 1988. Like is, like, focus. American Speech 63: 234-246.

Ward, Gregory and Betty Birner 1993. The semantics and pragmatics of and everything. Journal of Pragmatics 19: 205-214.

Wauchope, Mary Michele 1992. Contrastive study of a set of German and English pragmatic particles. In Irmengard Rauch, Gerald F. Carr and Robert L. Kyes (eds.) On Germanic Linguistics: Issues and Methods. Berlin: Mouton de Gruyter. 379-393.

Weber, Ursula 1986. Personalpronomina und die Partikeln "ja, also" und "ne" in Instruktionsdialogen. In Inger Rosengren (ed.) Sprache und Pragmatik. Stockholm: Almqvist \& Wiksell. 385-404.

Weydt, Harald 1969. Abtönungspartikel. Die deutschen Modalwörter und ihre französischen Entsprechungen. Bad Homburg: Gehlen.

Willkop, Eva-Maria 1988. Gliederungspartikeln im Dialog. München: Idicum Verlag.

Wolfson, Nessa 1988. The bulge: A theory of speech behaviour and social distance. In Jonathan Fine (ed.) Second Language Discourse: A Textbook of Current Research. Norwood, New Jersey: Ablex. 21-38.

Wolfson, Nessa, Thomas Marmor and Steve Jones 1989. Problems in the comparison of speech acts across cultures. In Shoshana Blum-Kulka, Juliana House and Gabriele Kasper (eds.) Cross-Cultural Pragmatics: Requests and Apologies. Norwood: Ablex. 174-196.

Zuengler, Jane 1991. Accommodation in native-nonnative interactions: Going beyond the "what" to the "why" in second-language research. In Howard Giles; Justine Coupland and Nikolas Coupland (eds.) Contexts of Accommodation: Developments in Applied Sociolinguistics. Cambridge, Cambridge University Press. 223-244. 